\title{
Advanced Technology Development Program for Lithium-Ion Batteries: Gen 2 Performance Evaluation Final Report
}

Jon P. Christophersen Ira Bloom

Edward V. Thomas

Kevin L. Gering

Gary L. Henriksen

Vincent S. Battaglia

David Howell

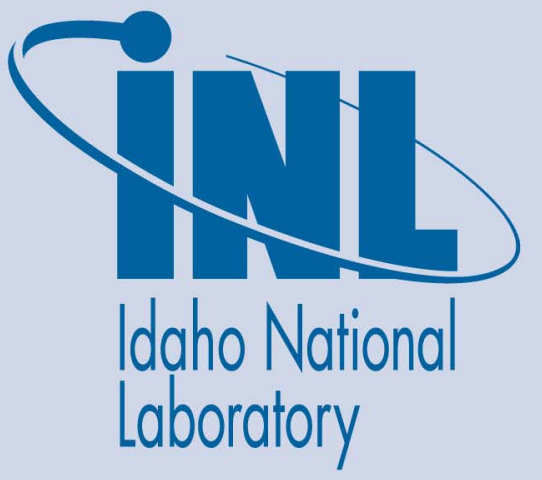

July 2006

The INL is a U.S. Department of Energy National Laboratory operated by Battelle Energy Alliance 
NL/EXT-05-00913

\title{
Advanced Technology Development Program for Lithium-Ion Batteries: Gen 2 Performance Evaluation Final Report
}

\author{
Jon P. Christophersen (INL) \\ Ira Bloom (ANL) \\ Edward V. Thomas (SNL) \\ Kevin L. Gering (INL) \\ Gary L. Henriksen (ANL) \\ Vincent S. Battaglia (LBNL) \\ David Howell (DOE)
}

July 2006

Idaho National Laboratory

Idaho Falls, Idaho 83415

Prepared for the

U.S. Department of Energy

Assistant Secretary for Energy Efficiency and Renewable Energy

Under DOE Idaho Operations Office

Contract DE-AC07-05ID14517 


\section{Disclaimer}

This report was prepared as an account of work sponsored by an agency of the United States Government. Neither the United States Government nor any agency thereof, nor any of their employees, makes any warranty, express or implied, or assumes any legal liability or responsibility for the accuracy, completeness, or usefulness of any information, apparatus, product, or process disclosed, or represents that its use would not infringe privately owned rights. References herein to any specific commercial product, process, or service by trade name, trademark, manufacturer, or otherwise does not necessarily constitute or imply its endorsement, recommendation, or favoring by the United States Government or any agency thereof. The views and opinions of authors expressed herein do not necessarily state or reflect those of the United States Government or any agency thereof. 


\section{ABSTRACT}

The Advanced Technology Development Program has completed performance testing of the second generation of lithium-ion cells (i.e., Gen 2 cells). The 18650-size Gen 2 cells, with a baseline and variant chemistry, were distributed over a matrix consisting of three states-of-charge (SOCs) $(60,80$, and $100 \%$ SOC), four temperatures $\left(25,35,45\right.$, and $\left.55^{\circ} \mathrm{C}\right)$, and three life tests (calendar-, cycle-, and accelerated-life). The calendar- and accelerated-life cells were clamped at an open-circuit voltage corresponding to the designated SOC and were subjected to a once-per-day pulse profile. The cycle-life cells were continuously pulsed using a profile that was centered around $60 \%$ SOC. Life testing was interrupted every four weeks for reference performance tests (RPTs), which were used to quantify changes in cell degradation as a function of aging. The RPTs generally consisted of $\mathrm{C}_{1} / 1$ and $\mathrm{C}_{1} / 25$ static capacity tests, a low-current hybrid pulse power characterization test, and electrochemical impedance spectroscopy. The rate of cell degradation generally increased with increasing test temperature, and SOC. It was also usually slowest for the calendar-life cells and fastest for the accelerated-life cells. Detailed capacity-, power-, and impedance-based performance results are reported. 


\section{EXECUTIVE SUMMARY}

In conjunction with the Partnership for a New Generation of Vehicles (PNGV), the Advanced Technology Development (ATD) Program was initiated in 1998 by the U.S. Department of Energy to find solutions to the barriers that limit the commercialization of high-power lithium-ion batteries. In 2002, PNGV was superseded by FreedomCAR (Freedom Cooperative Automotive Research) and this work is now under the auspices of the FreedomCAR and Vehicle Technologies Program. This report documents the performance evaluation of the second generation of 18650-size ATD lithium-ion cells (i.e., Gen 2 cells) that were calendar-life tested at the Argonne National Laboratory, cycle-life tested at the Idaho National Laboratory, and accelerated-life tested at Sandia National Laboratories. The Gen 2 cells consisted of a baseline chemistry and one variant chemistry (i.e., Variant C). The Variant $\mathrm{C}$ chemistry contained a higher concentration of aluminum dopant in the positive electrode. A second variant chemistry with a change to the negative electrode (GDR cells) was also investigated, but the data were inconclusive due to poor performance.

The calendar- and cycle-life cells were aged at 60\% state-of-charge (SOC) and various temperatures. For the Baseline cells, calendar-life testing was performed at 45 and $55^{\circ} \mathrm{C}$, and cycle-life testing at 25 and $45^{\circ} \mathrm{C}$. The Variant $\mathrm{C}$ calendar- and cycle-life cell groups were both aged at $45^{\circ} \mathrm{C}$. Accelerated-life testing consisted only of Baseline cells, which were distributed over a matrix covering three SOCs $(60,80$, and $100 \%$ SOC), and four temperatures $\left(25,35,45\right.$, and $\left.55^{\circ} \mathrm{C}\right)$. All cells were initially subjected to characterization testing, as defined in the cell-specific test plans. Although the standard FreedomCAR characterization consists of a $\mathrm{C}_{1} / 1$ static capacity and lowcurrent hybrid pulse power characterization test, the Gen 2 cells were also subjected to a $\mathrm{C}_{1} / 25$ static capacity test and electrochemical impedance spectroscopy (EIS) as new, exploratory tests to help gain a better understanding of cell degradation. These four tests were also a part of the reference performance tests (RPTs) that were performed every four weeks during aging. The RPTs were used to gauge the degradation in capacity, power, and impedance as a function of cell age, normalized to the characterization RPT. However, it was also determined that the RPTs contributed to cell degradation as well. Pairs of cells from each calendar- and cycle-life groups were removed from test at roughly equal power fade increments and sent to diagnostic laboratories for analysis. The end-of-test criterion for these cells was such that the next-to-last pair of cells was removed from test with approximately $30 \%$ power fade. The remaining cells were aged to $50 \%$ power fade.

The Baseline cell degradation generally increased with increasing temperature, SOC, and life test. The rate of degradation was usually slowest for the calendar-life

cells, in the middle for the cycle-life cells, and highest for the accelerated-life cells. The data also generally showed two different mechanisms that affected cell performance. The Baseline cells usually degraded more slowly earlier in life, and more rapidly once the second mechanism dominated cell behavior. The point at which the second mechanism took effect usually occurred earlier in life with increasing temperature and SOC. The $45^{\circ} \mathrm{C}$ Variant $\mathrm{C}$ cells also showed two different mechanisms, but with the opposite trend. These cells initially showed rapid degradation, followed by a very slow rate later in life. The Baseline cells aged to $50 \%$ 
power fade generally showed the same amount of $\mathrm{C}_{1} / 1$ capacity fade $(\sim 32 \%)$ regardless of test temperature and $\mathrm{SOC}$, and a small increase in $\mathrm{C}_{1} / 25$ capacity fade with increasing test temperature and SOC. The $45^{\circ} \mathrm{C}$ Variant $\mathrm{C}$ cells aged to $50 \%$ power fade showed about the same $\mathrm{C}_{1} / 1$ and $\mathrm{C}_{1} / 25$ capacity fades regardless of life test.

The two exploratory tests included as part of the RPT $\left(\mathrm{C}_{1} / 25\right.$ and EIS $)$ provided valuable additional information about cell degradation as a function of test time. Since the $\mathrm{C}_{1} / 25$ test requires very small currents, it showed the amount of accessible capacity as a function of life, and was useful for investigating the relationship between voltage and capacity under pseudo-equilibrium conditions. It was determined that side reactions on the negative electrode are the primary source of capacity loss. EIS is a low impact reference performance test that provides impedance data over a range of frequencies. However, the cable configuration is critical for consistent and repeatable results. It was determined that the impedance magnitude at the semicircle trough (between the charge transfer resistance and the Warburg) is correlated to the discharge impedance determined from the low-current hybrid pulse power characterization test.

The Gen 2 data has been used to develop various models for life prediction, each showing two mechanisms operating on the cell. An empirical model was applied to the accelerated-life cells and showed an initially quick degradation (i.e., during the first four weeks, possibly due to formation) followed by a $t^{3 / 2}$ kinetics. The two-step model provides a simple mechanistic explanation for the two different degradation rates in cell behavior (square root of time and linear time dependence). The multiple sigmoid model is an alternate method of cell data analysis and performance prediction. The double sigmoid model is a special case of the multiple sigmoid model that assigns two primary degradation mechanisms, and has demonstrated good accuracy in predicting power fade over extended aging for Gen2 Baseline and Variant $\mathrm{C}$ cells, as well as correlating other performance data such as the accelerated-life test data.

Spare Gen 2 Baseline cells (both fresh and aged cells) were also used for various low temperature studies that included EIS and cold cranking. It was determined that a phase transition occurs between 25 and $10^{\circ} \mathrm{C}$, and that the activation energy is independent of SOC. The cells were not capable of meeting the FreedomCAR cold crank goals at approximately -15 and $-5^{\circ} \mathrm{C}$ for the fresh and aged cells, respectively. Additionally, button cells were manufactured using the Gen 2 chemistry to assess the impact of cycling on capacity fade and impedance rise. Concentration polarization is doubtless a key contributor to the decrease in achievable charge and discharge capacities as a function of test temperature. 


\section{ACKNOWLEDGMENTS}

We thank the following people for their technical and programmatic support:

Daniel Abraham

Khalil Amine

Andrew Jansen

Scott Jones

Ben Potter

Jim McBreen

Xiao-Qing Yang

Michael R. Anderson

Jim Barnes

Tien Duong

Ted Miller

David Glenn

Chinh Ho

Gary Hunt

Chet Motloch

Tim Murphy

Randy Wright

Frank McLarnon

Hisashi Tsukamoto

Herb Case

Dan Doughty

Rudy Jungst

Ganesan Nagasubramanian

Pete Roth
Argonne National Laboratory

Argonne National Laboratory

Argonne National Laboratory

Argonne National Laboratory

Argonne National Laboratory

Brookhaven National Laboratory

Brookhaven National Laboratory

DOE-ID

DOE-HQ

DOE-HQ

Ford Motor Company

Idaho National Laboratory

Idaho National Laboratory

Idaho National Laboratory (consultant)

Idaho National Laboratory

Idaho National Laboratory

Idaho National Laboratory

Lawrence Berkeley National Laboratory

Quallion, LLC

Sandia National Laboratories

Sandia National Laboratories

Sandia National Laboratories

Sandia National Laboratories

Sandia National Laboratories 


\section{CONTENTS}

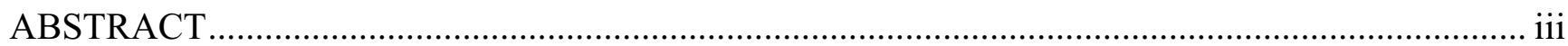

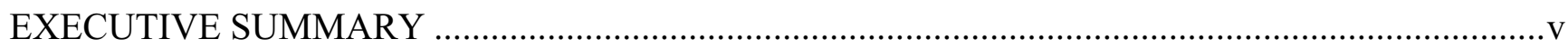

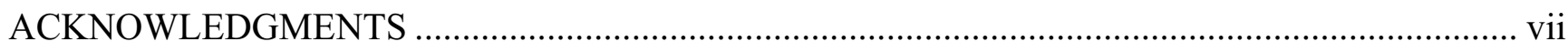

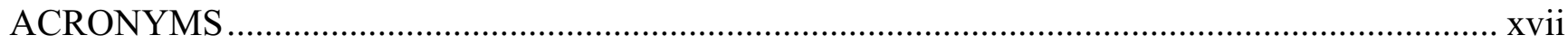

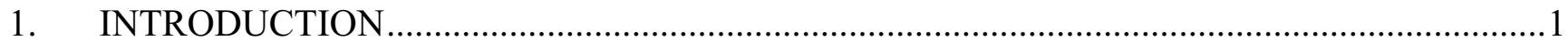

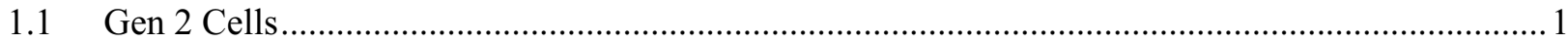

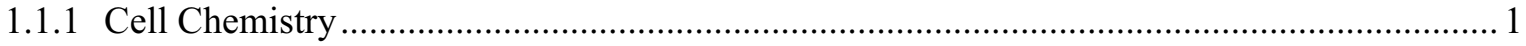

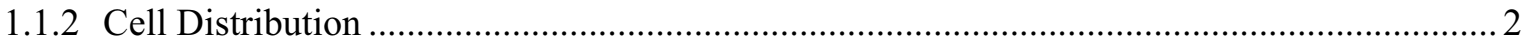

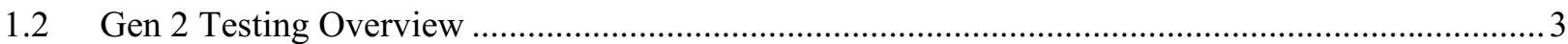

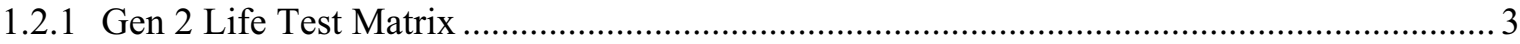

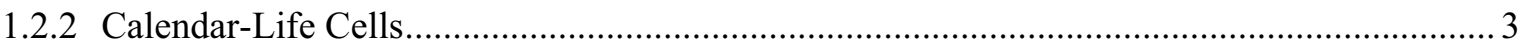

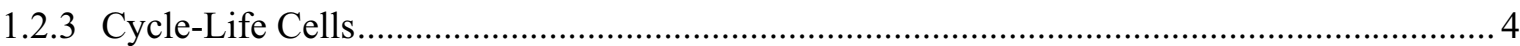

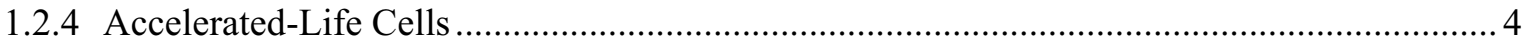

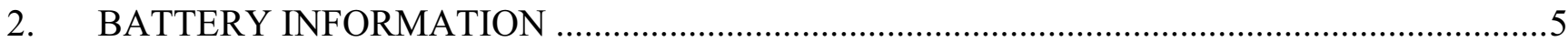

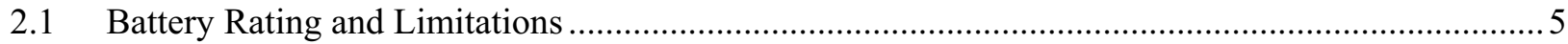

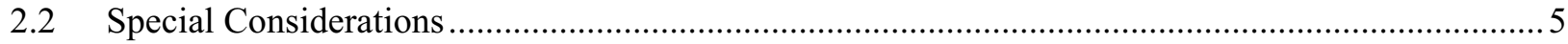

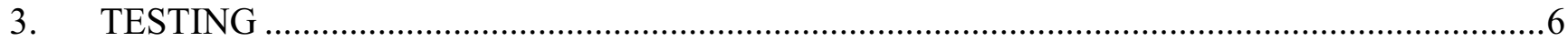

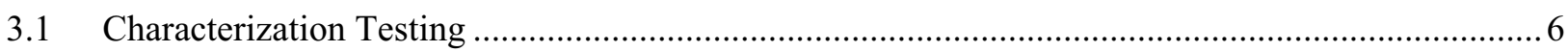

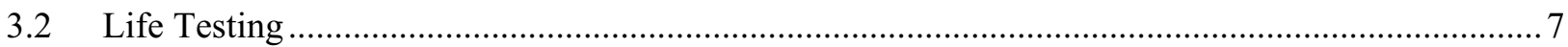

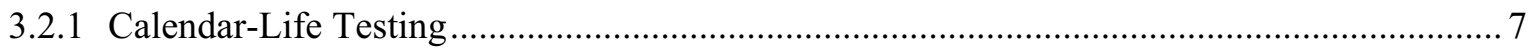

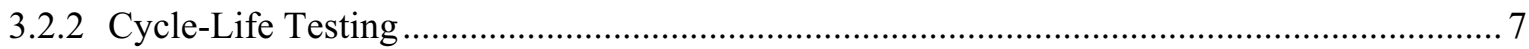

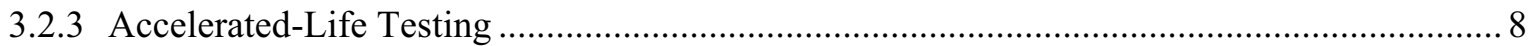

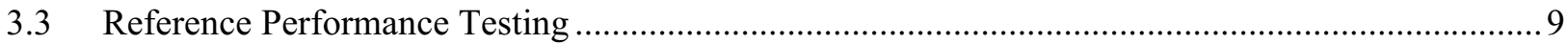

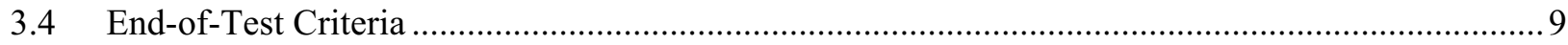

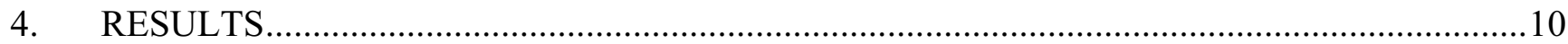

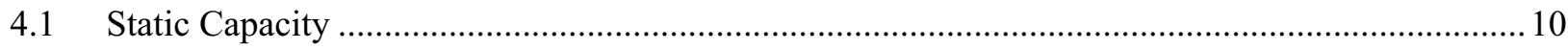

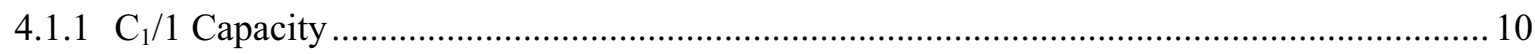

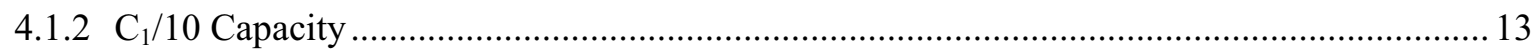

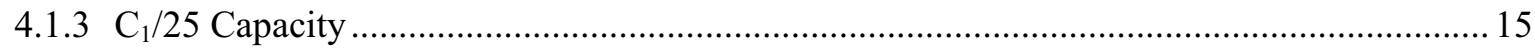

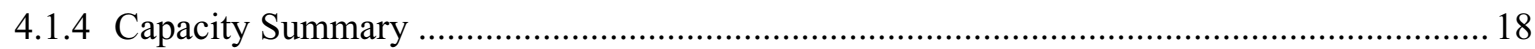

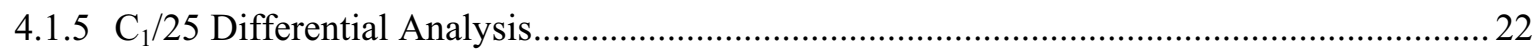

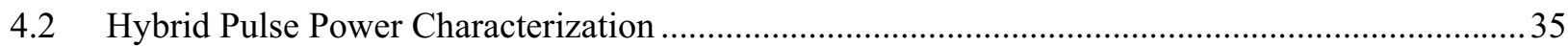

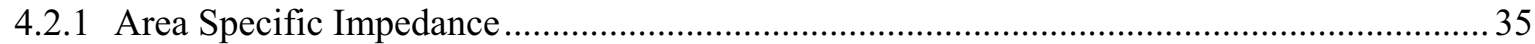




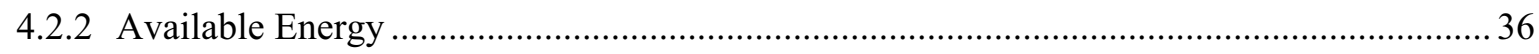

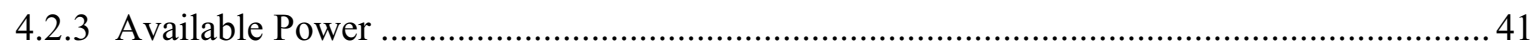

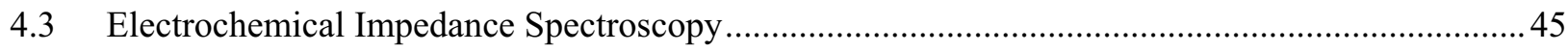

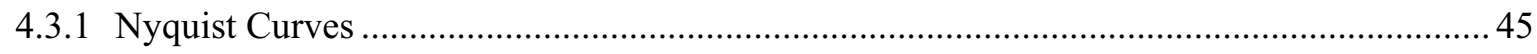

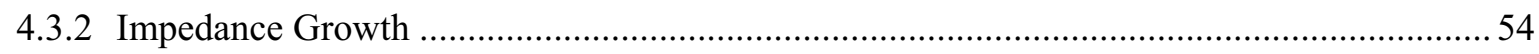

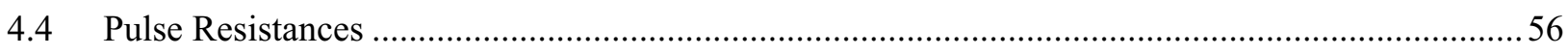

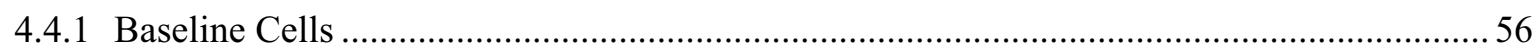

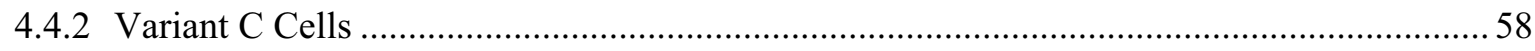

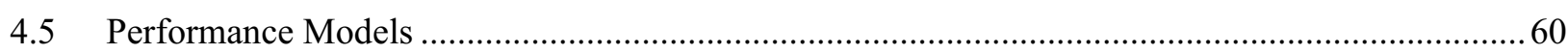

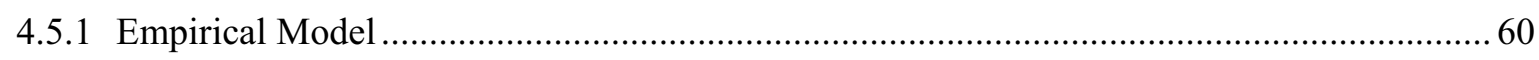

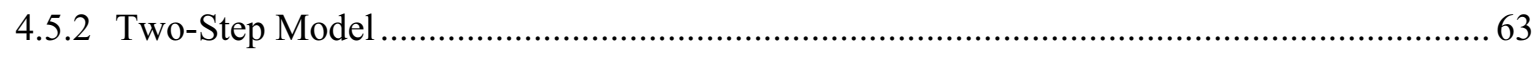

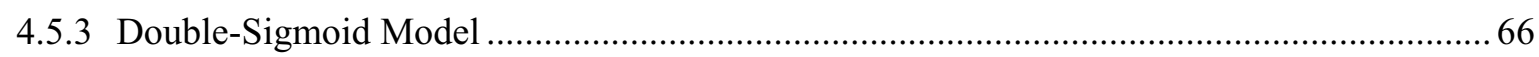

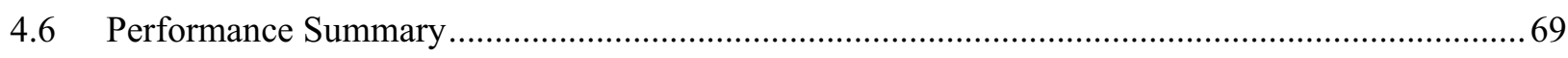

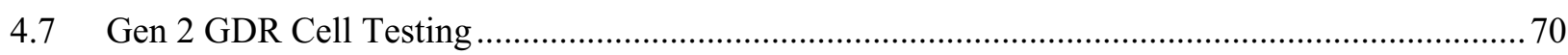

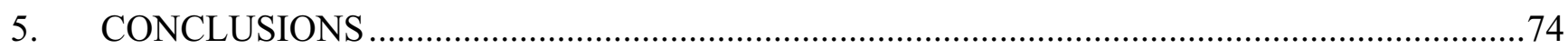

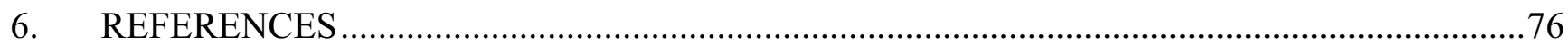

A. ADDITIONAL GEN 2 STUDIES AND SUPPLEMENTAL DATA ....................................81

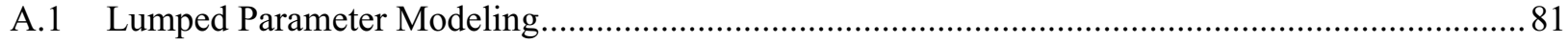

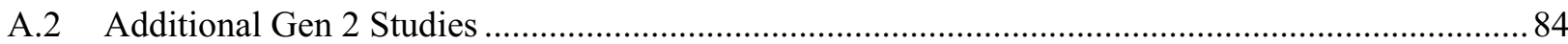

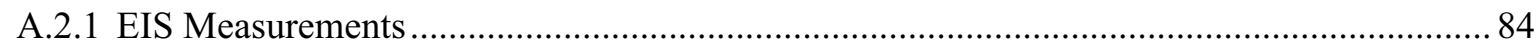

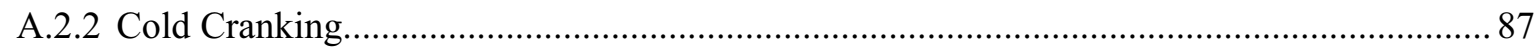

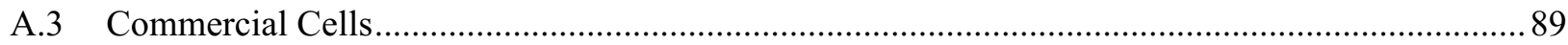

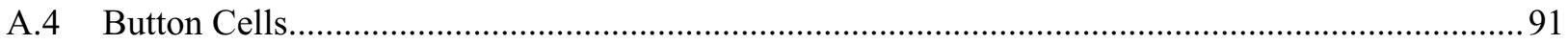

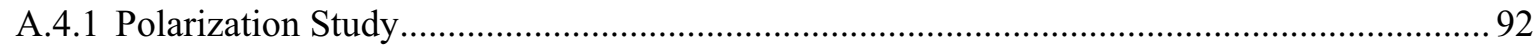

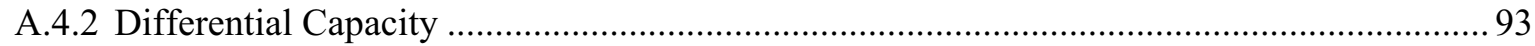

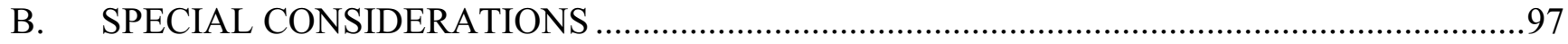

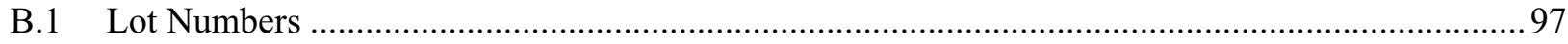

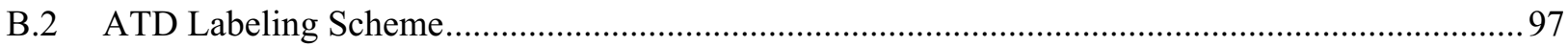

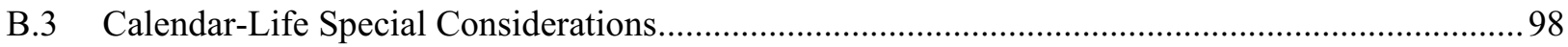

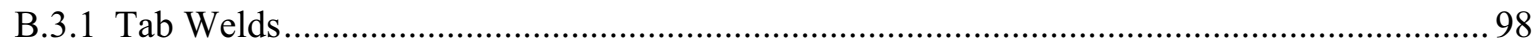

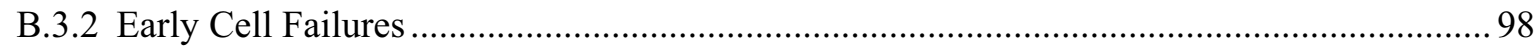

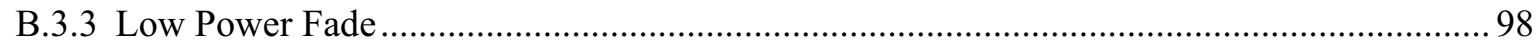

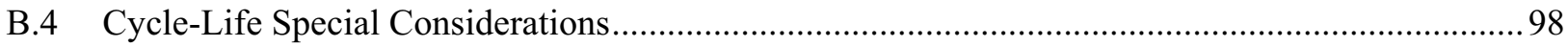

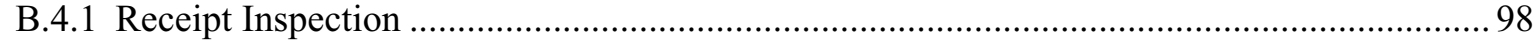




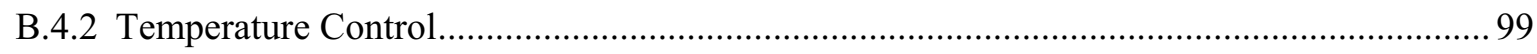

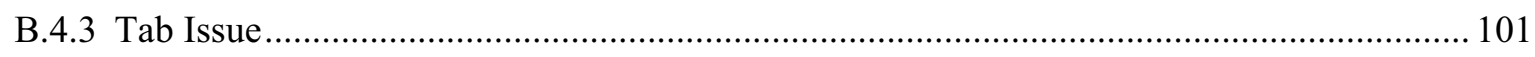

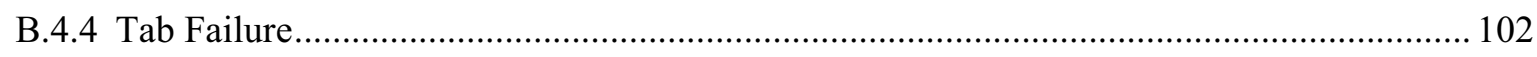

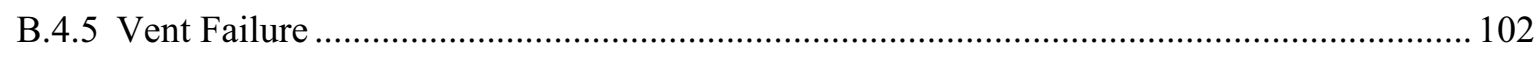

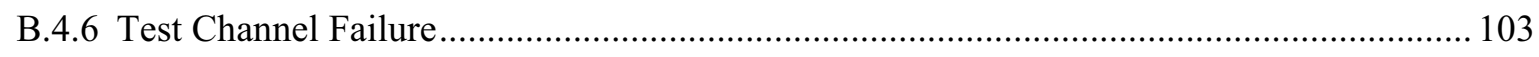

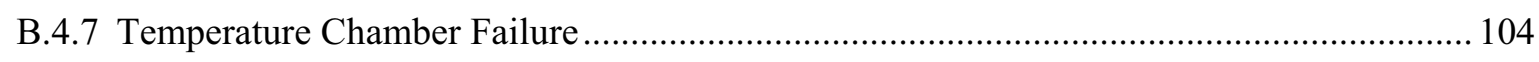

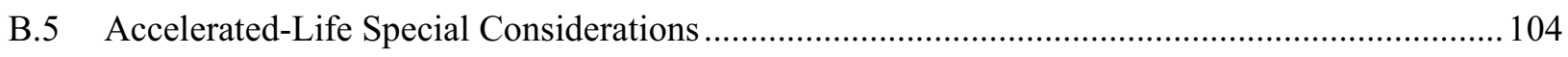

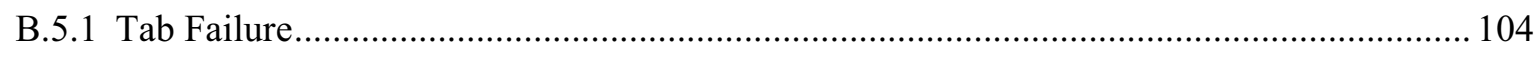

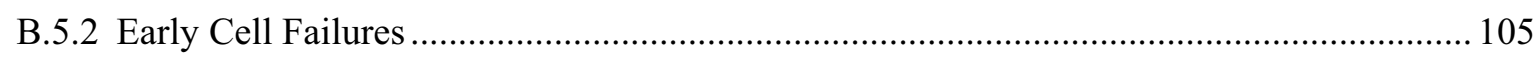

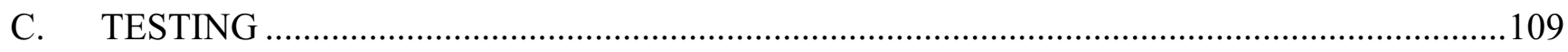

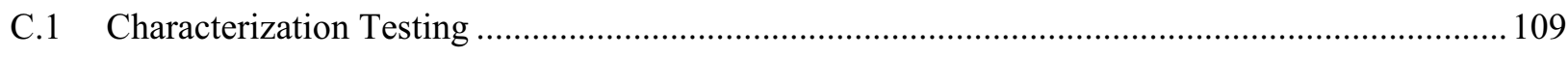

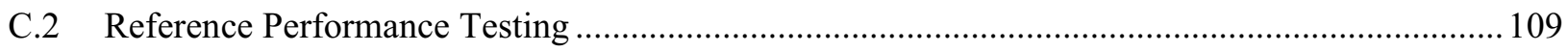

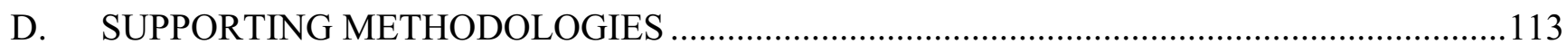

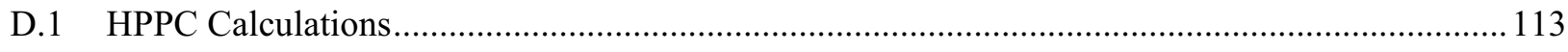

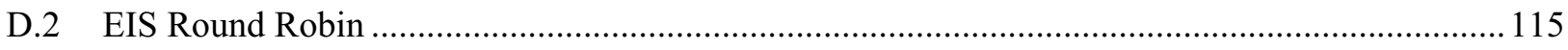

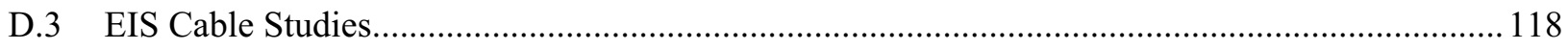

FIGURES

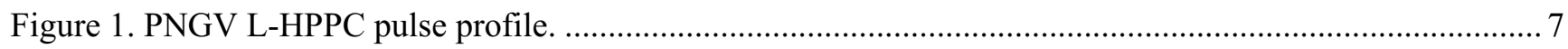

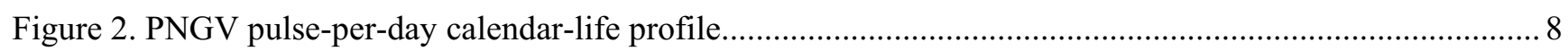

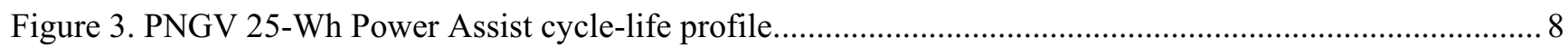

Figure 4. Average $C_{1} / 1$ discharge capacity for the Baseline CalLT and CycLT cell groups.............................. 11

Figure 5. Average $C_{1} / 1$ discharge capacity for the Baseline ALT cell groups at $60 \%$ SOC. ............................. 11

Figure 6. Average $C_{1} / 1$ discharge capacity for the Baseline ALT cell groups at 80\% SOC. ............................. 12

Figure 7. Average $C_{1} / 1$ discharge capacity for the Baseline ALT cell groups at $100 \%$ SOC............................ 12

Figure 8. Average $\mathrm{C}_{1} / 1$ discharge capacity for the Variant C CalLT and CycLT cell groups........................... 13

Figure 9. Static capacity tests for the accelerated-life cells at $60 \%$ SOC .................................................... 14

Figure 10. Static capacity tests for the accelerated-life cells at $80 \%$ SOC. .................................................. 14

Figure 11. Static capacity tests for the accelerated-life cells at 100\% SOC. ................................................ 15

Figure 12. Average $C_{1} / 25$ discharge capacity for the Baseline CalLT and CycLT cell groups......................... 16

Figure 13. Average $C_{1} / 25$ discharge capacity for the Baseline ALT cell groups at $60 \%$ SOC......................... 16

Figure 14. Average $C_{1} / 25$ discharge capacity for the Baseline ALT cell groups at $80 \%$ SOC......................... 17

Figure 15. Average $C_{1} / 25$ discharge capacity for the Baseline ALT cell groups at $100 \%$ SOC........................ 17

Figure 16. Average $\mathrm{C}_{1} / 25$ discharge capacity for the Variant C CalLT and CycLT cell groups........................ 18

Figure 17. Average $C_{1} / 1$ and $C_{1} / 25$ discharge capacity fade for the cycle-life cells....................................... 19 
Figure 18. Average $C_{1} / 1$ and $C_{1} / 25$ discharge capacity fade for the calendar-life cells.

Figure 19. Average $C_{1} / 1$ and $C_{1} / 25$ discharge capacity fade for the accelerated-life cells at $60 \%$ SOC. 20

Figure 20. Average $C_{1} / 1$ and $C_{1} / 25$ discharge capacity fade for the accelerated-life cells at $80 \%$ SOC. 21

Figure 21. Average $\mathrm{C}_{1} / 1$ and $\mathrm{C}_{1} / 25$ discharge capacity fade for the accelerated-life cells at $100 \%$ SOC. 21

Figure 22. Differential capacity for a representative $25^{\circ} \mathrm{C}$ cycle-life Baseline cell....................................... 23

Figure 23. Differential capacity for a representative $45^{\circ} \mathrm{C}$ cycle-life Baseline cell.........................................23

Figure 24. Differential capacity for a representative $45^{\circ} \mathrm{C}$ calendar-life Baseline cell....................................2 24

Figure 25. Differential capacity for a representative $55^{\circ} \mathrm{C}$ calendar-life Baseline cell.....................................24

Figure 26. Differential capacity for a representative $45^{\circ} \mathrm{C}$ cycle-life Variant $\mathrm{C}$ cell........................................ 25

Figure 27. Differential capacity for a representative $45^{\circ} \mathrm{C}$ calendar-life Variant $\mathrm{C}$ cell..................................26

Figure 28. Changes in $\mathrm{C}_{1} / 25$ cell voltage as a function of capacity for a representative Variant $\mathrm{C}$ cell..............27

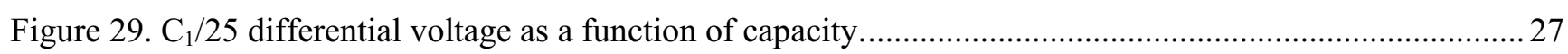

Figure $30 . \mathrm{C}_{1} / 25$ differential voltage as a function of capacity with peak 2 aligned. ....................................28

Figure 31. $\mathrm{C}_{1} / 25$ differential voltage as a function of capacity, peak 1 and 3 are related................................29

Figure 32. $\mathrm{C}_{1} / 25$ differential voltage calculated from half-cell data before and after capacity fade. ..................29

Figure 33. Variant $\mathrm{C}$ calendar life cell displaying a split peak 2 ................................................................. 30

Figure 34. Variant $\mathrm{C}$ calendar life cell showing one peak 2 that splits into two with aging.............................. 31

Figure 35. Calculated dV/dQ curves assuming non-uniform capacity fading at the anode................................ 31

Figure 36. Example of dV/dQ curves displaying a shrinking peak 2 for a representative cycle-life cell............. 33

Figure 37. Height of peak 2 vs. time for cycle- and calendar-life cells. .......................................................... 33

Figure 38. Height of peak 2 vs. the square root of time for the cycle life cells. .............................................. 34

Figure 39. $-Q_{0} d V / d Q$ vs. relative capacity from half-cells containing aged and unaged anode materials........... 34

Figure 40. Average discharge ASI for the Baseline calendar- and cycle-life cells at $60 \%$ SOC....................... 35

Figure 41. Average discharge ASI for the Variant C calendar- and cycle-life cells at $60 \%$ SOC ...................... 36

Figure 42. Available energy for the $25^{\circ} \mathrm{C}$ Baseline cycle-life cells at $60 \%$ SOC ............................................3

Figure 43. Available energy for the $45^{\circ} \mathrm{C}$ Baseline calendar-life cells at $60 \%$ SOC ....................................... 38

Figure 44. Available energy for the $45^{\circ} \mathrm{C}$ Baseline cycle-life cells at $60 \%$ SOC ............................................ 38

Figure 45. Available energy for the $45^{\circ} \mathrm{C}$ Baseline accelerated-life cells at $60 \%$ SOC................................... 39

Figure 46. Available energy for the $45^{\circ} \mathrm{C}$ Baseline accelerated-life cells at $80 \%$ SOC................................... 39

Figure 47. Available energy for the $45^{\circ} \mathrm{C}$ Baseline accelerated-life cells at $100 \%$ SOC.................................40

Figure 48. Available energy for the $55^{\circ} \mathrm{C}$ Baseline calendar-life cells at $60 \%$ SOC ...................................... 40

Figure 49. Available energy for the $45^{\circ} \mathrm{C}$ Variant $\mathrm{C}$ calendar-life cells at $60 \%$ SOC ..................................... 41

Figure 50. Available energy for the $45^{\circ} \mathrm{C}$ Variant $\mathrm{C}$ cycle-life cells at $60 \%$ SOC . ......................................... 42

Figure 51. Average power at $300 \mathrm{Wh}$ for the Baseline CalLT and CycLT cell groups..................................... 42

Figure 52. Average power at $300 \mathrm{Wh}$ for the Baseline ALT cell groups at $60 \%$ SOC................................... 43 
Figure 53. Average power at $300 \mathrm{Wh}$ for the Baseline ALT cell groups at $80 \% \mathrm{SOC}$

Figure 54. Average power at $300 \mathrm{Wh}$ for the Baseline ALT cell groups at 100\% SOC................................... 44

Figure 55. Average power at $300 \mathrm{Wh}$ for the Variant C CalLT and CycLT cell groups................................... 45

Figure 56. 60\% SOC EIS for a representative $25^{\circ} \mathrm{C}$ Baseline cycle-life cell at 140 weeks.............................. 46

Figure 57. $60 \%$ SOC EIS for a representative $25^{\circ} \mathrm{C}$ Baseline cycle-life cell................................................47

Figure 58. 60\% SOC EIS for a representative $45^{\circ} \mathrm{C}$ Baseline calendar-life cell. ............................................... 47

Figure 59. 60\% SOC EIS for a representative $45^{\circ} \mathrm{C}$ Baseline cycle-life cell................................................... 48

Figure $60.60 \%$ SOC EIS for a representative $45^{\circ} \mathrm{C}$ Baseline accelerated-life cell. .......................................... 48

Figure $61.60 \%$ SOC EIS for a representative $55^{\circ} \mathrm{C}$ Baseline calendar-life cell. .............................................. 49

Figure $62.60 \%$ SOC EIS for a representative $45^{\circ} \mathrm{C}$ Baseline accelerated-life cell at $80 \%$ SOC......................50

Figure $63.60 \%$ SOC EIS for a representative $45^{\circ} \mathrm{C}$ Baseline accelerated-life cell at $100 \%$ SOC ....................50

Figure $64.100 \%$ SOC EIS for a representative $45^{\circ} \mathrm{C}$ Baseline accelerated-life cell at $60 \%$ SOC.................... 51

Figure $65.100 \%$ SOC EIS for a representative $45^{\circ} \mathrm{C}$ Baseline accelerated-life cell at $80 \%$ SOC.................... 51

Figure $66.100 \%$ SOC EIS for a representative $45^{\circ} \mathrm{C}$ Baseline accelerated-life cell at $100 \%$ SOC.................... 52

Figure $67.60 \%$ SOC EIS for a representative $45^{\circ} \mathrm{C}$ Variant $\mathrm{C}$ calendar-life cell............................................. 53

Figure $68.60 \%$ SOC EIS for a representative $45^{\circ} \mathrm{C}$ Variant $\mathrm{C}$ cycle-life cell................................................. 53

Figure 69. Average EIS magnitude for the Baseline calendar- and cycle-life cells at $60 \%$ SOC......................5 54

Figure 70. Average EIS magnitude for the Variant $\mathrm{C}$ calendar- and cycle-life cells at $60 \%$ SOC.....................55

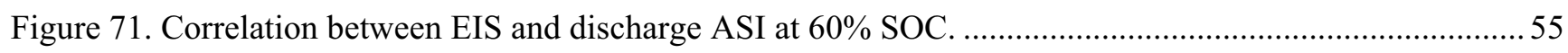

Figure 72. Cycle-life pulse resistance for a representative $25^{\circ} \mathrm{C}$ Baseline cell..............................................56

Figure 73. Cycle-life pulse resistance for a representative $45^{\circ} \mathrm{C}$ Baseline cell..............................................57

Figure 74. Calendar-life pulse resistance for a representative $45^{\circ} \mathrm{C}$ Baseline cell. .........................................5 57

Figure 75. Calendar-life pulse resistance for a representative $55^{\circ} \mathrm{C}$ Baseline cell. .........................................5 58

Figure 76. Cycle-life pulse resistance for a representative $45^{\circ} \mathrm{C}$ Variant $\mathrm{C}$ cell.............................................5 59

Figure 77. Calendar-life pulse resistance for a representative $45^{\circ} \mathrm{C}$ Variant $\mathrm{C}$ cell........................................55

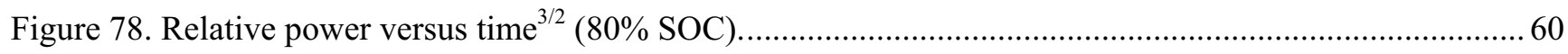

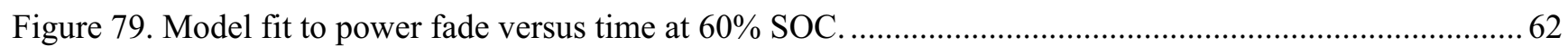

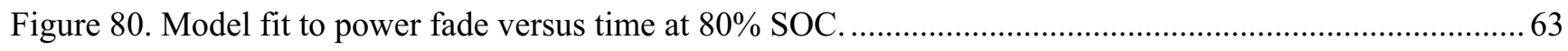

Figure 81. Model fit to the average $\mathrm{C}_{1} / 1$ discharge capacity for the CalLT and CycLT cell groups..................6 64

Figure 82. Model fit to the average discharge ASI for the CalLT and CycLT cell groups................................ 65

Figure 83. Model fit to the average $\mathrm{C}_{1} / 25$ discharge capacity for the CalLT and CycLT cell groups.................65

Figure 84. Average power fade versus time and the DSM predictions after 68 weeks of aging......................... 66

Figure 85. DSM fits for the accelerated-life average power fade at (a) 60\%, (b) 80\%, and (c) 100\% SOC. .......68

Figure 86. Average $\mathrm{C}_{1} / 1$ capacity versus time for the GDR-only and GDR+VEC cells................................71

Figure 87 . Average $C_{1} / 25$ capacity versus time for the GDR-only, GDR+VEC and Baseline cells. ................. 71 
Figure 88. Average discharge ASI versus time for the GDR-only, GDR+VEC and Baseline cells.................. 72

Figure 89. Average BSF-scaled power versus time for the GDR-only, GDR+VEC and Baseline cells. ............ 73

Figure 90. 60\% SOC EIS for a representative GDR-only cell.................................................................. 73

Figure 91. 60\% SOC EIS for a representative GDR+VEC cell................................................................. 74

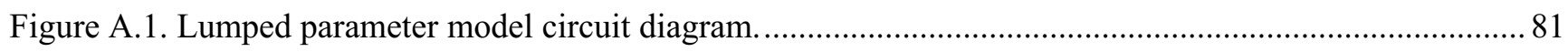

Figure A.2. LPM voltage response estimation for a L-HPPC pulse. ............................................................. 82

Figure A.3. LPM voltage response estimation for a cycle-life pulse............................................................ 82

Figure A.4. Average ohmic and polarization resistance for the $25^{\circ} \mathrm{C}$ Baseline cycle-life cells. ....................... 83

Figure A.5. Average ohmic and polarization resistance for the $45^{\circ} \mathrm{C}$ Baseline cycle-life cells. ........................ 83

Figure A.6. Average ohmic and polarization resistance for the $45^{\circ} \mathrm{C}$ Variant $\mathrm{C}$ cycle-life cells........................ 84

Figure A.7. 60\% SOC EIS for a representative aged and fresh cell. ............................................................ 85

Figure A.8. 60\% SOC EIS for a representative aged and fresh cell (zoomed in)........................................... 85

Figure A.9. 60\% SOC AC impedance at the semicircle trough as a function of temperature............................ 86

Figure A.10. 100\% SOC AC impedance at the semicircle trough as a function of temperature........................ 87

Figure A.11. Cold crank capability for the third discharge pulse. .............................................................. 88

Figure A.12. Cold cranking ohmic and polarization resistances for a fresh cell. ............................................ 88

Figure A.13. Cold cranking ohmic and polarization resistances for an aged cell............................................. 89

Figure A.14. Average power fade for the $45^{\circ} \mathrm{C}$ Baseline calendar-, cycle-, and accelerated-life cells. .............. 90

Figure A.15. Average capacity and power fade for each "partial” RPT group PowerfLite cells. ....................... 91

Figure A.16. Polarization plots obtained from button cells. ....................................................................... 93

Figure A.17. Differential capacity vs. temperature at a $\mathrm{C}_{1} / 10$ rate. ............................................................ 94

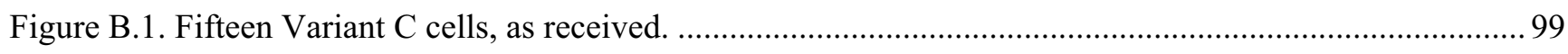

Figure B.2. Thermal block temperature control experiment with ten heat sources (RTD control).................. 100

Figure B.3. Thermal block temperature control experiment with ten heat sources (block control). ................. 100

Figure B.4. Thermal block with seven Gen 2 cycle-life cells................................................................... 101

Figure B.5. ATD Gen 2 cycle-life cell with brass connectors and vellum insulator on the negative tab. .......... 102

Figure B.6. G2.60L25.I101.00.NA.NA.T.A with failed tab. ...................................................................... 103

Figure B.7. G2C.60L45.I173.00.NA.NA.L.Q with broken vent and electrolyte leakage................................ 103

Figure B.8. Aluminum/nickel welds on the positive tab.......................................................................... 104

Figure B.9. Reinforcement aluminum strip on the positive tabs................................................................. 104

Figure D.1. Pulse resistance for a representative Baseline cell at BOL........................................................ 113

Figure D.2. Pulse power capability for a representative Baseline cell at BOL............................................... 114

Figure D.3. Available energy for a representative Baseline cell at BOL..................................................... 115

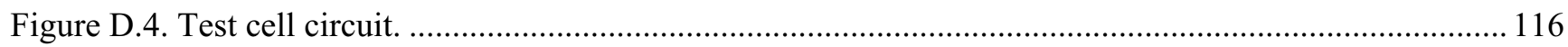

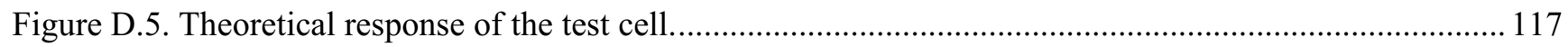




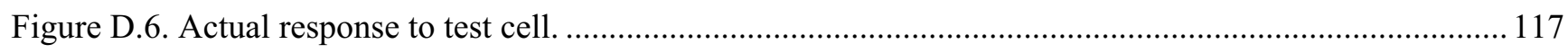

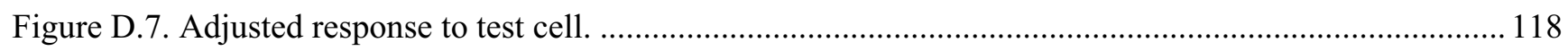

Figure D.8. (a) Simple four-terminal connection; (b) Resulting Nyquist curve. ............................................ 119

Figure D.9. (a) Small change in the simple four-terminal connection; (b) Resulting Nyquist curve. ............... 119

Figure D.10. (a) Braiding of the sense and working electrode leads; (b) Resulting Nyquist curve.................. 120

Figure D.11. (a) Further braiding of the sense and working electrode leads; (b) Resulting Nyquist curve........ 120

\section{TABLES}

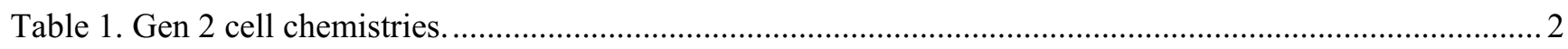

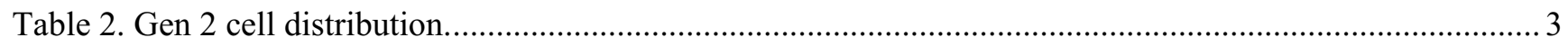

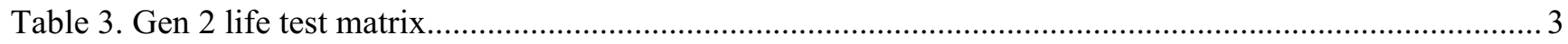

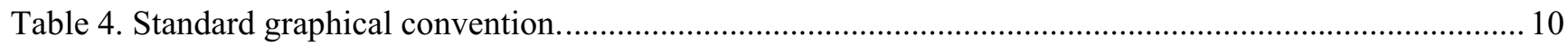

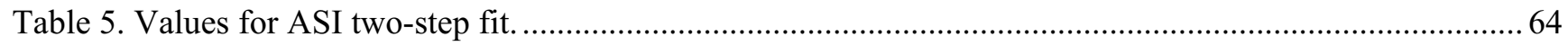

Table 6. Summary of DSM parameters for analysis of the accelerated-life cells (all four temperatures)............67

Table 7. End-of-life summary for the calendar- and cycle-life cells. ............................................................... 69

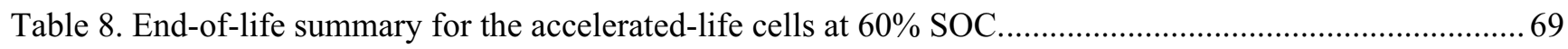

Table 9. End-of-life summary for the accelerated-life cells at $80 \%$ SOC .......................................................70

Table 10. End-of-life summary for the accelerated-life cells at 100\% SOC................................................... 70

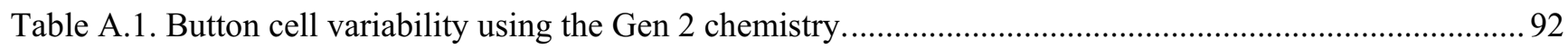

Table B.1. Receipt inspection measurements for the three cycle-life cell groups. ...........................................99

Table C.1. Characterization tests performed at each laboratory................................................................... 109

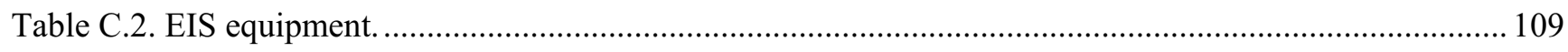

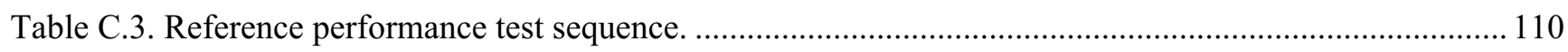




\section{ACRONYMS}

ALT accelerated-life test

ANL Argonne National Laboratory

ASI area-specific impedance

ATD Advanced Technology Development

BL Baseline cells

BNL Brookhaven National Laboratory

BOL beginning-of-life

BSF battery size factor

CalLT calendar-life test

CycLT cycle-life test

DOD depth-of-discharge

DOE Department of Energy

DSM double sigmoid model

EIS electrochemical impedance spectroscopy

EOT end of test

FreedomCAR Freedom Cooperative Automotive Research

Gen Generation

INL Idaho National Laboratory

LBNL Lawrence Berkeley National Laboratory

L-HPPC low-current hybrid pulse power characterization

MSM multiple sigmoid model

OCV open-circuit voltage

OSPS operating set point stability

PNGV Partnership for a New Generation of Vehicles

RPT reference performance test

RTD resistance temperature detector

SEI solid electrolyte interphase

SOC state-of-charge

SNL Sandia National Laboratories

VARC Variant $\mathrm{C}$ cells

VEC Vinyl Ethylene Carbonate 
xviii 


\section{Advanced Technology Development Program for Lithium-Ion Batteries: Gen 2 Performance Evaluation Final Report}

\section{INTRODUCTION}

In conjunction with the Partnership for a New Generation of Vehicles (PNGV), the U.S. Department of Energy (DOE) initiated the Advanced Technology Development (ATD) Program in 1998 to address the technical barriers impeding the commercialization of high-power lithium-ion batteries for hybrid electric vehicle applications. These barriers include insufficient calendar life, high production costs, poor response to abuse scenarios, and poor low temperature performance. In 2002, PNGV was superceded by FreedomCAR (Freedom Cooperative Automotive Research), and this work is now sponsored by the FreedomCAR and Vehicle Technologies Program. A full description of the ATD Program within the context of the overall FreedomCAR energy storage research and development is provided in Reference 1.

Five DOE National Laboratories are participating in the ATD Program. Argonne National Laboratory (ANL) has overall programmatic and technical lead responsibilities, including cell chemistry. The Idaho National Laboratory (INL) has lead responsibility for cell testing and aging, in collaboration with ANL and Sandia National Laboratories (SNL). SNL has lead responsibility for the investigation of abuse tolerance. Lawrence Berkeley National Laboratory (LBNL) is the lead diagnostic laboratory, in collaboration with Brookhaven National Laboratory (BNL), ANL, SNL, and INL. These five National Laboratories are working in close coordination to develop a fundamental understanding of life degradation mechanisms and an accurate life prediction methodology; identify and mitigate factors limiting abuse tolerance; identify low cost materials, components, and technologies; and identify and mitigate factors that contribute to poor performance at low temperatures.

This report supercedes the February 2003 interim report (Reference 2).

\subsection{Gen 2 Cells}

\subsubsection{Cell Chemistry}

The second generation of ATD lithium-ion cells (i.e., Gen 2 cells) consisted of a baseline chemistry and two variants. The first variant chemistry (Variant $\mathrm{C}$ ) consisted of a change to the composition of the positive electrode, and the second variant (GDR) consisted of a change to the composition of the negative electrode. The Baseline, Variant C, and GDR cells were 18650-size and were manufactured in batches by Quallion, LLC to ANL specifications. The Gen 2 cell chemistries are defined in Reference 3 and summarized in Table 1.

The Variant $\mathrm{C}$ cell chemistry differs from the Gen 2 baseline chemistry by an increase to the aluminum dopant from 5 to $10 \%$ and a decrease to the cobalt from 15 to $10 \%$ in the positive electrode (i.e., $\mathrm{LiNi}_{0.8} \mathrm{Co}_{0.1} \mathrm{Al}_{0.1} \mathrm{O}_{2}$ ). The purpose of the increased aluminum dopant was to stabilize the positive electrode to provide longer life and improved abuse tolerance. Otherwise, the Gen 2 Baseline and Variant $\mathrm{C}$ cell chemistries are identical. This change, however, resulted in a $20 \%$ drop in the $\mathrm{C}_{1} / 1$ rated capacity $(0.8 \mathrm{Ah})$ at beginning-of-life (BOL) compared to the Baseline cell rated capacity of $1.0 \mathrm{Ah}$, and also impacted degradation rates. The GDR cell chemistry differs from the Gen 2 baseline chemistry with a 90 $\mathrm{wt} \%$ GDR graphite on the negative electrode with $10 \mathrm{wt} \%$ PVDF binder. The GDR graphite is a roundedge natural graphite that has an amorphous carbon coating at the particle level. Potential advantages 
over the MAG-10 include enhanced safety (due to the rounded edges) and relatively low cost. Some of the GDR cells also included a $2 \mathrm{wt} \%$ vinyl ethylene carbonate (VEC) electrolyte additive. These changes resulted in a $10 \%$ drop in the $\mathrm{C}_{1} / 1$ rated capacity $(0.9 \mathrm{Ah})$ at BOL.

Table 1. Gen 2 cell chemistries.

\begin{tabular}{|c|c|c|c|}
\hline & Baseline Cells & Variant C Cells & GDR Cells \\
\hline \multirow{4}{*}{$\begin{array}{l}\text { Positive } \\
\text { Electrode }\end{array}$} & $8 \mathrm{wt} \%$ PVDF binder & $8 \mathrm{wt} \%$ PVDF binder & $8 \mathrm{wt} \%$ PVDF binder \\
\hline & $4 \mathrm{wt} \%$ SFG- 6 graphite & $4 \mathrm{wt} \%$ SFG-6 graphite & $4 \mathrm{wt} \%$ SFG-6 graphite \\
\hline & $4 \mathrm{wt} \%$ carbon black & $4 \mathrm{wt} \%$ carbon black & $4 \mathrm{wt} \%$ carbon black \\
\hline & $84 \mathrm{wt} \% \mathrm{LiNi}_{0.8} \mathrm{Co}_{0.15} \mathrm{Al}_{0.05} \mathrm{O}_{2}$ & $84 \mathrm{wt} \% \mathrm{LiNi}_{0.8} \mathrm{Co}_{0.1} \mathrm{Al}_{0.1} \mathrm{O}_{2}$ & $84 \mathrm{wt} \% \mathrm{LiNi}_{0.8} \mathrm{Co}_{0.15} \mathrm{Al}_{0.05} \mathrm{O}_{2}$ \\
\hline \multirow{2}{*}{$\begin{array}{l}\text { Negative } \\
\text { Electrode }\end{array}$} & $8 \mathrm{wt} \%$ PVDF binder & $8 \mathrm{wt} \%$ PVDF binder & $10 \mathrm{wt} \%$ PVDF binder \\
\hline & $92 \mathrm{wt} \%$ MAG-10 graphite & $92 \mathrm{wt} \%$ MAG-10 graphite & $90 \mathrm{wt} \%$ GDR graphite \\
\hline Electrolyte & $\begin{array}{l}1.2 \underline{\mathrm{M}}^{\mathrm{LiPF}}{ }_{6} \text { in } \mathrm{EC}: \mathrm{EMC} \\
(3: 7 \mathrm{wt} \%)\end{array}$ & $\begin{array}{l}\text { 1.2 } \underline{\mathrm{M}}^{\mathrm{LiPF}}{ }_{6} \text { in EC:EMC } \\
(3: 7 \mathrm{wt} \%)\end{array}$ & $\begin{array}{l}\text { 1.2 } \underline{\mathrm{M}}_{\mathrm{LiPF}} \text { in EC:EMC } \\
(3: 7 \mathrm{wt} \%)\end{array}$ \\
\hline Separator & $25 \mu \mathrm{m}$ thick PE (Celgard) & $25 \mu \mathrm{m}$ thick PE (Celgard) & $25 \mu \mathrm{m}$ thick PE (Celgard) \\
\hline
\end{tabular}

\subsubsection{Cell Distribution}

Quallion manufactured a total of 249 Gen 2 cells (165 Baseline cells, 30 Variant C cells, and 54 GDR cells) for testing and diagnostics, and the cell distribution is shown in Table 2. Life testing and analyses were performed in accordance with the procedures outlined in the PNGV Battery Test Manual, Revision 3 (Reference 4), and as detailed in the cell-specific test plans. Cycle-life and calendar-life testing procedures are outlined in the PNGV Test Plan for Advanced Technology Development Gen 2 Lithium-Ion Cells (Reference 5). Accelerated-life testing procedures are outlined in the SNL ATD Gen 2 Test Plan (Reference 6). Both of these test plans are provided on the CD with this report. These cells were tested against the PNGV Power Assist goals (Reference 4). The majority of the GDR cells were used to validate a newly developed technology life verification test manual (Reference 7). The test matrix and data are presented in a separate report (Reference 8). However, six cells (three GDR cells and three GDR cells with VEC) were used for PNGV calendar-life testing as defined in Reference 5. 
Table 2. Gen 2 cell distribution.

\begin{tabular}{|c|c|c|c|c|}
\hline & Life Testing & Diagnostics & Thermal Abuse & Archive \\
\hline \multirow{2}{*}{ INL } & 30 Baseline Cells & & & \\
\hline & 15 Variant C Cells & & & \\
\hline \multirow{4}{*}{ ANL } & 15 Baseline Cells & 1 Baseline Cell & & 7 Baseline Cells \\
\hline & 15 Variant C Cells & & & \\
\hline & 3 GDR Cells & & & \\
\hline & 3 GDR Cells with VEC & & & \\
\hline SNL & 62 Baseline Cells & & 48 Baseline Cells & \\
\hline LBNL & & 1 Baseline Cell & & \\
\hline BNL & & 1 Baseline Cell & & \\
\hline
\end{tabular}

\subsection{Gen 2 Testing Overview}

\subsubsection{Gen 2 Life Test Matrix}

The Gen 2 life test matrix is shown in Table 3. The Baseline (BL) and Variant C (VC) cells were distributed over a test matrix consisting of three states-of-charge (SOCs) $(60,80$, and $100 \%$ SOC), four temperatures $\left(25,35,45\right.$, and $\left.55^{\circ} \mathrm{C}\right)$, and three life tests. Life testing consisted of calendar-life (CalLT), cycle-life (CycLT) and accelerated-life (ALT). The six GDR cells were calendar-life tested at 60\% SOC and $45^{\circ} \mathrm{C}$.

Table 3. Gen 2 life test matrix.

\begin{tabular}{|c|c|c|c|c|}
\hline & $25^{\circ} \mathrm{C}$ & $35^{\circ} \mathrm{C}$ & $45^{\circ} \mathrm{C}$ & $55^{\circ} \mathrm{C}$ \\
\hline \multirow{6}{*}{$60 \% \mathrm{SOC}$} & & & 2 BL CalLT & 15 BL CalLT \\
\hline & & & 6 GDR CalLT & \\
\hline & 15 BL CycLT & & 15 BL CycLT & \\
\hline & $3 \mathrm{BL}$ ALT & $3 \mathrm{BL}$ ALT & 3 BL ALT & $3 \mathrm{BL}$ ALT \\
\hline & & & $10 \mathrm{VC}$ CalLT & \\
\hline & & & 15 VC CycLT & \\
\hline $80 \%$ SOC & $3 \mathrm{BL}$ ALT & $3 \mathrm{BL}$ ALT & $3 \mathrm{BL}$ ALT & $5 \mathrm{BL}$ ALT \\
\hline $100 \% \mathrm{SOC}$ & $3 \mathrm{BL}$ ALT & 3 BL ALT & $5 \mathrm{BL}$ ALT & $5 \mathrm{BL}$ ALT \\
\hline
\end{tabular}

\subsubsection{Calendar-Life Cells}

All calendar-life testing (Section 3.2.1) was performed at ANL. The 23 Baseline cells (15 for life testing, seven for archiving, and one for diagnostic analysis) were received on January 10, 2001, and testing of the fifteen $55^{\circ} \mathrm{C}$ Baseline cells was initiated between January 16 and March 13, 2001. Two of the archived cells were also placed on calendar-life testing at $45^{\circ} \mathrm{C}$ on May 16, 2001 (see Table 3). The 55 and $45^{\circ} \mathrm{C}$ cells reached end-of-test (EOT) on January 25, 2002 and July 2, 2003, respectively. The 15 
Variant C cells were received on July 26, 2001, and testing was initiated on September 12, 2001. Due to poor initial performance on some cells, only ten Variant $\mathrm{C}$ cells were placed on calendar-life testing at $45^{\circ} \mathrm{C}$. These cells reached EOT on July 1, 2005. The six GDR cells were received on May 10, 2004, and testing was initiated on June 2, 2004. These cells reached EOT on July 8, 2005.

\subsubsection{Cycle-Life Cells}

All cycle-life testing (Section 3.2.2) was performed at INL. The 30 Baseline cells were received on January 8, 2001 and testing was initiated between January 23 and February 2, 2001. As shown in Table 3 , these cells were split into two groups with cycle-life testing at 25 and $45^{\circ} \mathrm{C}$. The $25^{\circ} \mathrm{C}$ Baseline cells reached EOT on January 18, 2005 and the $45^{\circ} \mathrm{C}$ Baseline cells reached EOT on January 21, 2003. The 15 Variant C cells were received on July 30,2001, and testing was initiated on August 16, 2001. These cells reached EOT on February 8, 2005.

\subsubsection{Accelerated-Life Cells}

All accelerated-life (Section 3.2.3) testing was performed at SNL. The 62 Baseline cells designated for testing were received on February 6, 2001 and testing was initiated between March 5 and March 19, 2001. Twelve of these cells were either archived or failed prior to any testing (Appendix B). Another eight cells were designated for special cycle-life testing, with changes in pulse duration, amplitude, and frequency of the standard cycle-life profile (Section 3.2.2). Results from the special cycle-life testing are not discussed in this report. The remaining 42 cells reached EOT between January 21, 2002 and December 24, 2002. 


\section{BATTERY INFORMATION}

\subsection{Battery Rating and Limitations}

The following battery ratings and limitations were used for the testing:

\begin{tabular}{|c|c|c|c|}
\hline & $\underline{\text { Baseline Cells }}$ & $\underline{\text { Variant C Cells }}$ & $\underline{\text { GDR Cells }}$ \\
\hline $\mathrm{C}_{1} / 1$ rated capacity & $1.0 \mathrm{Ah}$ & $0.8 \mathrm{Ah}$ & $0.9 \mathrm{Ah}$ \\
\hline $\mathrm{C}_{1} / 1$ nominal capacity (average) & $0.961 \mathrm{Ah}$ & $0.828 \mathrm{Ah}$ & $0.890 \mathrm{Ah}$ \\
\hline Cell nominal weight (average) & $38.5 \mathrm{~g}$ & $38.4 \mathrm{~g}$ & $38.5 \mathrm{~g}$ \\
\hline Battery size factor: & 553 & 651 & 591 \\
\hline Electrode area: & $846.3 \mathrm{~cm}^{2}$ & $846.3 \mathrm{~cm}^{2}$ & $810.7 \mathrm{~cm}^{2}$ \\
\hline \multicolumn{4}{|l|}{ Temperature } \\
\hline Operating Range & \multicolumn{3}{|c|}{-20 to $+60^{\circ} \mathrm{C}$ (discharge) } \\
\hline Storage & \multicolumn{3}{|c|}{$10^{\circ} \mathrm{C} \pm 3^{\circ} \mathrm{C}$} \\
\hline Maximum (discharge) & \multicolumn{2}{|c|}{$60^{\circ} \mathrm{C}$} & \\
\hline Maximum (charge) & \multicolumn{2}{|l|}{$40^{\circ} \mathrm{C}$} & \\
\hline \multicolumn{4}{|l|}{ Voltage Limits } \\
\hline \multirow[t]{2}{*}{ Minimum discharge voltage } & \multicolumn{3}{|c|}{$3.0 \mathrm{~V}$ (18-s pulse) } \\
\hline & \multicolumn{3}{|c|}{$3.0 \mathrm{~V}$ (continuous) } \\
\hline \multirow[t]{2}{*}{ Maximum charge voltage } & \multicolumn{3}{|c|}{$4.3 \mathrm{~V}$ (10-s pulse) } \\
\hline & \multicolumn{3}{|c|}{$4.1 \mathrm{~V}$ (continuous) } \\
\hline \multicolumn{4}{|l|}{ HPPC Calculation voltages } \\
\hline Maximum & \multicolumn{2}{|l|}{$4.1 \mathrm{~V}$} & \\
\hline Minimum & \multicolumn{2}{|l|}{$3.0 \mathrm{~V}$} & \\
\hline \multicolumn{4}{|l|}{ Current Limits } \\
\hline \multirow[t]{2}{*}{ Maximum discharge current } & \multicolumn{3}{|c|}{$8.0 \mathrm{~A}$ (18-s pulse) } \\
\hline & \multicolumn{3}{|c|}{2.0 A (continuous) } \\
\hline \multirow[t]{2}{*}{ Maximum charge current } & \multicolumn{3}{|c|}{8.0 A (10-s pulse) } \\
\hline & \multicolumn{3}{|c|}{1.0 A (continuous) } \\
\hline
\end{tabular}

\subsection{Special Considerations}

Special considerations for the calendar-, cycle-, and accelerated-life cells (such as the lot numbers, ATD labeling scheme, temperature control, tab issues, etc.) are presented in Appendix B. 


\section{TESTING}

Characterization and life testing were performed in accordance with the PNGV Battery Test Manual, Revision 3 (Reference 4) and the ATD Gen 2 test plans (References 5 and 6). PNGV performance goals, procedures, analytical methodologies, and ATD specific testing requirements are detailed in these documents and are summarized below. At the conclusion of standard testing, some cells were also used for final studies in impedance measurements and low-temperature performance, as detailed in Appendix A. Laboratory-specific testing and analysis details are presented in Appendices B, C, and D.

\subsection{Characterization Testing}

Characterization testing was performed on all cells at $25^{\circ} \mathrm{C}$ prior to life testing to establish $\mathrm{BOL}$ performance parameters, including capacity, resistance, power, and energy. Following a receipt inspection (Appendix B), characterization testing was initiated with $C_{1} / 1$ and $C_{1} / 25$ static capacity tests. These tests consist of a constant current discharge to the minimum voltage from a fully charged state using a fraction of the rated capacity defined at the 1-h rate (i.e., subscript "1"). For example, the Variant $\mathrm{C} \mathrm{C}_{1} / 25$ discharge test is performed at $0.8 / 25$, or $32 \mathrm{~mA}$. The Gen 2 cell testing began with five consecutive $\mathrm{C}_{1} / 1$ discharges and charges, followed by a $\mathrm{C}_{1} / 25$ discharge test. The calendar- and cycle-life cells were then also fully charged to $4.1 \mathrm{~V}$ at a $\mathrm{C}_{1} / 25$ rate.

After the static capacity tests, all cells were subjected to electrical impedance spectroscopy (EIS). EIS may be used to determine impedance changes in the electrode-electrolyte interface in conjunction with equivalent circuit models (Reference 9). EIS measurements were initiated by discharging the cells from a fully-charged state to the specified open-circuit voltage (OCV) corresponding to the target SOC (Appendix D of Reference 5). Following an eight- to twelve-hour rest at OCV, which allowed the cells to reach electrochemical equilibrium, the impedance was measured using a four-terminal connection over a frequency range of $10 \mathrm{kHz}$ to $0.01 \mathrm{~Hz}$, with a minimum of eight points per decade of frequency. This test was performed on all cells at $60 \%$ SOC, and also at $100 \%$ SOC for the accelerated-life cells.

The low-current hybrid pulse power characterization (L-HPPC) test followed EIS measurements. The profile is shown in Figure 1, and consists of a constant-current discharge and regen pulse with a 32-s rest period in between, for a total duration of $60 \mathrm{~s}$. The 18-s constant-current discharge pulse is performed at a $5 \mathrm{C}_{1}$ rate (e.g., $5 \mathrm{~A}$ for the Baseline cells), and the 10 -s regen pulse is performed at $75 \%$ of the discharge rate (e.g., $3.75 \mathrm{~A}$ for the Baseline cells). This profile is repeated at every $10 \%$ depth-ofdischarge (DOD) increment, with a 1-h rest at OCV at each DOD increment to ensure that the cells have electrochemically and thermally equilibrated (Reference 4). The L-HPPC data are used to determine degradation in cell resistance, power and energy. The resistance is generally multiplied by the electrode area to determine area-specific impedance (ASI). 


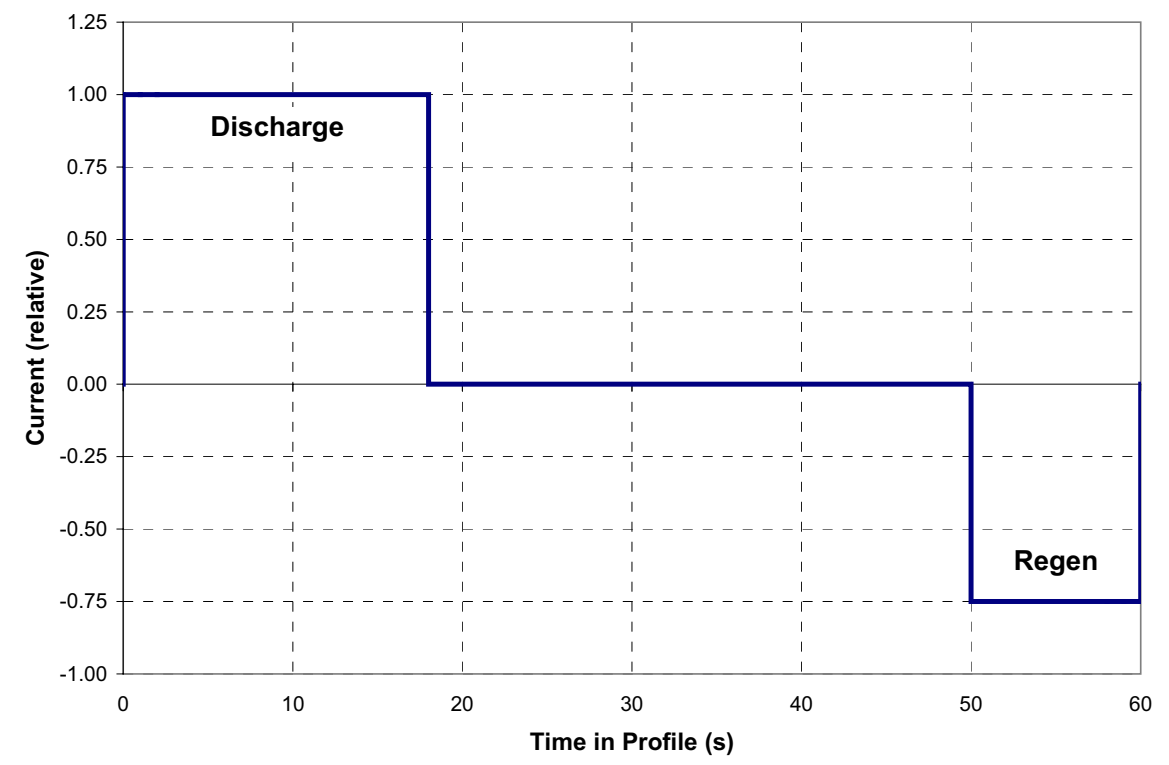

Figure 1. PNGV L-HPPC pulse profile.

\subsection{Life Testing}

\subsubsection{Calendar-Life Testing}

Calendar-life testing consists of a voltage clamp at a fixed SOC and test temperature with a onceper-day pulse profile. The purpose of the pulse-per-day is to determine changes in resistance and power capability during aging. The Gen 2 cells were calendar-life tested at $60 \%$ SOC (see Table 3 ) using the pulse profile defined in Reference 4 and shown in Figure 2. It consists of constant current discharge and regen pulses with interspersed rest periods for a total duration of $120 \mathrm{~s}$. The 9-s discharge is performed at a $3 \mathrm{C}_{1}$ discharge current (e.g., $3 \mathrm{~A}$ for the Baseline cells). In accordance with Reference 4, this profile is also performed once at the beginning and end of each life test period at $25^{\circ} \mathrm{C}$.

\subsubsection{Cycle-Life Testing}

The cycle-life test is based on the PNGV 25-Wh Power Assist profile, as defined in Reference 4 and shown in Figure 3. It consists of constant power discharge and regen pulses with interspersed rest periods for a total duration of $72 \mathrm{~s}$, and is repeated continuously while centered around $60 \%$ SOC (see Table 3 ). This profile assumes a full size battery pack and needs to be scaled to a cell-size level using the battery size factor (BSF), which is defined in Appendix D. As shown in Section 2.1, the BSF for the Baseline and Variant $C$ cells are 553 and 651, respectively. Consequently, the 9-s discharge pulse power for the Baseline cells is 18.1, and it is $15.4 \mathrm{~W}$ for the Variant $\mathrm{C}$ cells.

Although the cycle-life profile is nominally charge neutral (assuming a 90\% round trip efficiency), the actual cycling stability at the target SOC is first established by the Operating Set Point Stability (OSPS) test. The OSPS test consists of 100 consecutive cycle-life profiles, and requires that the actual SOC and the end of the test be within $\pm 2 \%$ of the target SOC ( $60 \%$ SOC), based on the OCV following a 1-h rest. If the SOC is charge positive or charge negative (i.e., unstable), then a 1-s voltage-controlled discharge step is added to the end of the 9-s discharge pulse to achieve stable cycling. The OSPS test is repeated, and the control voltage adjusted, until stable cycling occurs. 


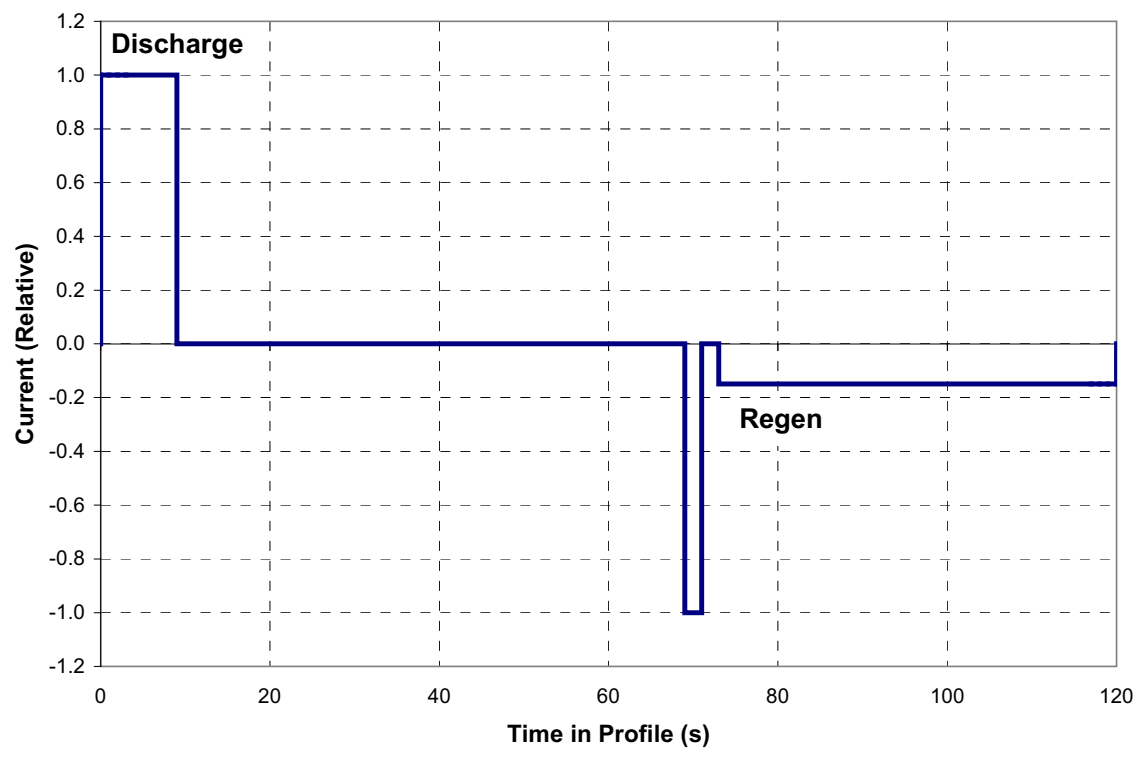

Figure 2. PNGV pulse-per-day calendar-life profile.

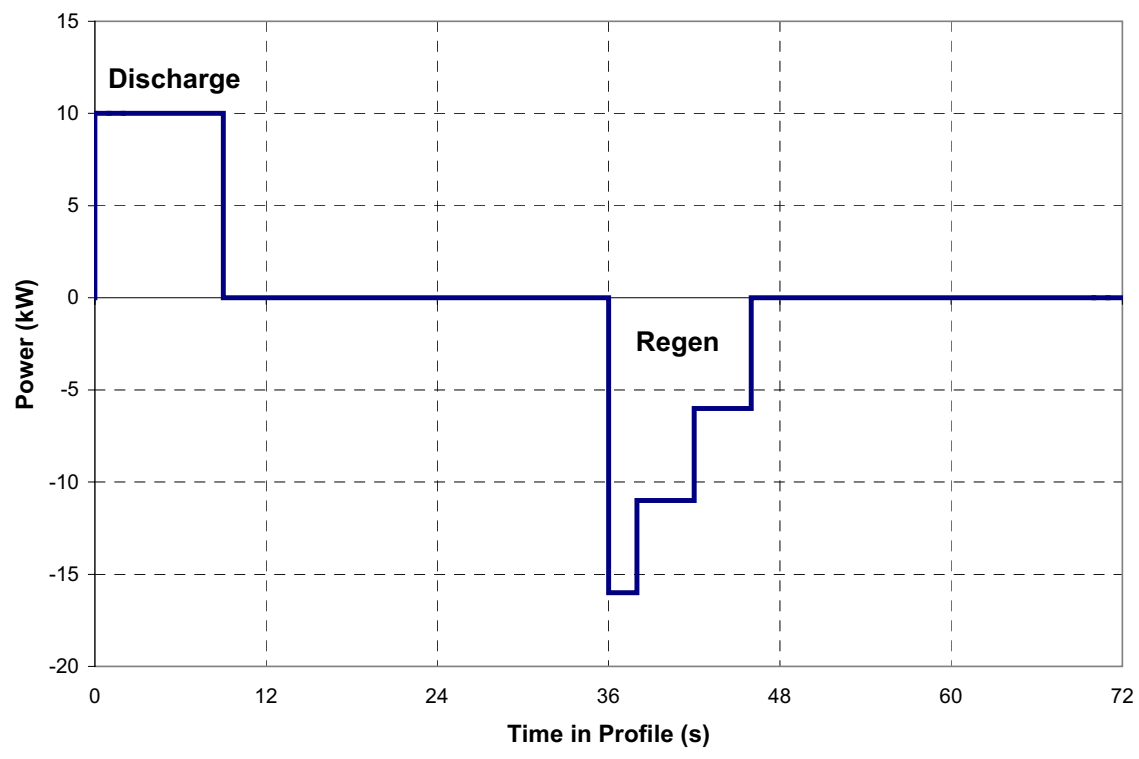

Figure 3. PNGV 25-Wh Power Assist cycle-life profile.

\subsubsection{Accelerated-Life Testing}

Accelerated-life testing consists of a voltage clamp at a fixed SOC with a once-per-day profile. Instead of the standard calendar-life profile, the ALT cells were subjected to the $25 \mathrm{Wh}$ Power Assist profile (Figure 3 ) every 24 hours with a voltage control step applied to the third regen pulse. The control step was determined based on an OSPS test performed before the special calendar-life testing began. As shown in Table 3, the ALT cell test matrix consisted of four temperatures and three SOCs. These parameters cover the range of expected use and allow for interpolation of measured power and capacity fade rates to the nominal use conditions (i.e., $25^{\circ} \mathrm{C}$ and $60 \% \mathrm{SOC}$ ). 


\subsection{Reference Performance Testing}

Life testing for the calendar-, cycle-, and accelerated-life cells was interrupted every four weeks (i.e., 33600 cycle-life profiles) for reference performance tests (RPTs), which are used to quantify changes in capacity, resistance, and power. RPTs generally consisted of a $C_{1} / 1$ static capacity test, a $C_{1} / 25$ static capacity test, a L-HPPC test, and an EIS test at $60 \%$ SOC. The accelerated-life cells were subjected to additional tests every four weeks to help gain a better understanding of cell degradation over life (see Appendix C). All RPTs were performed at $25^{\circ} \mathrm{C}$. Capacity fade is the percentage loss in the discharge capacity during the $\mathrm{C}_{1} / 1$ or $\mathrm{C}_{1} / 25$ test, power fade is the percentage loss in the power at $300 \mathrm{Wh}$ (Reference 4), and ASI growth is the percent increase in resistance measured from the L-HPPC test. These degradation measurements are normalized to the characterization RPT (i.e., at characterization, the percent-degradation is $0 \%$ ).

For the calendar- and cycle-life cells, only two cells per test group were initially subjected to full RPTs every four weeks and the remaining cells were subjected to a "partial" RPT (i.e., a $\mathrm{C}_{1} / 1$ and LHPPC test). For these cells, a full RPT was only to be performed at BOL (characterization testing, Section 3.1) and EOT. However, after assessing the first 12 weeks of aging data, the RPT criteria was changed to a full RPT every four weeks for each cell on test.

\subsection{End-of-Test Criteria}

The Gen 2 EOT criteria for the calendar- and cycle-life cells are specified in Appendix C of Reference 5. The cells were generally organized into groups of 15 . One cell from each group was sent to a diagnostic laboratory (ANL, LBNL, or BNL) for evaluation after characterization testing was completed. Following four weeks of aging, another two cells were removed from test and sent to the diagnostic laboratories. The EOT criteria for the remaining 12 cells were based on roughly equal power fade increments such that the penultimate pair of cells was sent for diagnostic evaluation when the power fade reached $30 \%$. The last pair of cells for each calendar- and cycle-life cell groups continued testing until they reached approximately $50 \%$ power fade.

The ALT cells were not removed from test in incremental stages. Rather, all 25,35 , and $45^{\circ} \mathrm{C}$ accelerated-life cells were removed from test when their power fades reached $50 \%$. The $55^{\circ} \mathrm{C}$ accelerated-life cells continued testing until the L-HPPC test data were unable to yield useful power fade data. 


\section{RESULTS}

Due to the vast amount of available Gen 2 data, only cell averages or results from representative cells are presented. Selected data for each cell at each condition are also given on the CD provided with this report. Detailed results for all tests are also available at two different websites. Most of the Gen 2 RPT data for all cells can be found on the ANL website (http://www.cmt.anl.gov/eadl/data/atd/ default_htm). Detailed cycle-life results can also be found at the INL website (http://atd.inel.gov). Individual usernames and passwords are required for each site and can be requested online.

Since testing is performed at multiple temperatures and SOCs, a standard method of graphically representing data is used in this report. Unless otherwise noted, the data are presented using the format summarized in Table 4.

Table 4. Standard graphical convention.

\begin{tabular}{ccc}
\hline \hline Temperature (color) & Test (symbol) & Chemistry (symbol background) \\
\hline \hline $25^{\circ} \mathrm{C}$ (blue) & calendar-life (circle) & Baseline cells (filled symbol) \\
$35^{\circ} \mathrm{C}$ (red) & cycle-life (square) & Variant C cells (empty symbol) \\
$45^{\circ} \mathrm{C}$ (purple) & accelerated-life (triangle) & \\
$55^{\circ} \mathrm{C}$ (green) & & \\
\hline \hline
\end{tabular}

\subsection{Static Capacity}

\subsection{1 $C_{1} / 1$ Capacity}

Figure 4 shows the average $\mathrm{C}_{1} / 1$ discharge capacity for the Baseline ("BL") calendar- ("CalLT") and cycle- ("CycLT") life cell groups aged at $60 \%$ SOC. The initial capacities are similar, but the rate of capacity loss generally increases with increasing test temperature. At $45^{\circ} \mathrm{C}$, the calendar-life cells show a slower fade rate than the cycle-life cells. This may be primarily attributable to the difference in throughput per month for each test (the cycle-life cells experience $\sim 450 \mathrm{Ah}$ per four-week period, whereas the calendar-life cells see only $\sim 6$ Ah every four weeks).

Figures 5 through 7 show the $C_{1} / 1$ capacities for the Baseline accelerated- ("ALT") life cells at 60 , 80 , and $100 \%$ SOC, respectively. These cell groups also show an increase in capacity fade with test temperature and SOC. The accelerated-life cell initial capacities are slightly lower than the calendar- and cycle-life cells, but are consistent among the three SOC groups. At $60 \%$ SOC, the capacity fade rates at 25 and $45^{\circ} \mathrm{C}$ are higher than the corresponding cycle-life cells, and, at $55^{\circ} \mathrm{C}$, higher than the corresponding calendar-life cells. Except at $55^{\circ} \mathrm{C}$, the accelerated life cells show the most capacity loss at $100 \%$ SOC and the least at $60 \%$ SOC. At $55^{\circ} \mathrm{C}$, the $80 \%$ SOC cells show more fade that at $100 \%$ SOC, which may indicate that a higher-temperature mechanism has taken effect. 


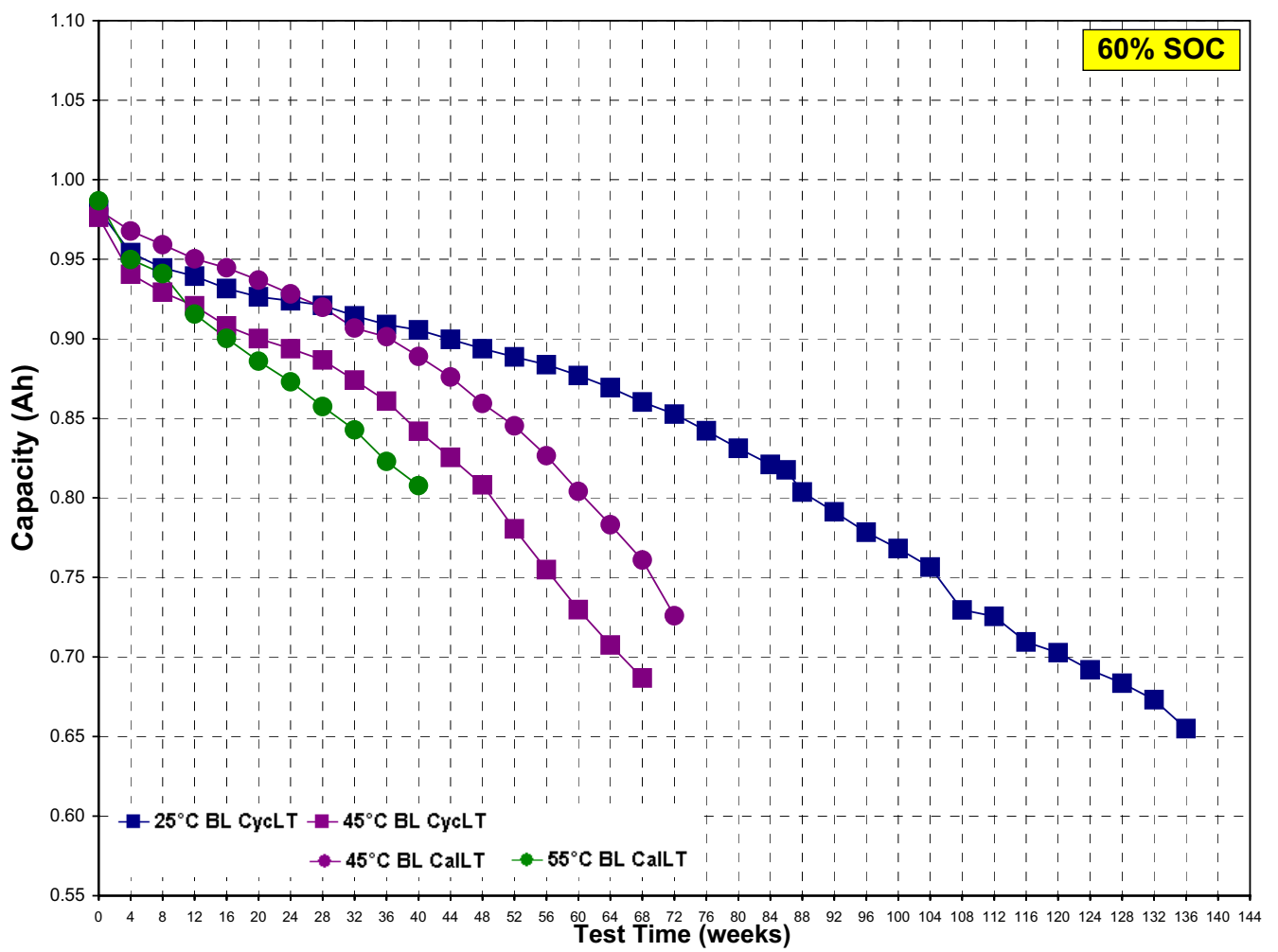

Figure 4. Average $\mathrm{C}_{1} / 1$ discharge capacity for the Baseline CalLT and CycLT cell groups.

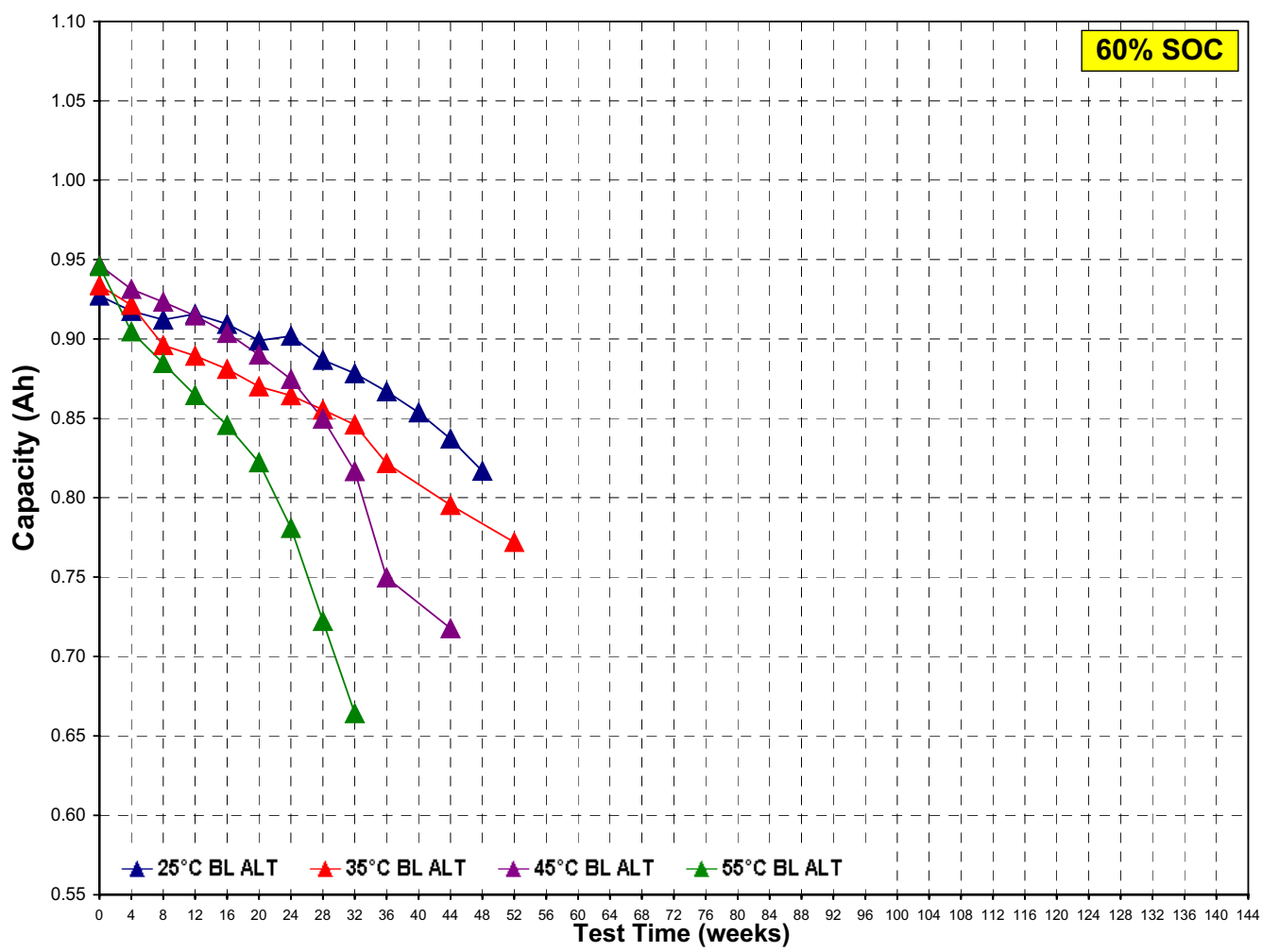

Figure 5. Average $\mathrm{C}_{1} / 1$ discharge capacity for the Baseline ALT cell groups at $60 \%$ SOC. 


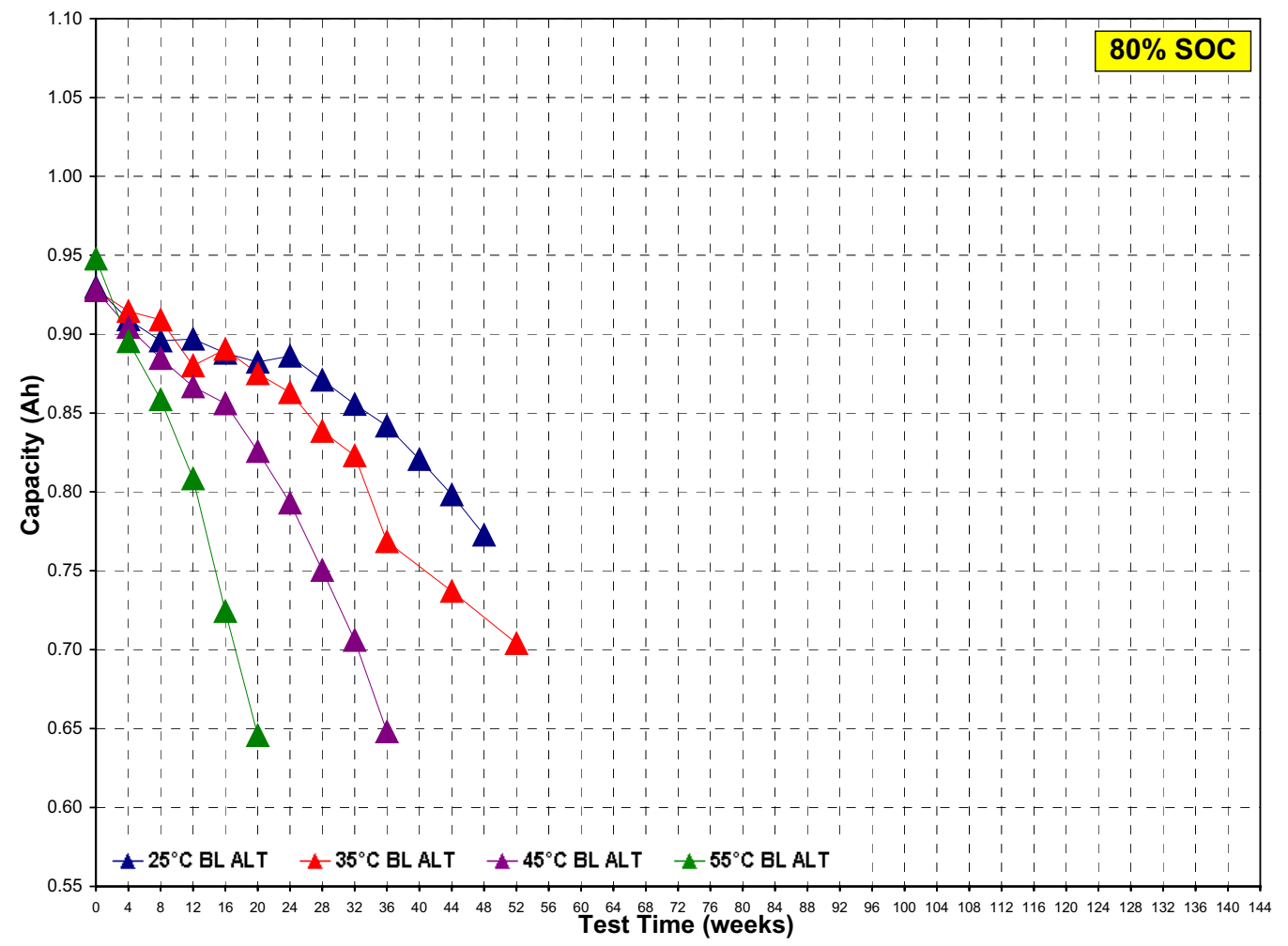

Figure 6 . Average $\mathrm{C}_{1} / 1$ discharge capacity for the Baseline ALT cell groups at $80 \%$ SOC.

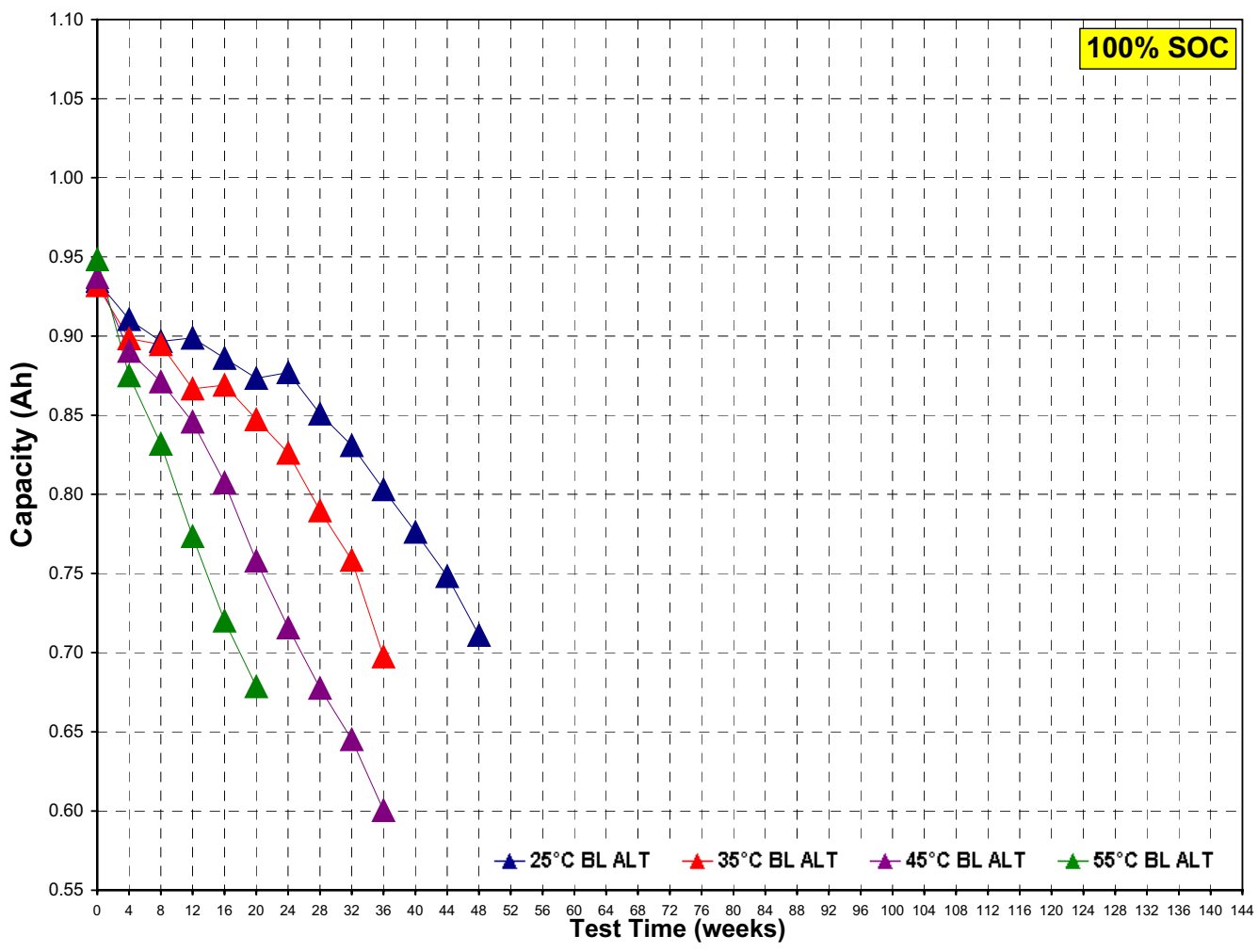

Figure 7. Average $\mathrm{C}_{1} / 1$ discharge capacity for the Baseline ALT cell groups at $100 \%$ SOC. 
Figure 8 shows the average $\mathrm{C}_{1} / 1$ discharge capacities for each Variant $\mathrm{C}$ ("VARC") cell group aged at $60 \%$ SOC. The initial capacity is lower due to the change in composition of the positive electrode (Section 1.1.1), but the rate of capacity loss is also significantly less than what is seen for the corresponding Baseline cells (Figure 4). Although the Variant $\mathrm{C}$ calendar-life cells show a slightly lower capacity than the cycle-life cells through 60 weeks, the fade rates are similar. The cycle-life cells show a slight increase in fade rate after 60 weeks, wherein they closely resemble the $25^{\circ} \mathrm{C}$ Baseline cycle-life fade rate.

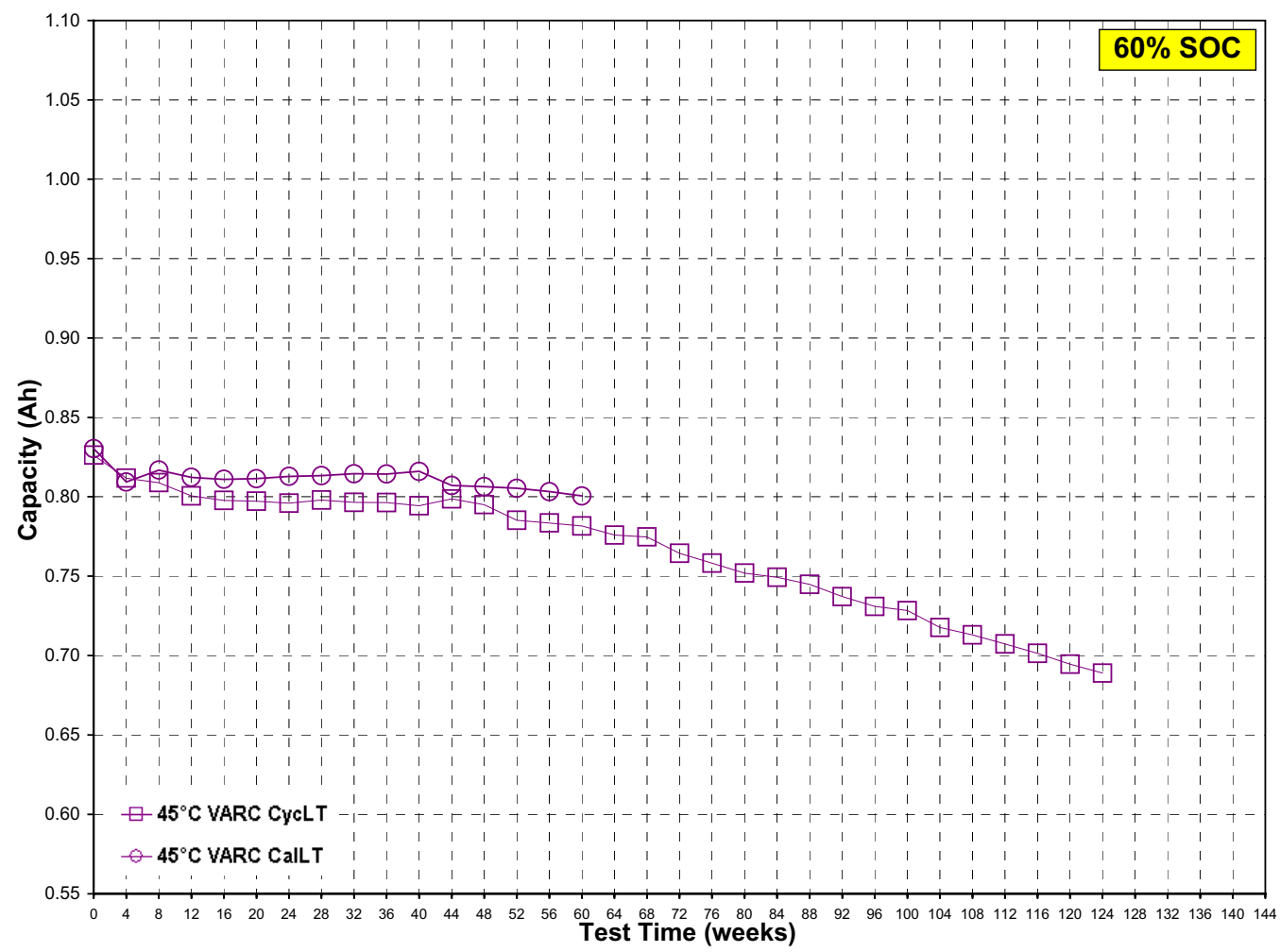

Figure 8. Average $\mathrm{C}_{1} / 1$ discharge capacity for the Variant C CalLT and CycLT cell groups.

\subsection{2 $\mathrm{C}_{1} / 10$ Capacity}

Figures 9 through 11 show the average $C_{1} / 1, C_{1} / 10$ and $C_{1} / 25$ discharge capacities at 60,80 and $100 \%$ SOC, respectively, for the accelerated-life cells. The $\mathrm{C}_{1} / 10$ static capacity test was added to the accelerated-life RPT sequence after eight weeks of aging (see Appendix C). As expected, the average available capacities increase as the C-rate decreases. The $60 \%$ SOC cell groups show higher available capacities than the 80 and $100 \%$ SOC cell groups. The $100 \%$ SOC cell groups show the lowest $\mathrm{C}_{1} / 1$ capacities, but the $C_{1} / 10$ and $C_{1} / 25$ capacities are generally similar to the ones measured at $80 \%$ SOC capacities. Also, as expected, the average capacities generally decrease more rapidly with increasing temperature. 


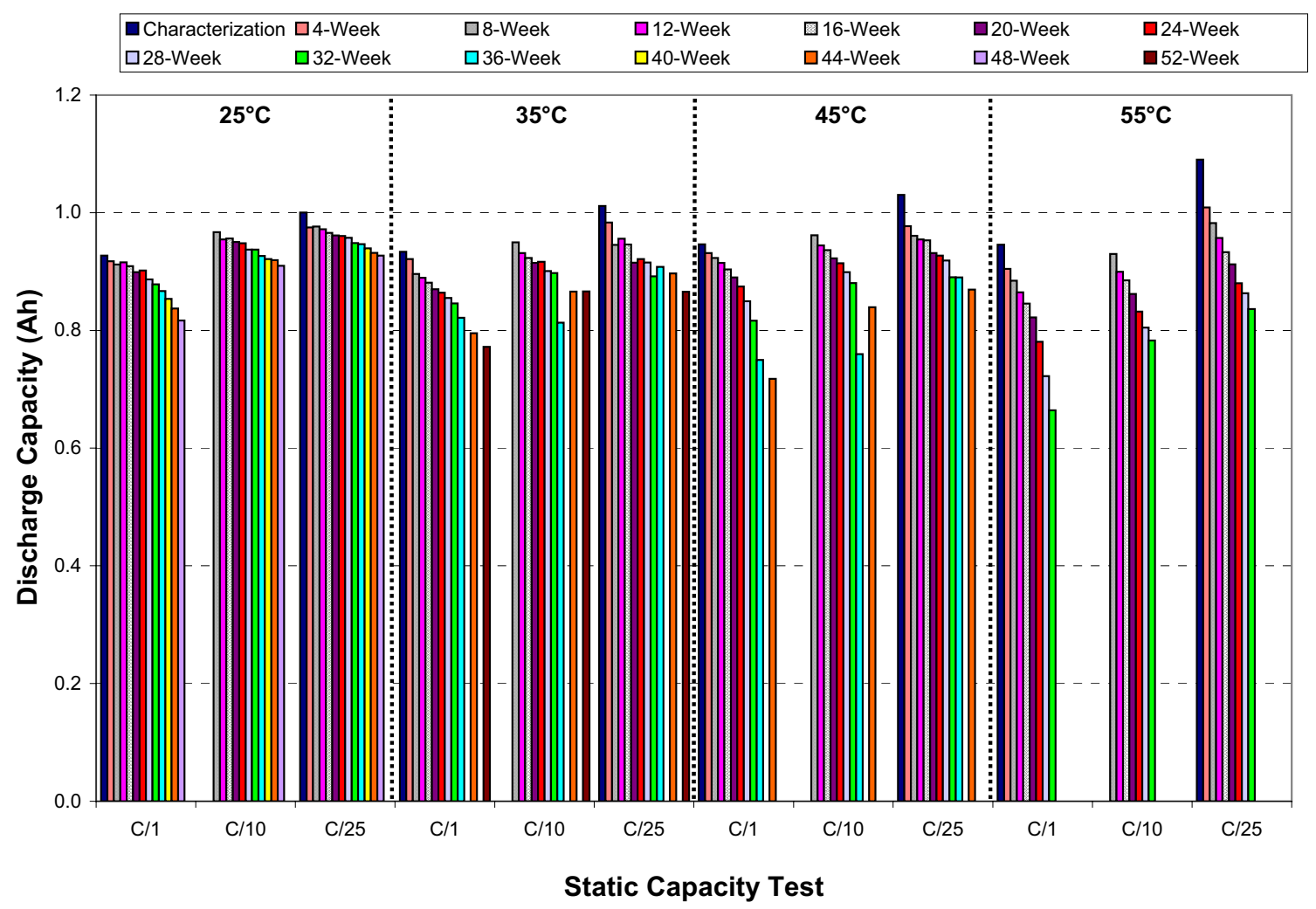

Figure 9. Static capacity tests for the accelerated-life cells at $60 \%$ SOC.

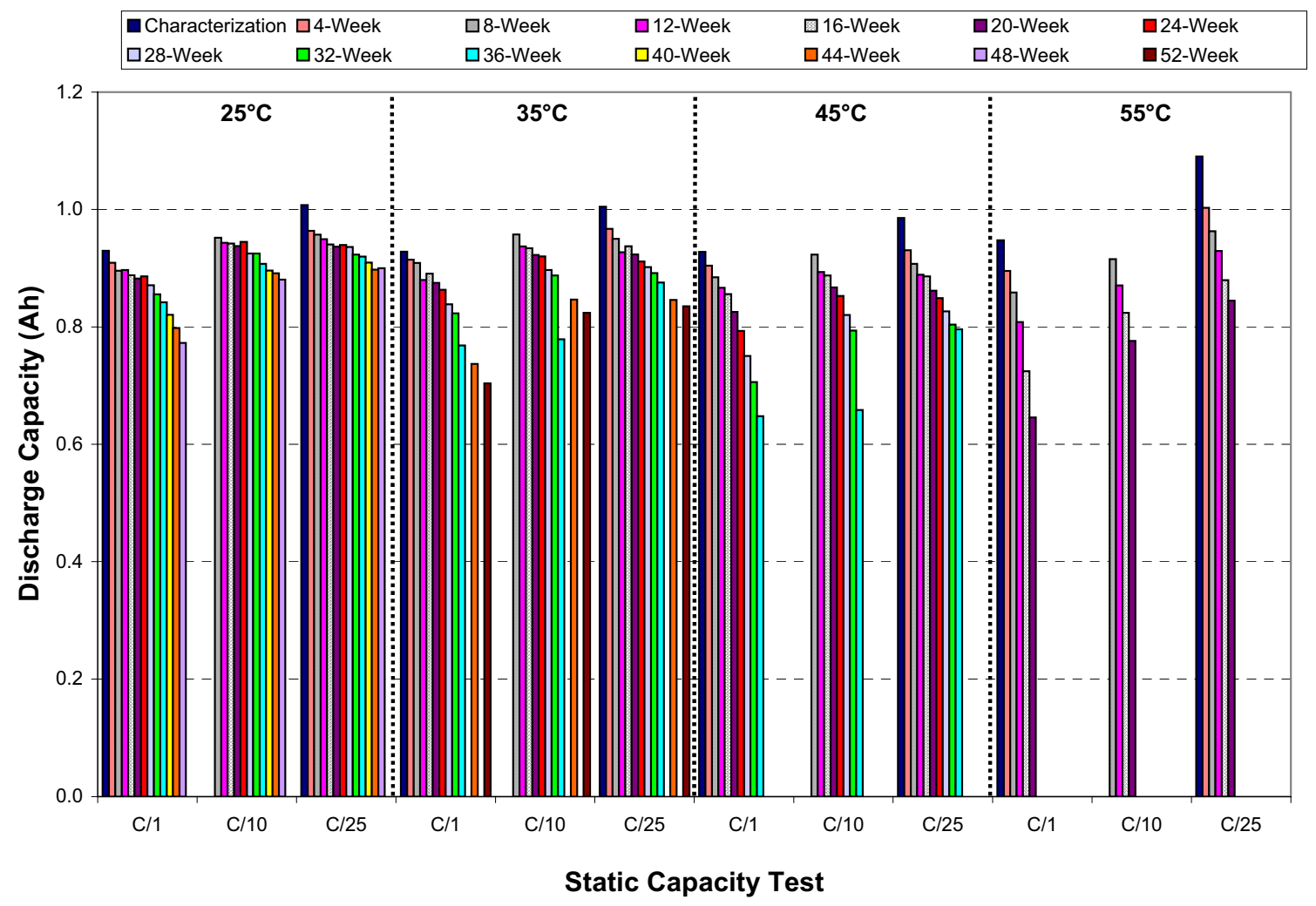

Figure 10. Static capacity tests for the accelerated-life cells at $80 \%$ SOC. 


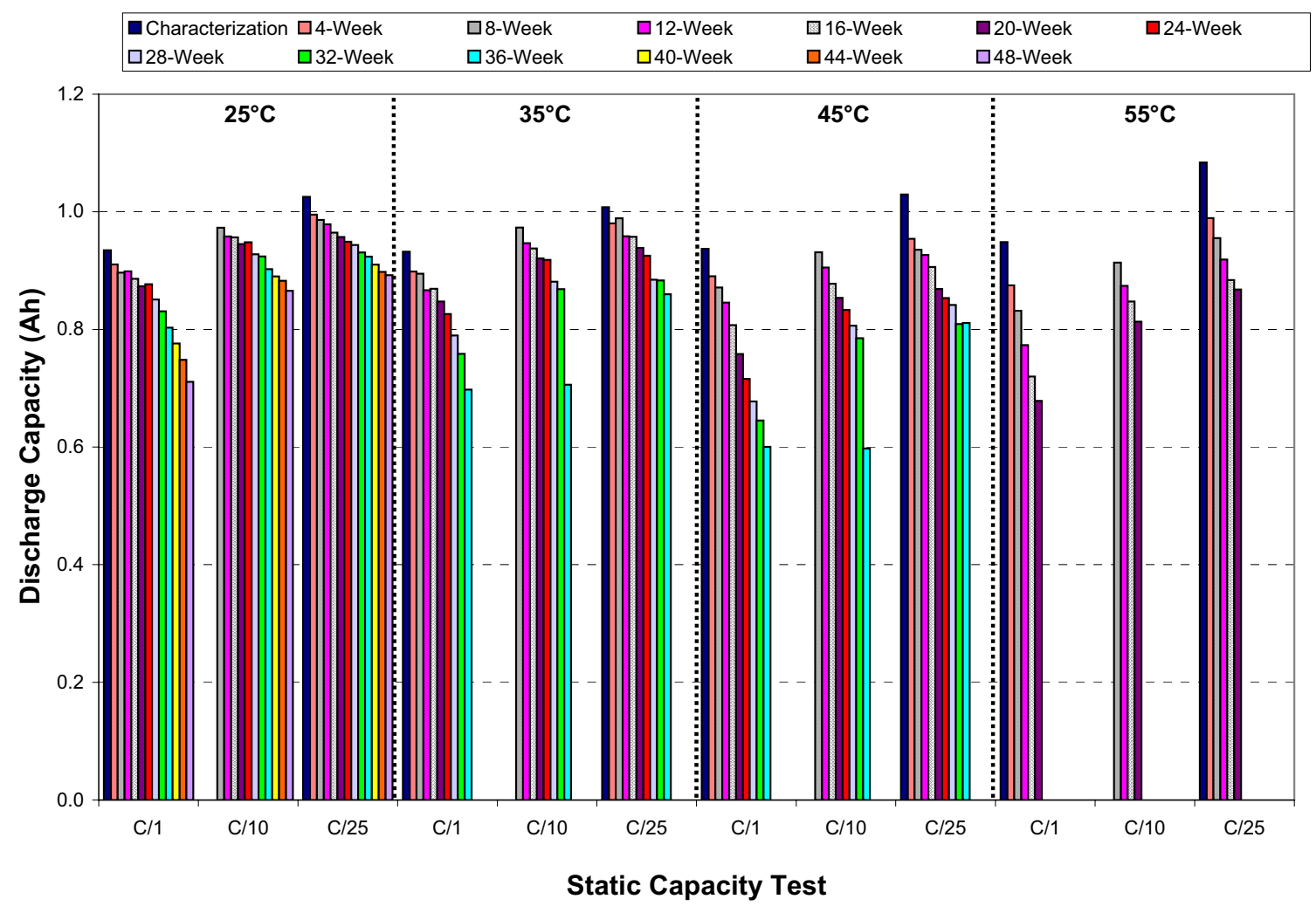

Figure 11. Static capacity tests for the accelerated-life cells at $100 \%$ SOC.

\subsection{3 $C_{1} / 25$ Capacity}

Figure 12 shows the average $\mathrm{C}_{1} / 25$ discharge capacities for the Baseline calendar- and cycle-life cell groups aged at $60 \%$ SOC. As seen with the $\mathrm{C}_{1} / 1$ capacity, the rate of $\mathrm{C}_{1} / 25$ capacity loss generally increases with increasing test temperature. The initial capacities for the cycle-life cell groups were slightly higher than the calendar-life cells by approximately $60 \mathrm{mAh}$, but the calendar-life cells still show less overall capacity loss through 72 weeks. Unlike the $\mathrm{C}_{1} / 1$ data, the $45^{\circ} \mathrm{C}$ calendar- and cycle-life capacity fade rates are similar for the $\mathrm{C}_{1} / 25$ rate.

Figures 13 through 15 show the $\mathrm{C}_{1} / 25$ discharge capacities for the accelerated-life cell groups at 60 , 80 , and $100 \%$ SOC, respectively. The SOC effect is not as clear at the slower discharge rate. There is an increased loss of capacity from 60 to $80 \%$ SOC, but the 80 and $100 \%$ capacity losses are very similar. The initial capacities at each SOC are consistent, but the $55^{\circ} \mathrm{C}$ cells show almost a 0.1 Ah greater capacity than the other temperature groups. However, the fade rates at $55^{\circ} \mathrm{C}$ are also noticeably higher at each SOC. Unlike the $\mathrm{C}_{1} / 1$ data, the capacity fade rates for the accelerated-life cells at $60 \% \mathrm{SOC}$ are also very similar to the calendar- and cycle-life cells. 


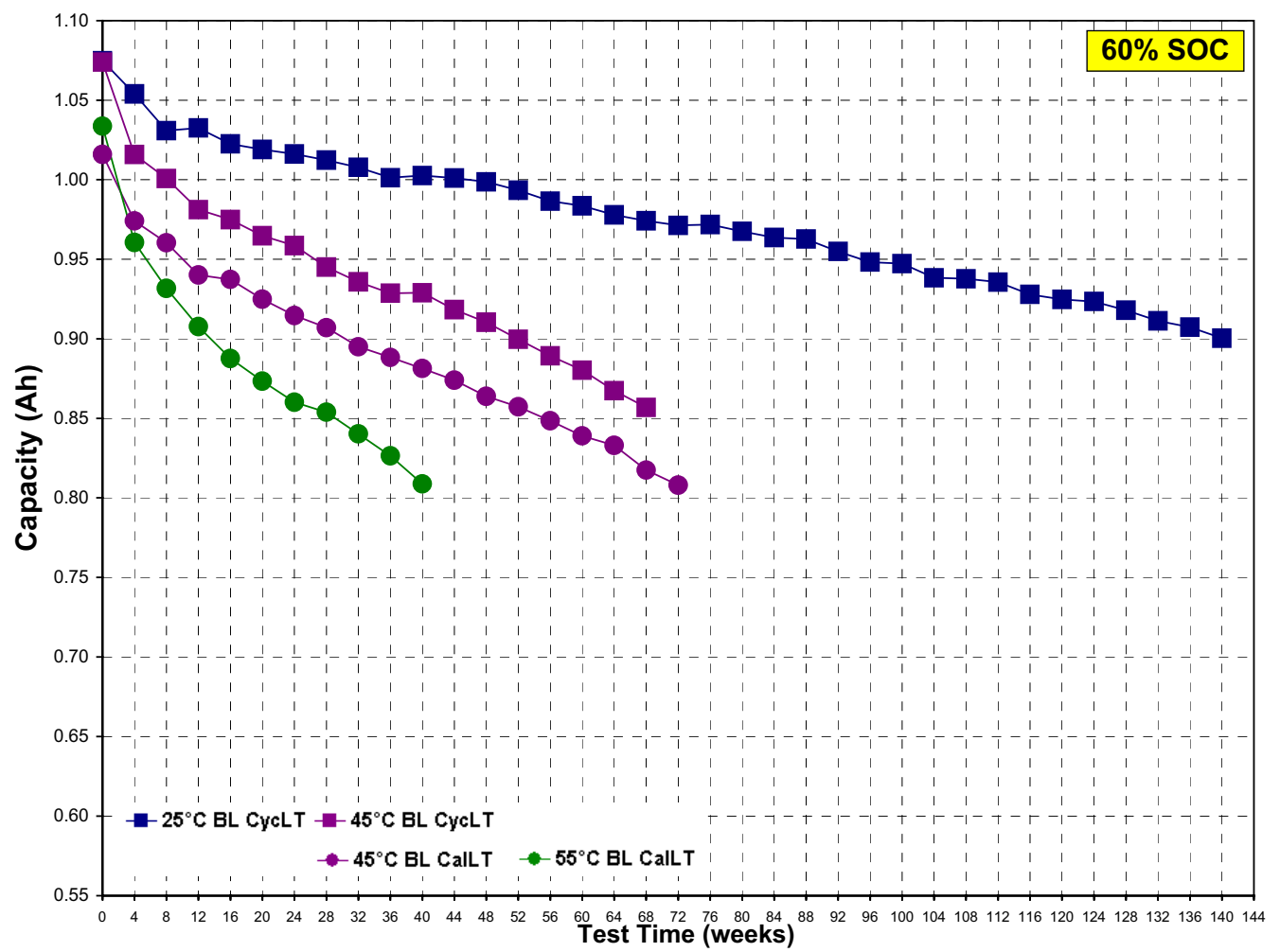

Figure 12. Average $\mathrm{C}_{1} / 25$ discharge capacity for the Baseline CalLT and CycLT cell groups.

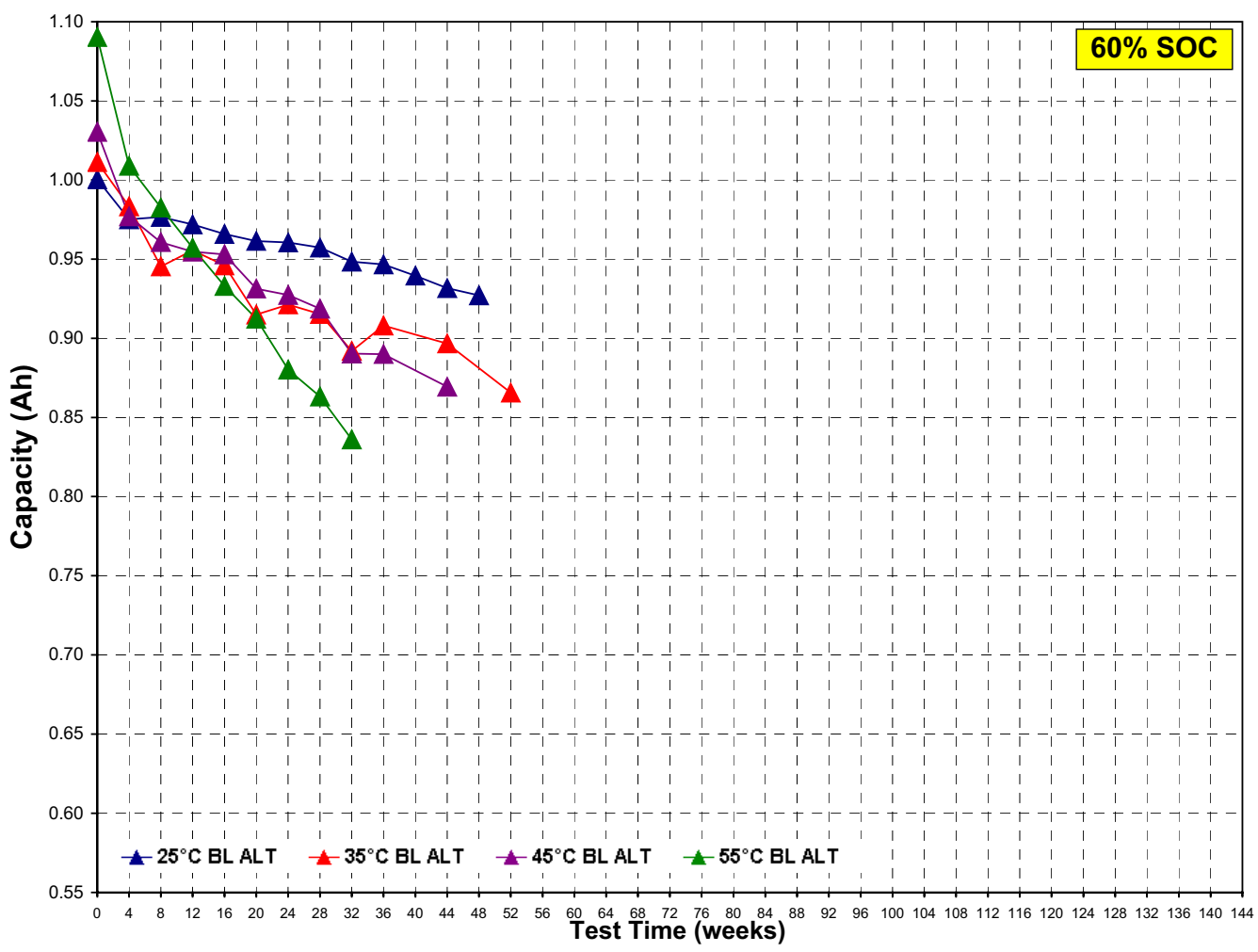

Figure 13. Average $\mathrm{C}_{1} / 25$ discharge capacity for the Baseline ALT cell groups at $60 \%$ SOC. 


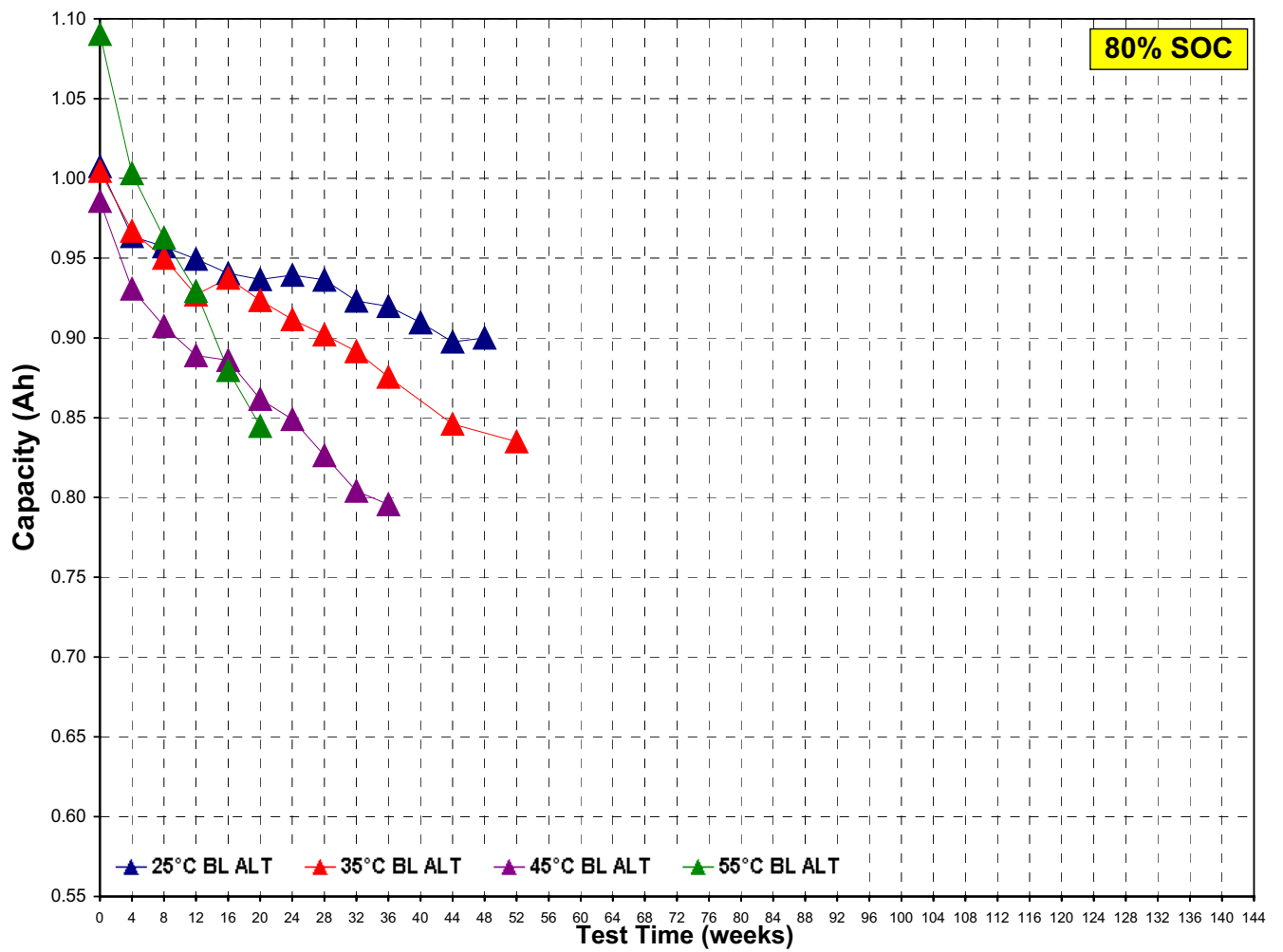

Figure 14. Average $C_{1} / 25$ discharge capacity for the Baseline ALT cell groups at $80 \%$ SOC.

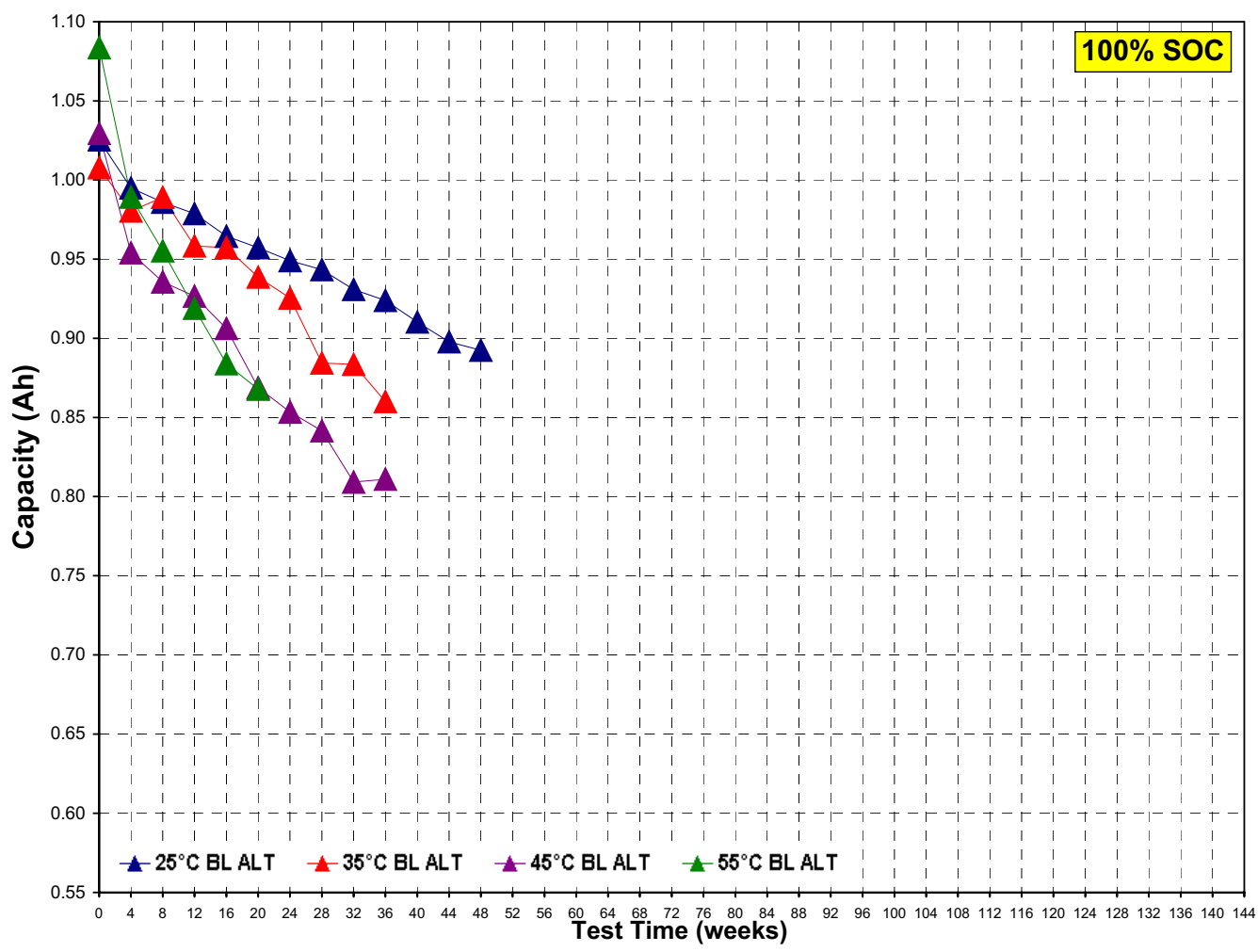

Figure 15 . Average $C_{1} / 25$ discharge capacity for the Baseline ALT cell groups at $100 \%$ SOC. 
Figure 16 shows the average $\mathrm{C}_{1} / 25$ discharge capacities for the calendar- and cycle-life Variant $\mathrm{C}$ cells aged at $60 \%$ SOC. As with the corresponding Baseline cells, the Variant C capacity fades for calendar- and cycle-life are similar. Although their initial capacities are lower, the rate of capacity loss for the Variant $\mathrm{C}$ cells at $45^{\circ} \mathrm{C}$ is similar to the $25^{\circ} \mathrm{C}$ cycle-life Baseline cells. The slight increase in cycle-life capacity between 44 and 72 weeks is primarily due to a defective test channel (see Appendix B). The channel was replaced after 72 weeks, and the rate of degradation returned to normal.

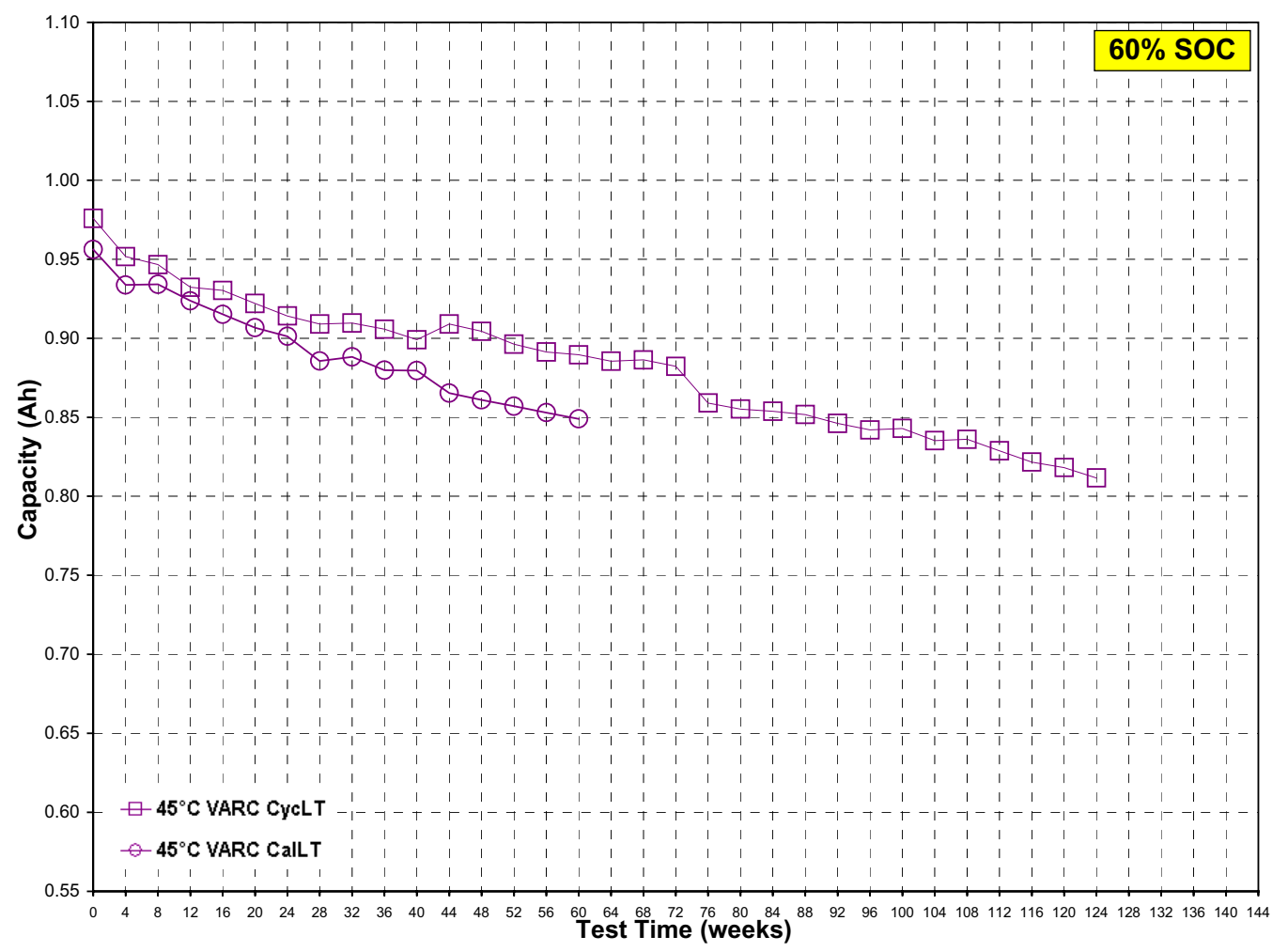

Figure 16. Average $\mathrm{C}_{1} / 25$ discharge capacity for the Variant C CalLT and CycLT cell groups.

\subsubsection{Capacity Summary}

Figure 17 shows the average Baseline and Variant $C$ discharge $C_{1} / 1$ (large symbols) and $C_{1} / 25$ (small symbols) capacity fades as a function of test time for the cycle-life cells. The $25^{\circ} \mathrm{C}$ cell group shows a similar fade rate for both tests through approximately 60 weeks, but then the $\mathrm{C}_{1} / 1$ fade rate starts to increase more rapidly. At $45^{\circ} \mathrm{C}$, the $\mathrm{C}_{1} / 25$ capacity fade for both the Baseline and Variant $\mathrm{C}$ cells are initially higher than the $C_{1} / 1$ fade. This is primarily due to the higher percent-change in the $C_{1} / 25$ capacity during the first four weeks of aging. After the first four weeks, the Baseline cell fade rates for both the $C_{1} / 1$ and $C_{1} / 25$ are similar until a mechanistic change caused an increased $C_{1} / 1$ fade rate at 32 weeks. The $45^{\circ} \mathrm{C}$ Variant $\mathrm{C}$ cells show converging fade rates later in life, which is similar to the initial $25^{\circ} \mathrm{C}$ Baseline cell data. This indicates that the $\mathrm{C}_{1} / 1$ fade rate may have started increasing more rapidly had the cells been aged beyond $50 \%$ power fade.

Figure 18 shows the average Baseline and Variant $\mathrm{C}$ capacity fades for the calendar-life cells. As with the cycle-life cells, the initially higher $\mathrm{C}_{1} / 25$ fades are due to the larger drop in capacity during the first 4 weeks of aging. Both the Baseline cell groups at 45 and $55^{\circ} \mathrm{C}$ show an increased $\mathrm{C}_{1} / 1$ fade rate as a result of a mechanistic change. The $45^{\circ} \mathrm{C}$ Variant $\mathrm{C}$ cells, however, show a very small $\mathrm{C}_{1} / 1$ fade through 60 weeks, while the $\mathrm{C}_{1} / 25$ fade continued to rise slowly. 


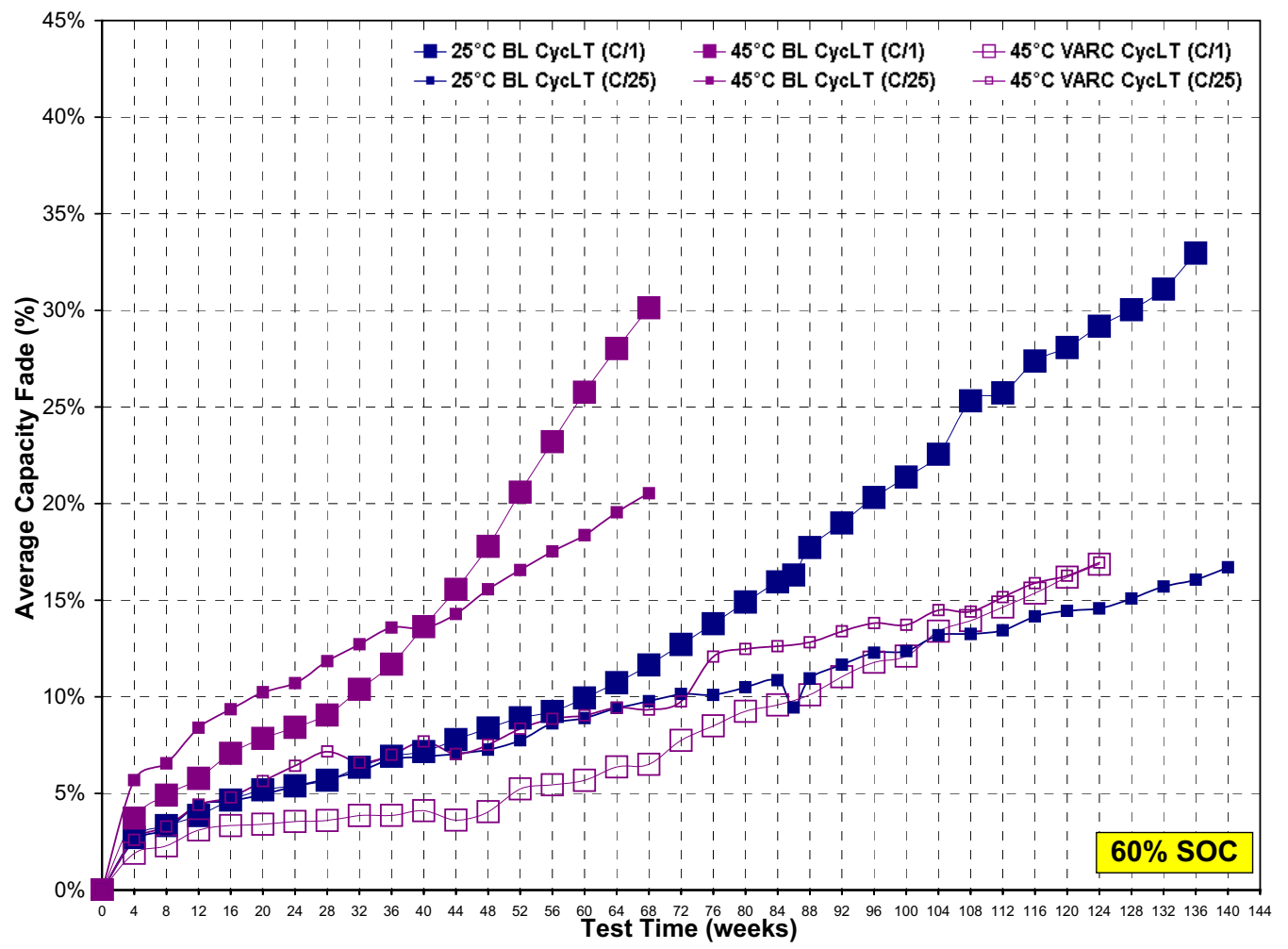

Figure 17. Average $C_{1} / 1$ and $C_{1} / 25$ discharge capacity fade for the cycle-life cells.

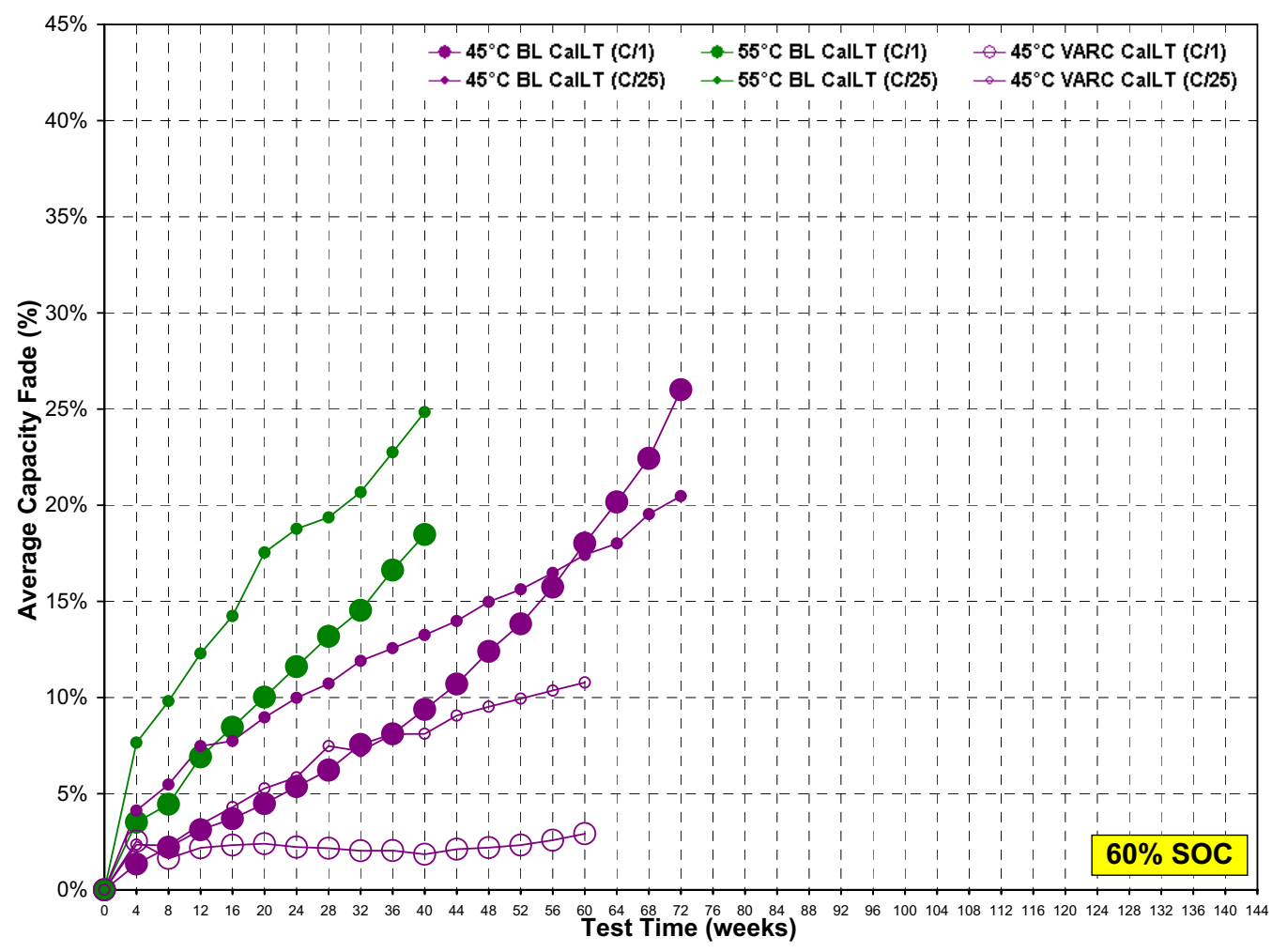

Figure 18. Average $\mathrm{C}_{1} / 1$ and $\mathrm{C}_{1} / 25$ discharge capacity fade for the calendar-life cells. 
Figures 19 through 21 show the average capacity fades for the accelerated-life cells at 60, 80, and $100 \%$ SOC, respectively. As with the calendar- and cycle-life cells, the $\mathrm{C}_{1} / 25$ capacity loss during the first four weeks is greater than the $C_{1} / 1$ fade. After the first four weeks of aging, the $C_{1} / 25$ fade rate is generally slower than the $\mathrm{C}_{1} / 1$ fade rate. The point at which the $\mathrm{C}_{1} / 1$ and $\mathrm{C}_{1} / 25$ curves cross each other generally occurs earlier in life with increasing temperature and SOC.

The $60 \%$ SOC cycle-, calendar- and accelerated-life cells (Figures 17 through 19 ) show that the $\mathrm{C}_{1} / 1$ fade increases as a function of life test (accelerated-life showing the highest fade rate, and the calendarlife cells showing the slowest fade rate). However, the $\mathrm{C}_{1} / 25$ fade rates are very similar for all three life tests. This indicates that the actual remaining capacity is about the same for all cells after each RPT regardless of life testing, but is not available at higher $\mathrm{C}$-rates possibly due to a structural collapse of the active material.

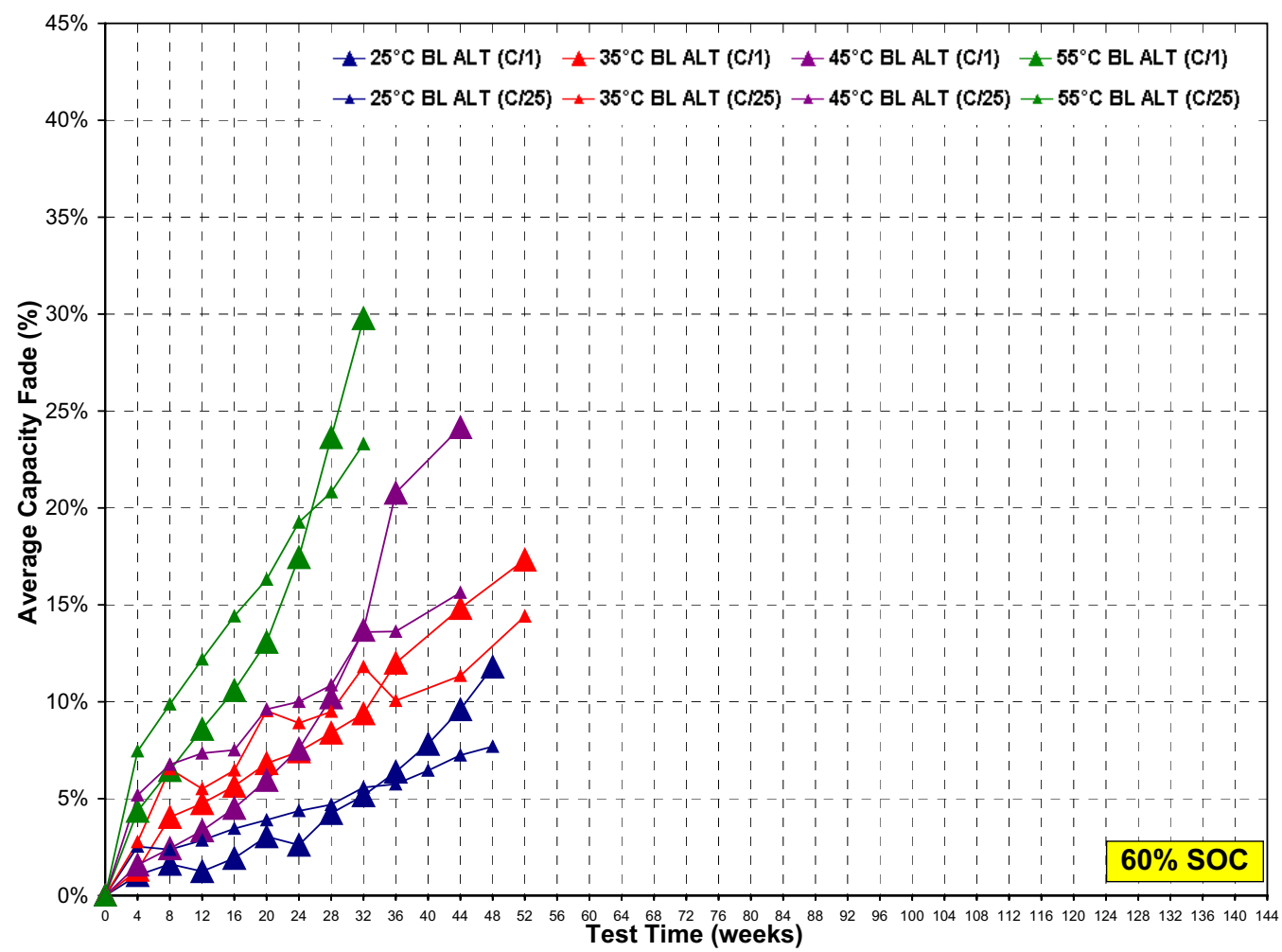

Figure 19. Average $\mathrm{C}_{1} / 1$ and $\mathrm{C}_{1} / 25$ discharge capacity fade for the accelerated-life cells at $60 \%$ SOC. 


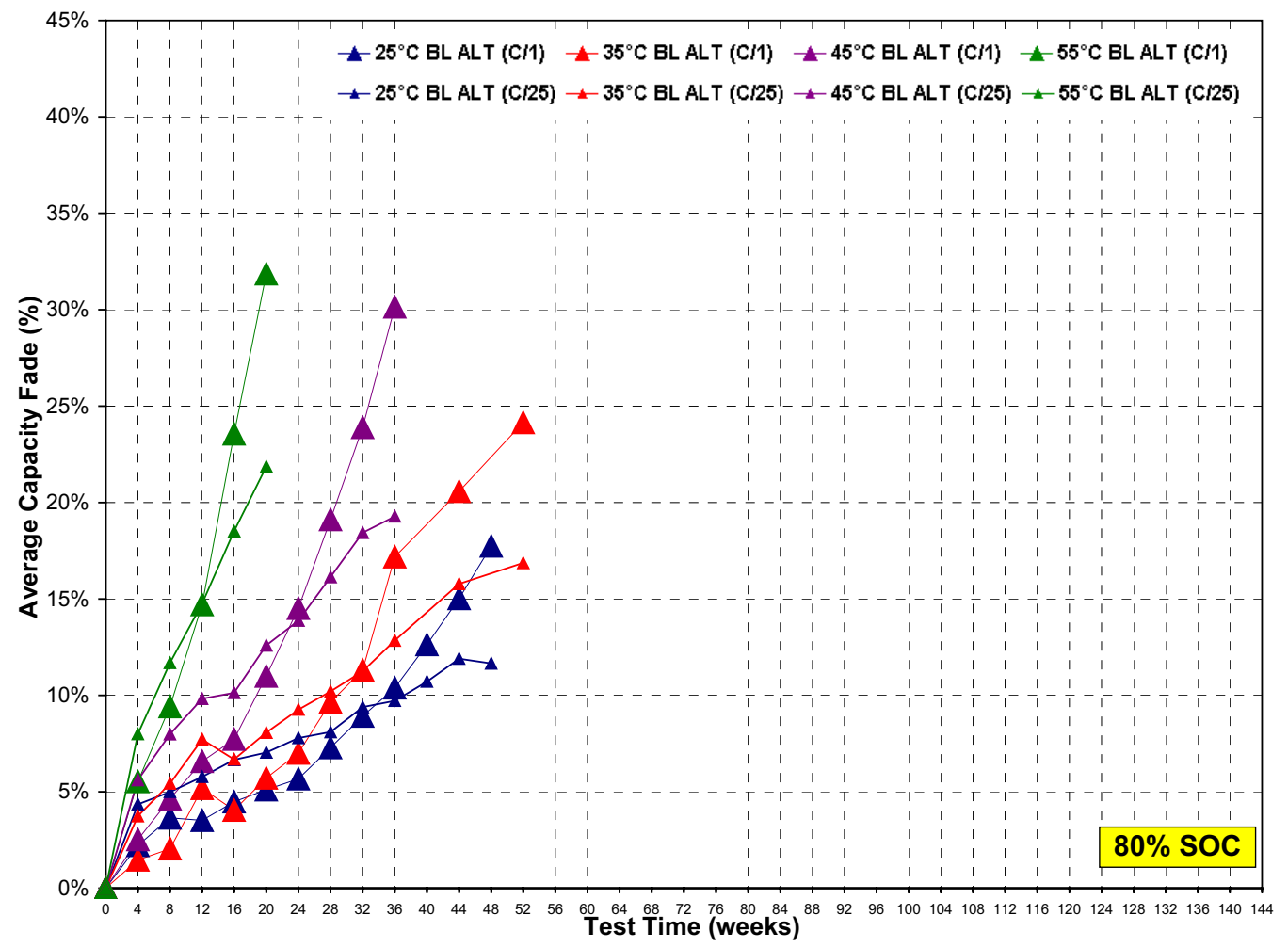

Figure 20. Average $C_{1} / 1$ and $C_{1} / 25$ discharge capacity fade for the accelerated-life cells at $80 \%$ SOC.

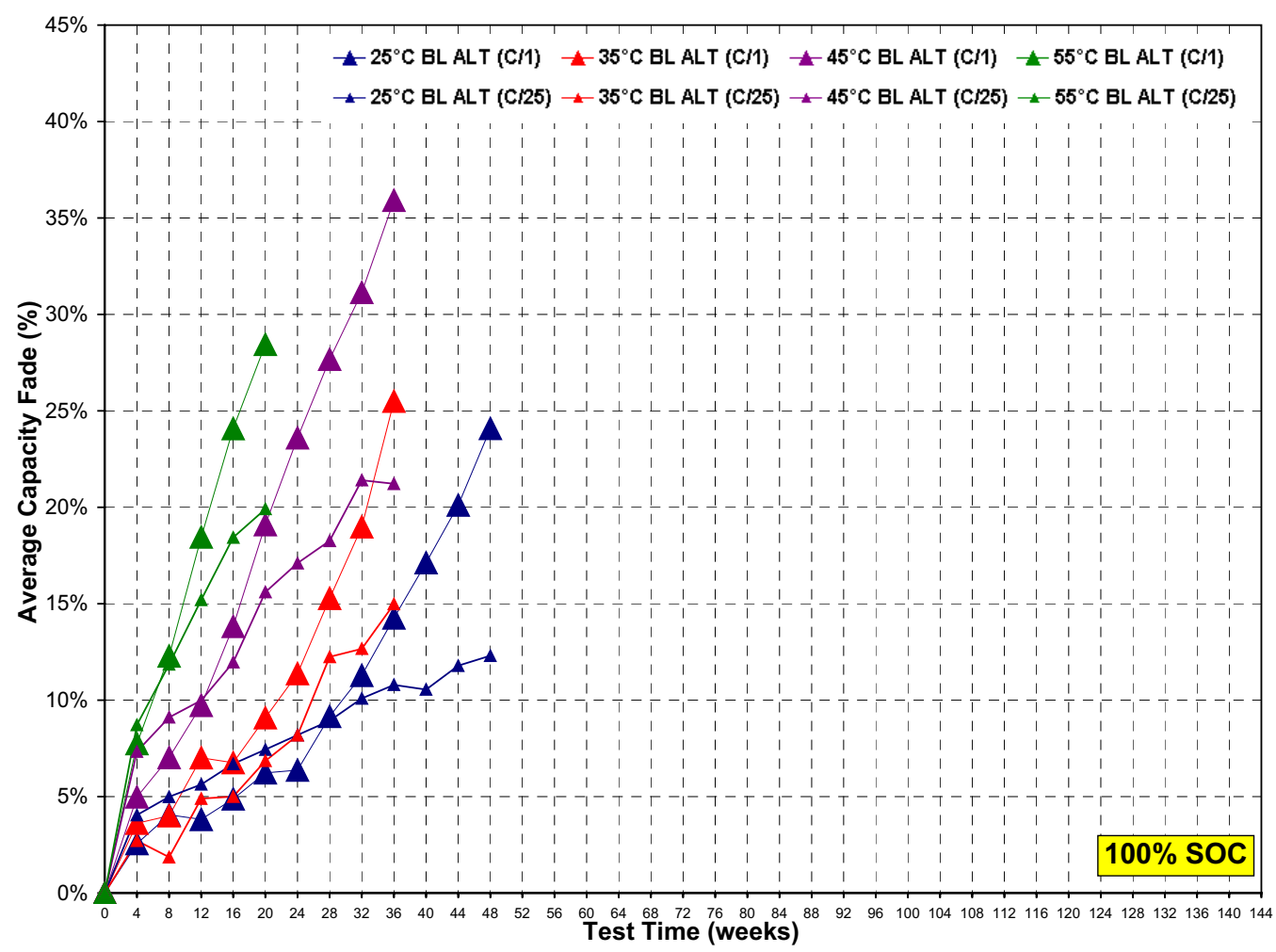

Figure 21. Average $C_{1} / 1$ and $C_{1} / 25$ discharge capacity fade for the accelerated-life cells at $100 \%$ SOC. 


\subsection{5 $C_{1} / 25$ Differential Analysis}

The sealed, 18650 cells do not allow the easy introduction of a reference electrode in them. Without a suitable, fixed point, obtaining electrode-specific information from the sealed cells is, thus, problematic. Differential analysis allows some of the limitations to be circumvented and help gain useful thermodynamic and some kinetic information about individual electrodes. At low currents, the deviation from thermodynamics is expected to be small. Thus, the $\mathrm{C}_{1} / 25$ discharge data indicate the amount of accessible capacity and show the relationship between cell potential and capacity under pseudoequilibrium conditions. Two different methods of differential analysis are considered below.

\subsubsection{1 $C_{1} / 25$ Differential Capacity}

Differential capacity is the relative change in capacity as a function of the voltage, normalized by the average $\mathrm{BOL} \mathrm{C}_{1} / 25$ capacity, $\mathrm{Q}_{\mathrm{BOL}}$. The $\mathrm{C}_{1} / 25$ discharge and charge data are first smoothed, then the differential capacity is calculated using Equation (1) with a two-point numerical differentiation.

$$
\text { Differential Capacity }=\frac{1}{\mathrm{Q}_{\mathrm{BOL}}} * \frac{\mathrm{d}(\mathrm{A} \cdot \mathrm{h})}{\mathrm{dV}}
$$

\subsection{Baseline Cells}

Figure 22 shows the Baseline cell $\mathrm{C}_{1} / 25$ differential capacity for a representative Baseline cell cyclelife tested at $25^{\circ} \mathrm{C}$ and $60 \%$ SOC for 140 weeks. The average BOL capacity for the $25^{\circ} \mathrm{C}$ Baseline cyclelife cells was $1.075 \mathrm{~A} \cdot \mathrm{h}$ (i.e., the value for $\mathrm{Q}_{\text {воL }}$ ). The differential capacity decreases as a function of test time in conjunction with the total capacity loss (see Figure 12). The loss in available capacity occurs predominantly at the three different SOC peaks (i.e., 9, 40, and 77\% SOC from the BOL discharge curve), with little losses outside the peak regions. The locations of these peaks also shift slightly in SOC as a function of aging. The peaks at 40 and $80 \%$ SOC appear to shift towards each other to form one peak centered around $60 \%$ SOC. This could be attributable to the alteration of the crystalline lattice in the electrodes. Interestingly, the discharge peaks tend to shift less than the corresponding charge peaks.

Figure 23 shows the differential capacity for a representative Baseline cycle-life cell tested at $45^{\circ} \mathrm{C}$ and $60 \%$ SOC through 68 weeks. As expected, the differential capacity decreases more rapidly at higher temperatures. The BOL location of the peaks occur at similar SOCs to the $25^{\circ} \mathrm{C}$ Baseline cells, and the capacity loss also occurs predominately at the location of these peaks. The shift in the peak locations is more pronounced at $45^{\circ} \mathrm{C}$, with the charge differential capacity showing a greater shift than the discharge differential capacity.

Figure 24 shows the Baseline cell $\mathrm{C}_{1} / 25$ differential capacity for a representative $45^{\circ} \mathrm{C}$ Baseline calendar-life cell tested at $60 \%$ SOC through 72 weeks. The BOL location of the peaks occur at similar SOCs to the cycle-life cells. Whereas the cycle-life cells show small shifts in peak locations and large drops in differential capacity (Figure 23), the calendar-life cells show large shifts in the peak locations and relatively small drops in differential capacity. The new peak formed from the 80 and $40 \%$ SOC peaks is much more pronounced for the calendar-life cells.

Figure 25 shows the differential capacity for a representative $55^{\circ} \mathrm{C}$ Baseline calendar-life cell tested at $60 \%$ SOC through 40 weeks. The initial peak locations are similar to the other cell groups (Figures 22 through 24). As expected, the shift in the differential capacity peaks is greater at $55^{\circ} \mathrm{C}$. 


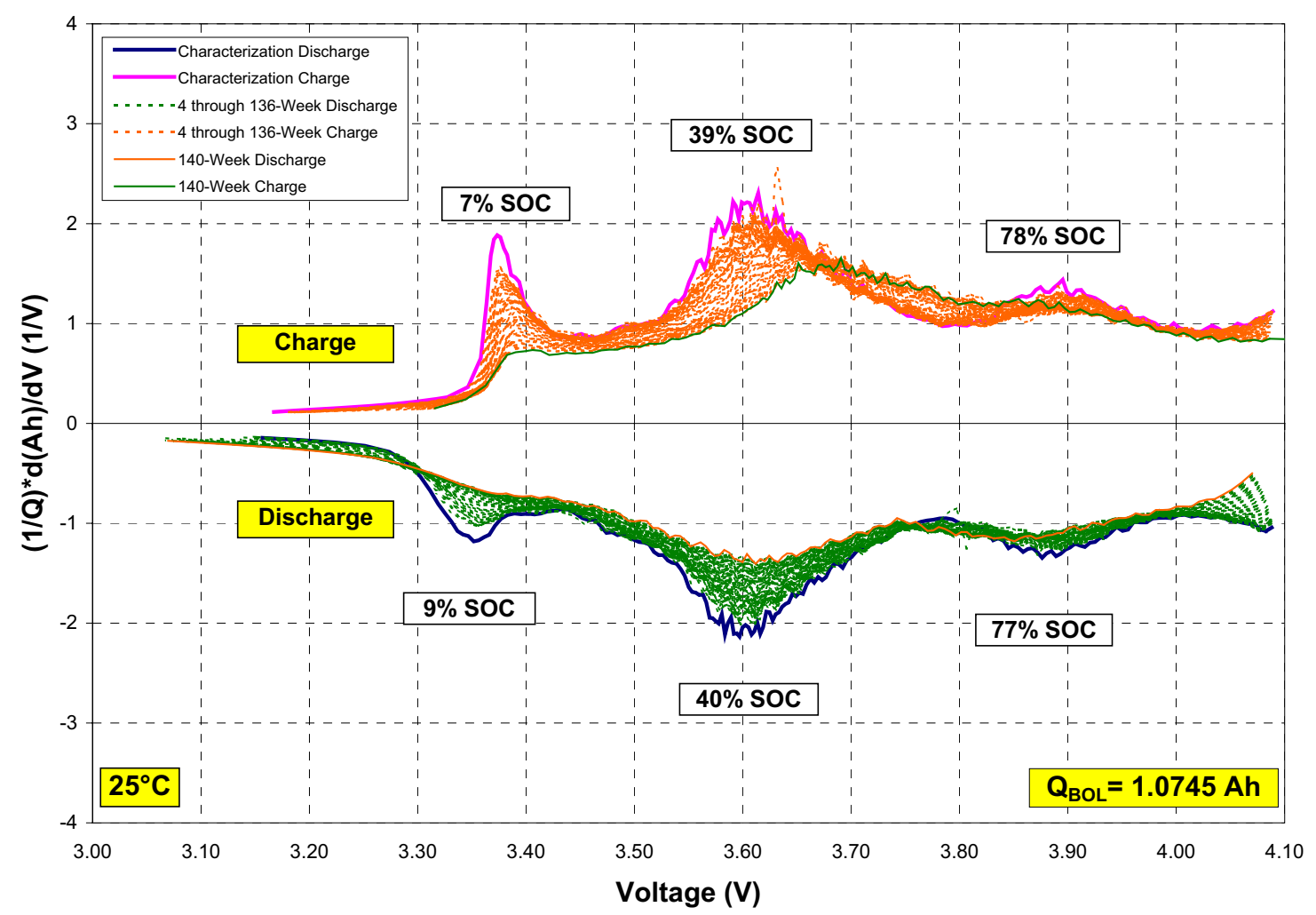

Figure 22. Differential capacity for a representative $25^{\circ} \mathrm{C}$ cycle-life Baseline cell.

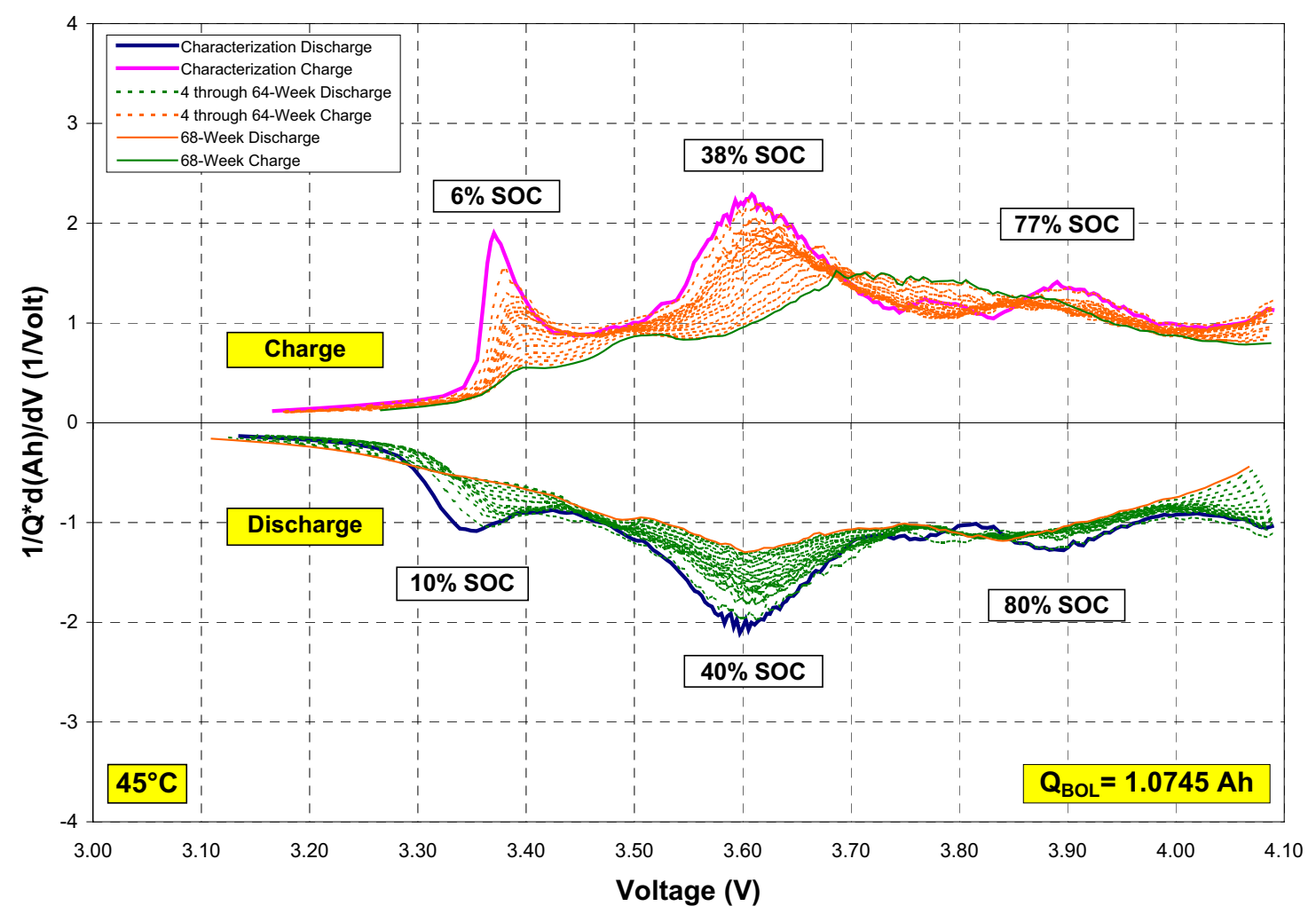

Figure 23. Differential capacity for a representative $45^{\circ} \mathrm{C}$ cycle-life Baseline cell. 


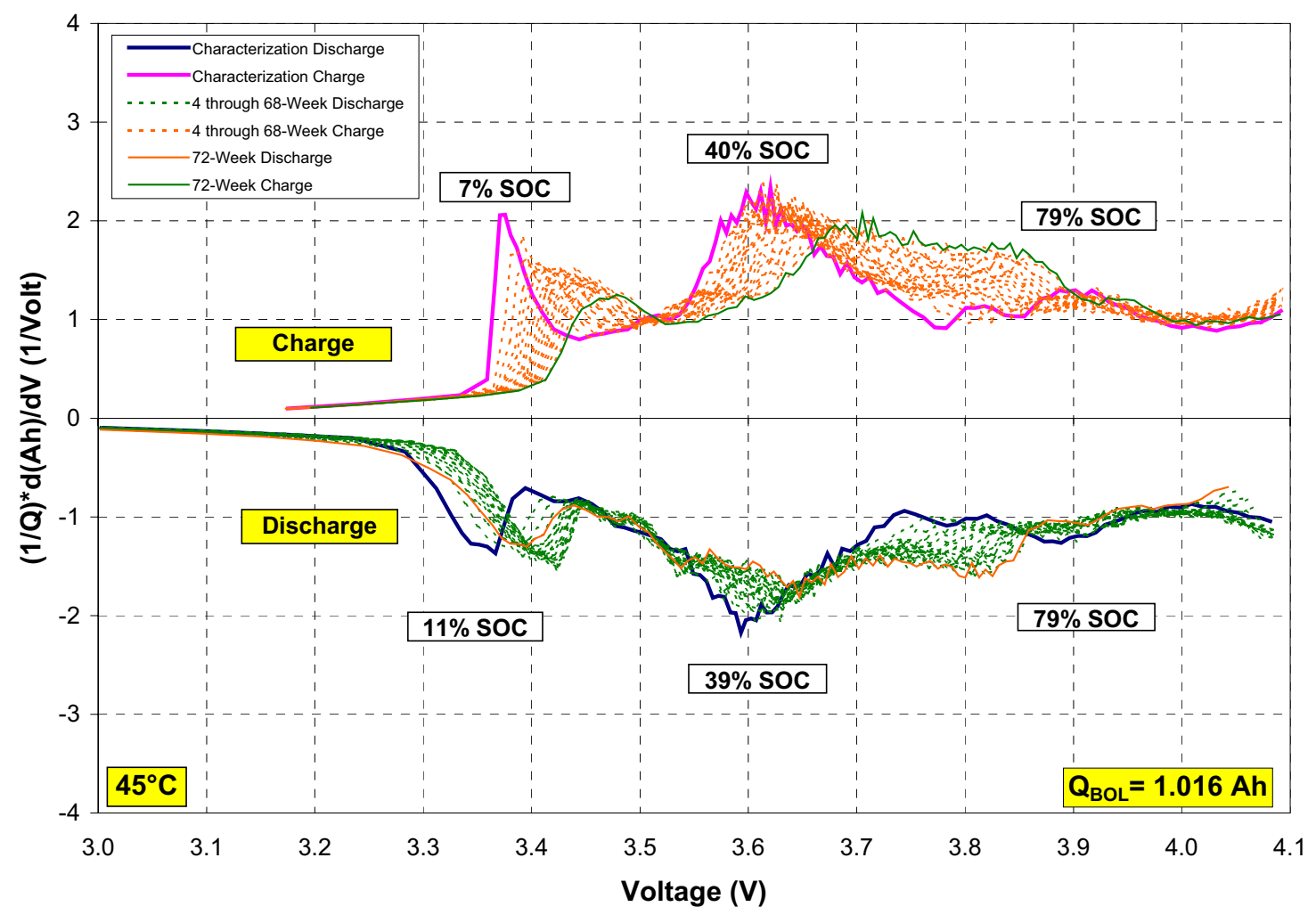

Figure 24. Differential capacity for a representative $45^{\circ} \mathrm{C}$ calendar-life Baseline cell.

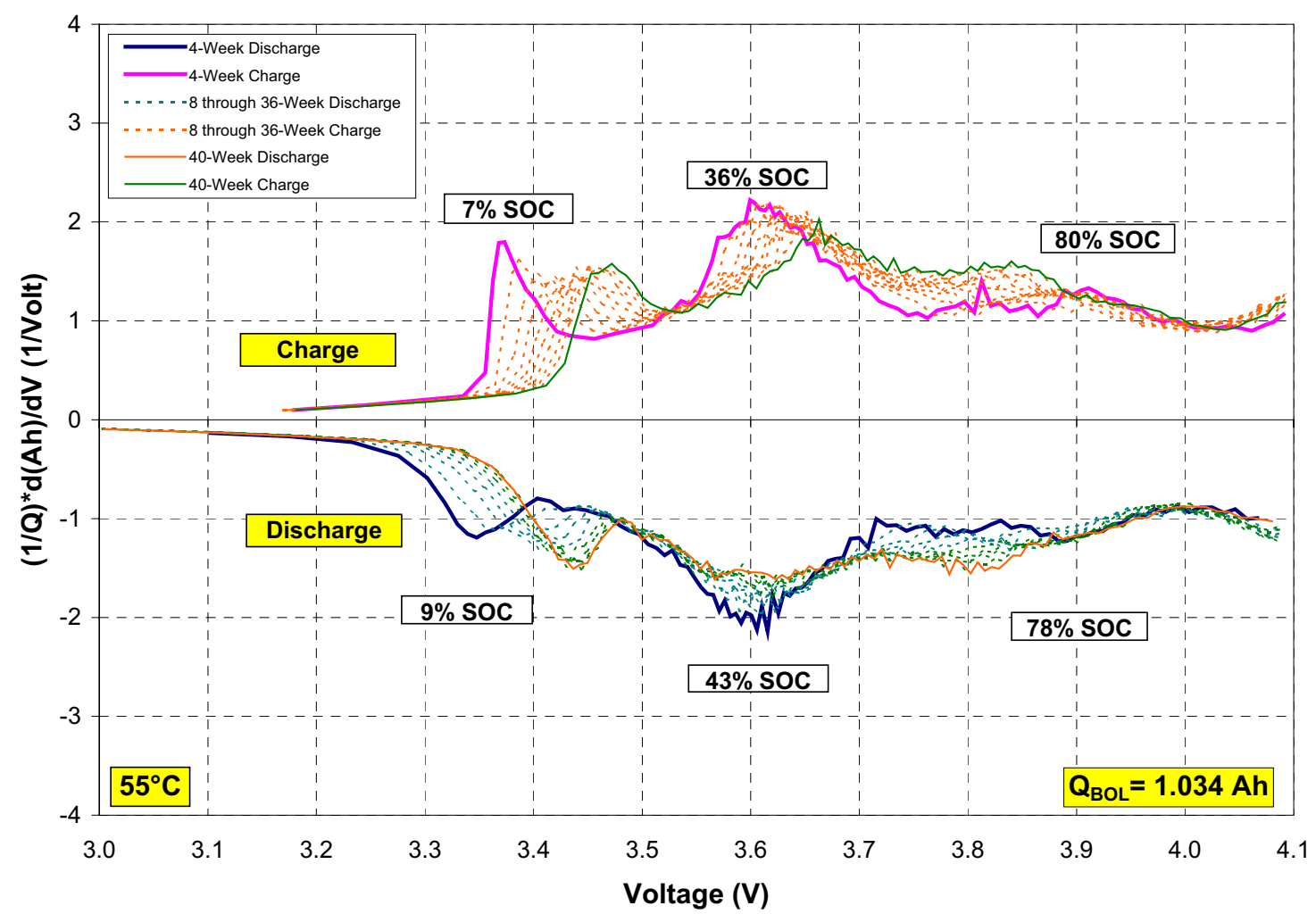

Figure 25. Differential capacity for a representative $55^{\circ} \mathrm{C}$ calendar-life Baseline cell. 


\subsection{Variant C Cells}

Figure 26 shows the differential capacity for a representative $45^{\circ} \mathrm{C}$ Variant $\mathrm{C}$ cycle-life cell through 124 weeks of aging at $60 \%$ SOC. The differential capacity for the Variant C cycle-life cells is missing the initial discharge peak (at approximately 8 to $10 \%$ SOC), and the charge peak at $5 \%$ SOC has a lower amplitude than the Baseline cycle-life cells (Figures 22 and 23). The rate of decrease and shift in the differential capacity for the $45^{\circ} \mathrm{C}$ Variant $\mathrm{C}$ cycle-life cells is similar to that of the $25^{\circ} \mathrm{C}$ Baseline cyclelife cells (Figure 22). This is consistent with the results seen in the $C_{1} / 25$ capacity fade (Figure 17). The Variant $\mathrm{C}$ cells also show a greater shift in the charge peaks than the discharge peaks.

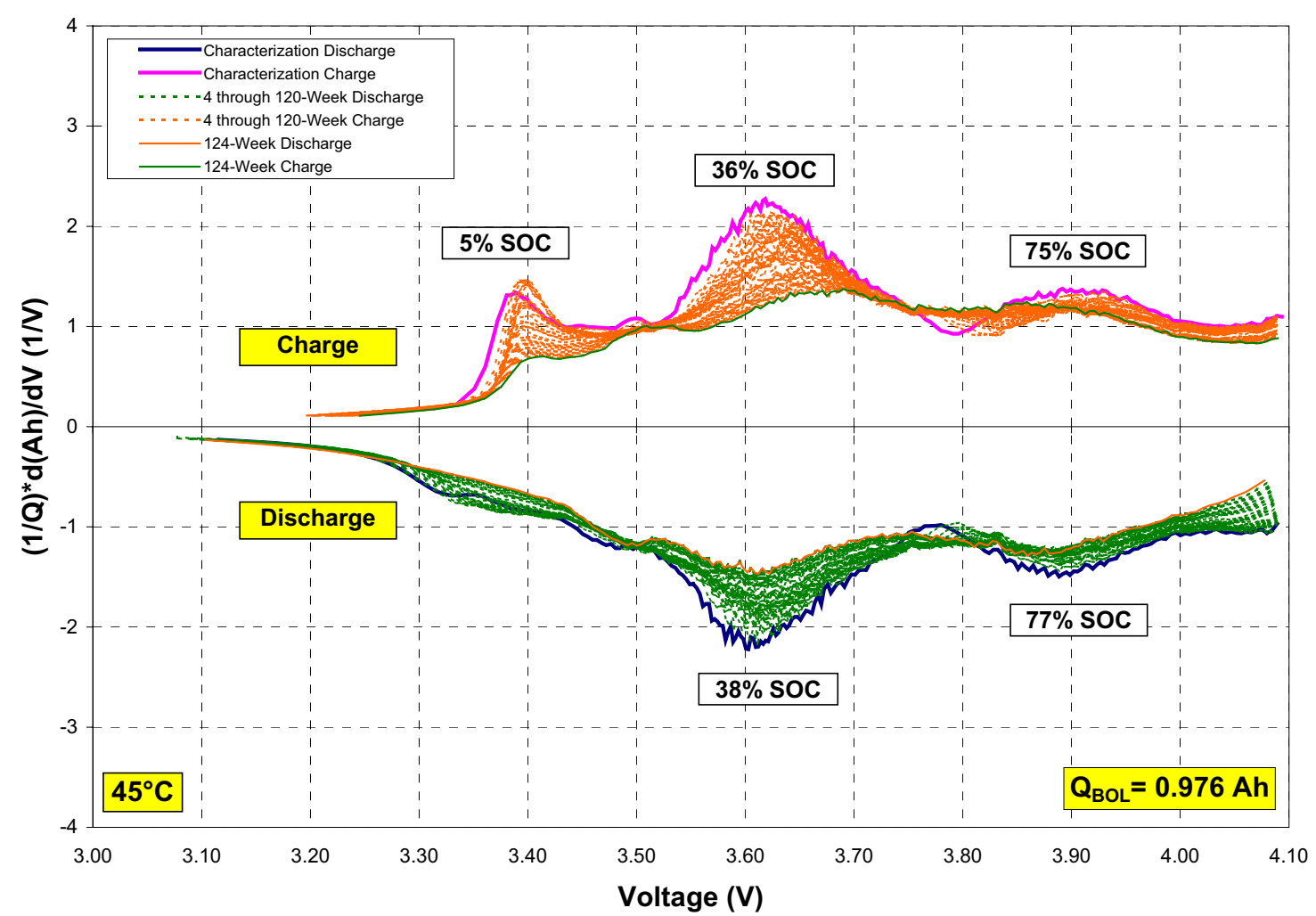

Figure 26. Differential capacity for a representative $45^{\circ} \mathrm{C}$ cycle-life Variant $\mathrm{C}$ cell.

Figure 27 shows the differential capacity for a representative $45^{\circ} \mathrm{C}$ Variant $\mathrm{C}$ calendar-life cell through 60 weeks of aging at $60 \%$ SOC. As was seen with the Baseline cells, the Variant C calendar-life cells show less amplitude drop and more peak shifting than the cycle-life cells. As a result, the development of the peak between 80 and $40 \%$ SOC forms more quickly for the calendar-life cells. Unlike the Variant $\mathrm{C}$ cycle-life cells, the calendar-life cells have an initial discharge peak at $8 \%$ SOC that grows as a function of test time. 


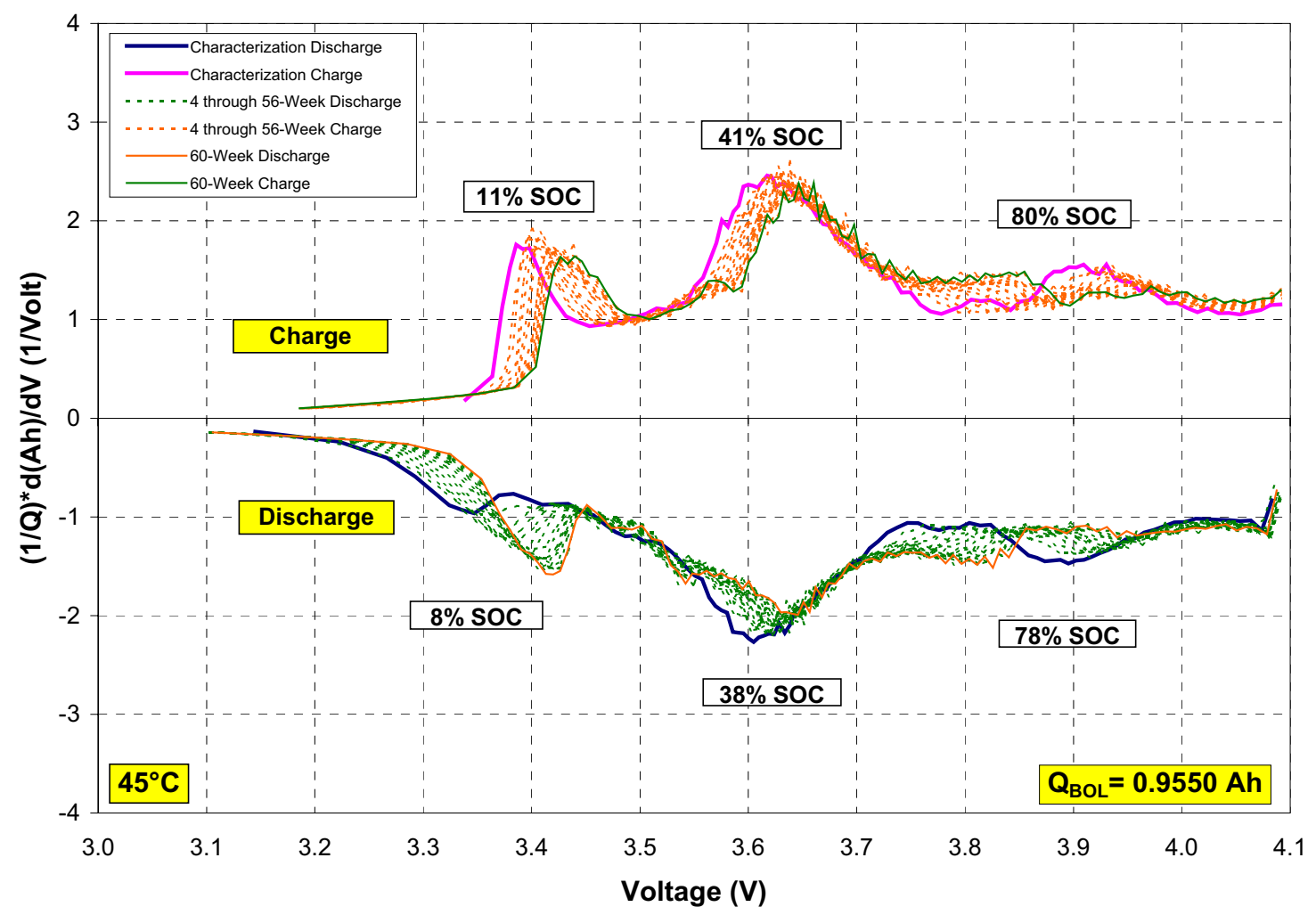

Figure 27. Differential capacity for a representative $45^{\circ} \mathrm{C}$ calendar-life Variant C cell.

\subsubsection{2 $C_{1} / 25$ Differential Voltage}

An alternative way of viewing the data is differential voltage, as described in Equation (2).

$$
\text { Differential Voltage }=\mathrm{Q}_{\mathrm{BOL}} * \frac{\mathrm{dV}}{\mathrm{d}(\mathrm{A} \cdot \mathrm{h})}
$$

The following describes analyses performed on the $\mathrm{C}_{1} / 25$ discharge data for the Variant $\mathrm{C}$ cells and represents a summary of the data and conclusions. The Variant $\mathrm{C}$ cells display the phenomena of interest more clearly and with more variety. A more complete discussion of differential voltage analysis, including Baseline cell data, is provided in References 10 through 12.

\subsection{Simple Case}

As the cell ages, the $\mathrm{C}_{1} / 25$ capacity decreases. This is shown in Figure 28 . Differentiation of the data in Figure 28 with respect to capacity, Equation (2), yields the family of curves in Figure 29. A vertical offset was added for the sake of clarity. 


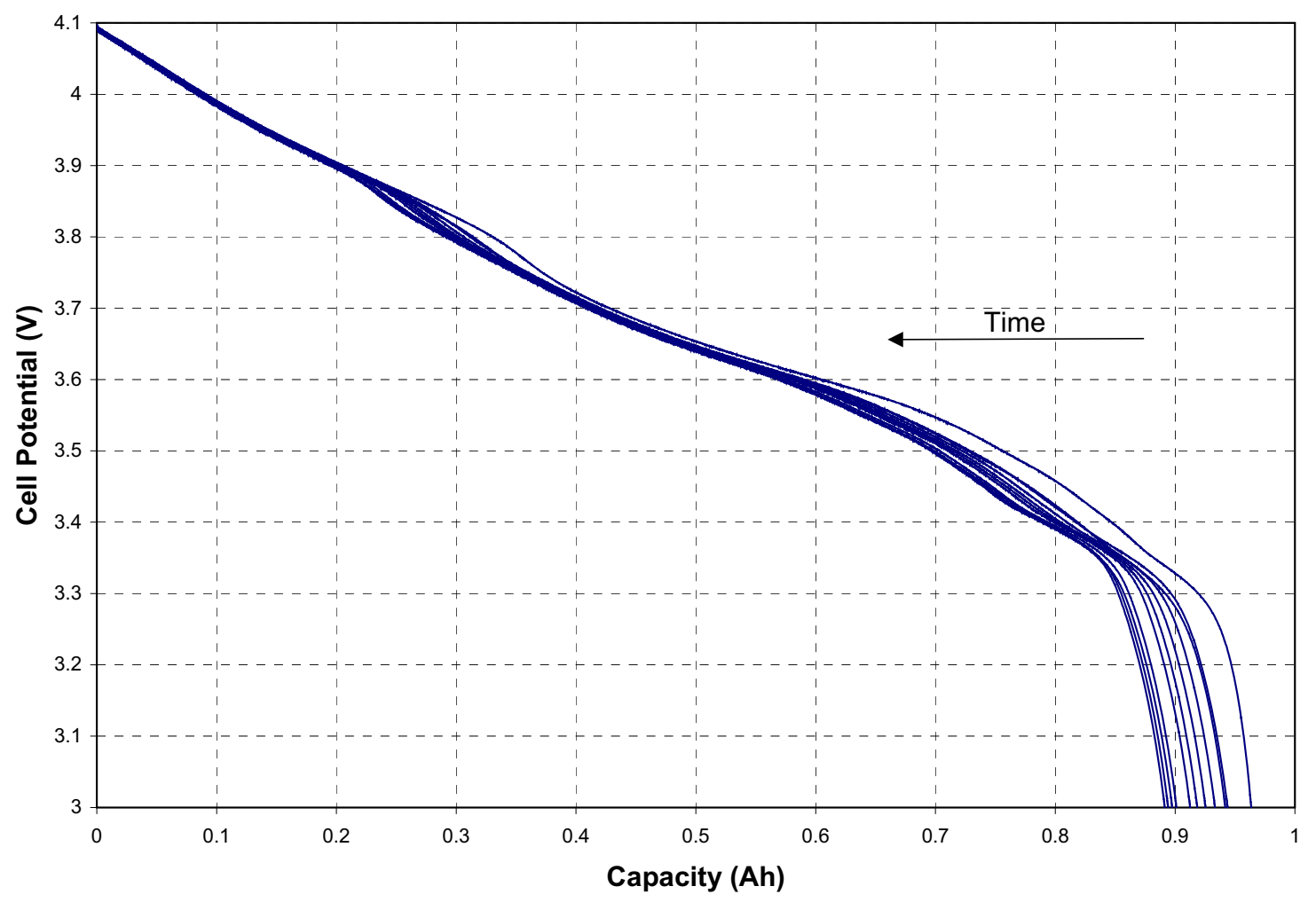

Figure 28. Changes in $C_{1} / 25$ cell voltage as a function of capacity for a representative Variant $\mathrm{C}$ cell.

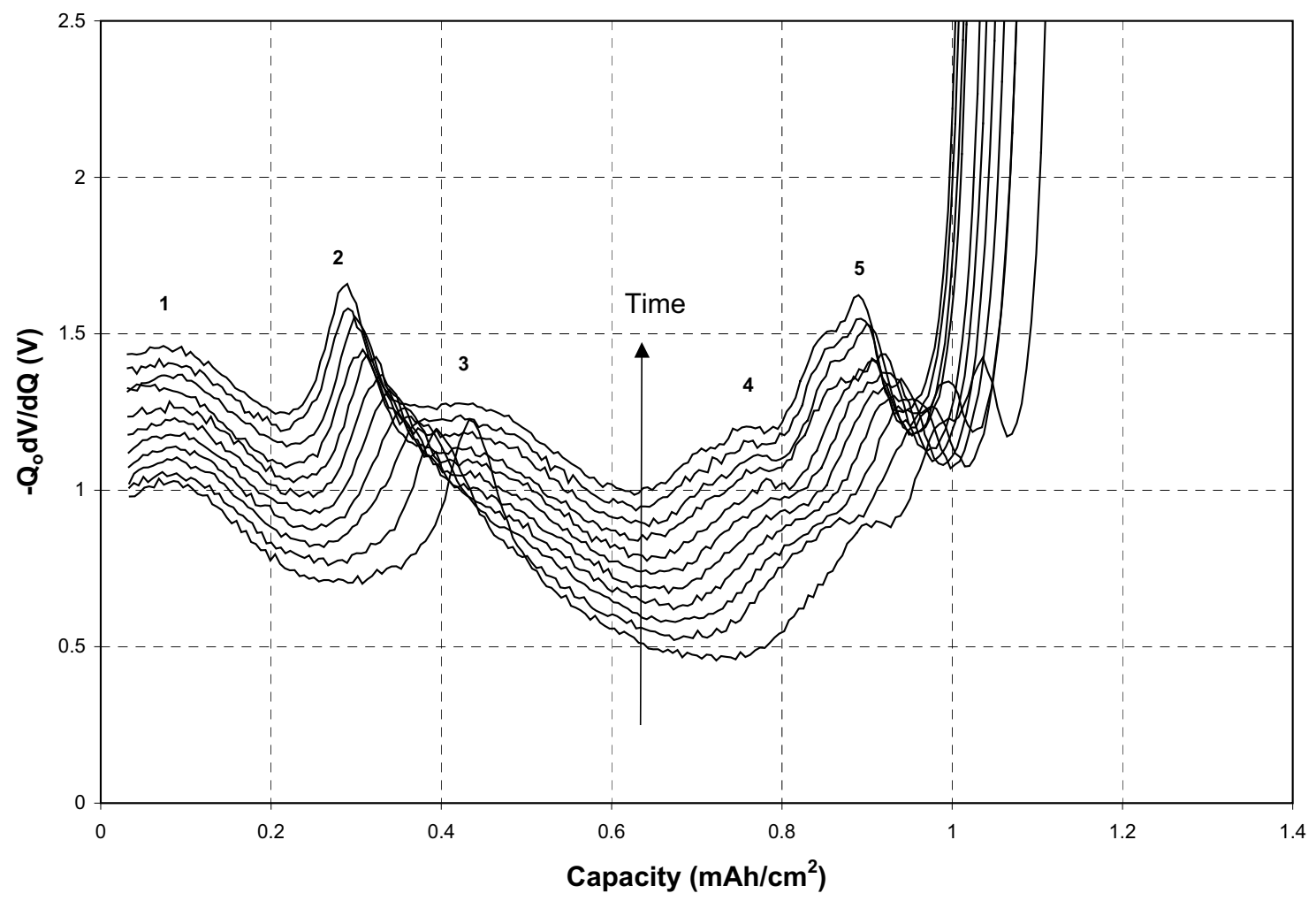

Figure 29. $C_{1} / 25$ differential voltage as a function of capacity. 
There are four peaks in the initial dV/dQ curve, 1, 2, 4, and 5 (see Figure 29). As the cell ages, the peaks appear to shift to the left and a new peak, 3, emerges from beneath peak 2. Using data from halfcells (vs. lithium), peaks 2, 4 and 5 were assigned to the anode, and peaks 1 and 3 were assigned to the cathode. Thus, peak 3 was initially obscured by peak 2 and emerged as capacity faded. Replotting these data with certain peaks aligned also show which peaks are related and that the distances between peaks from a given electrode do not change. Figure 30 shows the alignment of peak 2, and that the distances between the anode peaks do not change with time. Figure 31 shows that peaks 1 and 3 are related at that the distance between them does not change with aging time.

Based on what is known about the Variant $\mathrm{C}$ cell chemistry, it can be assumed that there are two major causes of capacity loss. They are the loss of accessible active material and side reactions. In the former, capacity of the electrode is uniformly lost. Also, capacity between $\mathrm{dV} / \mathrm{dQ}$ peaks is uniformly decreased, causing the peaks from the same electrode to move together with time. In the latter, some lithium capacity is consumed in a self-discharge process, but actual capacity does not change. These reactions produce the SEI layer, etc. The net effect on the dV/dQ curves is that peaks appear and disappear at different ends of the SOC curves. Since the distances between the peaks from an electrode do not change and capacity was lost, it can be deduced that the second cause, side reactions, is the major reason for the loss of capacity. From modeling calculations, such as those shown in Figure 32, the anode is the most likely place where these reactions occur.

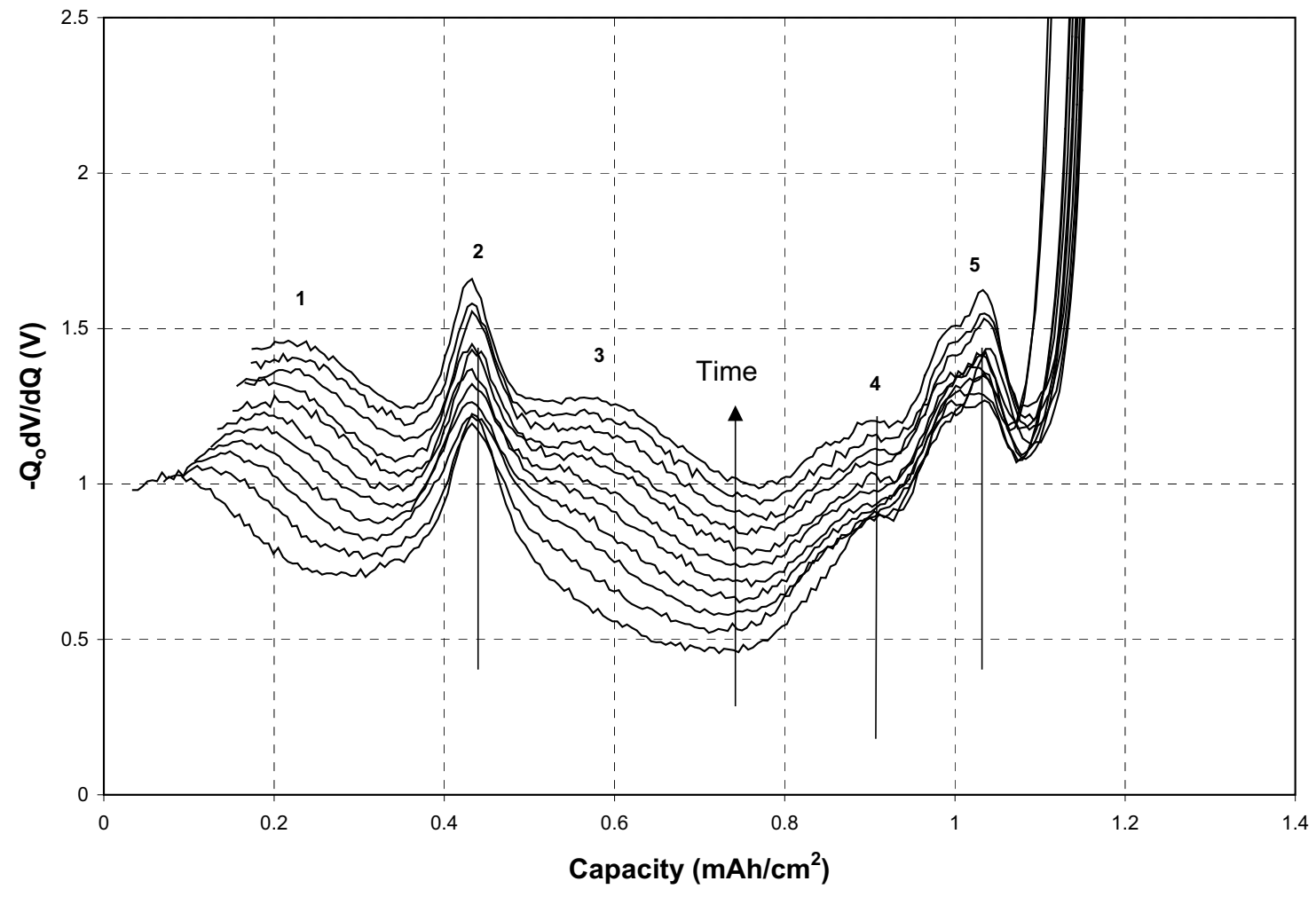

Figure $30 . \mathrm{C}_{1} / 25$ differential voltage as a function of capacity with peak 2 aligned. 


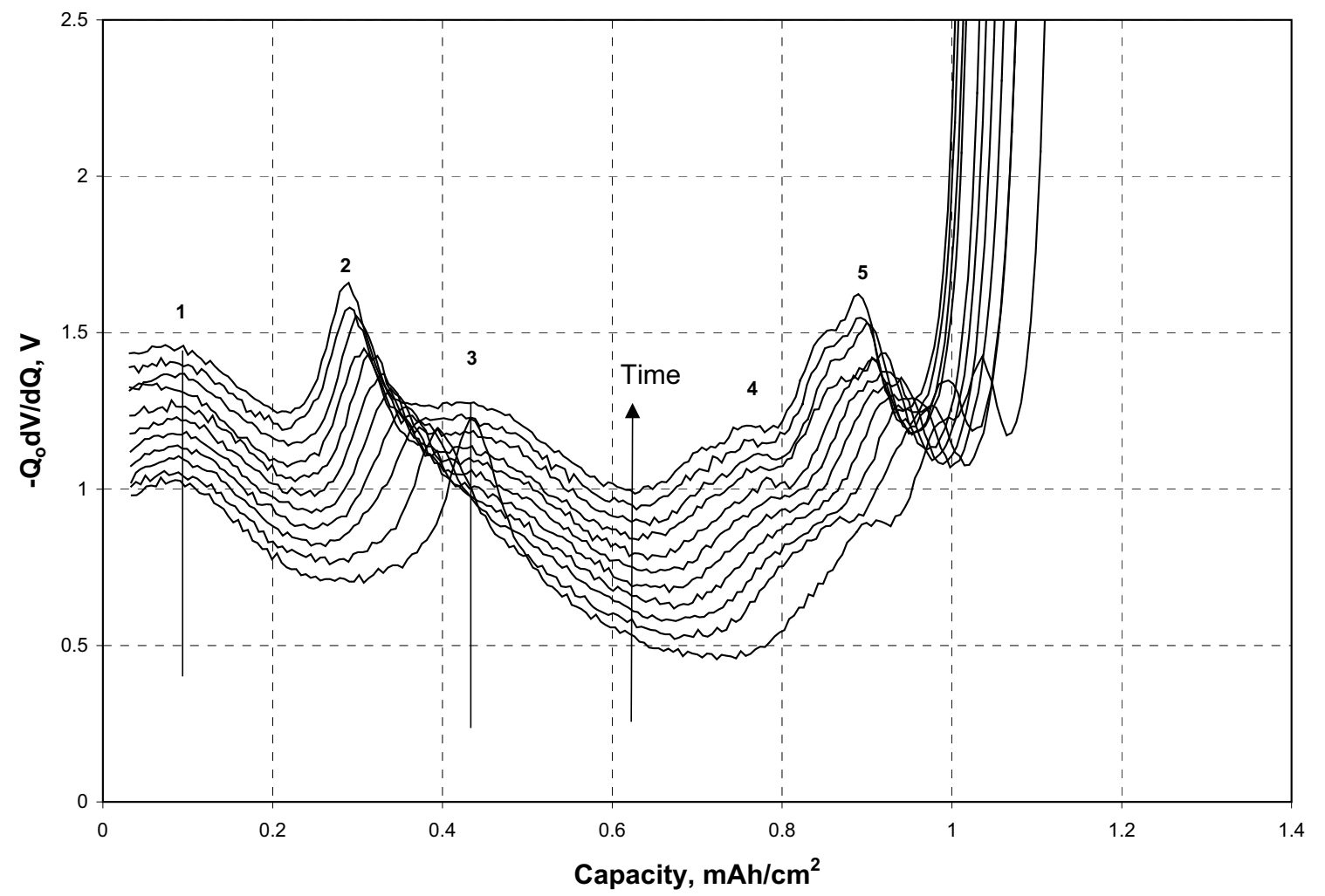

Figure $31 . \mathrm{C}_{1} / 25$ differential voltage as a function of capacity, peak 1 and 3 are related.

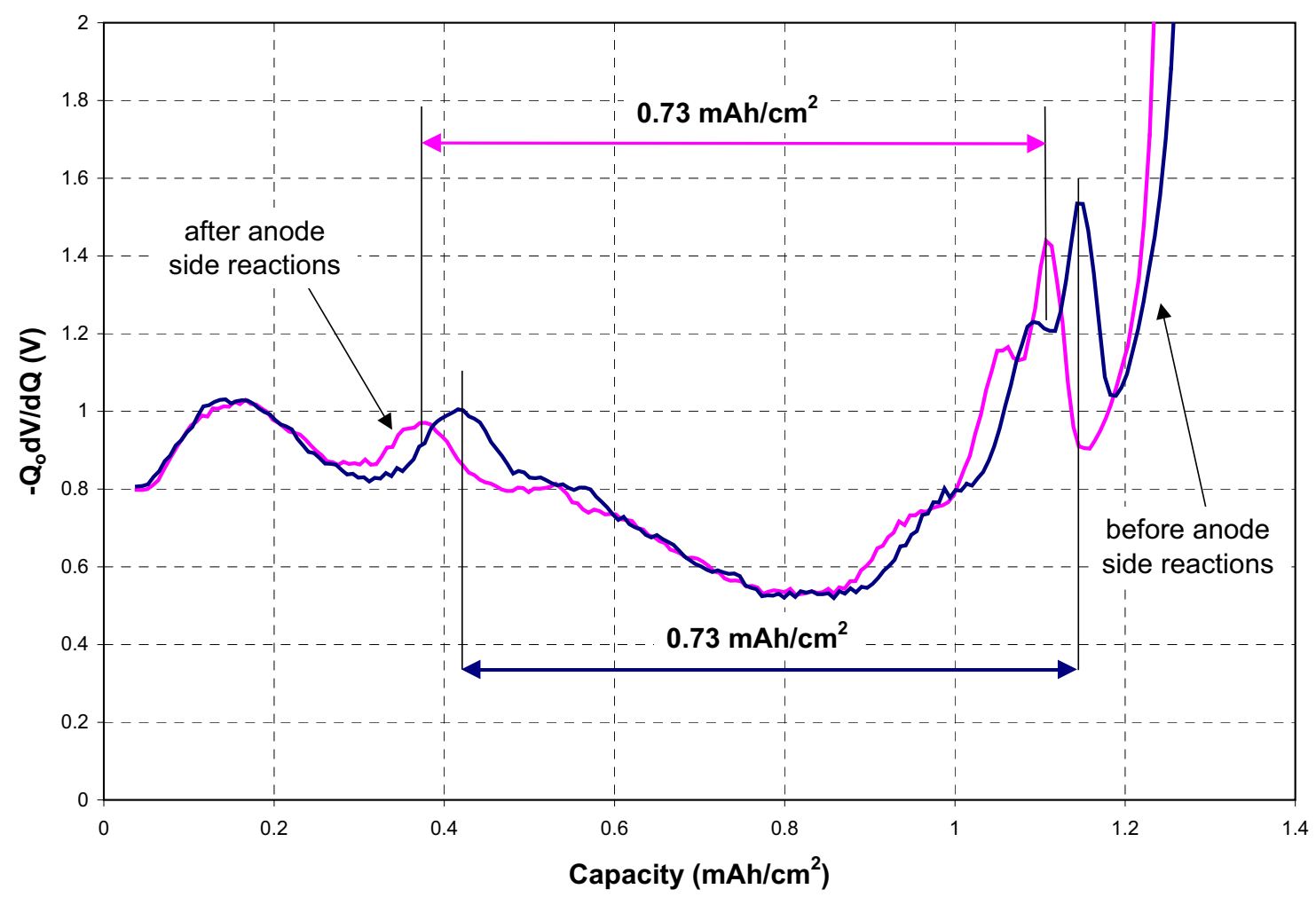

Figure 32. $\mathrm{C}_{1} / 25$ differential voltage calculated from half-cell data before and after capacity fade. 


\subsection{Complex Cases}

\subsection{Split Peaks}

Eighteen of the Variant C cells had only one anode peak (peak 2), six had two peaks and another two cells had peak 2 split into two. Examples of the last two phenomena are given in Figures 33 and 34, respectively. A rationalization of these behaviors is that if the anode experienced non-uniform aging or damage due to higher-than-expected current density (poor current collection) or manufacturing flaws (poor electrical contact, uneven pressure), it may behave differently from the bulk. The net effect is loss of accessible anode material. Indeed, calculations show that this behavior can be simulated using anode half-cell data. This is shown in Figure 35. The peak numbering is the same as in Figure 33, and a vertical offset was added for clarity. The amount of fade in the non-uniform part varies from 0 to $25 \%$. By comparing the degree of separation of peaks $2 \mathrm{a}$ and $2 \mathrm{~b}$ in Figures 33 and 35, the amount of non-uniform fading is about 14\%. Indeed, using the curves in Figure 35, the behaviors shown in Figures 33 and 34 can be simulated with good fidelity.

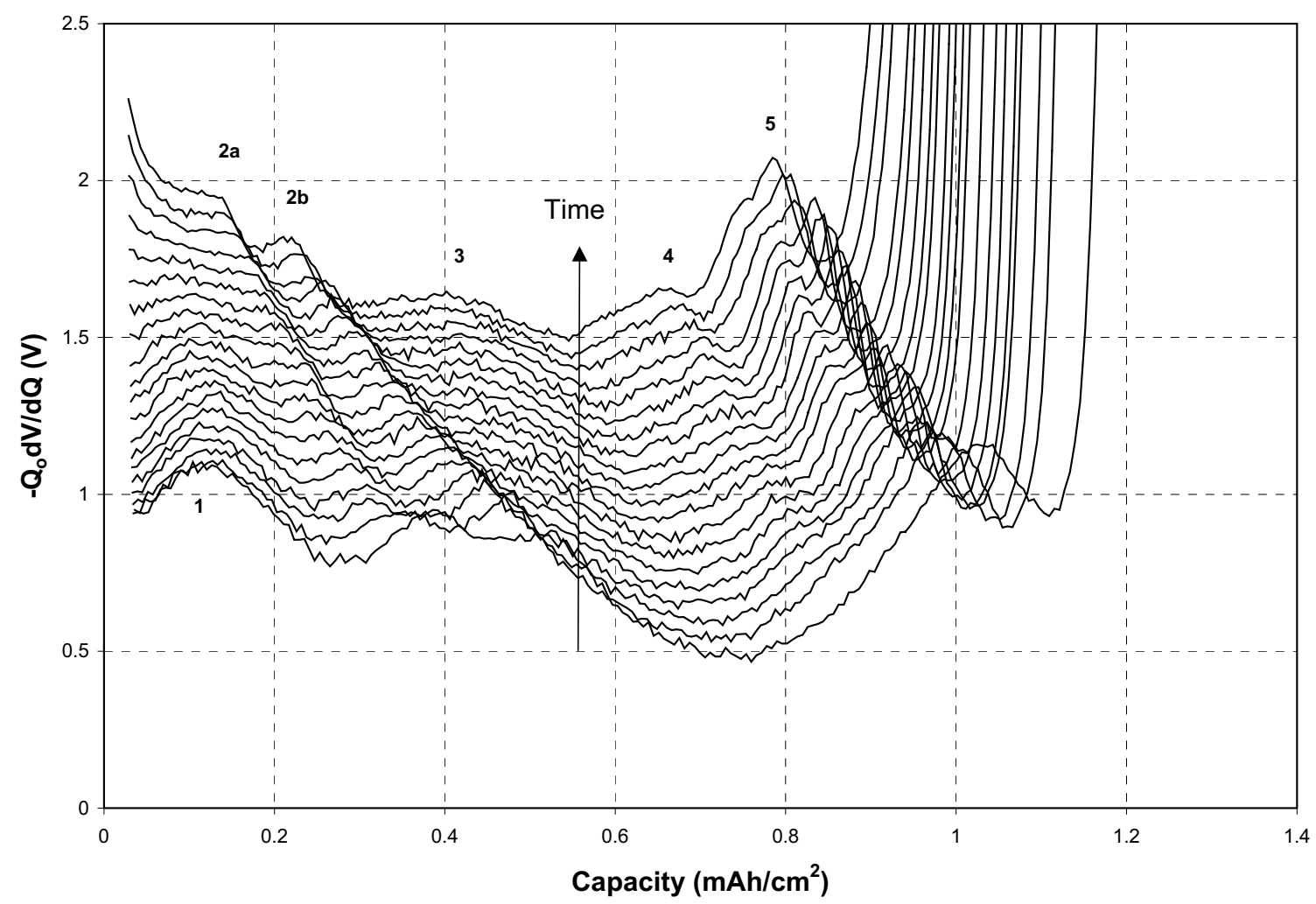

Figure 33. Variant $\mathrm{C}$ calendar life cell displaying a split peak 2. 


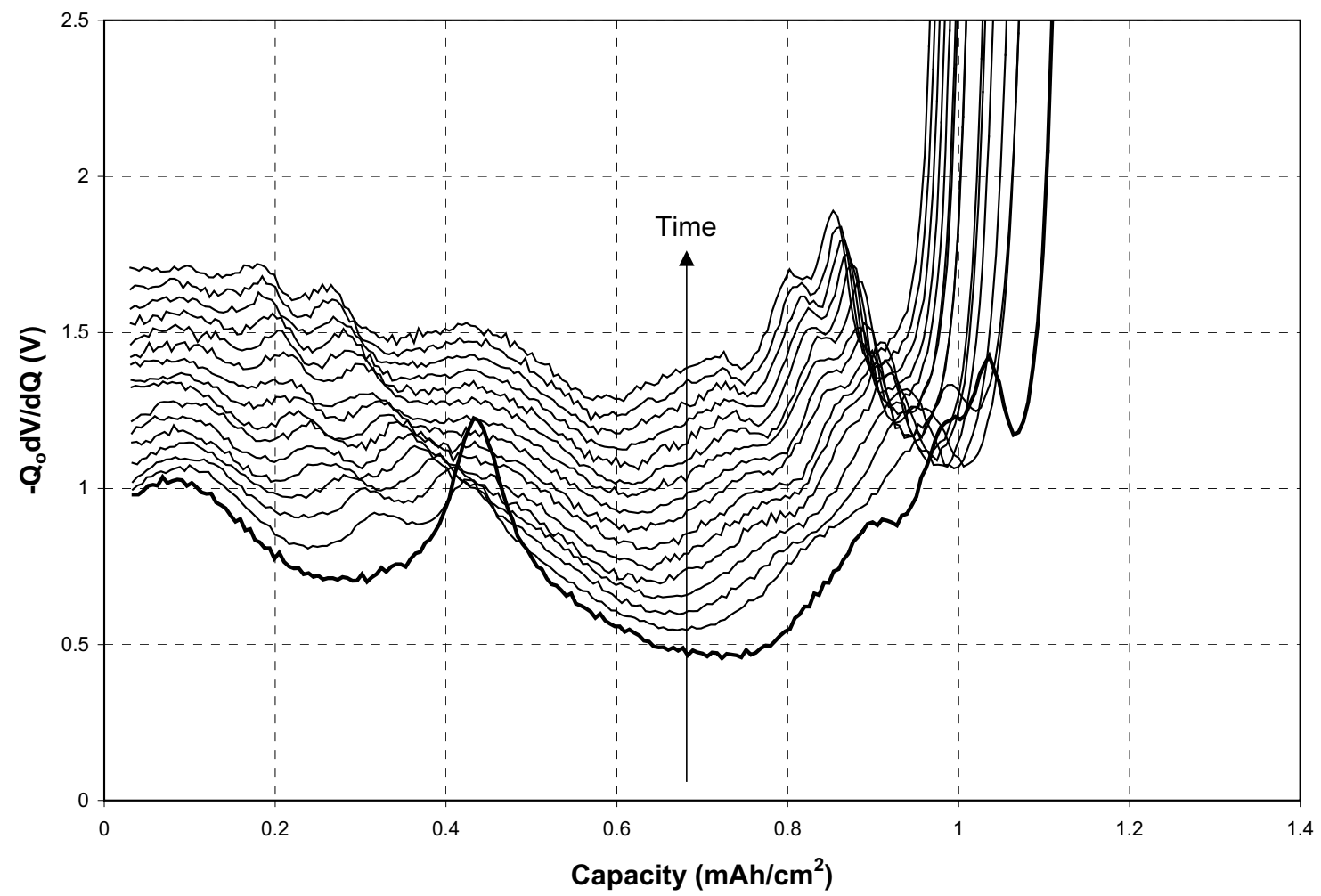

Figure 34. Variant $\mathrm{C}$ calendar life cell showing one peak 2 that splits into two with aging.

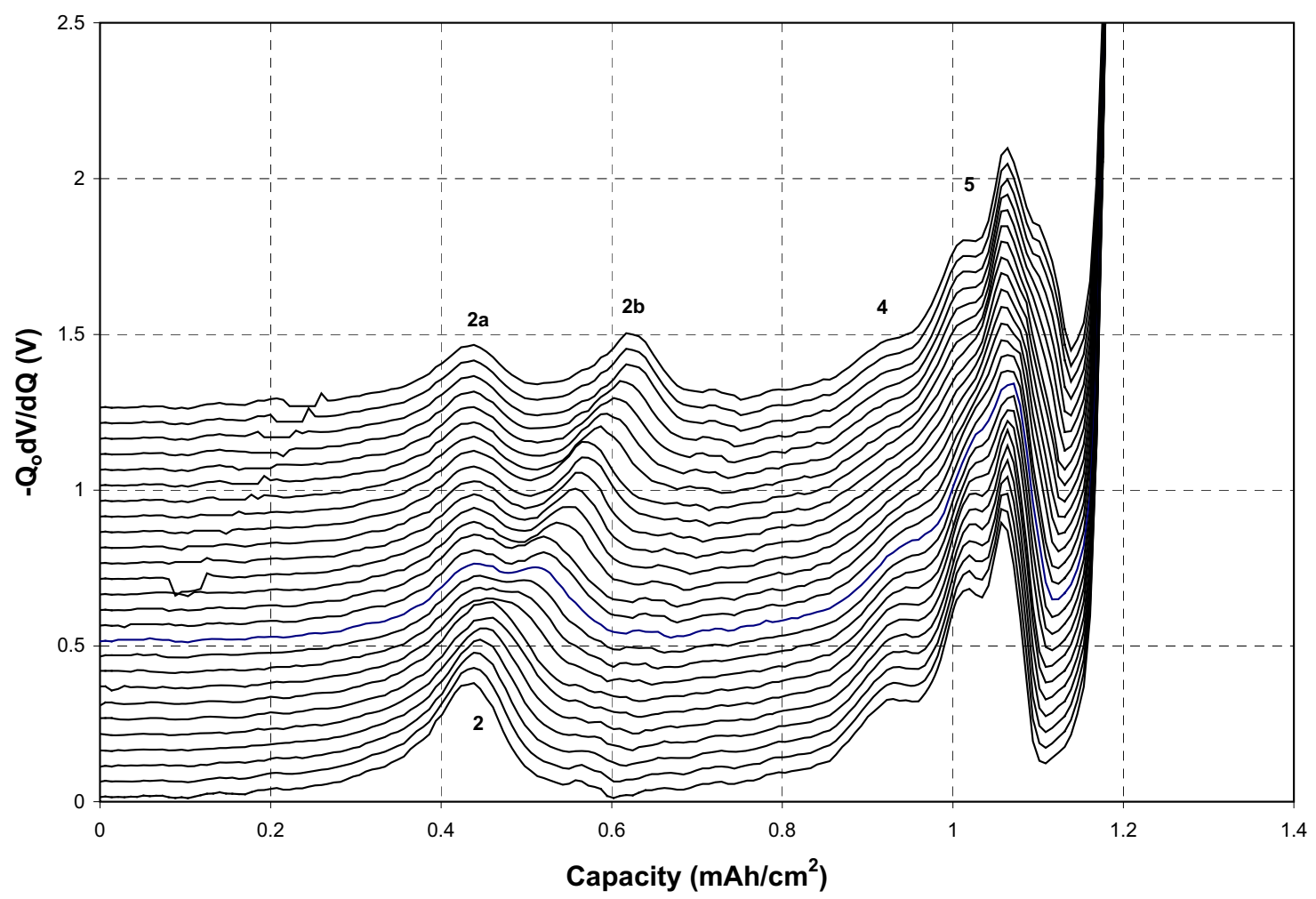

Figure 35. Calculated dV/dQ curves assuming non-uniform capacity fading at the anode. 


\subsection{Shrinking Peaks}

The phenomenology described below applies mainly to the cycle-life cells, and was most clearly seen in four of them. It was not clearly seen in the calendar-life cells, but it may still be there.

A decrease in the amplitude of peak 2 was seen in four cycle-life cells with increased aging, as shown in Figure 36. Plotting the amplitude of peak 2 for two of these cells shows the phenomenon (Figure 37). As a point of comparison, similar data from a Variant $\mathrm{C}$ calendar-life cell is also given in Figure 37. The data indicate that the height of peak 2 from a calendar-life cell does not appreciably change with time, but does for a cycle-life cell. The difference is most likely due to the amount of lithium exchanged during life testing. In the calendar-life test, the amount of lithium exchanged during charge and discharge during the test was about 6 Ah per four-week period; in the cycle-life test, it was about 450 Ah per four-week period.

Further analysis of the data in Figure 37 (see Figure 38) shows that the decrease in height of peak 2 follows a $t^{1 / 2}$ kinetic rate law. This indicates that the underlying process(es) is (are) diffusion controlled (see Section 4.5.2). Peak 3 and the background were subtracted before plotting. The height of peak 2 in cell 1 was not resolvable from the background after 44 weeks of aging. The value of the regression coefficient, $r^{2}$, in both cases was 0.99 .

Conceptually, the process(es) decrease the lithium activity difference between two voltage plateaus in the lithium -graphite phase diagram. To answer the questions about whether the decrease is due to the cell chemistry or artifacts of cell construction, a portion of the aged anode was characterized in terms of its $\mathrm{C}_{1} / 25$ voltage vs. capacity curve and compared to an unaged sample. The $\mathrm{dV} / \mathrm{dQ}$ curves from these data were calculated and are given in Figure 39 (the aged cell data is from the second cycle-life cell shown in Figures 37 and 38). As can be seen, there is a significant difference in the height of the peak in the capacity range of 0.4 to $0.5 \mathrm{mAh} / \mathrm{cm}^{2}$.

The most likely cause of $\mathrm{C}_{1} / 25$ capacity loss is by side reactions at the anode. The above results outline one of many undesirable side reactions. Here, the electrochemically active layers within the carbon anode particles are reacting with solvated lithium ions in such a way that the products of the reaction remain in the "galleries" between the graphene layers. The effects of solvent co-intercalation and reactions on the physical properties of various graphites have been reported in the literature (References 13 through 20). For example, Besenhard et al. studied the film-forming reactions of graphite materials in organic electrolytes (References 14 and 18). They found that there was an initial irreversible reaction that led to a complex film from the chemical decomposition of solvated graphite-intercalation compounds, $\operatorname{Li}(\text { solv })_{y} \mathrm{C}_{x}$, where "solv" is a mixture of solvent molecules. Further, Besenhard states that, since the unsolvated $\mathrm{Li}^{+}$ion is small, it can still participate in the reversible intercalation process even if the space between the graphene layers is filled with organic decomposition productions (Reference 18). Thus, one would expect that the cell would continue to operate as the space between the layers fills. The filling of the interlayer space with lithiated organic materials is the most likely source of the decrease in lithium activity difference between the two phases. Filling of the galleries has been reported by Peled et al. (Reference 19). 


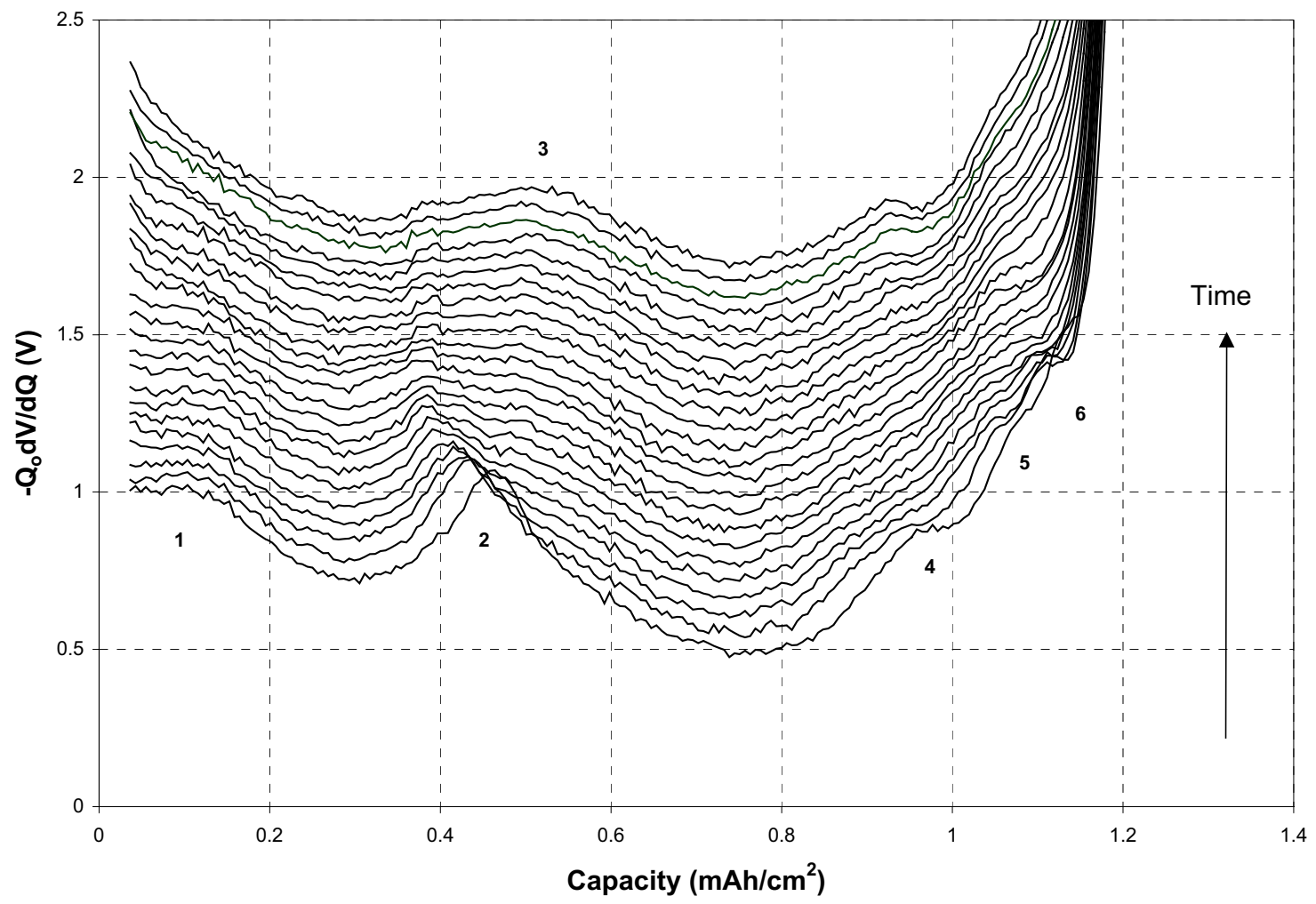

Figure 36. Example of dV/dQ curves displaying a shrinking peak 2 for a representative cycle-life cell.

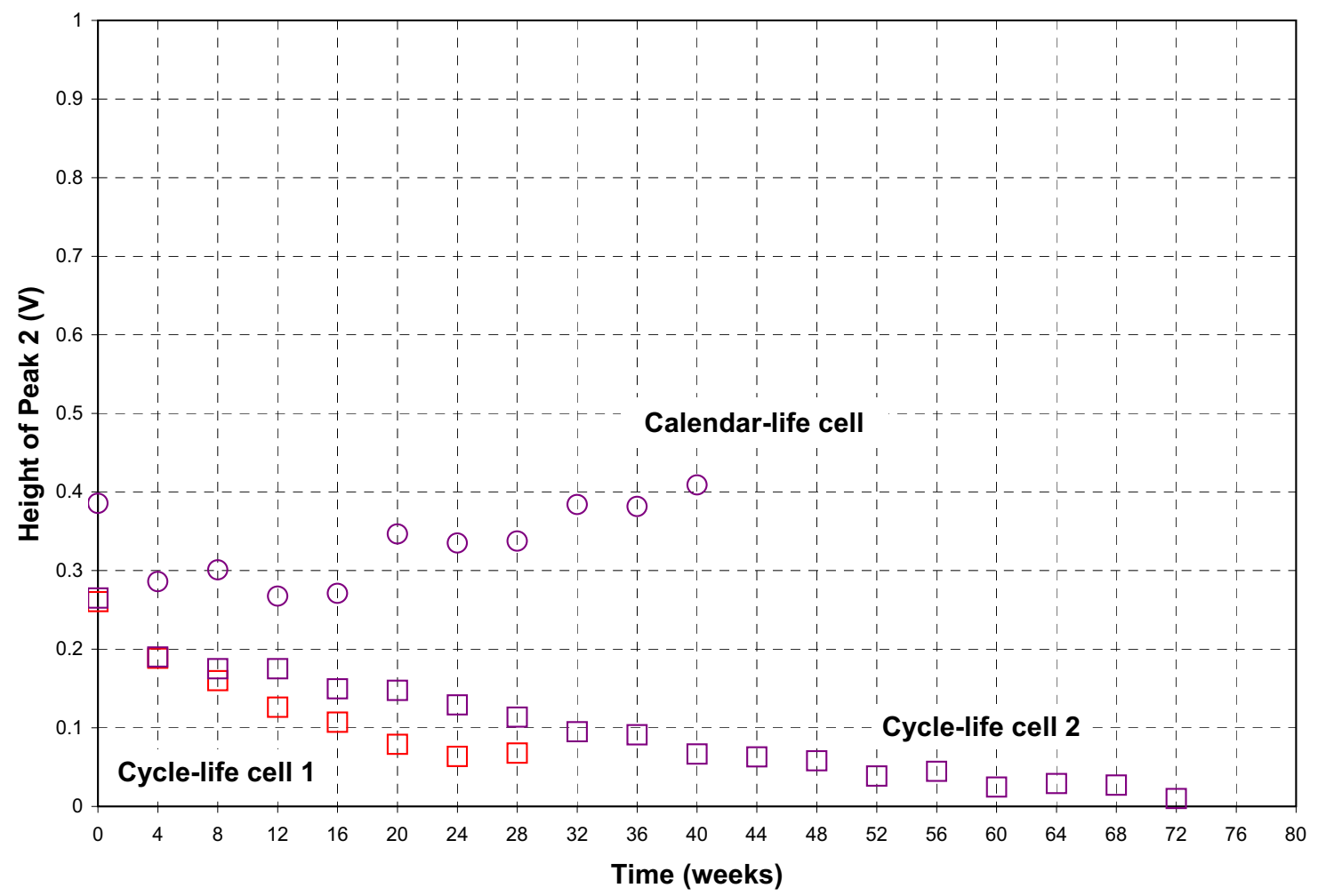

Figure 37. Height of peak 2 vs. time for cycle- and calendar-life cells. 


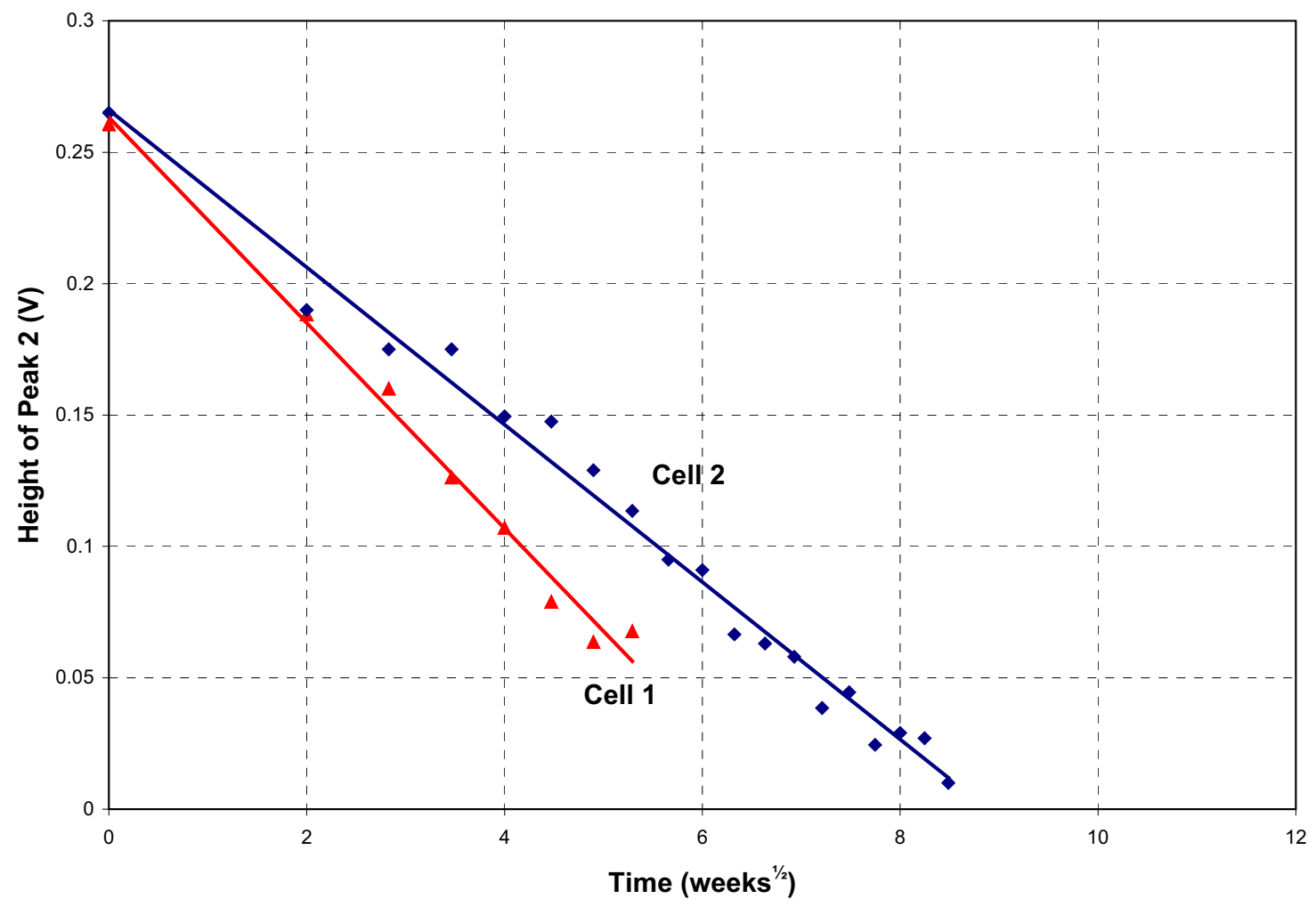

Figure 38. Height of peak 2 vs. the square root of time for the cycle life cells.

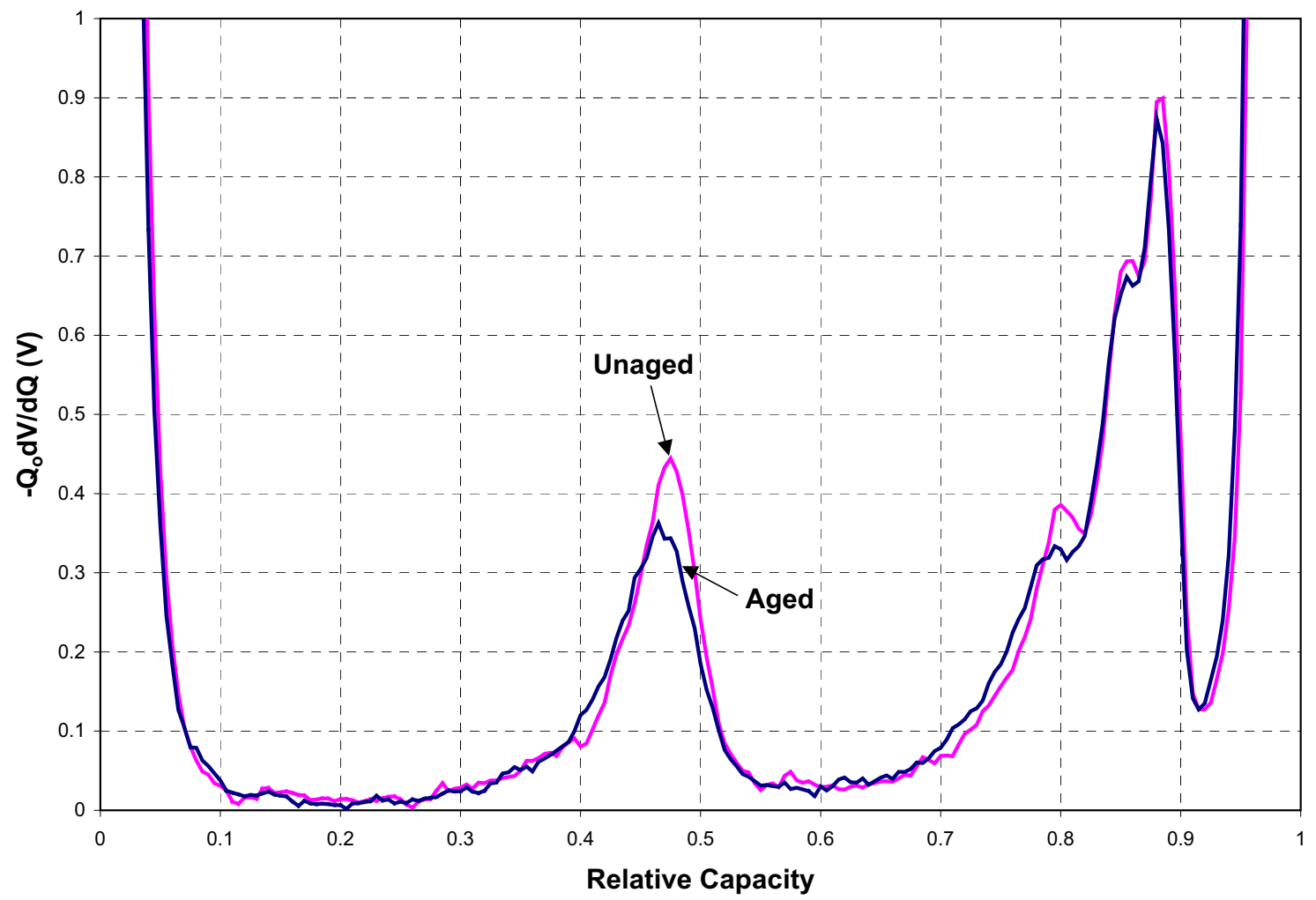

Figure 39. $-Q_{0} d V / d Q$ vs. relative capacity from half-cells containing aged and unaged anode materials. 


\subsection{Hybrid Pulse Power Characterization}

The L-HPPC test is used to calculate changes in resistance, energy, and power. A detailed description of the calculation methodology is provided in Appendix D.

\subsubsection{Area Specific Impedance}

Figure 40 shows the average discharge area-specific impedance (ASI) at $60 \%$ SOC for the Baseline calendar- and cycle-life cells. As seen with the capacity data, the initial ASIs are similar, but the growth rate increases with increasing temperature and life test. The calendar-life ASI growth at $45^{\circ} \mathrm{C}$ is less than the corresponding cycle-life data. Figure 41 shows the average discharge ASI for the Variant $\mathrm{C}$ calendarand cycle-life cells. The initial ASIs are higher for the Variant $\mathrm{C}$ cells, but shows a slower growth rate than the corresponding Baseline cells. At end-of-test, the $45^{\circ} \mathrm{C}$ Variant $\mathrm{C}$ growth rate is similar to the $25^{\circ} \mathrm{C}$ Baseline cells.

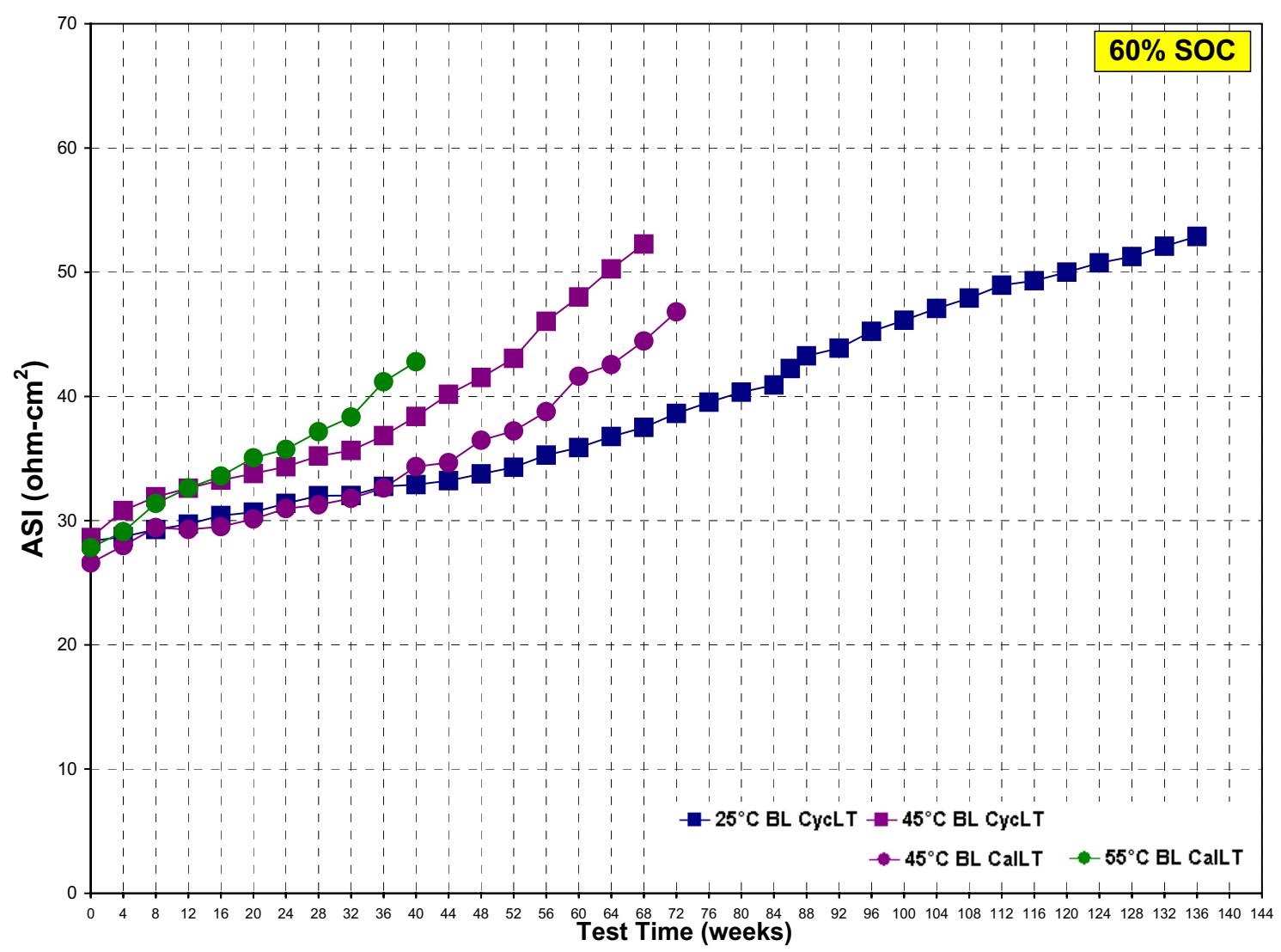

Figure 40. Average discharge ASI for the Baseline calendar- and cycle-life cells at $60 \%$ SOC. 


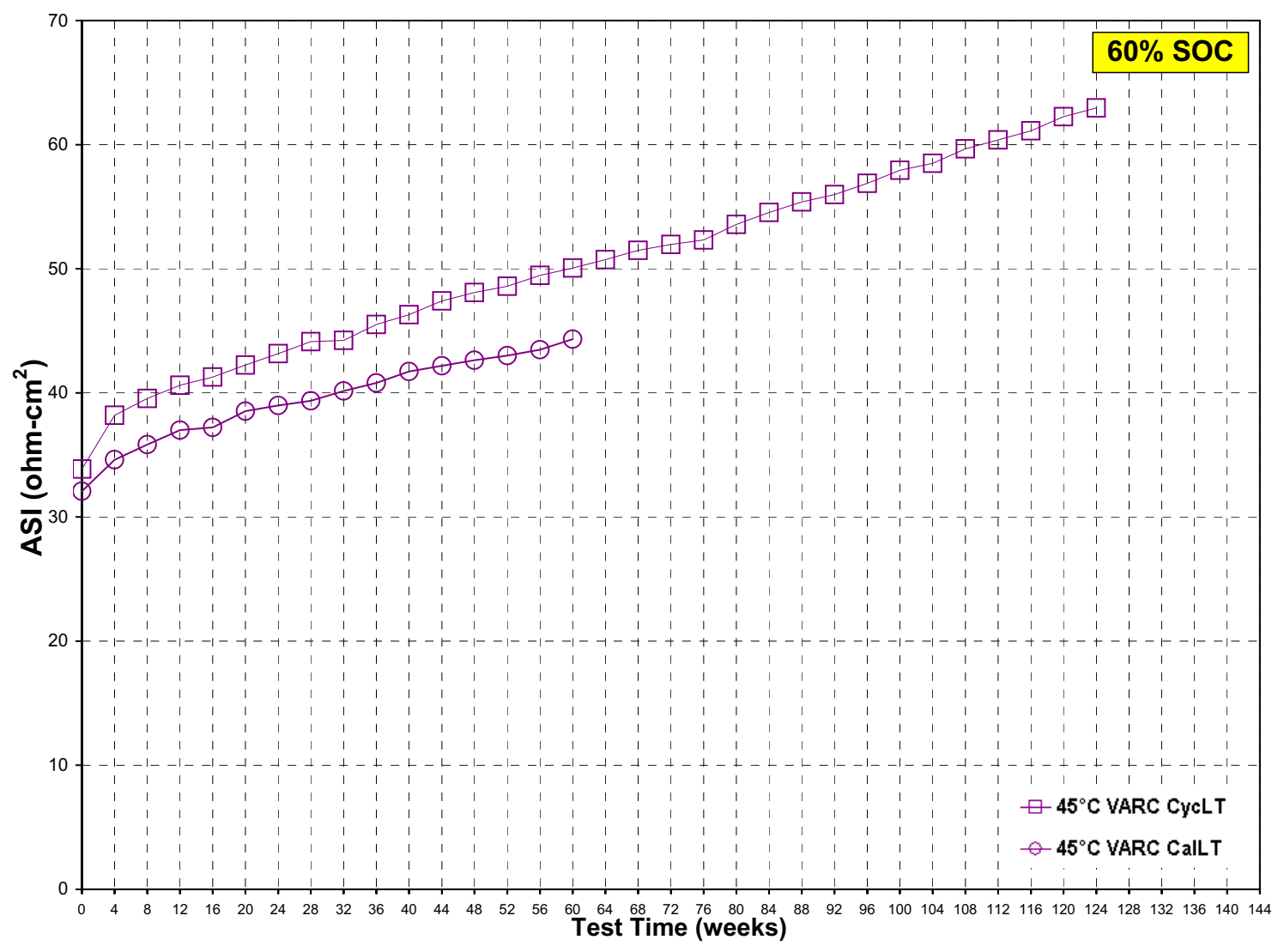

Figure 41. Average discharge ASI for the Variant C calendar- and cycle-life cells at $60 \%$ SOC.

\subsubsection{Available Energy}

Figure 42 shows the battery size factor (BSF) scaled available energy curve for a representative Baseline cell cycle-life tested at $25^{\circ} \mathrm{C}$. The power and energy goals of $25 \mathrm{~kW}$ and $300 \mathrm{Wh}$ are also shown by the bold lines (Reference 4). The available energy decreases steadily as a function of time. When the available energy curve intersects the cross-point between the two bold lines, the cell can no longer simultaneously meet the power and energy goals and has reached end-of-life. However, the diagnostic laboratories requested that some cells continue testing beyond the power and energy cross-point in order to gain a better understanding of power fade (Section 3.4). This representative cell was no longer able to meet the power and energy goals after 60 weeks of cycling at $25^{\circ} \mathrm{C}$. Another concurrent requirement for cycle-life is the successful completion of 300,000 cycles of the PNGV 25-Wh Power Assist profile (Figure 3). After 60 weeks of aging, this cell had completed more than 500,000 cycles. 


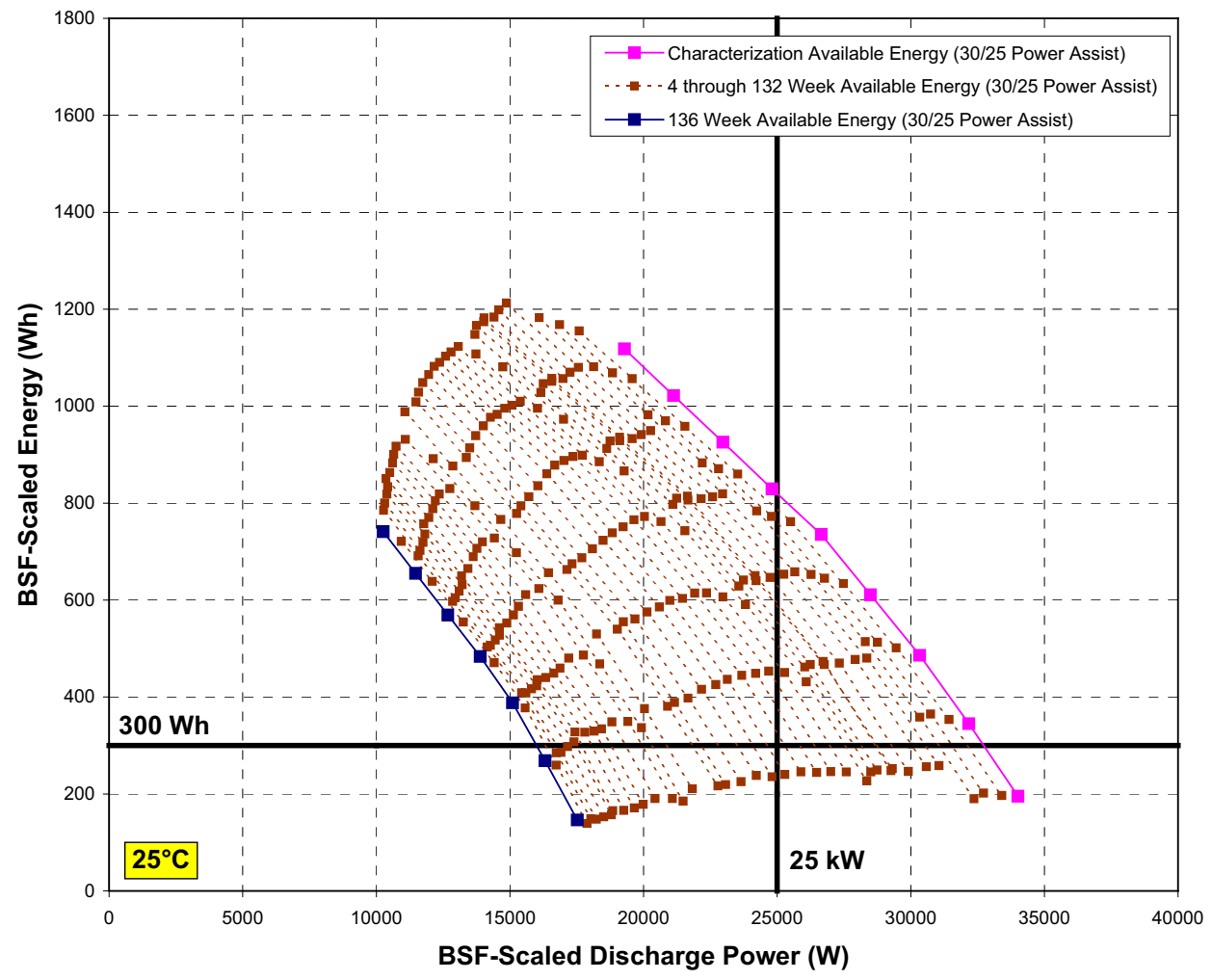

Figure 42 . Available energy for the $25^{\circ} \mathrm{C}$ Baseline cycle-life cells at $60 \%$ SOC.

Figures 43 through 45 show the BSF-scaled available energies at each RPT for a representative calendar-, cycle- and accelerated-life cell, respectively, aged at $60 \% \mathrm{SOC}$ and $45^{\circ} \mathrm{C}$. As seen with the discharge capacity and ASI, the decrease in available energy is slowest for the calendar-life cells and fastest for the accelerated-life cells. The representative calendar-life cell was no longer capable of simultaneously meeting the power and energy goals between 44 and 48 weeks (approximately 310 days of aging). The cycle-life cell failed to meet the goals between 32 and 36 weeks of aging, or, approximately 270,000 cycles (less than the goal of 300,000 cycles). The representative accelerated life cell dropped below the $25 \mathrm{~kW}$ goal after only 20 weeks of aging ( 140 days). Unlike the $25^{\circ} \mathrm{C}$ data, the $45^{\circ} \mathrm{C}$ data show an initially large decrease in available energy (between BOL and four weeks), followed by a steady and monotonic drop in power and energy. Figures 46 and 47 show the available energy curves for representative accelerated-life cells aged at $45^{\circ} \mathrm{C}$ and 80 and $100 \% \mathrm{SOC}$, respectively. The available energy also decreases more rapidly with increasing SOC. Whereas the $60 \%$ SOC representative cell stopped meeting the power and energy goals after 20 weeks (Figure 44), the $80 \%$ SOC cell reached end-of-life after 16 weeks, and the $100 \%$ SOC cell failed to meet the goals after only 8 weeks of aging. Figure 48 shows the available energy for a representative Baseline cell calendar-life tested at $55^{\circ} \mathrm{C}$ for 40 weeks. As expected, the available energy decreases more rapidly with increasing test temperature. This representative cell was no longer able to simultaneously meet the power and energy goals after 24 weeks of aging. 


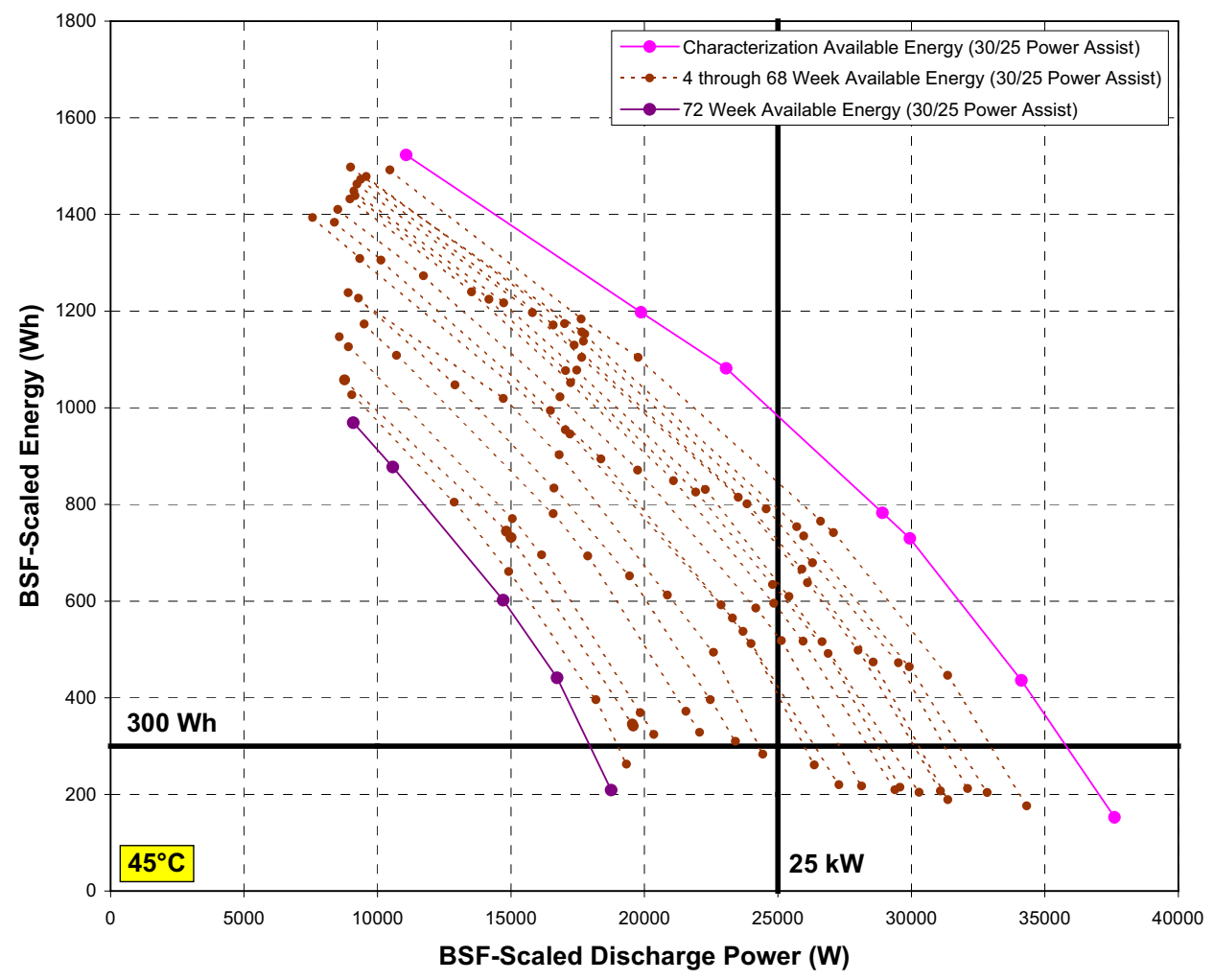

Figure 43 . Available energy for the $45^{\circ} \mathrm{C}$ Baseline calendar-life cells at $60 \%$ SOC.

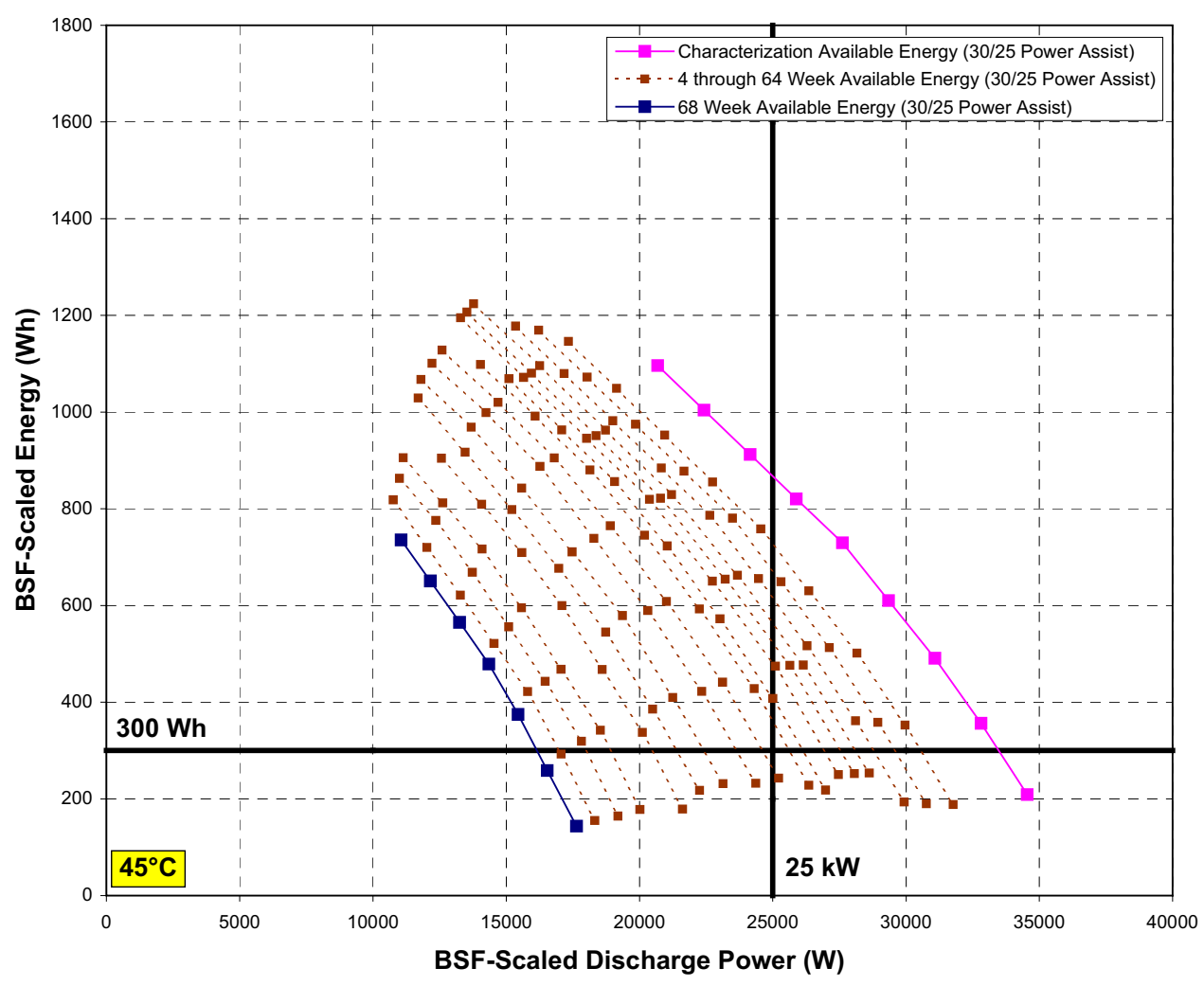

Figure 44. Available energy for the $45^{\circ} \mathrm{C}$ Baseline cycle-life cells at $60 \%$ SOC. 


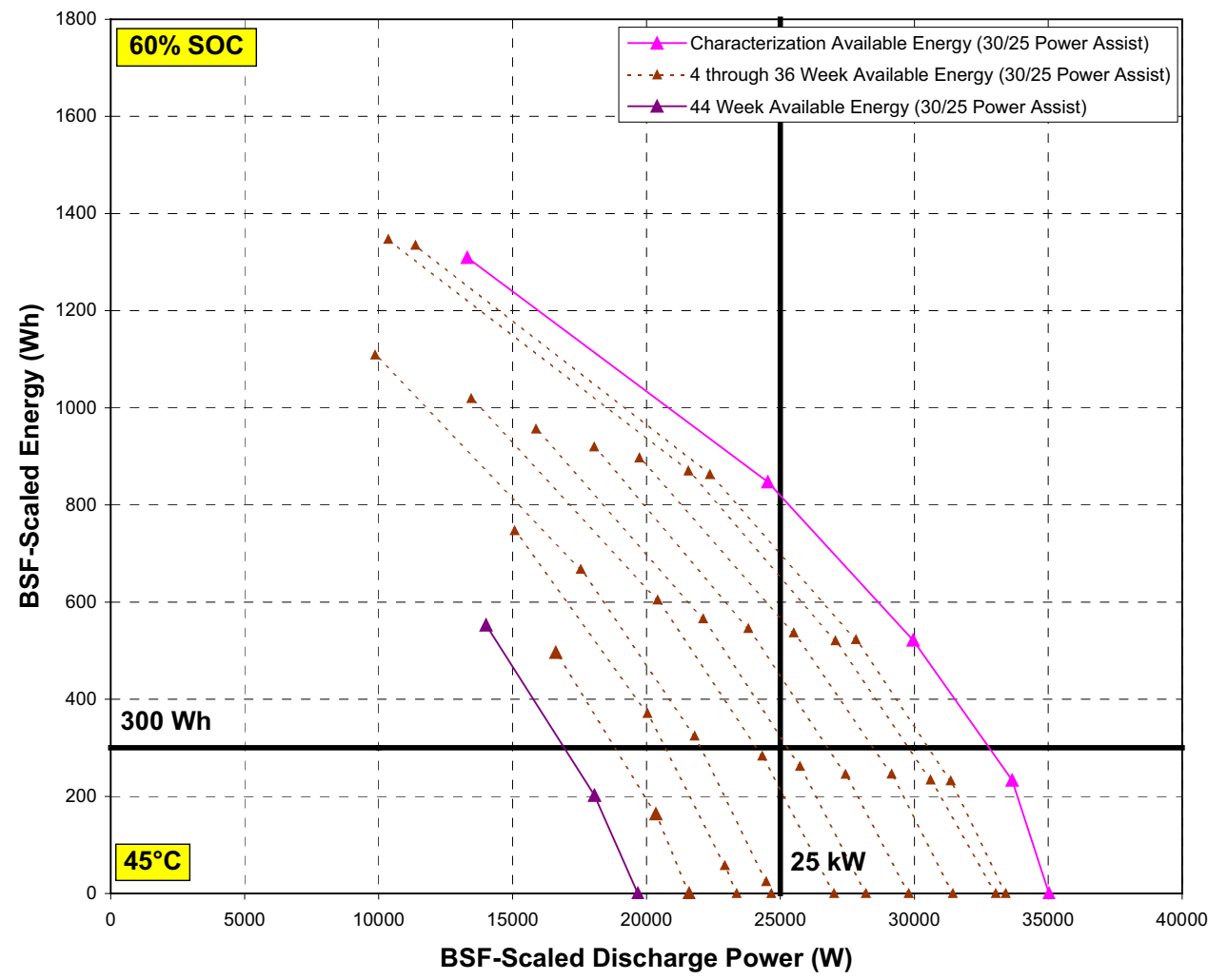

Figure 45 . Available energy for the $45^{\circ} \mathrm{C}$ Baseline accelerated-life cells at $60 \%$ SOC.

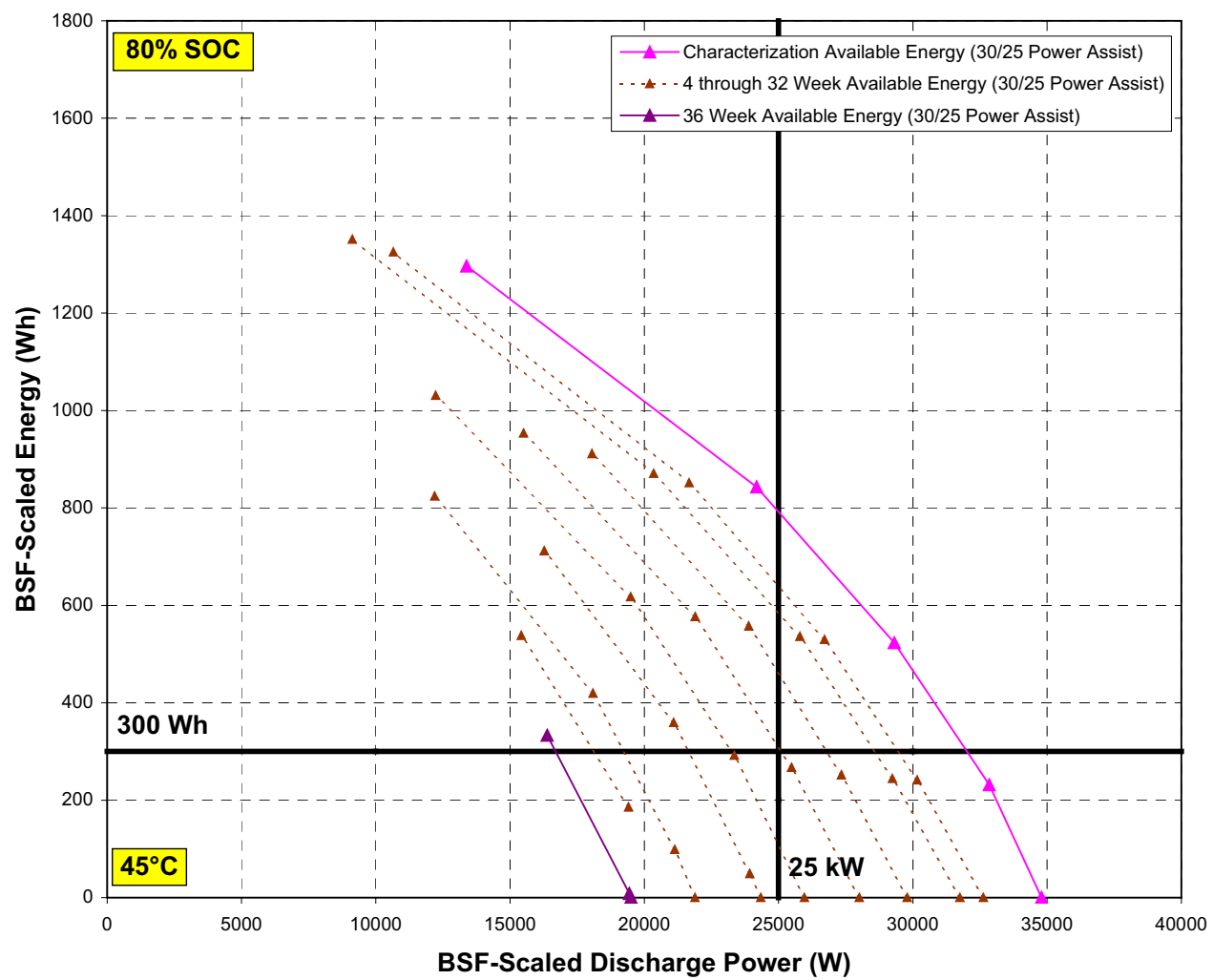

Figure 46 . Available energy for the $45^{\circ} \mathrm{C}$ Baseline accelerated-life cells at $80 \%$ SOC. 


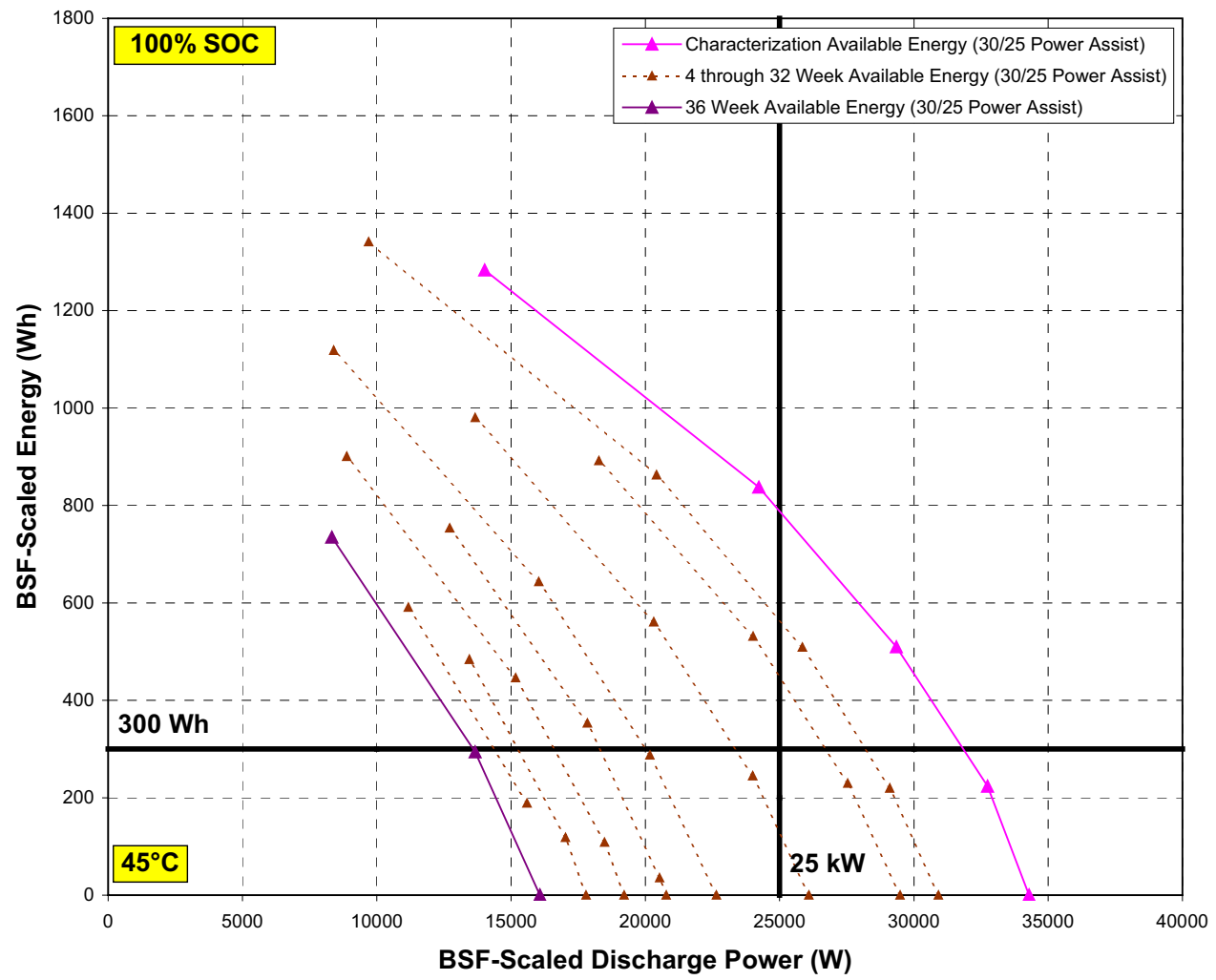

Figure 47. Available energy for the $45^{\circ} \mathrm{C}$ Baseline accelerated-life cells at $100 \%$ SOC.

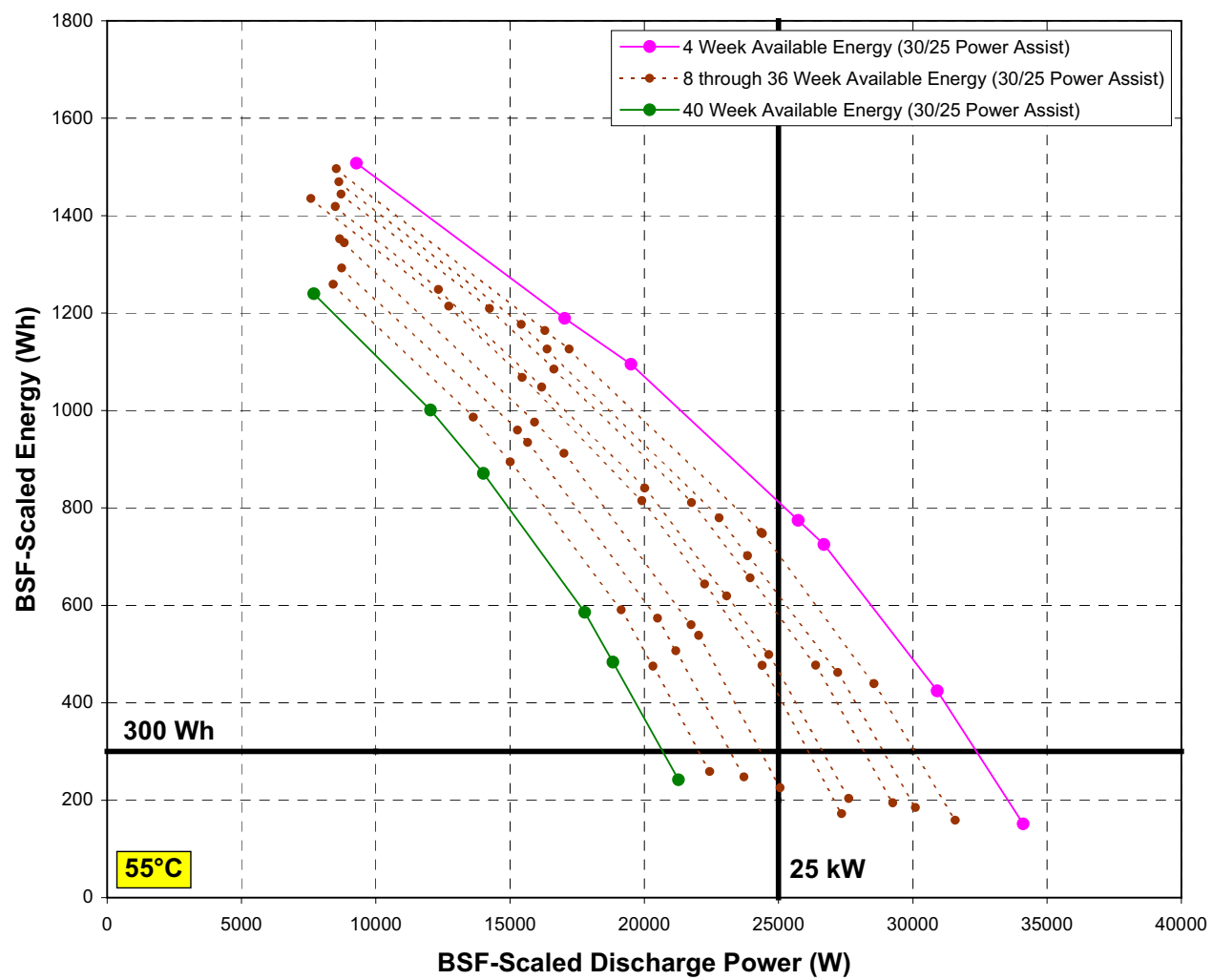

Figure 48. Available energy for the $55^{\circ} \mathrm{C}$ Baseline calendar-life cells at $60 \%$ SOC. 
Figures 49 and 50 show the available energy curves for representative Variant $\mathrm{C}$ calendar- and cyclelife cells aged at $45^{\circ} \mathrm{C}$ and $60 \%$ SOC. Both cells show an initially large drop in available energy between BOL and four weeks, but the calendar-life cell shows a slower drop in available energy as a function of test time. After 48 weeks of aging, the calendar-life cell fell below the power and energy goals and reached end-of-life. The cycle-life cell reached end-of-life after only 20 weeks of cycling $(168,000$ cycles) due to the large initial drop. Like the discharge capacity and ASI results, the rate of decrease in available energy for the $45^{\circ} \mathrm{C}$ Variant $\mathrm{C}$ cells is initially larger than the corresponding Baseline cells, but decreases significantly later in life. At end-of-test, the available energy decrease more closely resembles the $25^{\circ} \mathrm{C}$ Baseline cell results.

\subsubsection{Available Power}

Figure 51 shows the average BSF-scaled available power at $300 \mathrm{Wh}$ for the Baseline calendar-and cycle-life cells aged at $60 \%$ SOC. The Baseline cell BSF was 553 for all groups (Section 2.1). The initial powers for most cells are similar and centered around $32.5 \mathrm{~kW}$ (which is the $25 \mathrm{~kW}$ power goal with a BOL power margin of $30 \%$, as specified in Reference 4 ). The rate of power loss also generally increases with increasing test temperature. Figures 52 through 54 show the average available power for the accelerated-life cells aged at 60,80 , and $100 \%$ SOC, respectively. As seen with the $\mathrm{C}_{1} / 1$ capacity loss, the $55^{\circ} \mathrm{C}$ power loss at $80 \% \mathrm{SOC}$ is similar to the $100 \%$ SOC data. Otherwise, the power fade rate increases as a function of SOC as well. The calendar-life cells also continue to show the least fade, and the accelerated-life cells the most fade, within each temperature and SOC group.

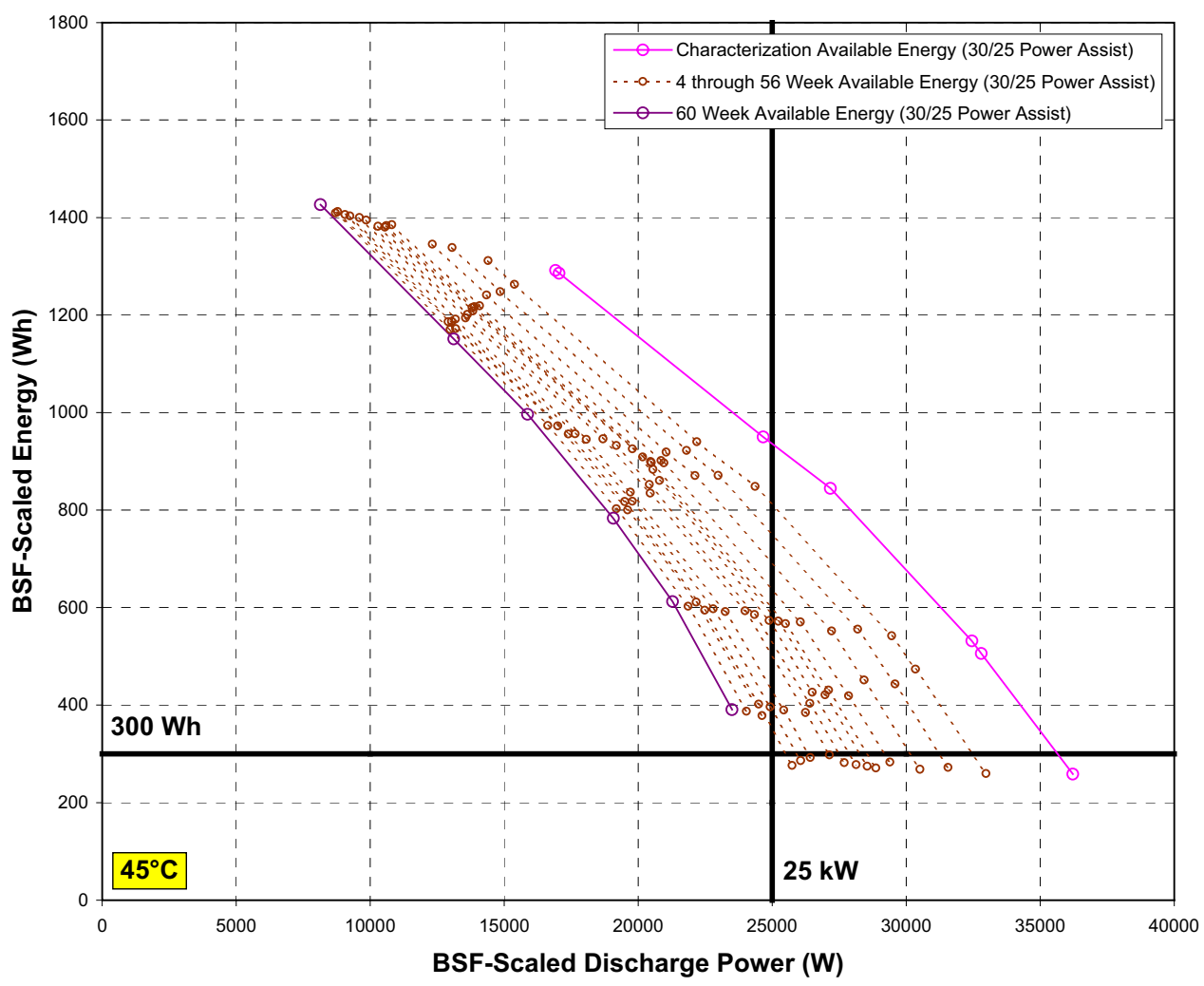

Figure 49. Available energy for the $45^{\circ} \mathrm{C}$ Variant $\mathrm{C}$ calendar-life cells at $60 \%$ SOC. 


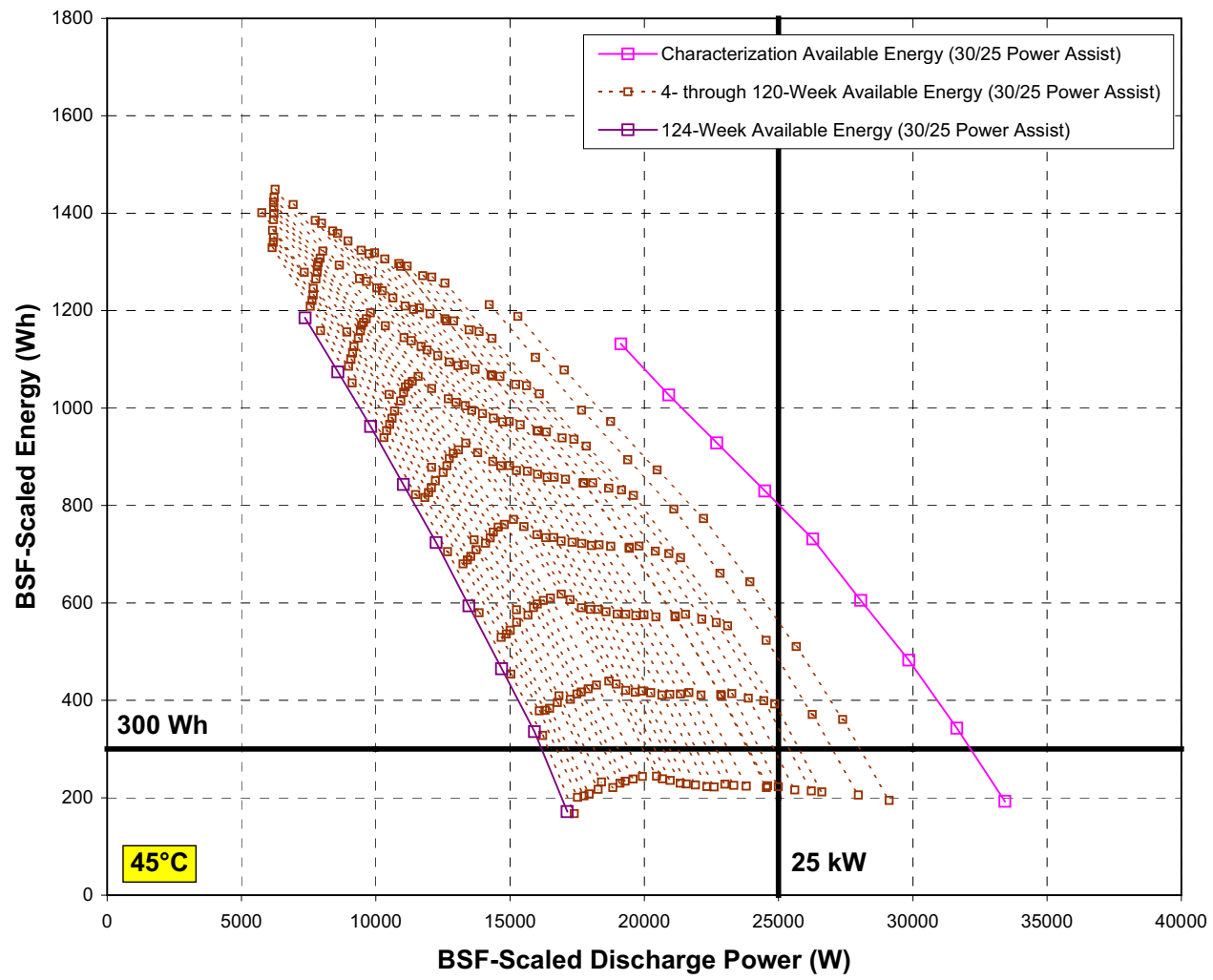

Figure 50. Available energy for the $45^{\circ} \mathrm{C}$ Variant $\mathrm{C}$ cycle-life cells at $60 \%$ SOC.

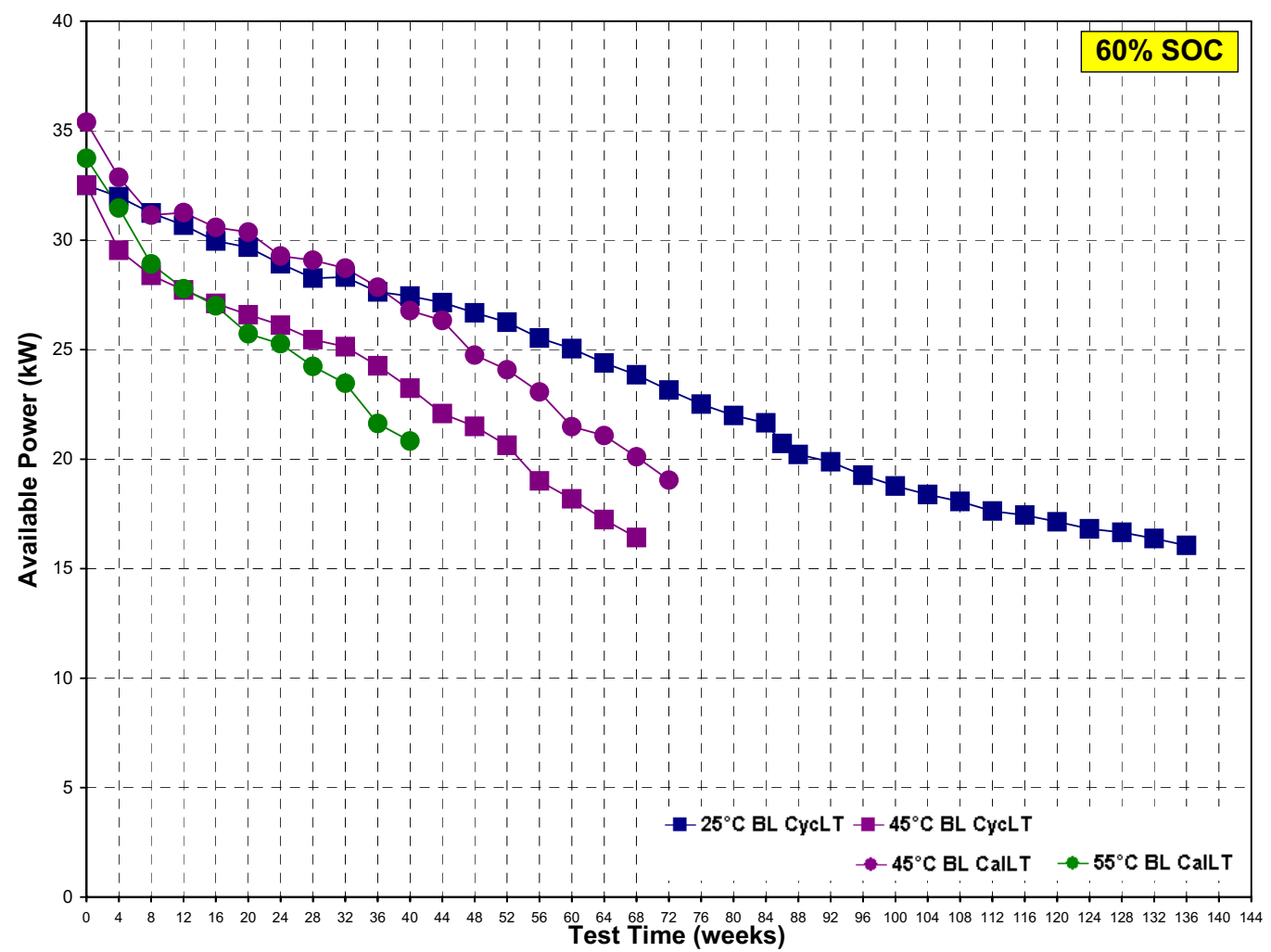

Figure 51. Average power at $300 \mathrm{Wh}$ for the Baseline CalLT and CycLT cell groups. 


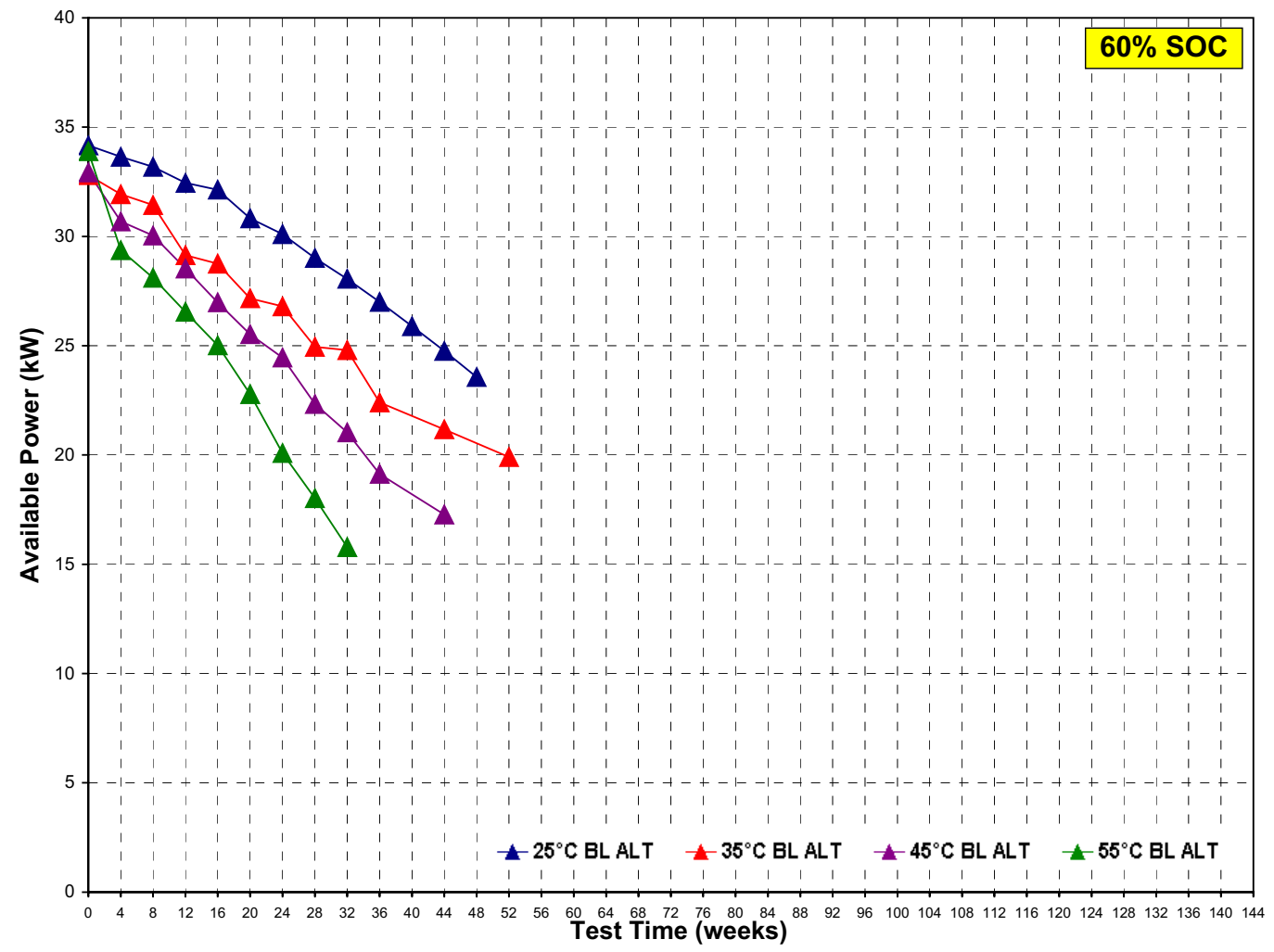

Figure 52. Average power at $300 \mathrm{Wh}$ for the Baseline ALT cell groups at $60 \%$ SOC.

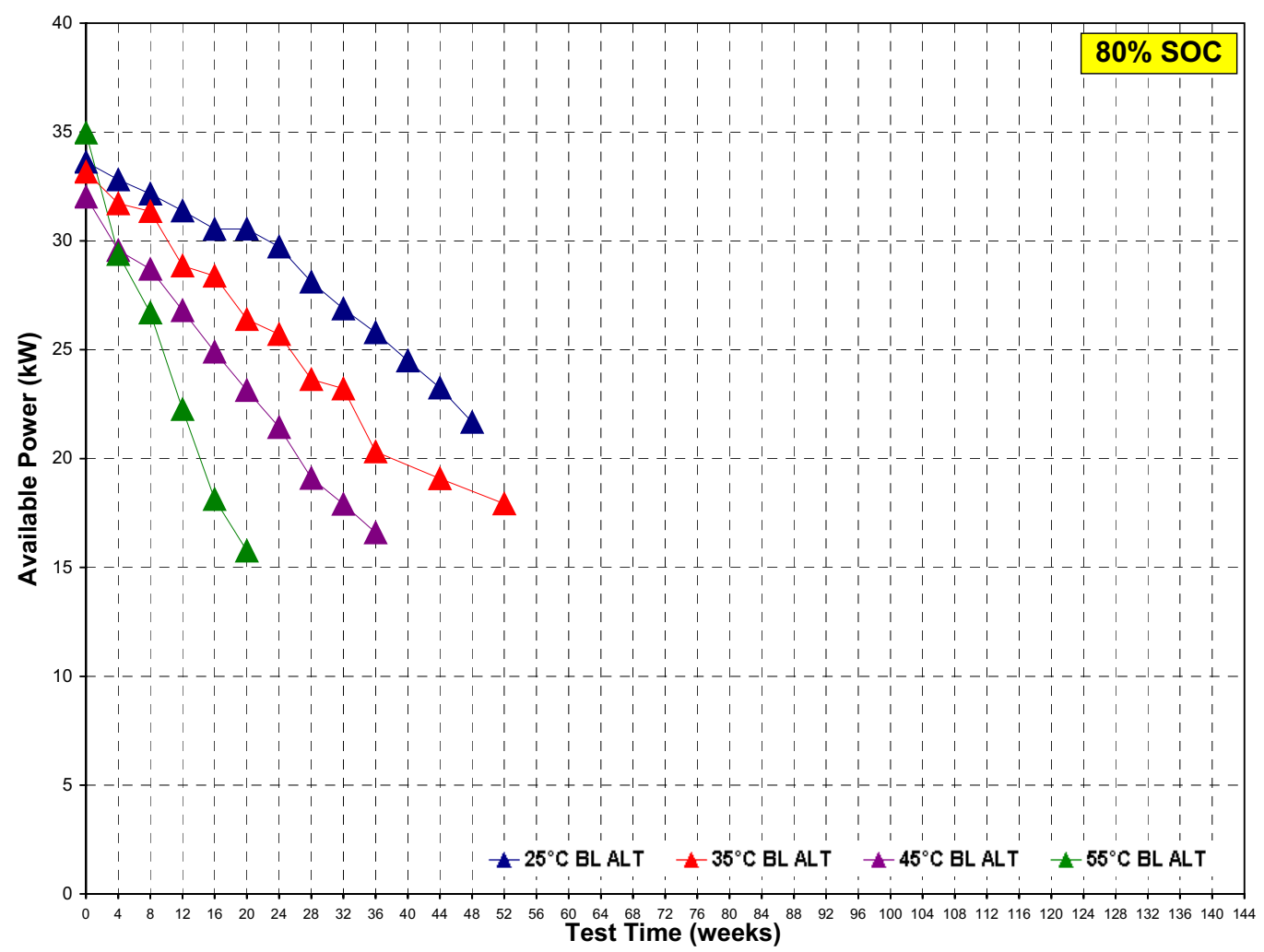

Figure 53. Average power at $300 \mathrm{Wh}$ for the Baseline ALT cell groups at $80 \%$ SOC. 


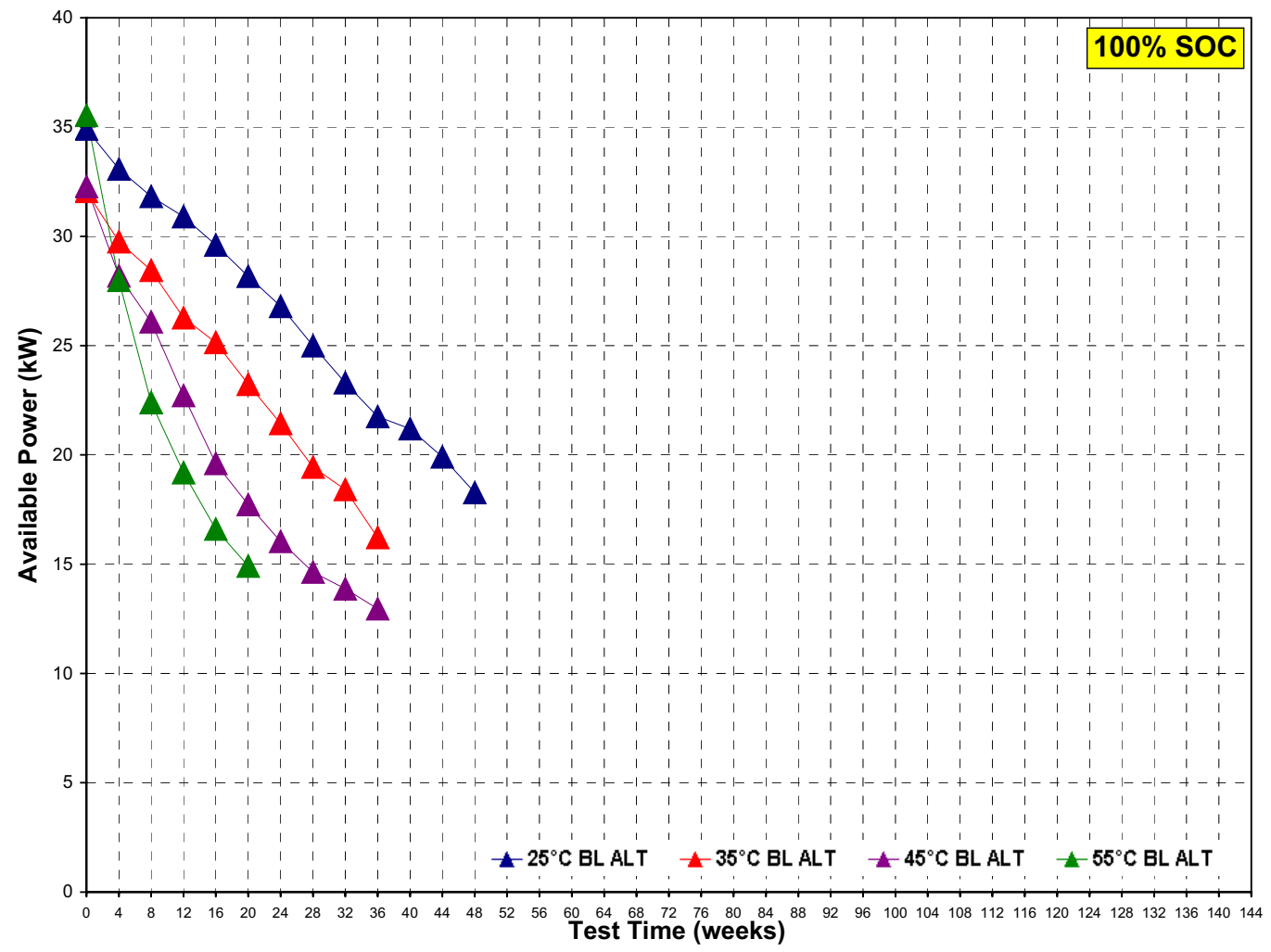

Figure 54. Average power at $300 \mathrm{Wh}$ for the Baseline ALT cell groups at $100 \%$ SOC.

Figure 55 shows the average power at $300 \mathrm{Wh}$ for the Variant $\mathrm{C}$ cell groups life tested at $60 \% \mathrm{SOC}$ and $45^{\circ} \mathrm{C}$. The Variant $\mathrm{C} \mathrm{BSF}$ was 651 for both groups. It was higher than the Baseline BSF since the rated capacity was lower, but the same initial power goal of $32.5 \mathrm{~kW}$ was required. Like ASI growth, the Variant $\mathrm{C}$ power fade is initially larger than the corresponding Baseline cells, but slows down significantly later in life. At end-of-test, the power fade rate more closely resembles the $25^{\circ} \mathrm{C}$ Baseline cells. 


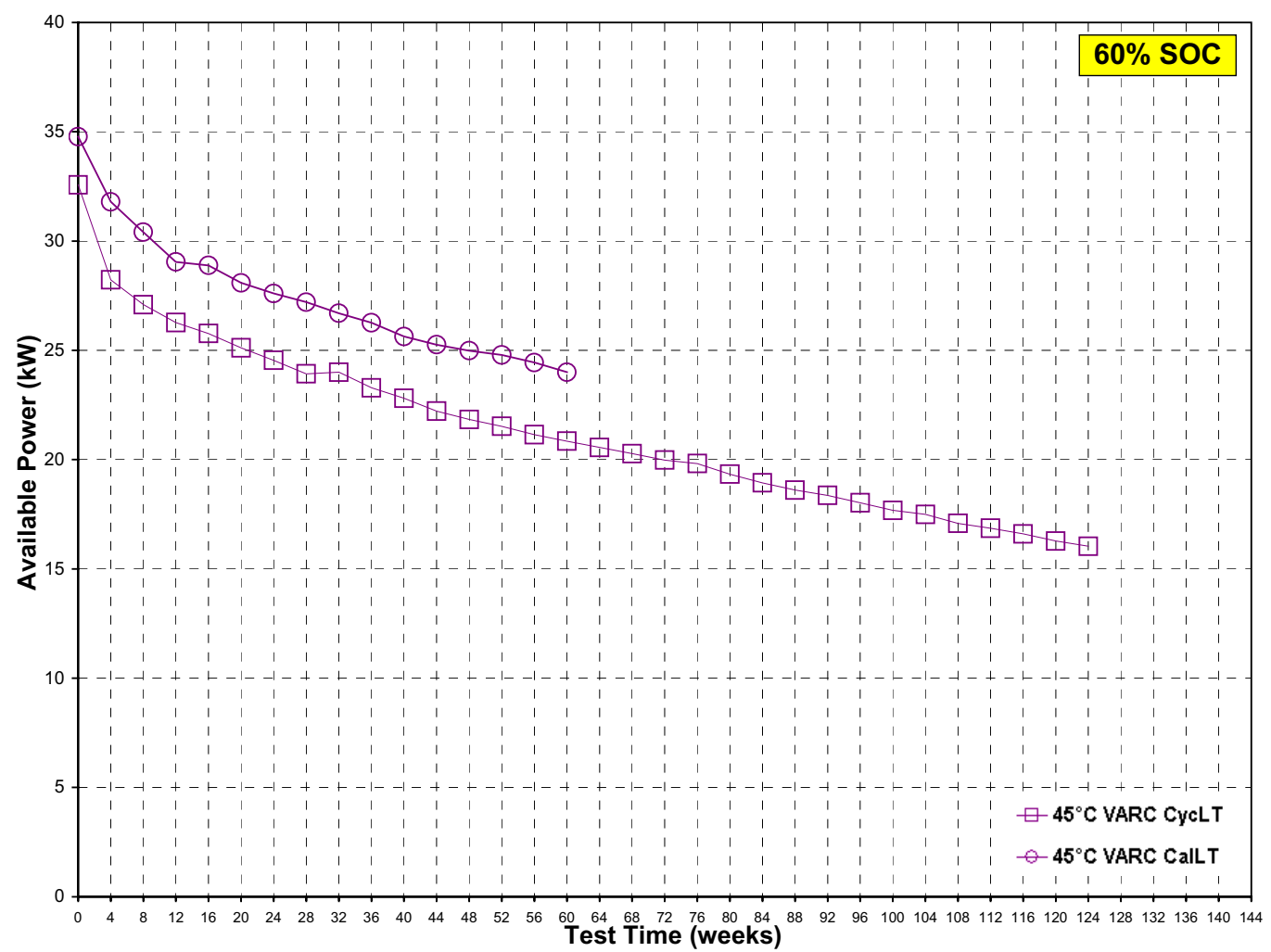

Figure 55. Average power at $300 \mathrm{Wh}$ for the Variant C CalLT and CycLT cell groups.

\subsection{Electrochemical Impedance Spectroscopy}

\subsubsection{Nyquist Curves}

\subsubsection{Baseline Cells}

Figure 56 shows the $60 \%$ SOC EIS Nyquist curve at 140 weeks for a representative $25^{\circ} \mathrm{C}$ cycle-life Baseline cell. The Nyquist curve consists of a real and imaginary axis, which can also be considered a

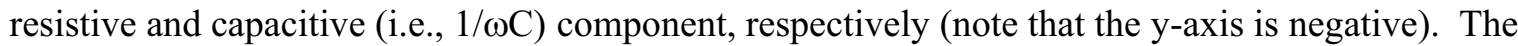
resulting curve can be divided into three regions. Progressing from high to low frequencies (left to right), the first region provides the electrolyte resistance $\left(\mathrm{R}_{\mathrm{E}}\right)$. Ideally, the electrolyte resistance would be the point at which the high frequency region crosses the $\mathrm{x}$-axis (i.e., no imaginary component). However, the capacitive tail never crosses zero due to an artifact arising from apparatus contributions from the fourterminal connection (Appendix D). The second region is a semicircle that gives the charge transfer resistance $\left(\mathrm{R}_{\mathrm{CT}}\right)$ and the nonfaradic capacitance $\left(\mathrm{C}_{\mathrm{NF}}\right)$. This region is primarily influenced by the negative and positive electrodes, and is modeled with a parallel RC network (Reference 21). The low frequency (i.e., leftmost) region is the Warburg impedance, which generally represents a resistance caused by the diffusion of ions (Reference 9). 


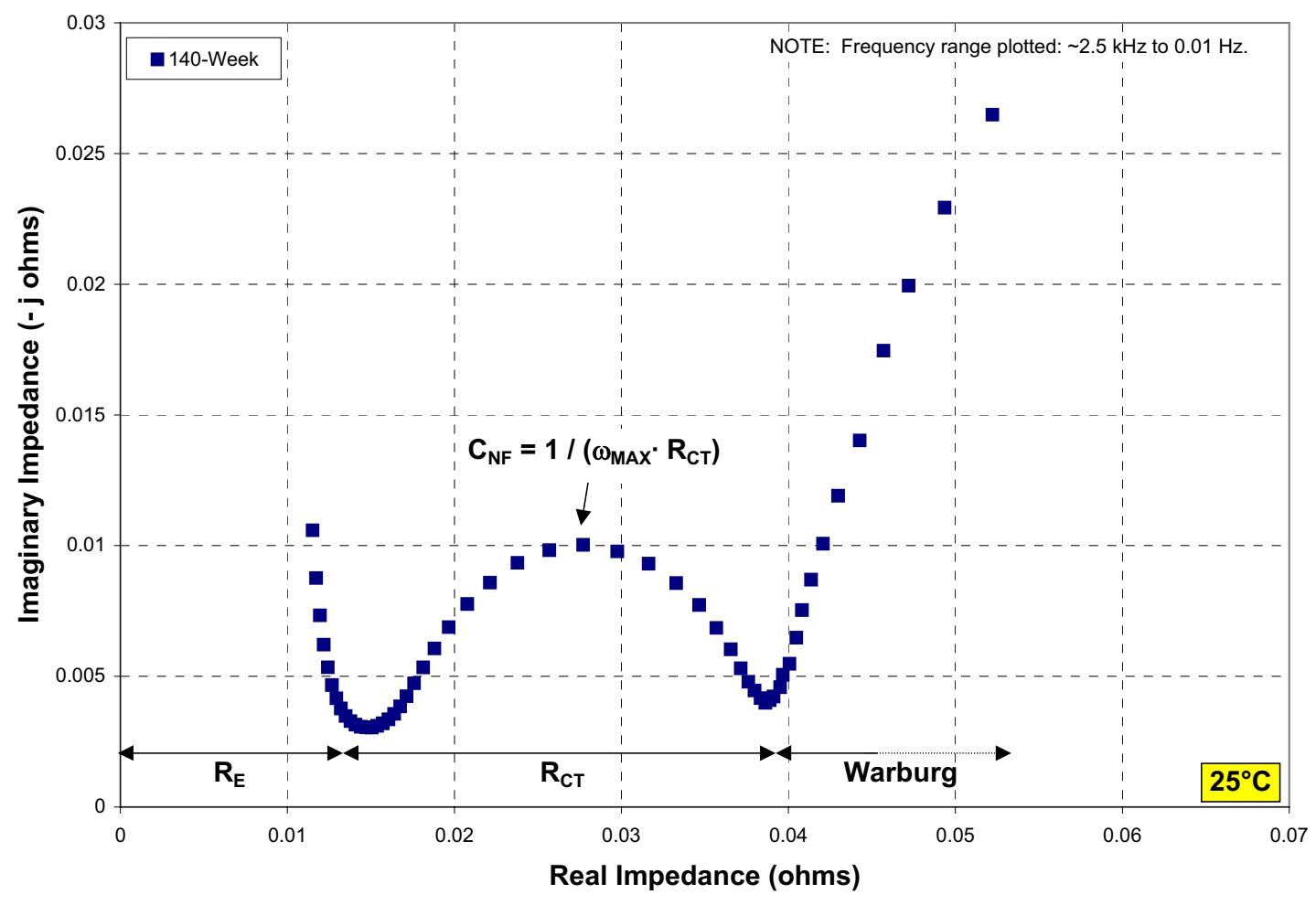

Figure 56. $60 \%$ SOC EIS for a representative $25^{\circ} \mathrm{C}$ Baseline cycle-life cell at 140 weeks.

Figure 57 shows the EIS measurements each RPT increment from BOL to 140 weeks for the same representative cell shown in Figure 56. The impedance grows as a function of test time, but the most significant change occurs in the charge transfer resistance with minimal change to the electrolyte resistance. As the cell ages, the semicircle region increases with time. This is most evident in the transition from the charge transfer resistance to the Warburg (i.e., the semicircle trough). This indicates that both the charge transfer resistance and the nonfaradic capacitor increases with age. At the lowest measured frequency $(0.01 \mathrm{~Hz}$, right-most data point on the Nyquist curve), the impedance also shows a small drop before a monotonic increase in both the imaginary and real components. This indicates that the nonfaradic capacitor is initially growing more rapidly than the charge transfer resistance.

Figures 58 through 60 show the $60 \%$ SOC EIS Nyquist curves for representative $45^{\circ} \mathrm{C}$ calendar-, cycle-, and accelerated-life Baseline cells. Consistent with the discharge capacity, ASI, and power data, the impedance increases as a function of life test, with the calendar-life cells showing the slowest growth and the accelerated-life cells showing the fastest growth. The $45^{\circ} \mathrm{C}$ cells also show a small initial drop in the impedance at $0.01 \mathrm{~Hz}$ before it starts to increase as a function of test time. The drop is larger than at $25^{\circ} \mathrm{C}$ indicating that temperature also has an effect on the nonfaradic capacitor. Figure 61 shows the $60 \%$ SOC EIS Nyquist curves for a representative $55^{\circ} \mathrm{C}$ calendar-life cell for each RPT through 40 weeks of aging. As expected, the cell's resistances grew more rapidly due to the higher test temperature.

Interestingly, the drop in the Warburg impedance at $0.01 \mathrm{~Hz}$ occurred later than the cells aged at 25 and $45^{\circ} \mathrm{C}$, which may be attributable to a higher temperature mechanism taking effect. 


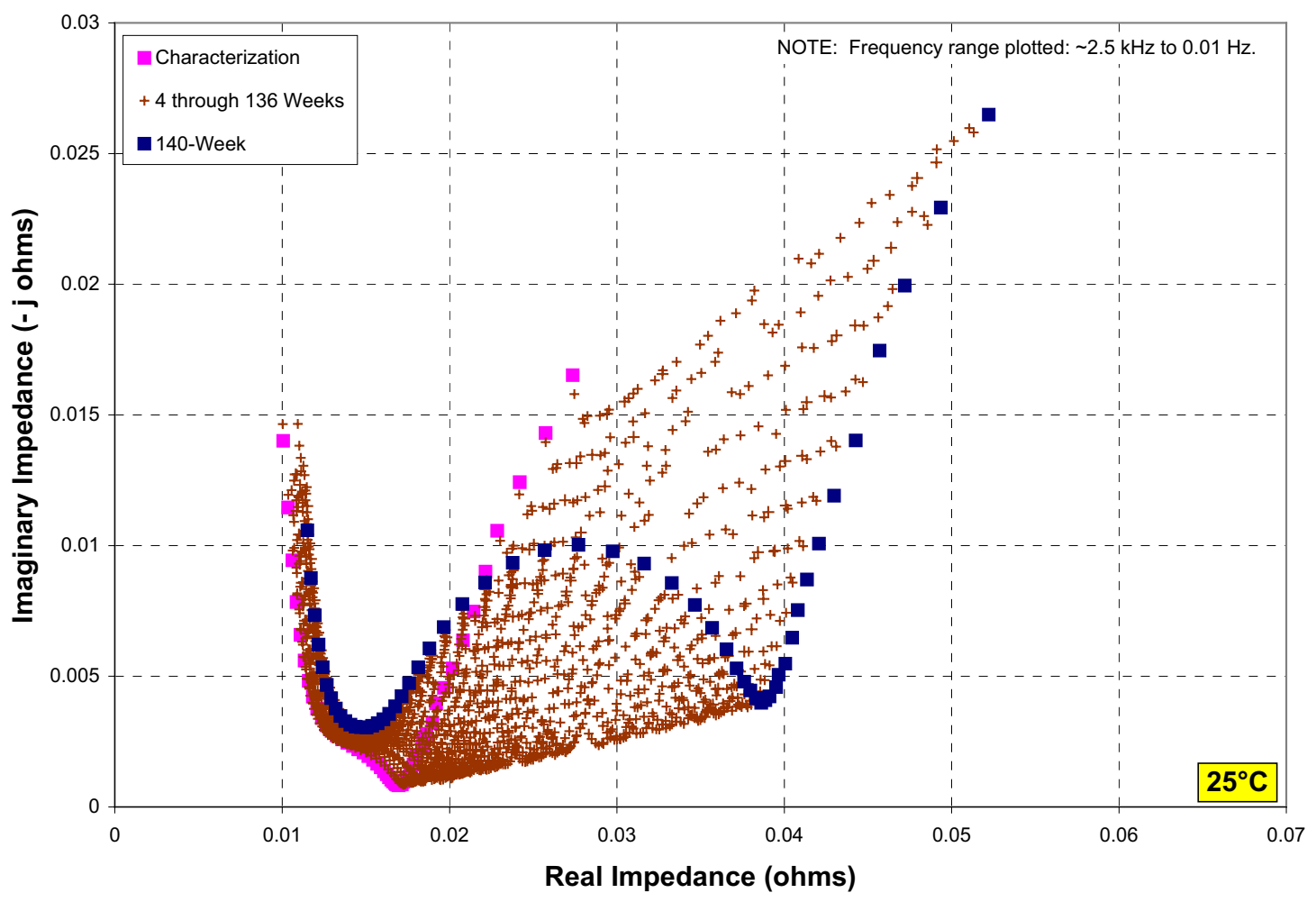

Figure 57. $60 \%$ SOC EIS for a representative $25^{\circ} \mathrm{C}$ Baseline cycle-life cell.

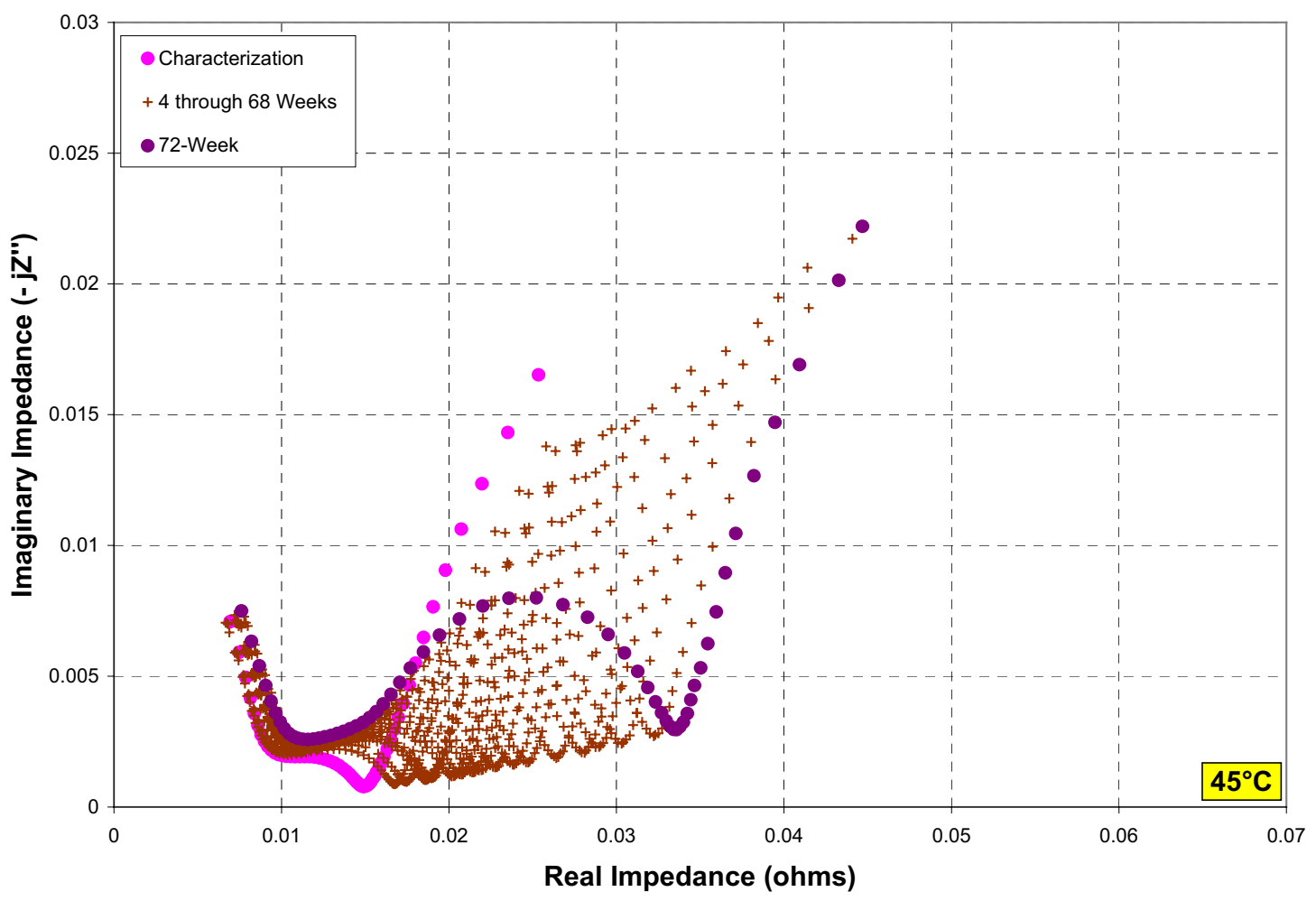

Figure 58. $60 \%$ SOC EIS for a representative $45^{\circ} \mathrm{C}$ Baseline calendar-life cell. 


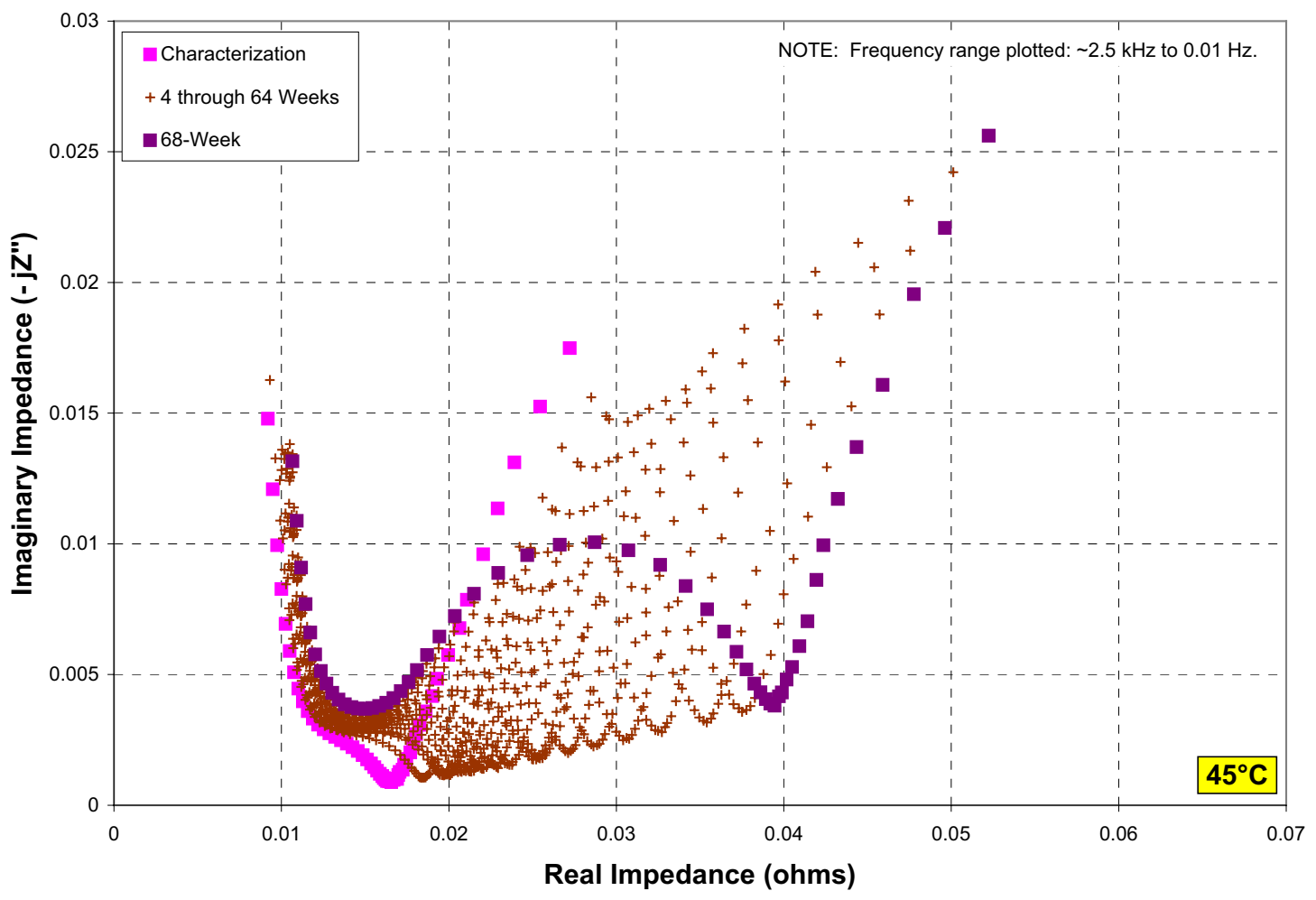

Figure 59. $60 \%$ SOC EIS for a representative $45^{\circ} \mathrm{C}$ Baseline cycle-life cell.

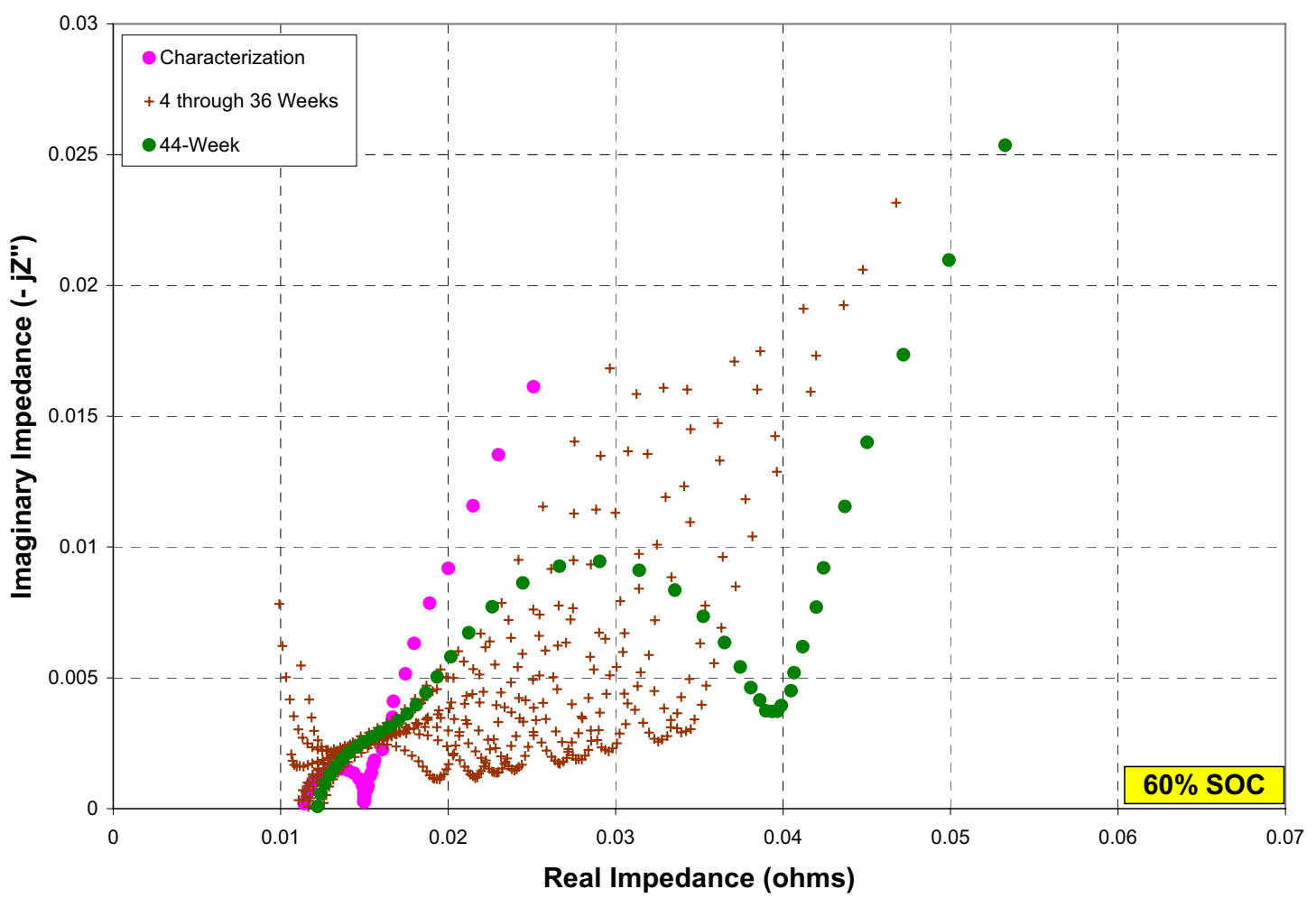

Figure $60.60 \%$ SOC EIS for a representative $45^{\circ} \mathrm{C}$ Baseline accelerated-life cell. 


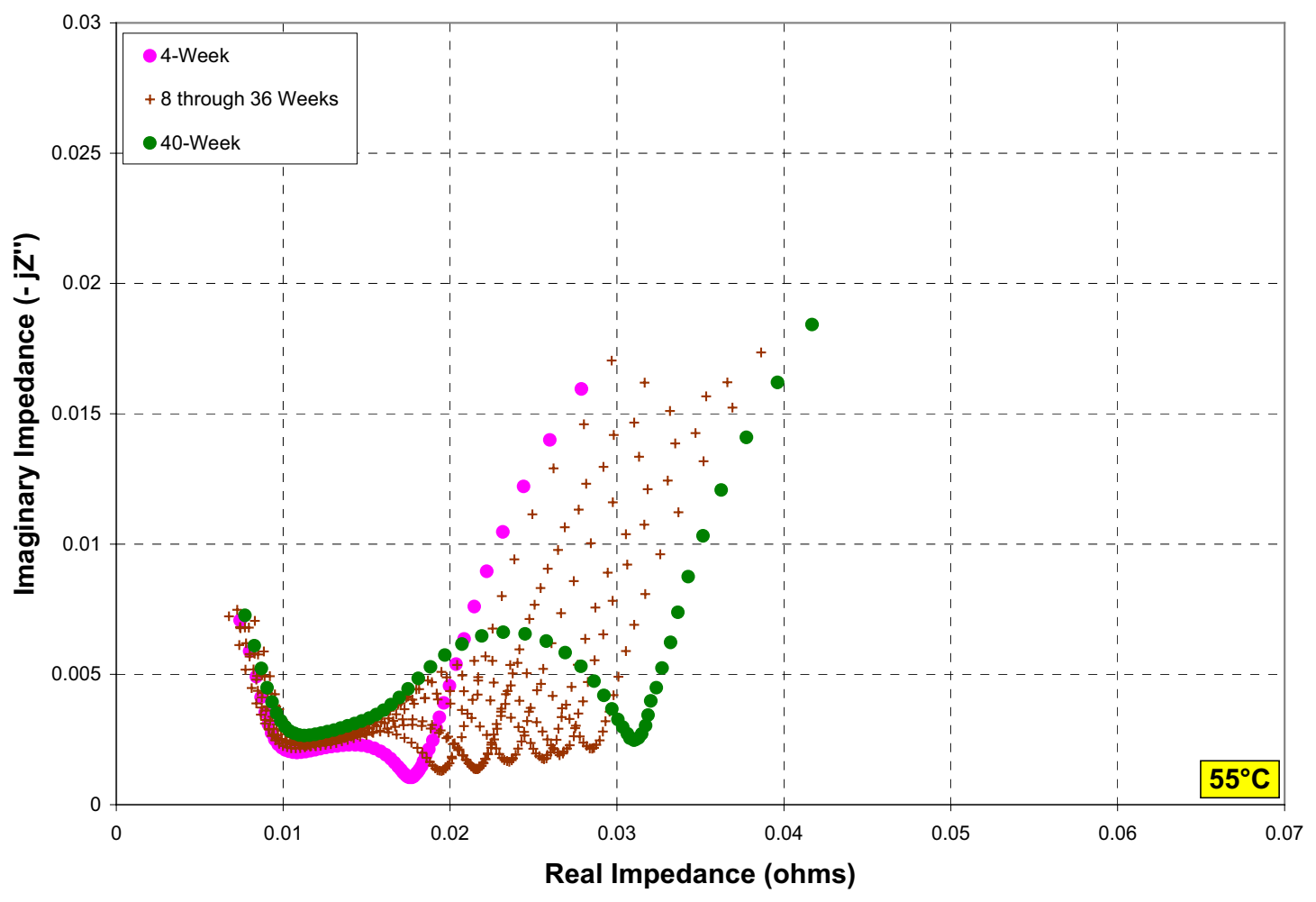

Figure $61.60 \%$ SOC EIS for a representative $55^{\circ} \mathrm{C}$ Baseline calendar-life cell.

Figures 62 and 63 show the EIS Nyquist curves measured at $60 \%$ SOC for representative $45^{\circ} \mathrm{C}$ accelerated-life Baseline cells aged at 80 and $100 \%$ SOC, respectively. The $80 \%$ SOC cells show very similar impedance growth to the 60\% SOC cells (Figure 60), but the 100\% SOC cell group shows a clearly accelerated impedance growth rate. The initial drop in Warburg impedance is reduced for the $80 \%$ SOC cells, and virtually non-existent for the cell aged at $100 \%$ SOC, indicating that the nonfaradic capacitance is also SOC dependent.

Figures 64 through 66 show the EIS Nyquist curves measured at 100\% SOC for the accelerated life cells aged at 60,80 , and $100 \%$ SOC, respectively. The impedance growth measured at $100 \% \mathrm{SOC}$ is more rapid than the corresponding measurements at $60 \%$ SOC (Figures 60, 62, and 63). The 100\% SOC measurements, however, still show an increase in impedance growth with increasing life test SOC. The drop in Warburg impedance at $0.01 \mathrm{~Hz}$ is not visible for the $100 \%$ SOC measurements. This is consistent with the cells aged at 100\% SOC, with measurements taken at $60 \%$ SOC (Figure 63). 


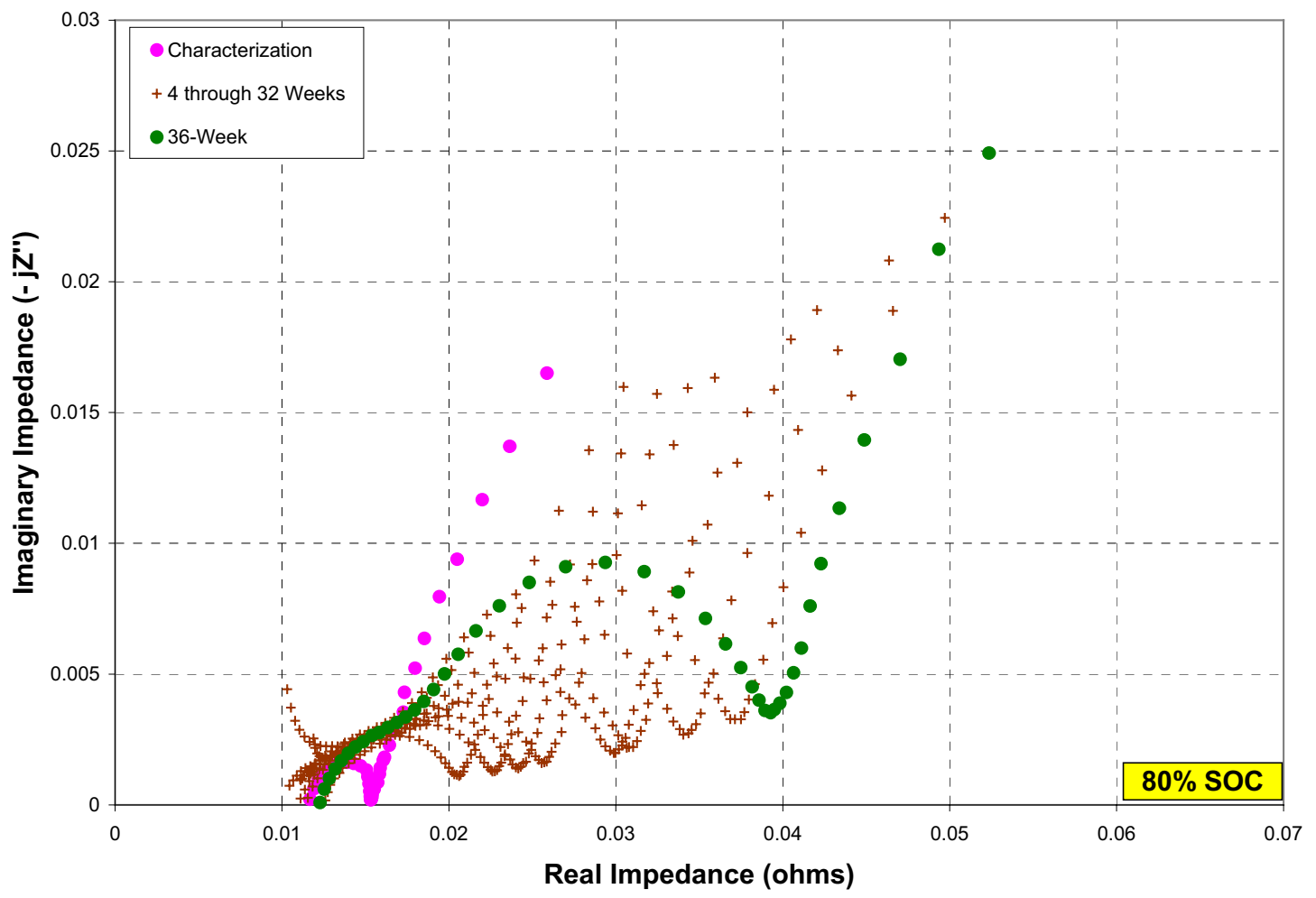

Figure $62.60 \%$ SOC EIS for a representative $45^{\circ} \mathrm{C}$ Baseline accelerated-life cell at $80 \%$ SOC.

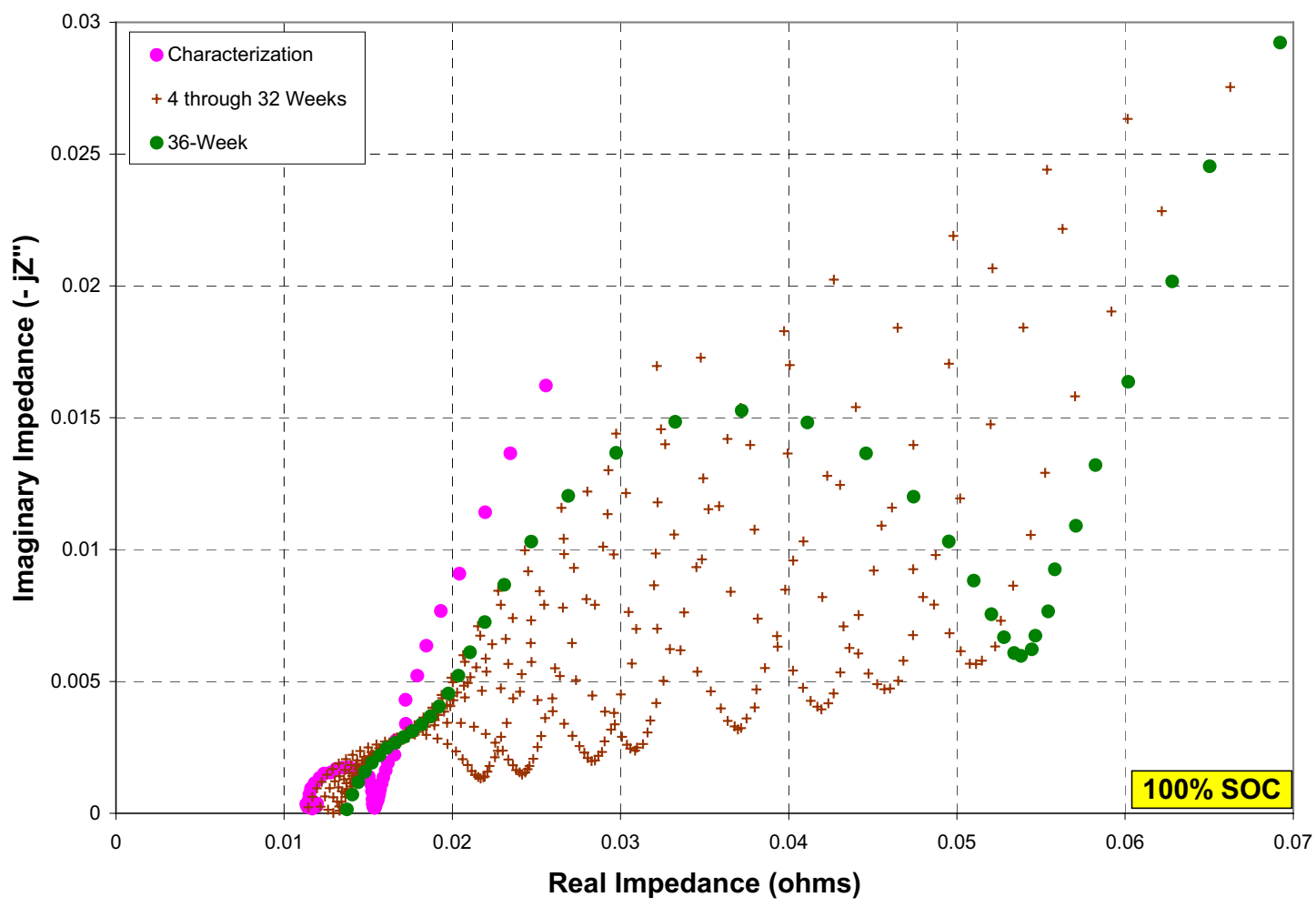

Figure $63.60 \%$ SOC EIS for a representative $45^{\circ} \mathrm{C}$ Baseline accelerated-life cell at $100 \%$ SOC. 


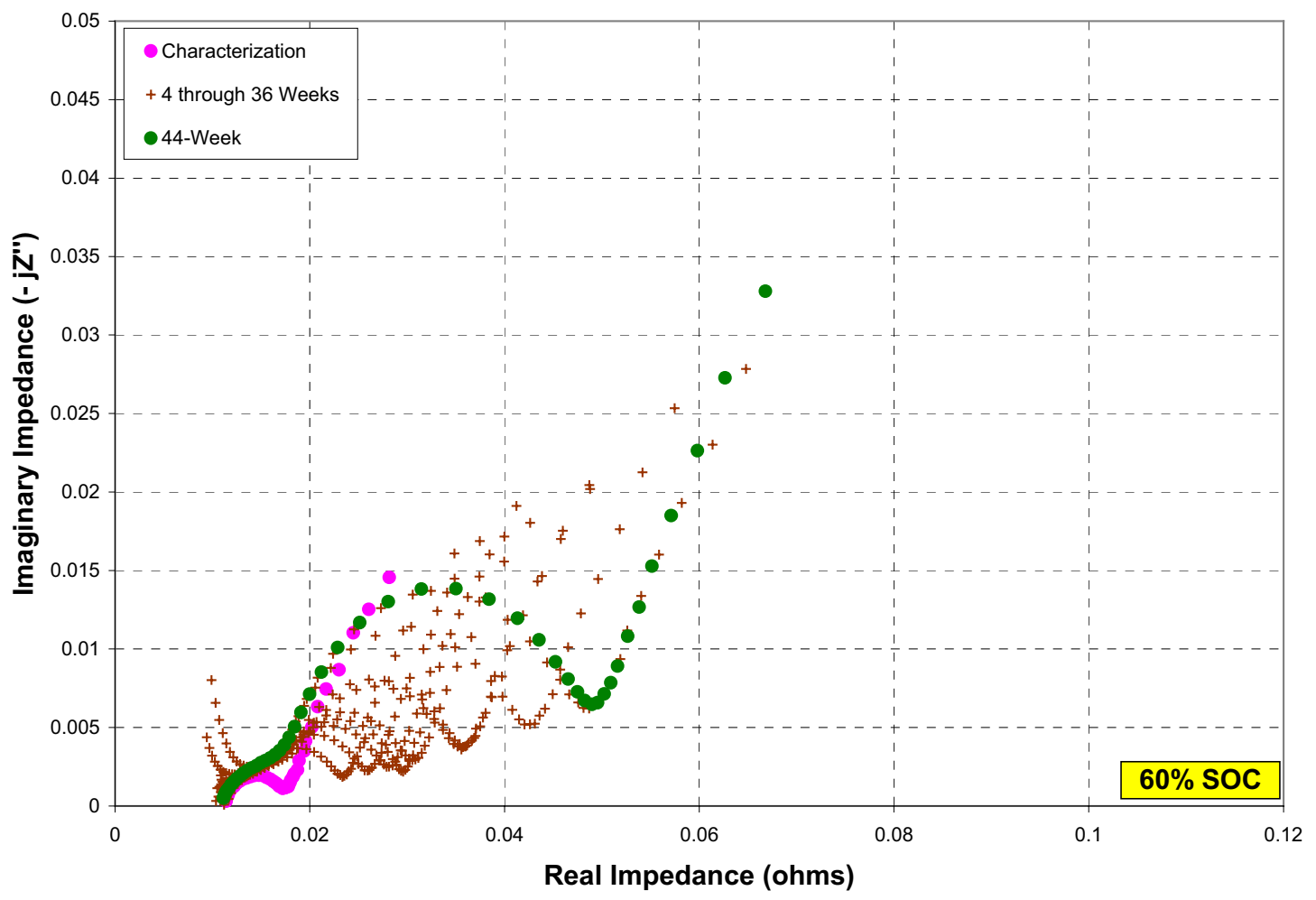

Figure $64.100 \%$ SOC EIS for a representative $45^{\circ} \mathrm{C}$ Baseline accelerated-life cell at $60 \%$ SOC.

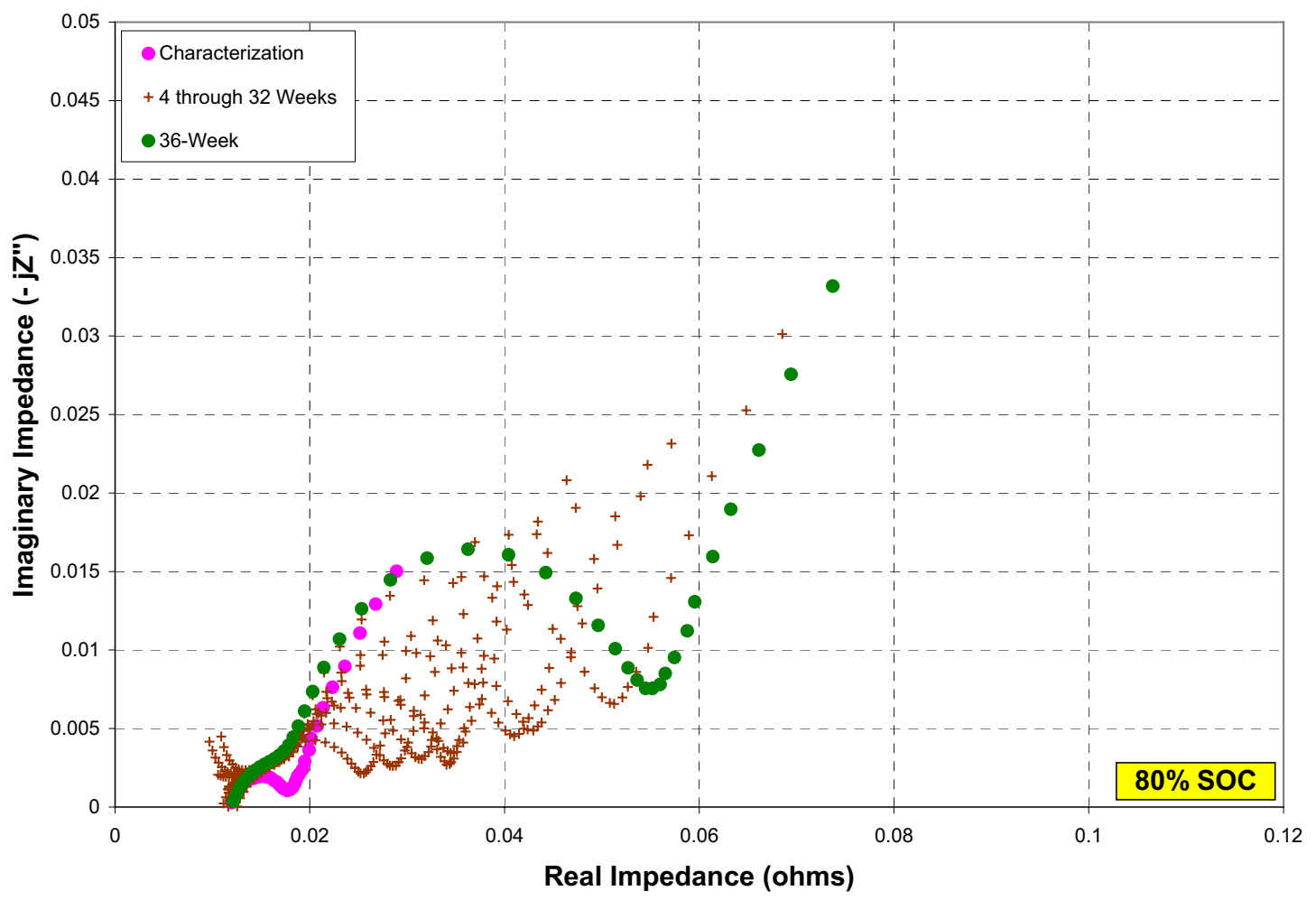

Figure $65.100 \%$ SOC EIS for a representative $45^{\circ} \mathrm{C}$ Baseline accelerated-life cell at $80 \%$ SOC. 


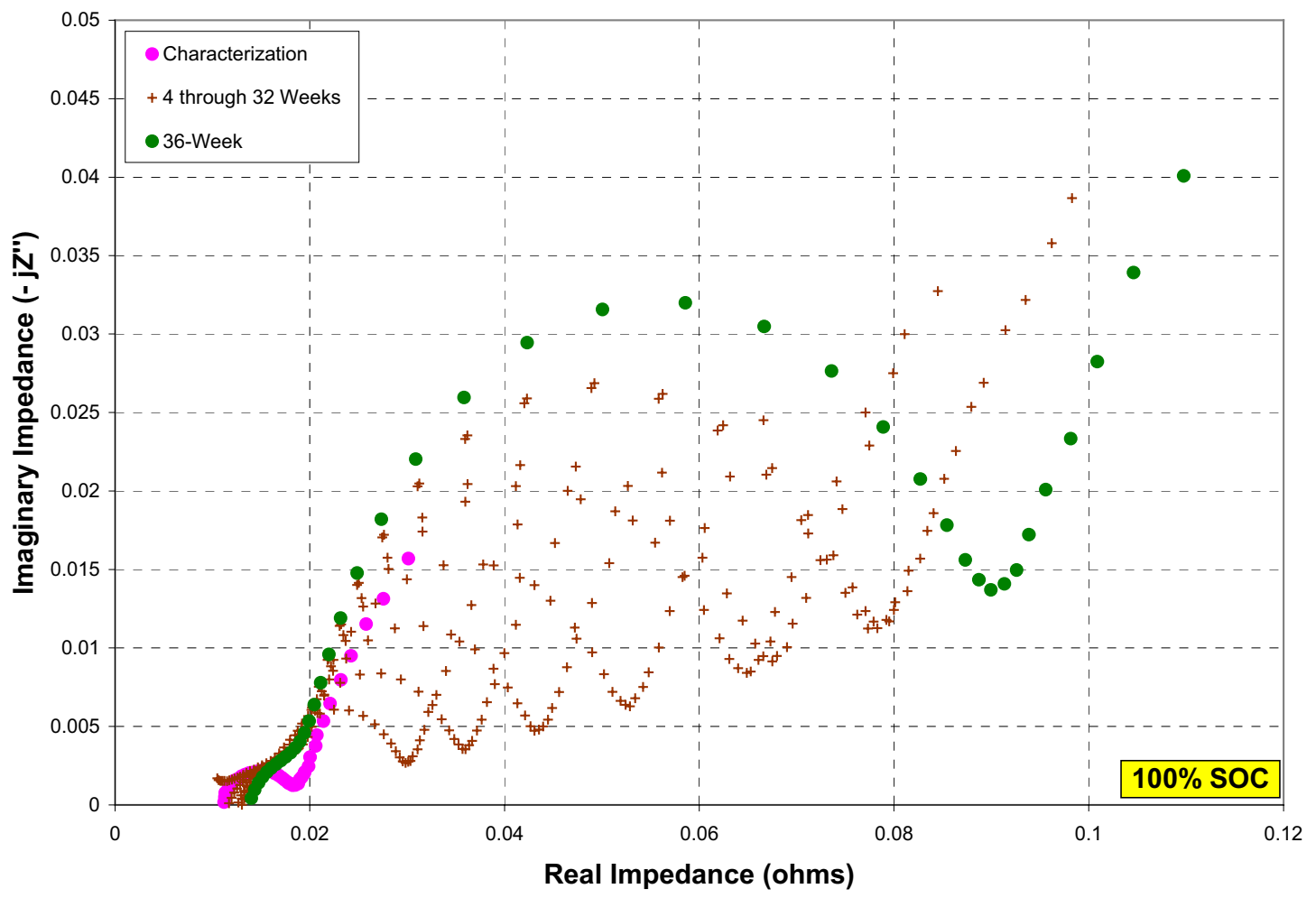

Figure $66.100 \%$ SOC EIS for a representative $45^{\circ} \mathrm{C}$ Baseline accelerated-life cell at $100 \%$ SOC.

\subsubsection{Variant C Cells}

Figures 67 and 68 show the EIS Nyquist plots measured at 60\% SOC for representative calendarand cycle-life Variant $\mathrm{C}$ cells. As expected, the cycle-life impedance increased more rapidly than the calendar-life cells. Both the nonfaradic capacitance and charge transfer resistance grow as a function of test time while the electrolyte resistance shows little change. Interestingly, the Variant $C$ Warburg impedance at $0.01 \mathrm{~Hz}$ does not show an initial drop, as was seen with the Baseline cells. The change in cathode composition to the Variant $\mathrm{C}$ cells obviously had an impact on the growth rate of the nonfaradic capacitance. 


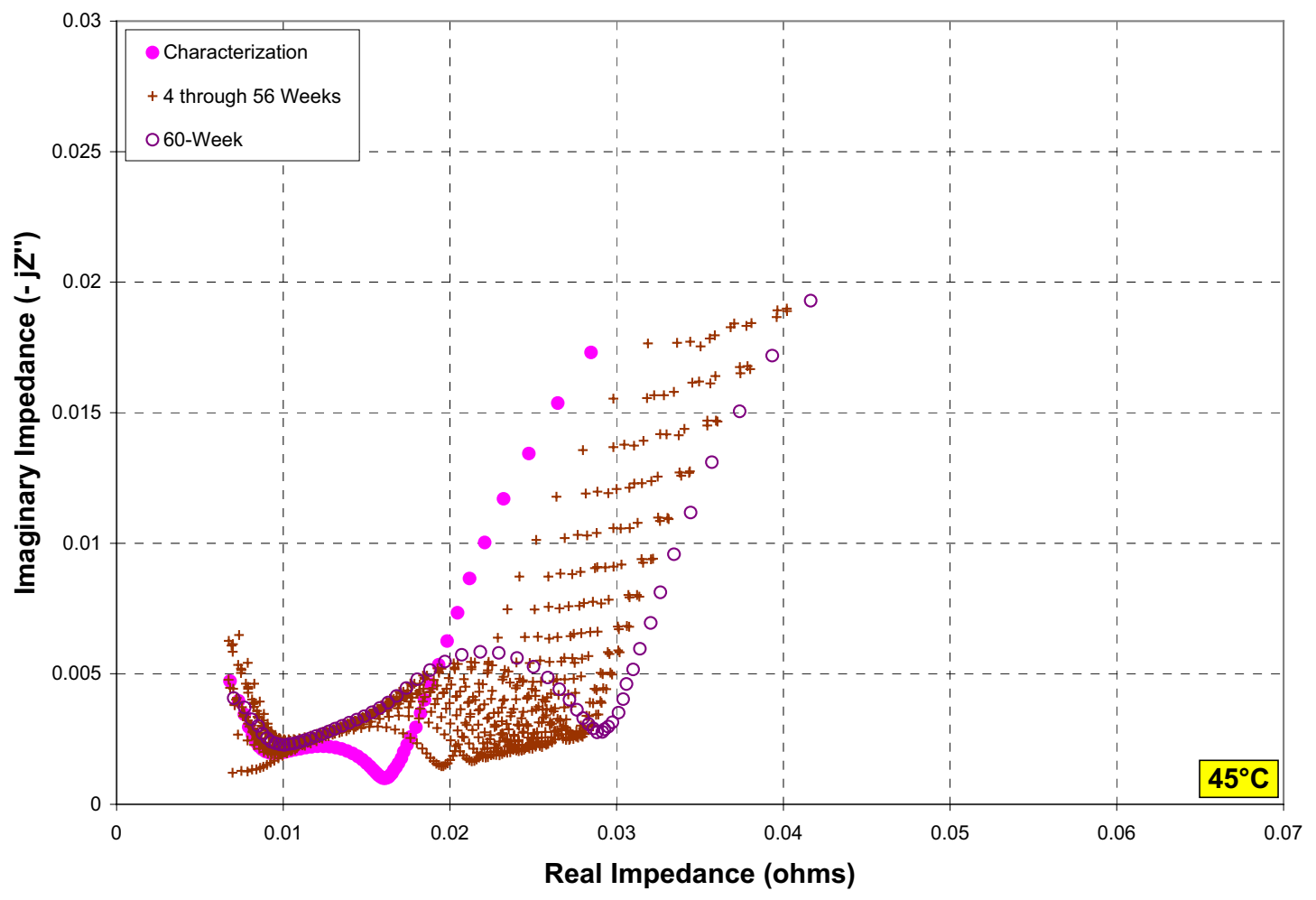

Figure $67.60 \%$ SOC EIS for a representative $45^{\circ} \mathrm{C}$ Variant $\mathrm{C}$ calendar-life cell.

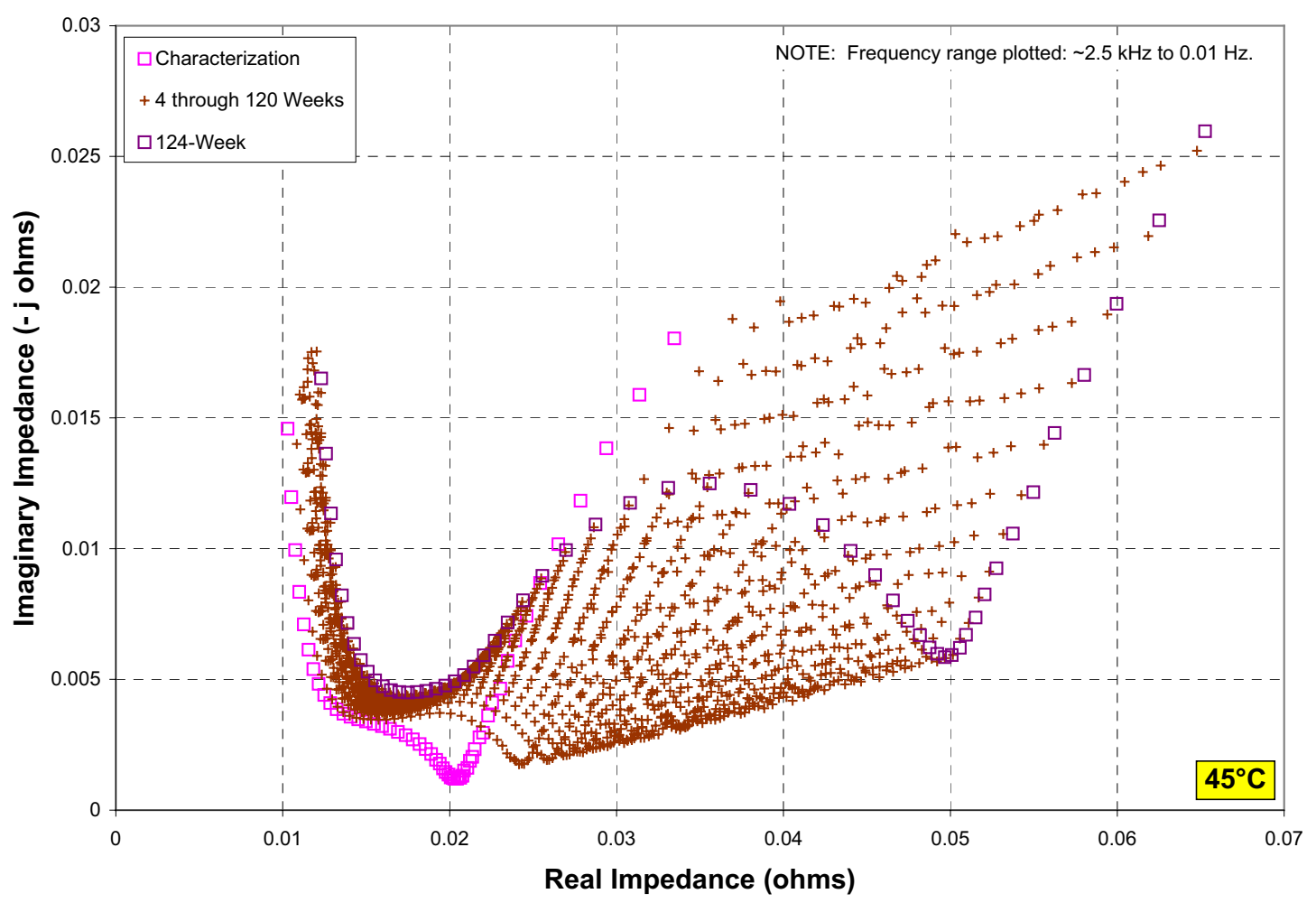

Figure $68.60 \%$ SOC EIS for a representative $45^{\circ} \mathrm{C}$ Variant $\mathrm{C}$ cycle-life cell. 


\subsubsection{Impedance Growth}

Figure 69 shows the average EIS magnitude growth at the semicircle trough at $60 \%$ SOC for the Baseline calendar- and cycle-life cells. The initial values are similar, and, as expected, shows both a temperature and life test dependence. Figure 70 shows the average EIS growth at the semicircle trough for the Variant $\mathrm{C}$ calendar- and cycle-life cells at $45^{\circ} \mathrm{C}$. These data continue to show an initially higher impedance growth compared to their corresponding Baseline cells, but slow down later in life to look more like the $25^{\circ} \mathrm{C}$ Baseline cells.

The change in the EIS magnitude impedance at the semicircle trough (Figures 69 and 70) as a function of test time is very similar to the change in discharge ASI as measured from the L-HPPC test (Figures 40 and 41). Figure 71 shows that the correlation between the L-HPPC ASI and EIS measurements form a very straight line with similar slopes regardless of test temperature, life test, or chemistry. The slopes of the linear fit range from 1.2 to 1.4 , with $\mathrm{r}^{2}$ fits of 0.98 or better. This indicates that EIS may be a useful, less degrading alternative to the L-HPPC test while still providing useful information about cell behavior. This behavior was also observed with commercially available lithiumion cells (References 22 and 23).

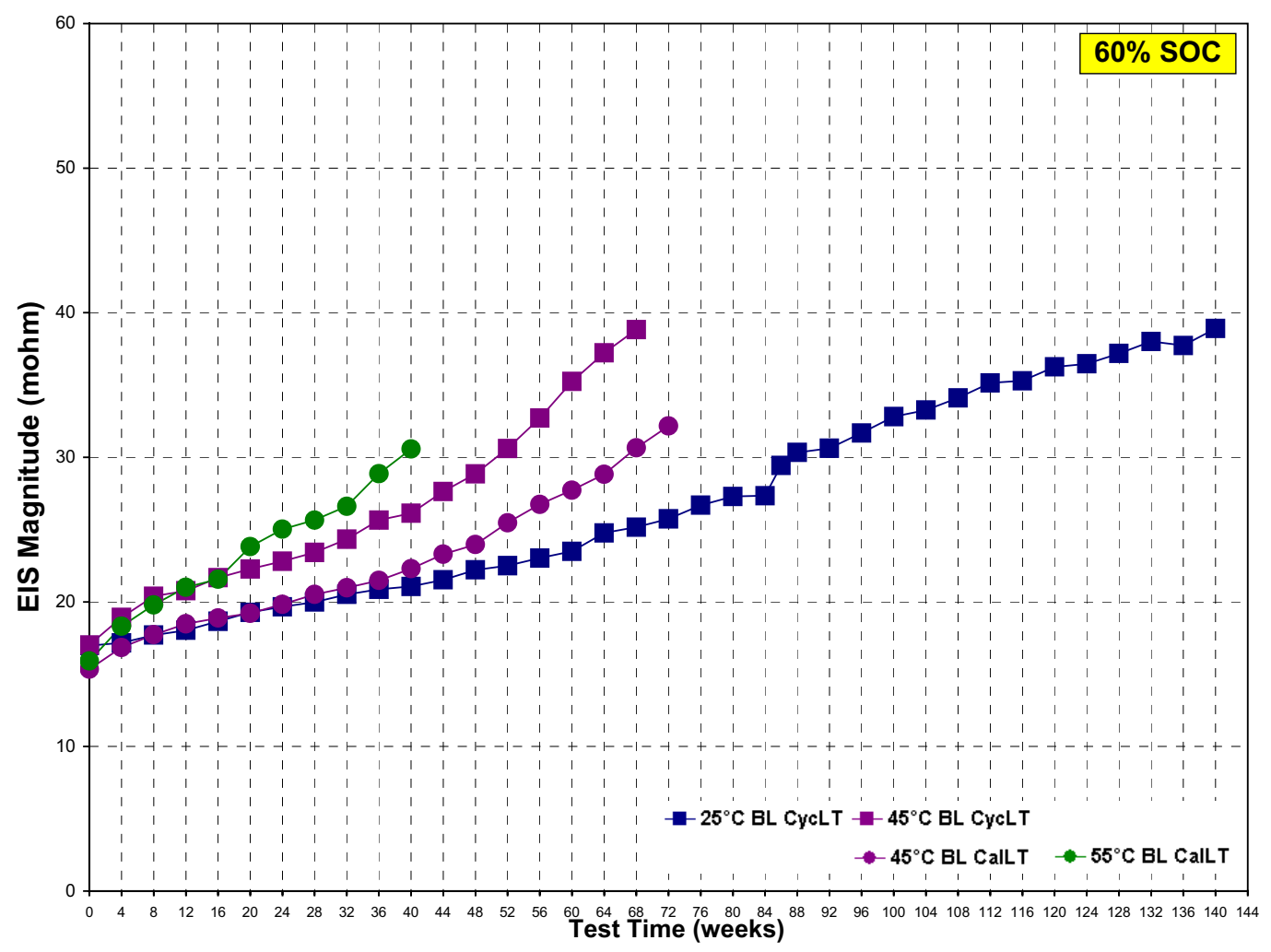

Figure 69. Average EIS magnitude for the Baseline calendar- and cycle-life cells at $60 \%$ SOC. 


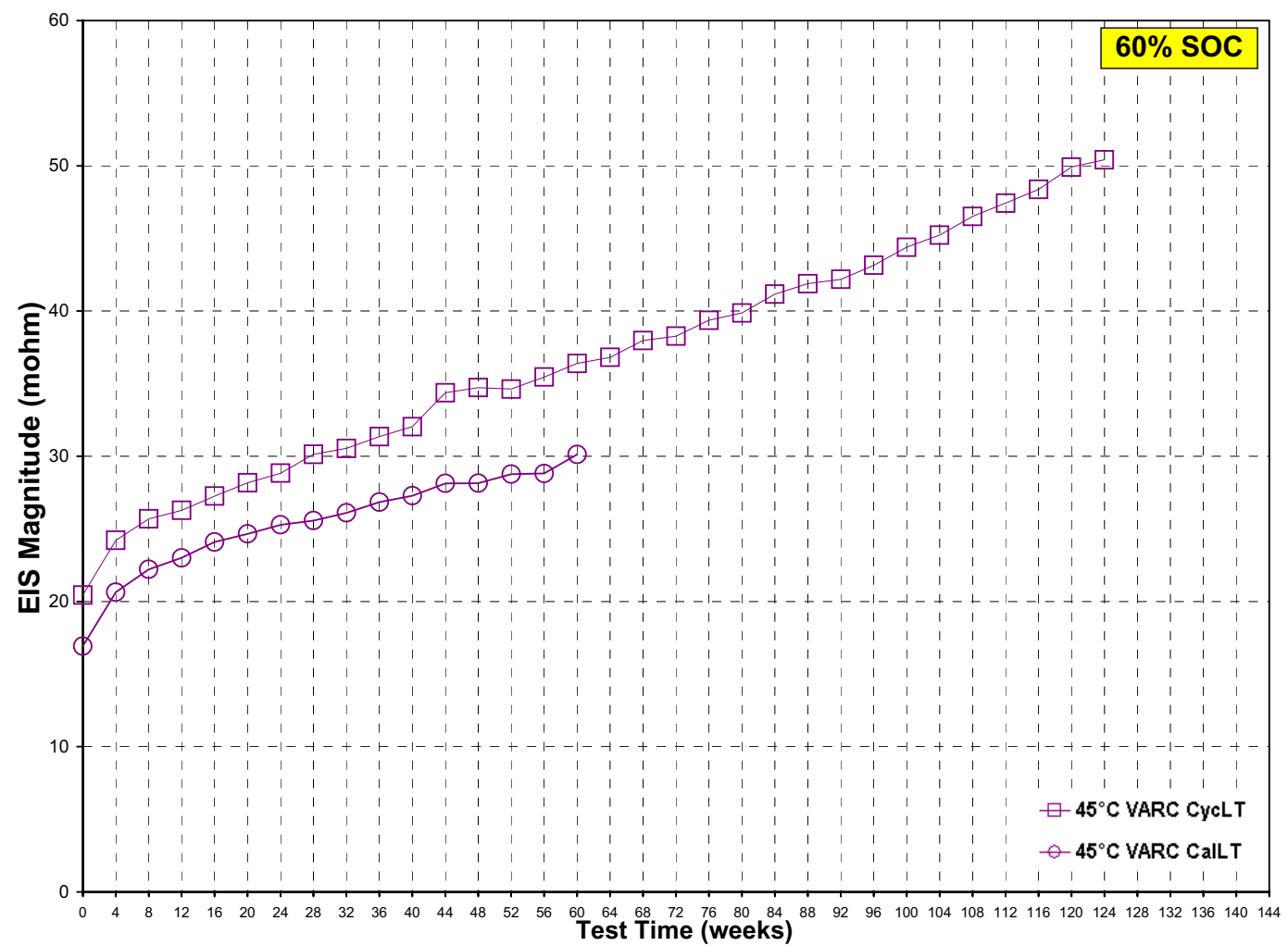

Figure 70. Average EIS magnitude for the Variant $\mathrm{C}$ calendar- and cycle-life cells at $60 \%$ SOC.

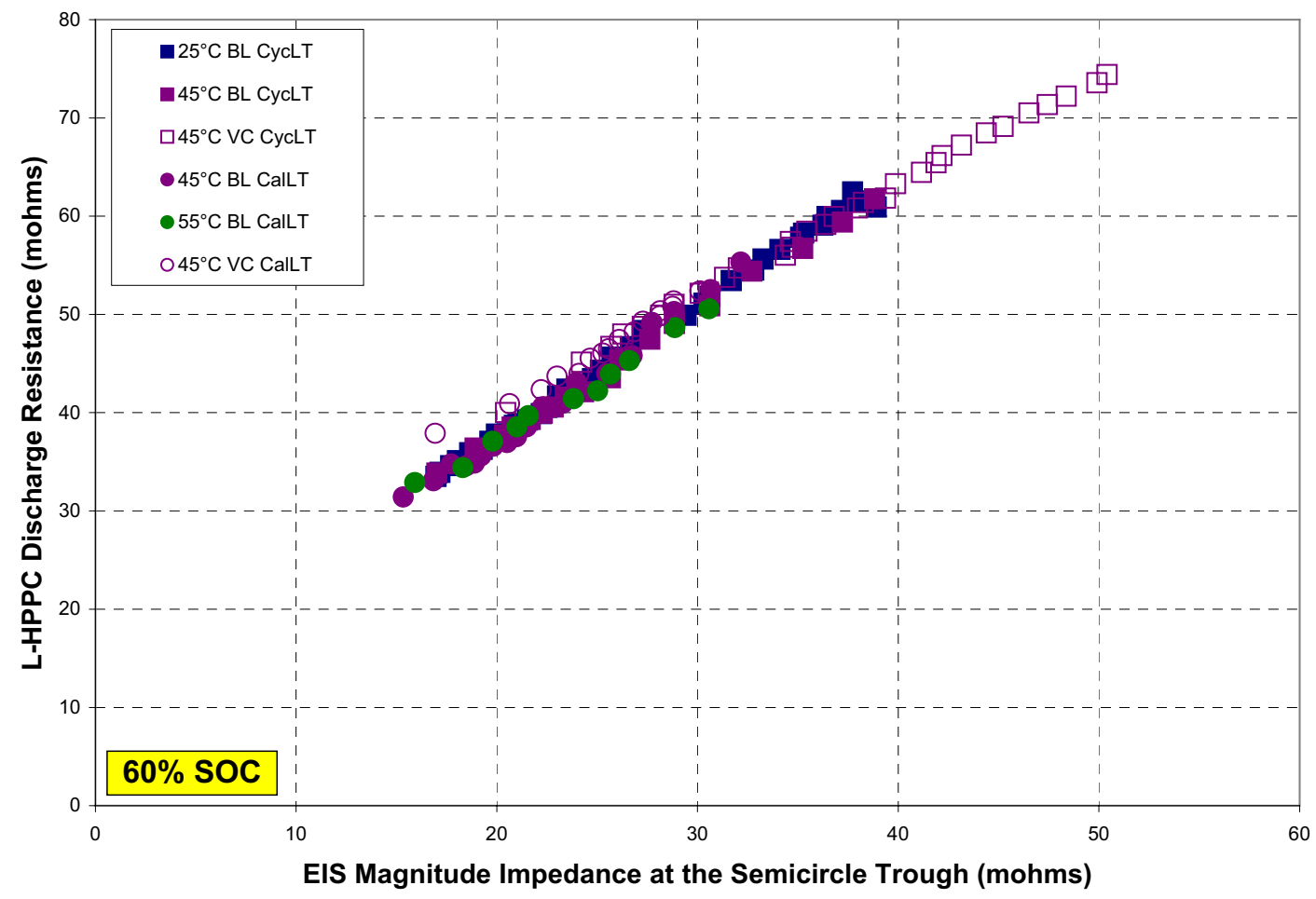

Figure 71. Correlation between EIS and discharge ASI at 60\% SOC. 


\subsection{Pulse Resistances}

\subsubsection{Baseline Cells}

Figure 72 shows the cycle-life 9-s discharge and 2-s regen pulse resistance (see Figure 3) for a representative $25^{\circ} \mathrm{C}$ cycle-life Baseline cell aged for 140 weeks. During cycling, data are collected for the first and last 100 pulses and every hundredth pulse in between. Pulse resistance grows as a function of test time, but show sudden drops every 672 hours (four weeks) when RPTs are performed. These drops are primarily due to the full discharge and charge that occur between the end of the life test interval and the start of the RPT sequence (Reference 22). However, the resistance quickly recovers back to the expected level, and continues to grow.

Figure 73 shows the cycle-life pulse resistance for a representative $45^{\circ} \mathrm{C}$ cycle-life cell through 68 weeks of aging. The cells are affected by increasing temperature, with the $45^{\circ} \mathrm{C}$ data showing less resistance than at $25^{\circ} \mathrm{C}$. The growth rate, however, is higher at $45^{\circ} \mathrm{C}$. Figure 74 shows the calendar-life pulse resistance (see Figure 2) for a representative $45^{\circ} \mathrm{C}$ cell aged for 88 weeks. As expected, the resistances are initially similar to the cycle-life cells, but grow at a slower rate. These data also show drops in pulse resistance, but not as much as was seen with the $25^{\circ} \mathrm{C}$ cells.

Figure 75 shows the calendar-life pulse resistance for a representative $55^{\circ} \mathrm{C}$ cell aged for 40 weeks. As mentioned in Appendix B, the first four weeks of aging for the $55^{\circ} \mathrm{C}$ cell group was actually at $45^{\circ} \mathrm{C}$. Consequently, the initial pulse resistance data are higher. Once the test temperature was increased to $55^{\circ} \mathrm{C}$, the resistance dropped, and showed a higher growth rate than the $45^{\circ} \mathrm{C}$ cells.

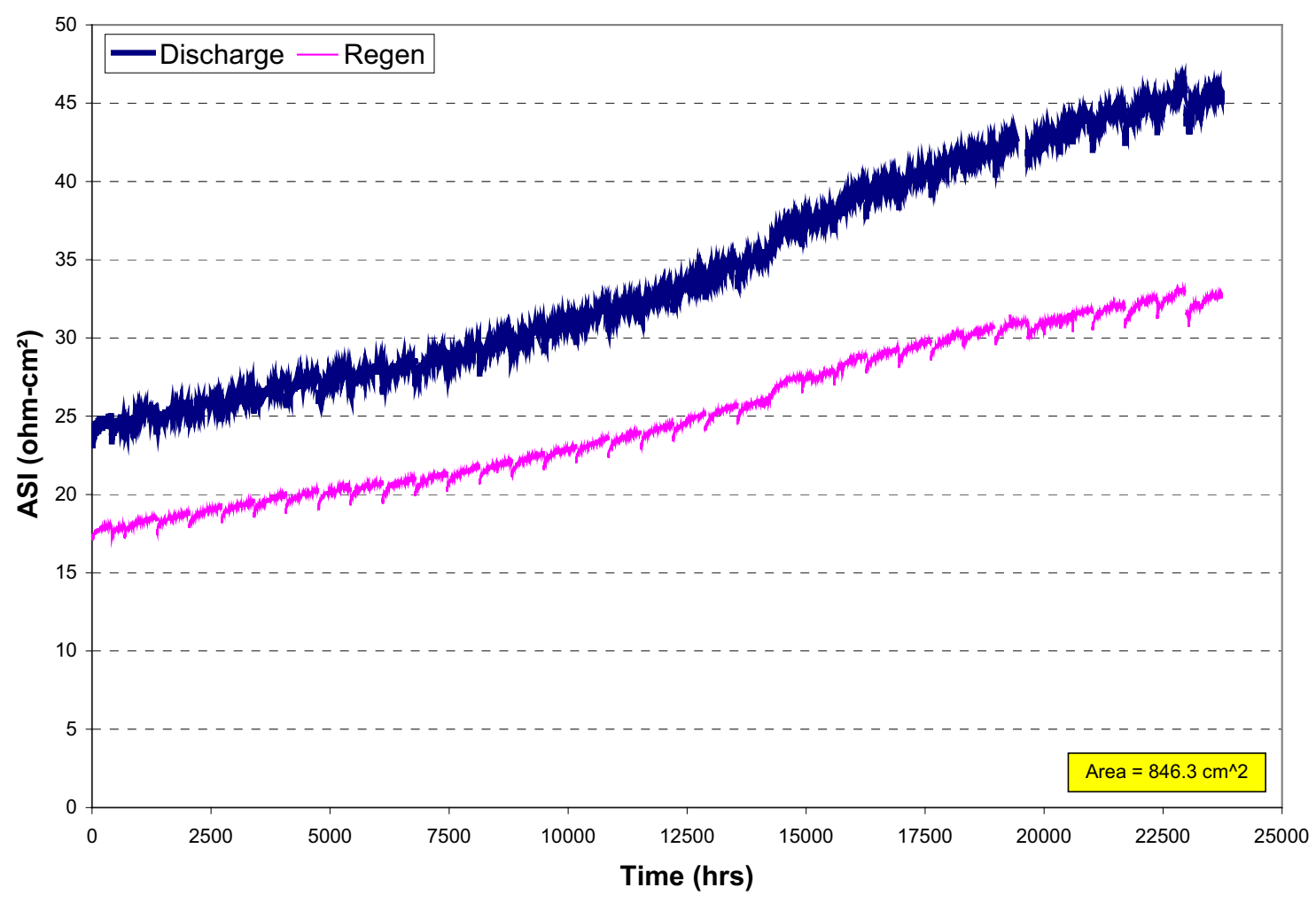

Figure 72. Cycle-life pulse resistance for a representative $25^{\circ} \mathrm{C}$ Baseline cell. 


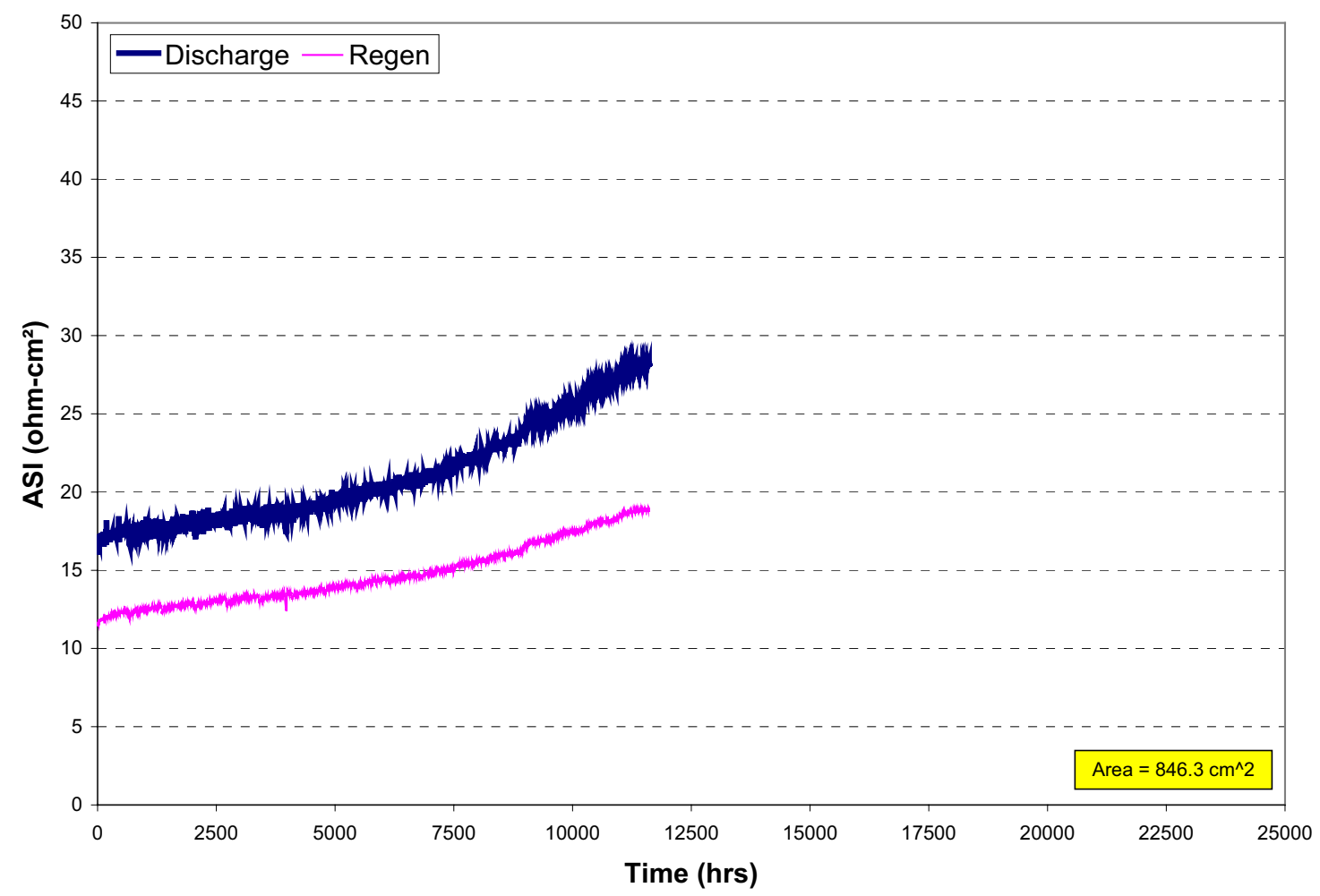

Figure 73. Cycle-life pulse resistance for a representative $45^{\circ} \mathrm{C}$ Baseline cell.

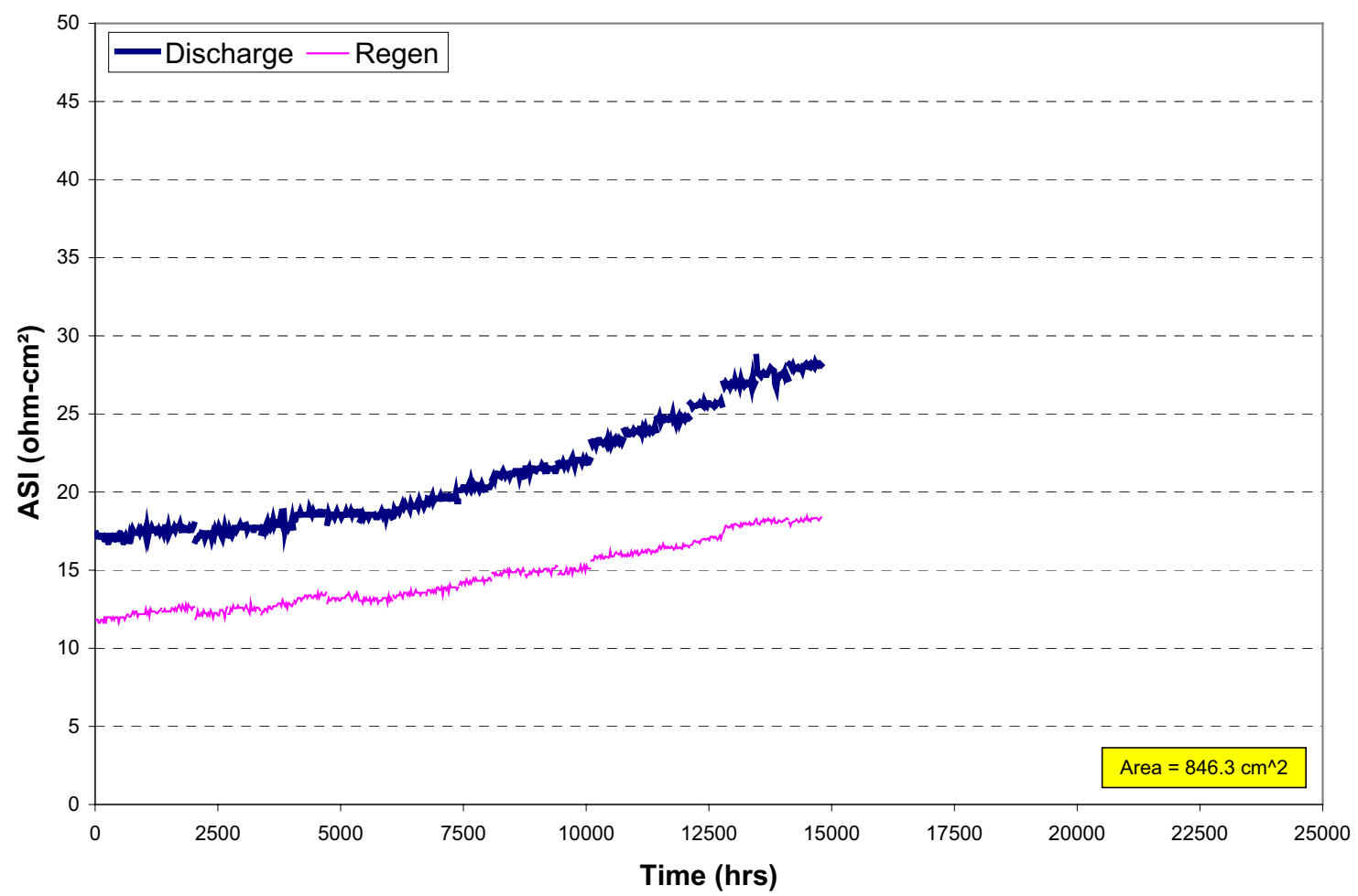

Figure 74. Calendar-life pulse resistance for a representative $45^{\circ} \mathrm{C}$ Baseline cell. 


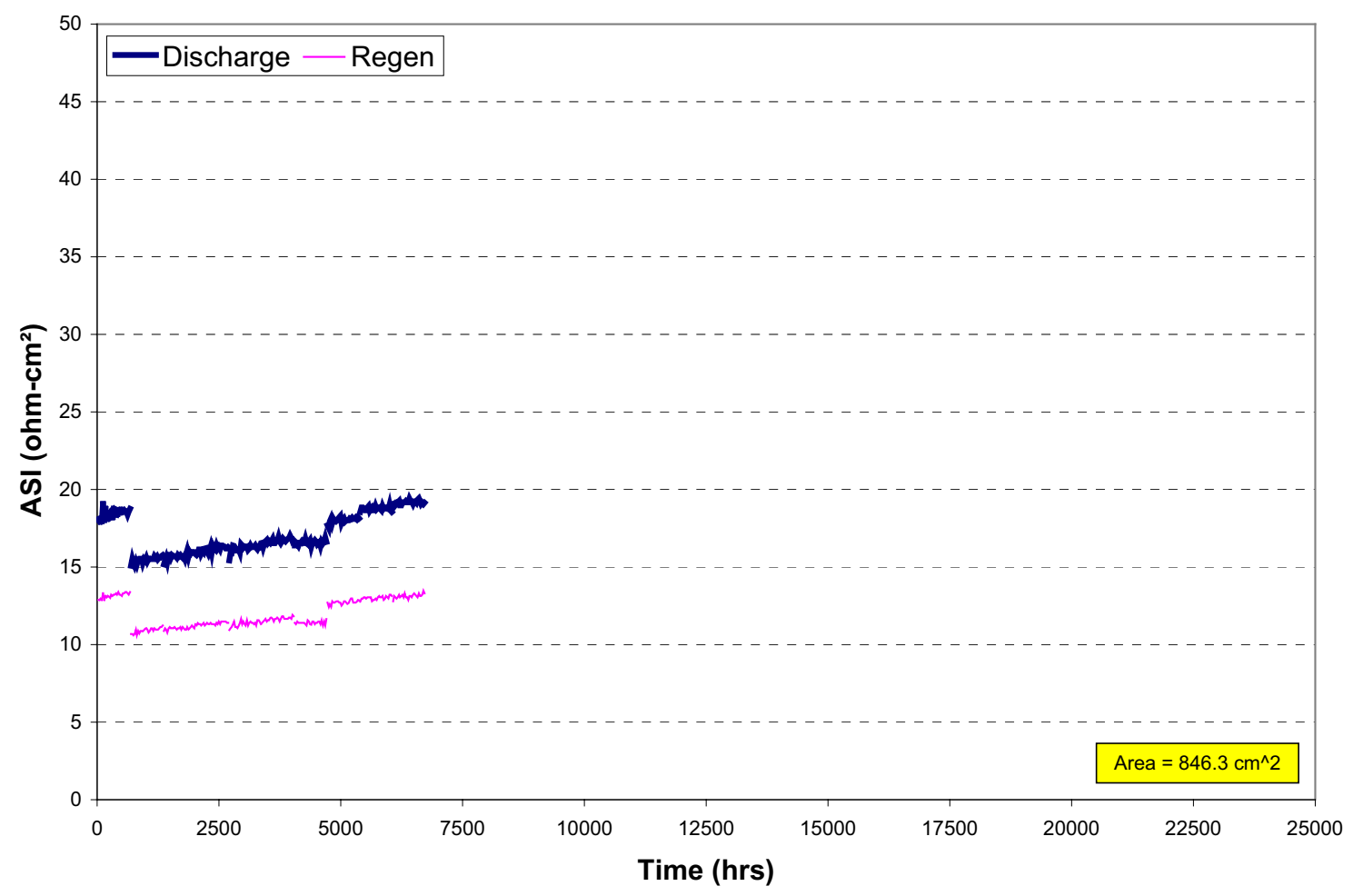

Figure 75. Calendar-life pulse resistance for a representative $55^{\circ} \mathrm{C}$ Baseline cell.

\subsubsection{Variant C Cells}

Figure 76 shows the pulse resistance for a representative $45^{\circ} \mathrm{C}$ cycle-life Variant $\mathrm{C}$ cell through 124 weeks of aging. As seen with the RPT data, the Variant C cell pulse resistance is initially higher than the corresponding Baseline cells, but then shows a slower growth rate later in life. In fact, the Variant $\mathrm{C}$ pulse resistance growth is less than the $25^{\circ} \mathrm{C}$ Baseline cells at end-of-test. Also, the Variant $\mathrm{C}$ cells at $45^{\circ} \mathrm{C}$ show a more significant drop in pulse resistance compared to the corresponding Baseline cells.

Figure 77 shows the calendar-life pulse resistance for a representative $45^{\circ} \mathrm{C}$ cell aged for 148 weeks at $45^{\circ} \mathrm{C}$. As with the Baseline cells, the calendar-life growth rate is slower than the cycle-life cells. Interestingly, the calendar-life cells do not show as much of a drop in pulse resistance as the cycle-life cells. 


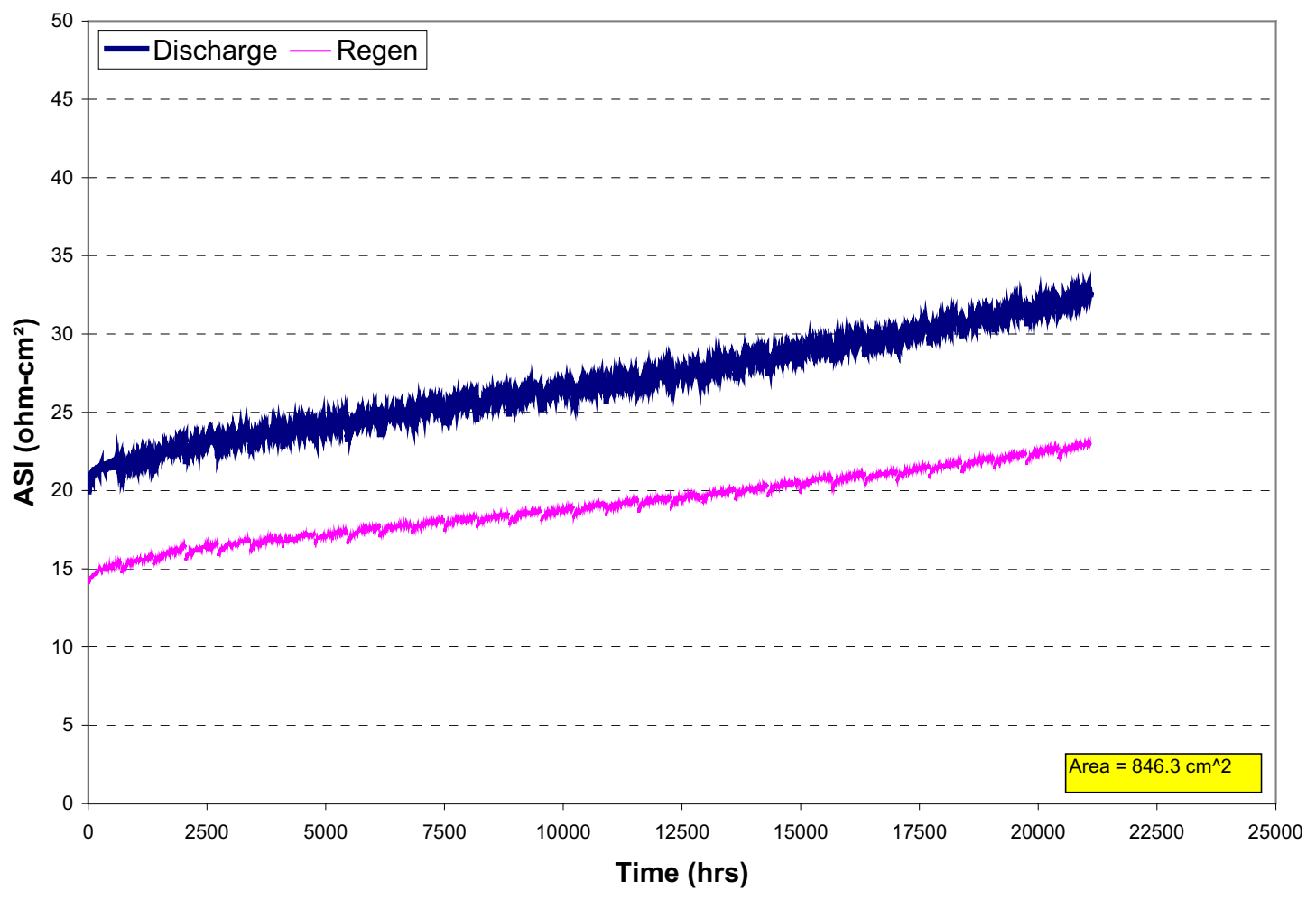

Figure 76. Cycle-life pulse resistance for a representative $45^{\circ} \mathrm{C}$ Variant $\mathrm{C}$ cell.

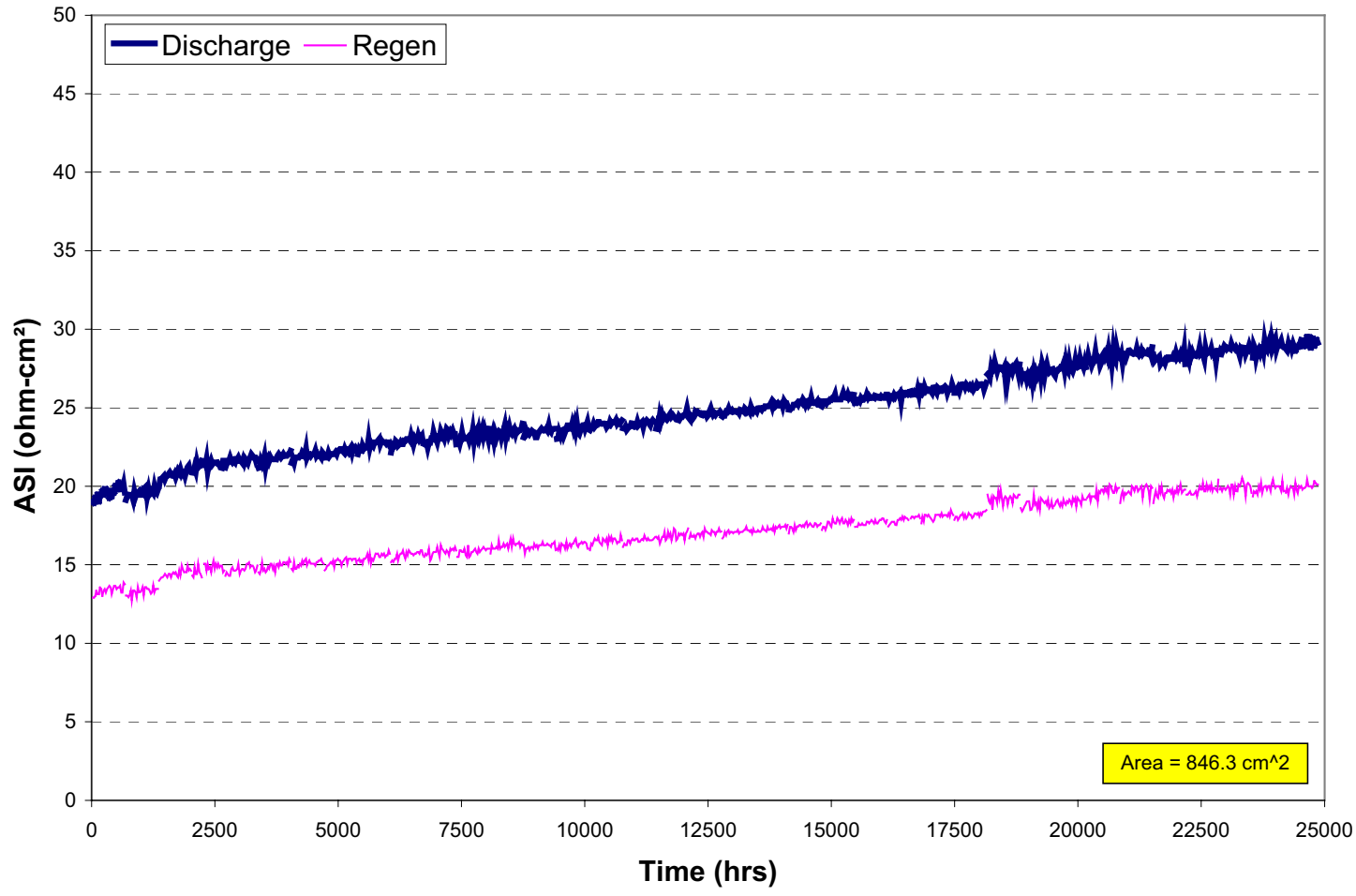

Figure 77. Calendar-life pulse resistance for a representative $45^{\circ} \mathrm{C}$ Variant $\mathrm{C}$ cell. 


\subsection{Performance Models}

\subsubsection{Empirical Model}

The Gen 2 accelerated-life degradation data (through 44 weeks on test) were used to develop a single statistical/empirical model of power fade that is applicable over a wide (and clearly understood) range of temperature and SOCs. Targeted characteristics of the model included simplicity (minimal number of model parameters) and high fidelity in regions where high fidelity is required. High fidelity beyond the point of degradation that defines the end of useful cell lifetime ( $\sim 23 \%$ power fade) was not a high priority. Additionally, the modeling process sought to help determine the experimental conditions where there is unusual aging behavior in the cells, perhaps due to an aging mechanism that is not representative of "normal" use conditions.

The model building process included the following steps. First, the time dependence of power fade was investigated. In particular, graphical analyses were performed in order to determine a simple transformation of time that linearizes the relationship between power fade and transformed time over the various experimental conditions. Such a useful transformation of time $(t)$ was determined to be $\mathrm{t}^{3 / 2}$ (e.g., see Figure 78). The slope and intercept of the linear relationship were estimated for each aging condition. Next, the estimated intercepts and slopes were modeled separately as a function of temperature and SOC. Regions in the temperature / SOC plane where the estimated slope and intercept are consistent with simple models were identified. Finally, a global model of power fade (as a function of temperature and SOC) was developed based on the forms of the slope and intercept models and the experimental data within the consistent regions in the temperature / SOC plane.

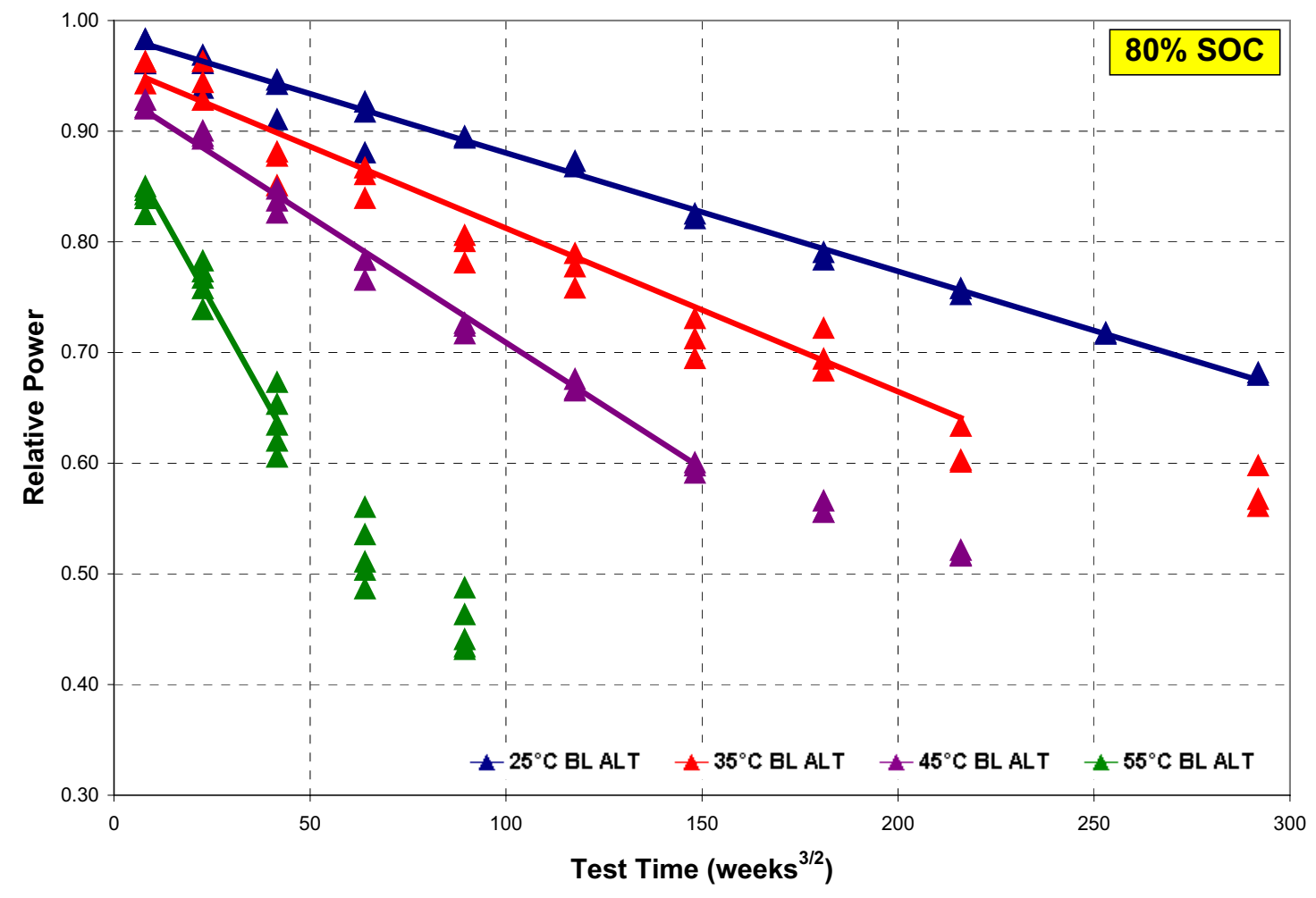

Figure 78. Relative power versus time ${ }^{3 / 2}(80 \%$ SOC). 
The form of the model regarding the relative power of a cell (at time $t$ ) compared to when it was fresh (at $t=0$ ) is given by Equation (3),

$$
Y(t ; T, S O C)=A(T, S O C)-B(T, S O C) \cdot t^{3 / 2}
$$

where $A(T, S O C)$ and $B(T, S O C)$ represent the intercept and slope as a function of temperature and SOC. Useful approximations for $A(T, S O C)$ and $B(T, S O C)$ are given by Equations (4) and (5).

$$
\begin{aligned}
& A=\frac{\exp \left(a_{0}+a_{1} \cdot \frac{1}{T}\right)}{1+\exp \left(a_{0}+a_{1} \cdot \frac{1}{T}\right)} \\
& B=\exp \left(b_{0}+b_{1} \cdot \frac{1}{T}+b_{2} \cdot S O C\right)
\end{aligned}
$$

This yields the global model form shown in Equation (6),

$$
Y(t ; T, S O C)=\frac{\exp \left(a_{0}+a_{1} \cdot \frac{1}{T}\right)}{1+\exp \left(a_{0}+a_{1} \cdot \frac{1}{T}\right)}-\exp \left(b_{0}+b_{1} \cdot \frac{1}{T}+b_{2} \cdot S O C\right) \cdot t^{3 / 2}
$$

References 24 and 25 provide details regarding the models for $A$ and $B$. Noting that the intercept does not depend on the SOC, this global model form involves five parameters $\left(a_{0}, a_{1}, b_{0}, b_{1}\right.$, and $\left.b_{2}\right)$ and provides a good approximation to the experimental data within the region defined by $60 \% \mathrm{SOC}\left(25^{\circ} \mathrm{C}\right.$ to $\left.55^{\circ} \mathrm{C}\right)$ and $80 \% \operatorname{SOC}\left(25^{\circ} \mathrm{C}\right.$ to $\left.45^{\circ} \mathrm{C}\right)$ for $t \geq 4$ weeks. Degradation at the other experimental conditions $\left(100 \%\right.$ SOC [all temperatures] and $80 \%$ SOC $\left.\left[55^{\circ} \mathrm{C}\right]\right)$ was not consistent with the global model. Values for the model parameters were estimated by robust nonlinear regression using data within the aging conditions identified and further restricted such that observations with power fade exceeding $40 \%$ were omitted. Estimates of the model parameters (with estimated standard errors) are:

$\hat{a}_{0}=-21.01(.72), \hat{a}_{1}=7.585 \times 10^{3}\left(2.3 \times 10^{2}\right), \hat{b}_{0}=4.0387(.24), \hat{b}_{1}=-3.547 \times 10^{3}(73)$, and $\hat{b}_{2}=.01331(.00063)$.

The fitted global model provides a prediction of the relative power of cells as a function of time, temperature and SOC is given by Equation 7,

$$
\hat{Y}(t ; T, S O C)=\frac{\exp \left(\hat{a}_{0}+\hat{a}_{1} \cdot \frac{1}{T}\right)}{1+\exp \left(\hat{a}_{0}+\hat{a}_{1} \cdot \frac{1}{T}\right)}-\exp \left(\hat{b}_{0}+\hat{b}_{1} \cdot \frac{1}{T}+\hat{b}_{2} \cdot S O C\right) \cdot t^{3 / 2}
$$


restricted to $t \geq 4$ weeks. The predicted percent-power fade is simply $100 \cdot(1-\hat{Y}(t ; T, S O C))$. Figures 79 and 80 illustrate the quality of the predictive model over the identified experimental region that exhibits this aging behavior.

In summary, this model and the data upon which it is based indicate that there are at least two concurrent degradation processes involved. The first degradation process (perhaps incomplete cell formation) is relatively rapid (nearly complete within 4 weeks) and is accelerated by temperature with unknown kinetics. The second degradation process (accelerated by temperature and SOC) is less rapid and exhibits time $\mathrm{e}^{3 / 2}$ kinetics. This degradation behavior is evident over the range of experimental conditions excluding aging at $100 \%$ SOC (all temperatures) and $80 \%$ SOC (at $55^{\circ} \mathrm{C}$ ).

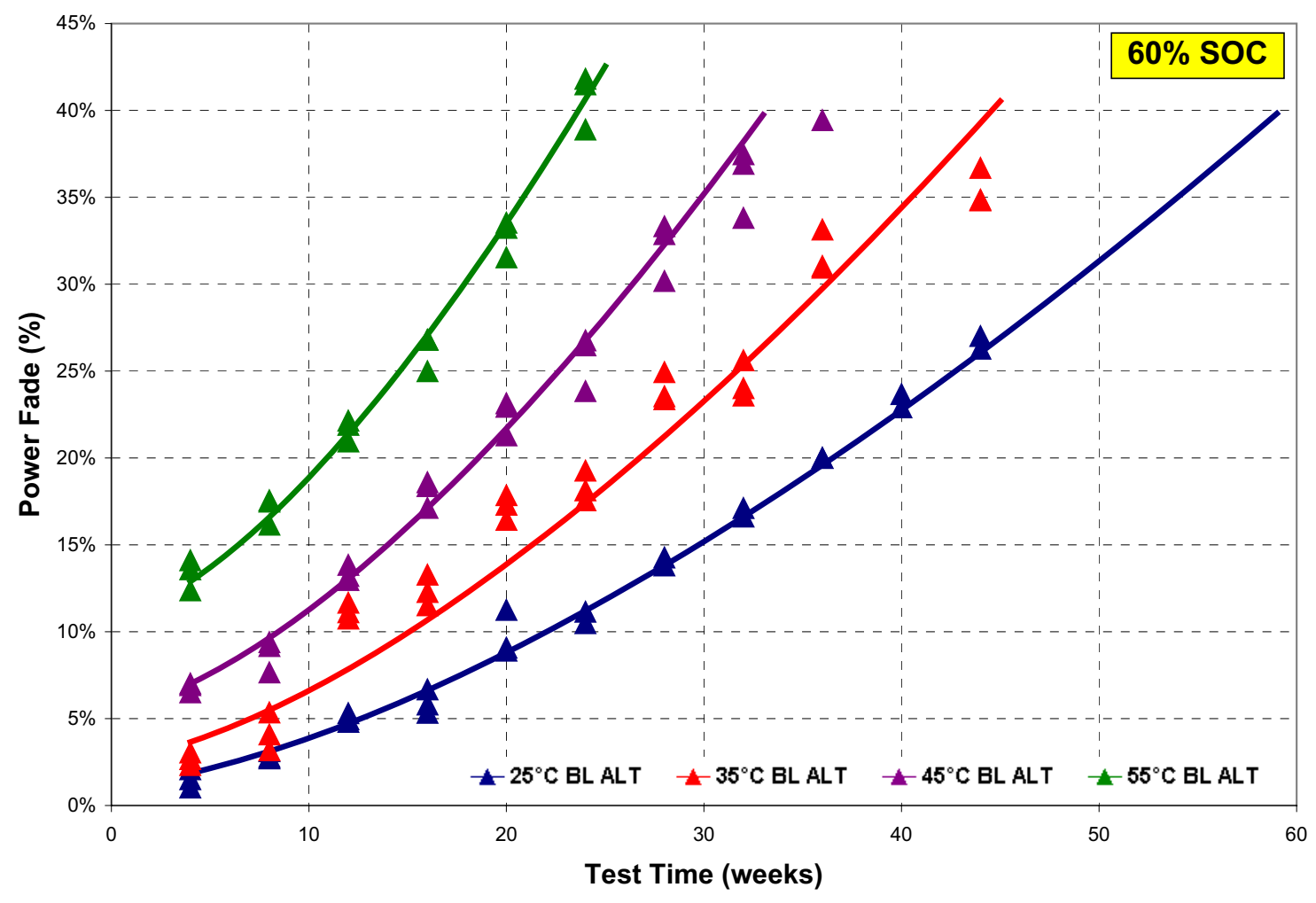

Figure 79. Model fit to power fade versus time at $60 \%$ SOC. 


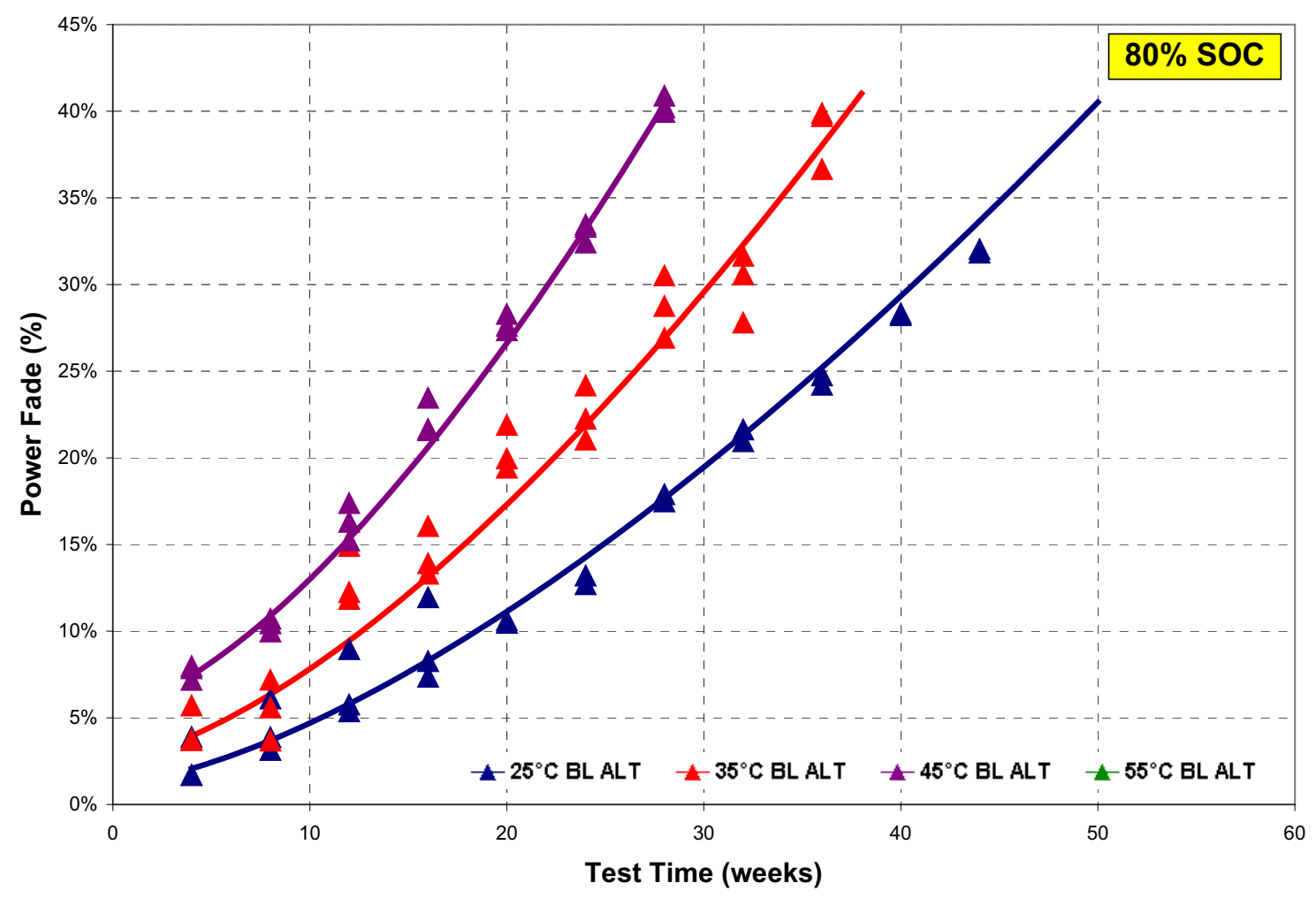

Figure 80 . Model fit to power fade versus time at $80 \%$ SOC.

\subsubsection{Two-Step Model}

The degradation in calendar- and cycle-life cell performance as measured from the RPT generally showed a change in mechanism, with an increased degradation rate when the second mechanism dominates. Consequently, the data were fit to a two-step model as shown in Equation 8,

$$
A S I=A S I_{0}+a t^{1 / 2}+c\left(t-t_{0}\right)
$$

where $\mathrm{t}$ is time, $\mathrm{ASI}_{0}$ is the ASI at $\mathrm{t}=0$, and $\mathrm{a}, \mathrm{c}$, and $\mathrm{t}_{0}$ are constants $\left(\mathrm{c}=0\right.$ when $\left.\mathrm{t}<\mathrm{t}_{0}\right)$. A parabolic (i.e., square root of time) dependence can be related to a thermal diffusion process for the formation of a solid electrolyte interphase (SEI) layer. A linear time dependence can be related to a steady-state formation of the SEI layer, where the electrolyte/salt decomposition reaction at the surface of the SEI layer determines the rate of SEI growth (Reference 26). The combination of a parabolic and linear behavior has been seen in the high temperature oxidation of Niobium (Reference 27). Preliminary results of this model are provided in Reference 28.

Figure 81 shows the average $\mathrm{C}_{1} / 1$ discharge capacity for the calendar- and cycle-life Baseline and Variant $\mathrm{C}$ cells with the two-step model fit for each cell group. The mechanistic change from parabolic to linear occurs earlier with increasing test temperature. The Variant $\mathrm{C}$ cells show a more subtle change, and later in life, than the corresponding Baseline cells. Figure 82 shows the average discharge ASI for the Baseline and Variant $\mathrm{C}$ cells with the model fit. The values for the parameters in Equation (8) to the ASI data are summarized in Table 5. The regression coefficients $\left(\mathrm{r}^{2}\right.$ values) were greater than or equal to 0.99 . These data show the effect of the cathode composition, test type, and temperature on aging. The mechanistic change occurs at $\mathrm{t}_{0}$, which, as shown in Table 5 , decreases with increasing test temperature. 
The effect of the greater aluminum content in the Variant $\mathrm{C}$ cells is seen in the much higher value for $\mathrm{t}_{0}$ (approximately 60 weeks) compared to the corresponding Baseline cells (approximately 35 weeks).

Table 5. Values for ASI two-step fit.

\begin{tabular}{ccccc}
\hline \hline Test Group & $\begin{array}{c}\mathrm{ASI}_{0} \\
\left(\Omega-\mathrm{cm}^{2}\right)\end{array}$ & a & $\mathrm{c}$ & $\begin{array}{c}\mathrm{t}_{0} \\
(\text { weeks })\end{array}$ \\
\hline \hline Baseline cycle-life at $25^{\circ} \mathrm{C}$ & 27.34 & 0.85 & 0.14 & 44.30 \\
Baseline cycle-life at $45^{\circ} \mathrm{C}$ & 28.46 & 1.23 & 0.40 & 35.15 \\
Baseline calendar-life at $45^{\circ} \mathrm{C}$ & 26.44 & 0.89 & 0.30 & 34.48 \\
Baseline calendar-life at $55^{\circ} \mathrm{C}$ & 27.04 & 1.63 & 0.31 & 22.78 \\
Variant C cycle-life at $45^{\circ} \mathrm{C}$ & 34.44 & 1.96 & 0.10 & 62.60 \\
Variant C calendar -life at $45^{\circ} \mathrm{C}$ & 32.16 & 1.64 & 0.05 & 59.70 \\
\hline \hline
\end{tabular}

Figure 83 shows the average discharge $C_{1} / 25$ discharge capacity for the calendar- and cycle-life Baseline and Variant $\mathrm{C}$ cells with the two-step model fit for each cell group. The data appear to only follow a square root of time dependence with no transition to the linear region. The $\mathrm{C}_{1} / 25$ capacity is not sensitive to cathode composition and may reflect the anode chemistry.

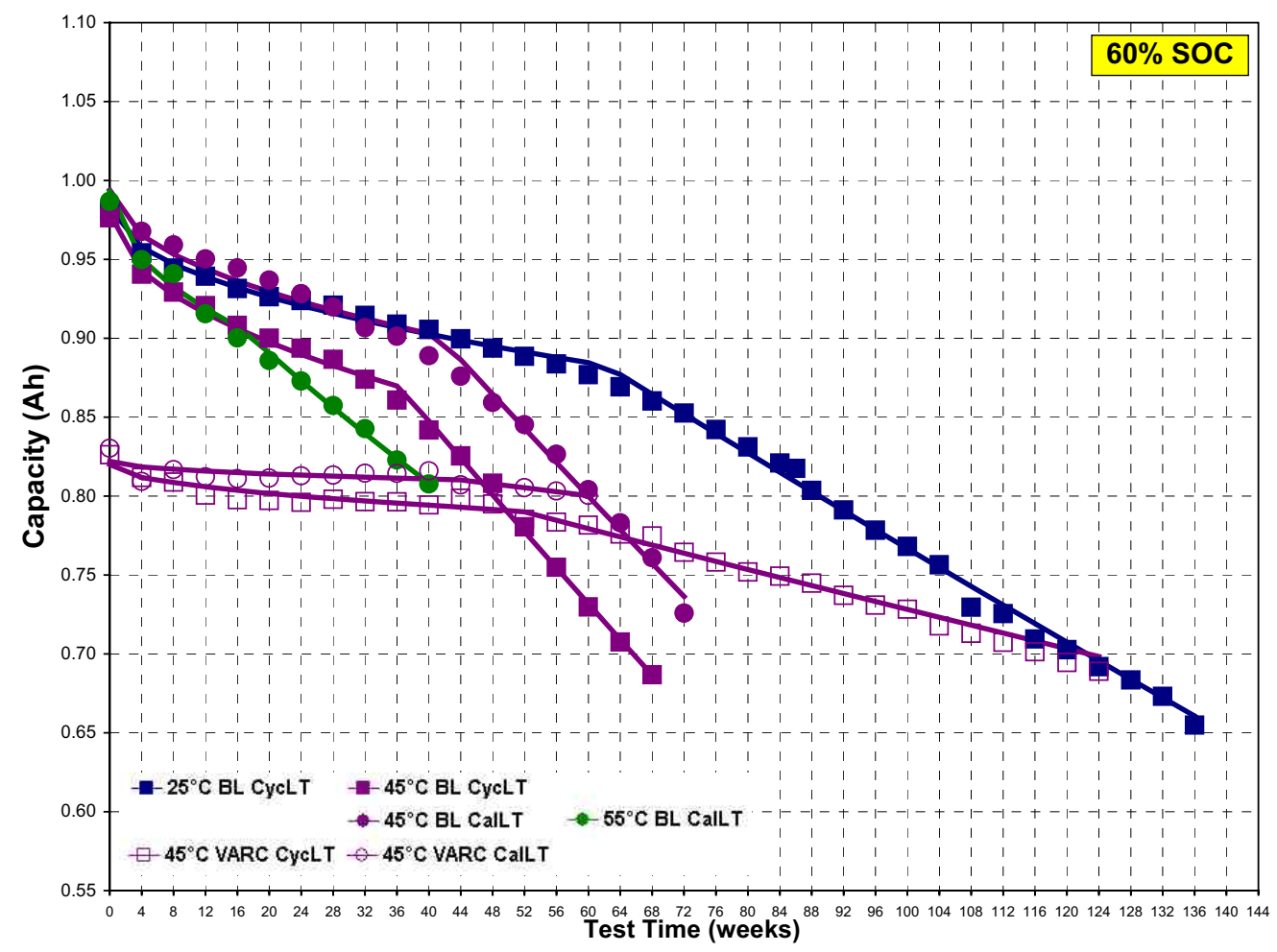

Figure 81. Model fit to the average $\mathrm{C}_{1} / 1$ discharge capacity for the CalLT and CycLT cell groups. 


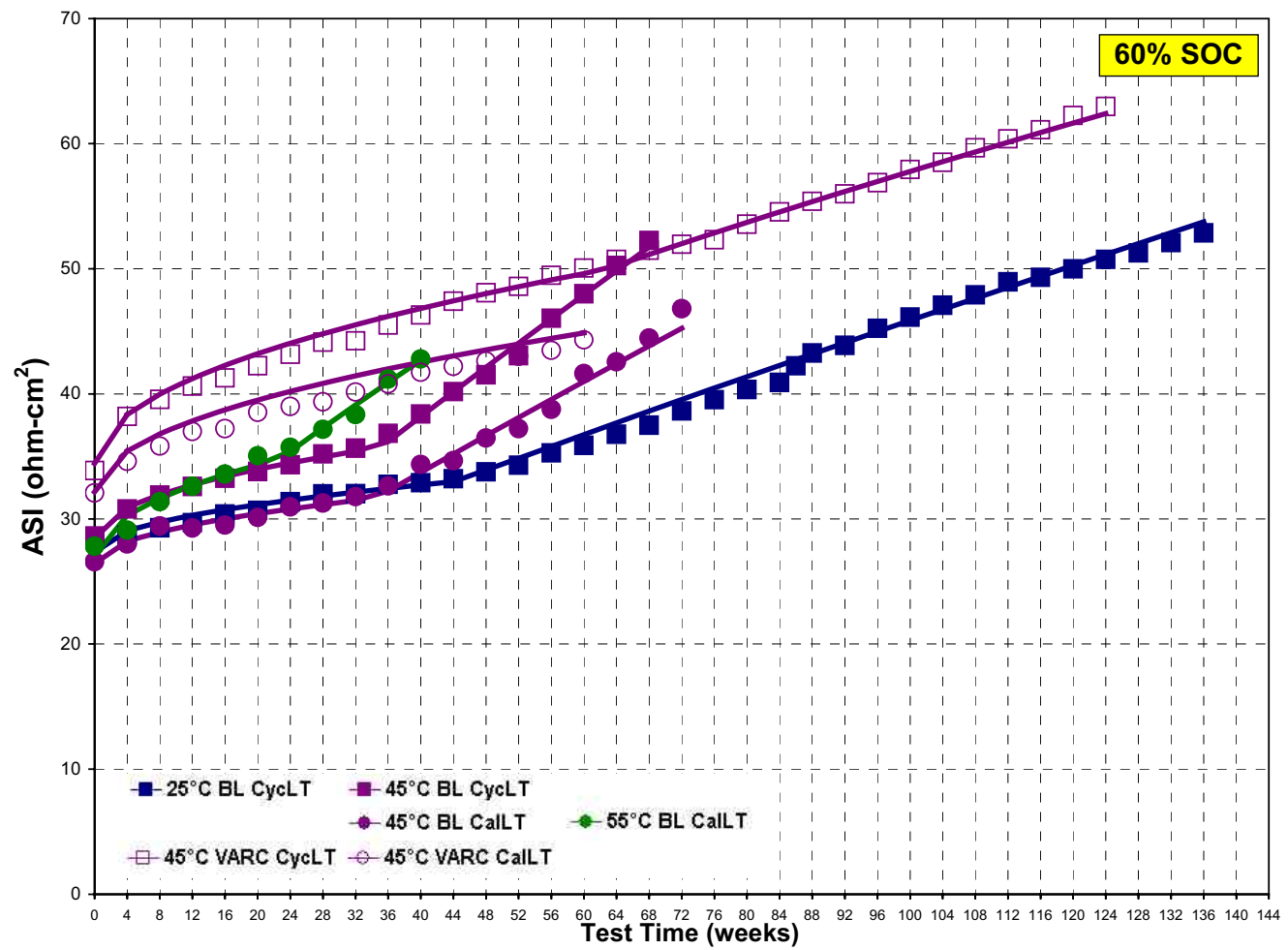

Figure 82. Model fit to the average discharge ASI for the CalLT and CycLT cell groups.

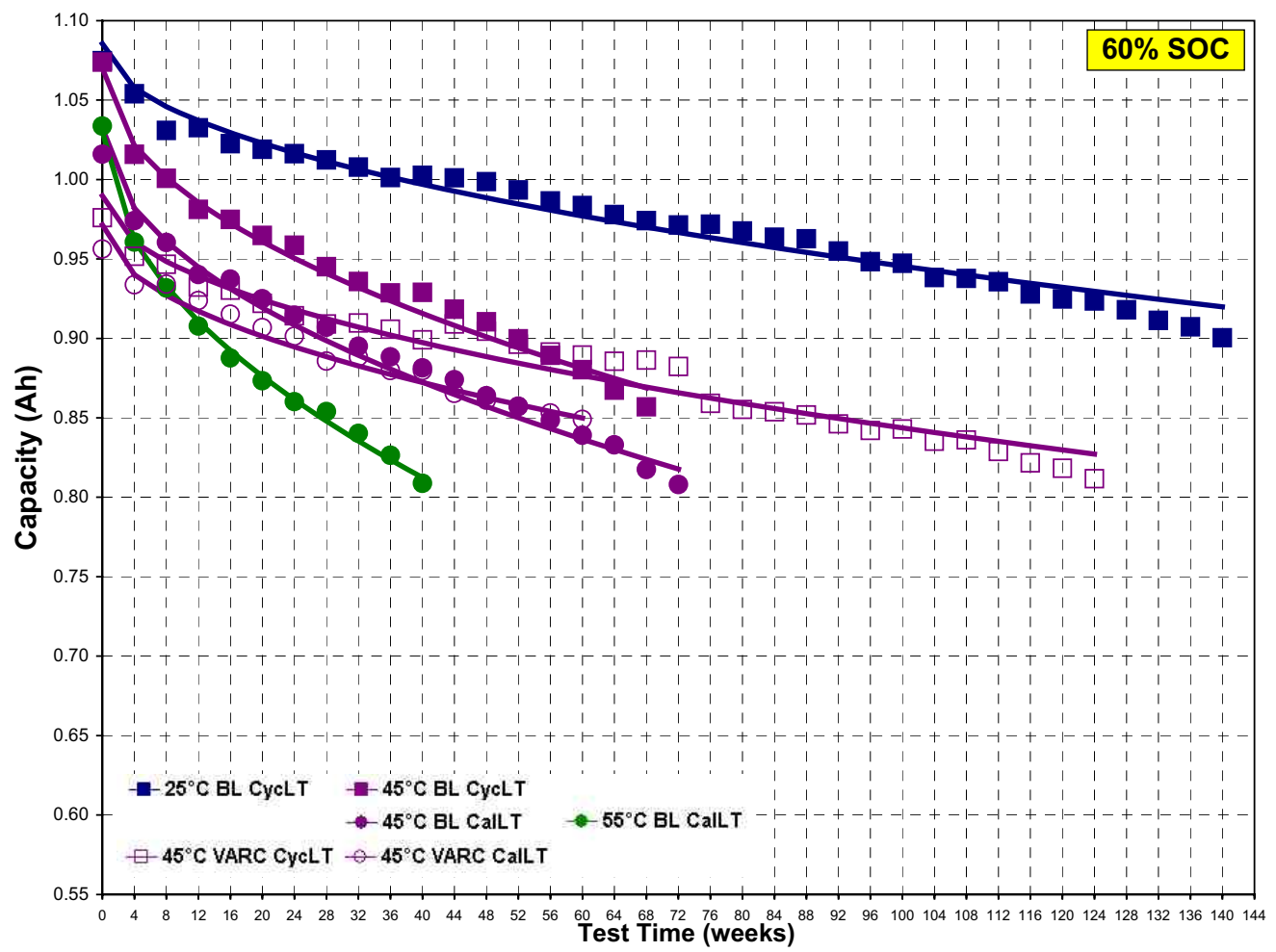

Figure 83. Model fit to the average $\mathrm{C}_{1} / 25$ discharge capacity for the CalLT and CycLT cell groups. 


\subsubsection{Double-Sigmoid Model}

Another model has been developed to evaluate aging data for ATD cells. The Multiple Sigmoid Model (MSM) is a physics-based model that can project the effects of cumulative test time on cell performance. The MSM asserts that a given time-dependent performance indicator $\Psi$ (e.g., impedance rise, power fade, capacity fade, etc.) can be expressed as a summation of $n$ sigmoid functions, wherein each function represents a major or net degradation mechanism, typically isolated at one or more of the major cell components (cathode, anode, separator, electrolyte, etc.) as defined in Equation (9)

$$
\Psi(t)=\sum_{i=1}^{n} \Psi_{i}(t)=\sum_{i=1}^{n}\left\{2 M_{i}\left[\frac{1}{1+\exp \left(-\left(t^{b_{i}} / a_{i}\right)\right)}-\frac{1}{2}\right]\right\}
$$

where $(\mathrm{a}, \mathrm{b}, \mathrm{M})_{\mathrm{i}}$ are model parameters related to the rate constant, effective reaction order, and upper boundary for the $\mathrm{i}^{\text {th }}$ degradation mechanism. This approach is mathematically self-consistent and thus provides logical, realistic upper limits for $\Psi_{\mathrm{i}}$ as time grows very large. The MSM can be linked to physical parameters within the cell, most notably the effective capacity or the net active surface of each electrode. If net degradation mechanisms are assumed to reside primarily at the electrodes, then a Double Sigmoid Model (DSM) is determined from the above expression. Additional sigmoid terms can be added to the DSM to account for other factors such as the potential increase of electrolyte viscosity with aging, or separator degradation. An example of DSM results is given in Figure 84. Here, the DSM was fit to power fade data from the Baseline and Variant $\mathrm{C}$ cycle-life cells through 68 weeks, and then used for predictions thereafter. From this figure, the DSM fit is very good, and provides good predictions of when cells reach $50 \%$ power fade. Note that the "adjusted" notation refers to data adjusted to the true test temperature using a temperature compensation methodology similar to one defined in Reference 7.

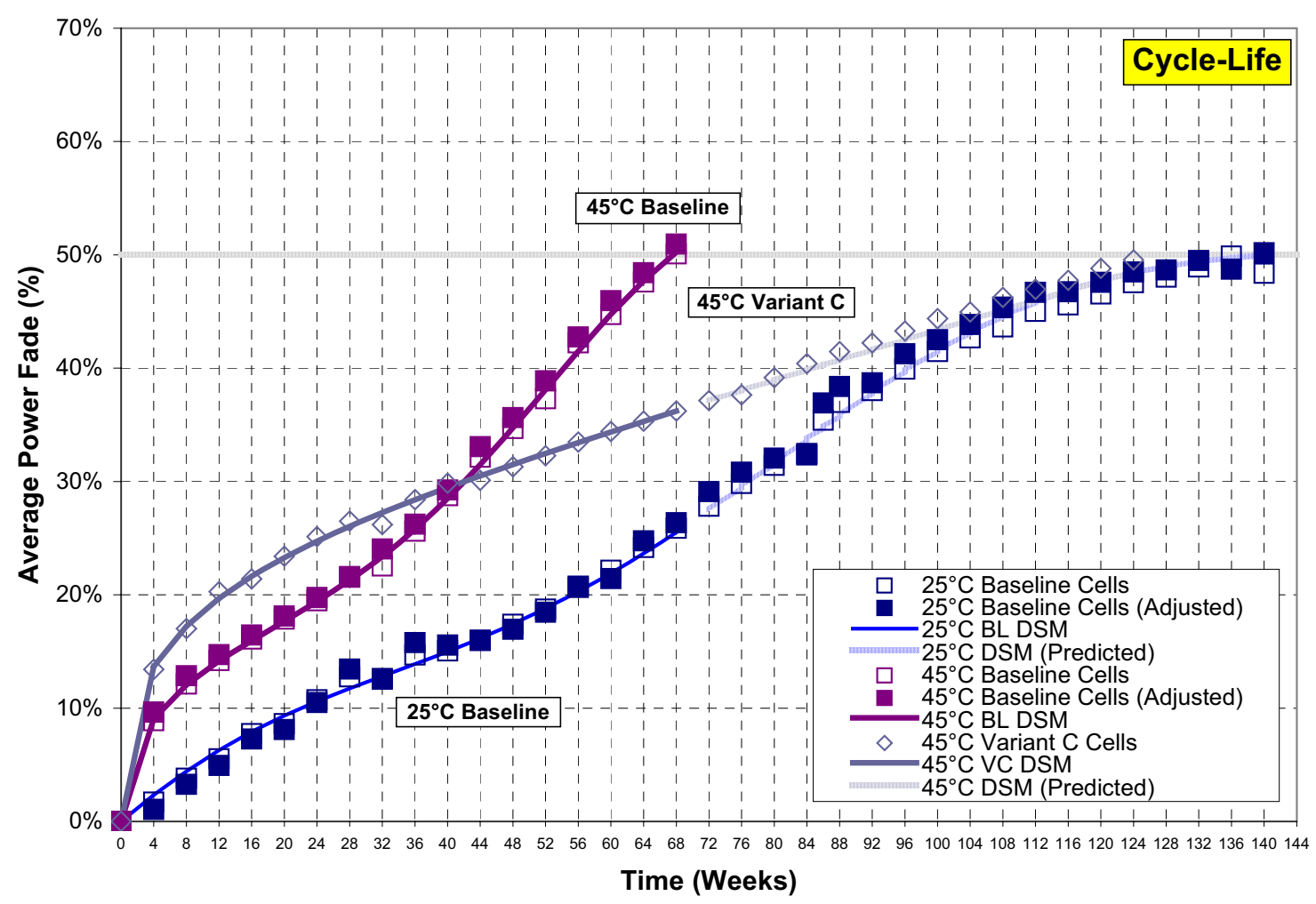

Figure 84. Average power fade versus time and the DSM predictions after 68 weeks of aging. 
Further demonstration of the DSM capability is given in Figure 85 (a through c), which contain data and model fits of the accelerated life test data. Considering the noticeable scatter of the data in some cases (e.g., 60 and $80 \% \mathrm{SOC}$ at $35^{\circ} \mathrm{C}$ ), the overall model fit to the data is exceptional. DSM parameters used to correlate the accelerated-life data are given in Table 6 , where summary observations on trends are listed following the table. If the cell degradation mechanisms are assumed to be linked to each electrode, then analysis of the Table 6 parameters will shed light on the rate of degradation at each electrode. In simple terms, if we assign degradation process 1 to the positive electrode, and process 2 to negative electrode, it appears that the performance degradation rate of the positive electrode is greater than that of the negative electrode at earlier time (then tapers off), whereas the degradation rate of the negative electrode tends to increase slowly over time.

Table 6. Summary of DSM parameters for analysis of the accelerated-life cells (all four temperatures).

\begin{tabular}{cccc}
\hline \hline Regression Constants & $60 \%$ SOC & $80 \%$ SOC & $100 \%$ SOC \\
\hline \hline $\mathrm{a}_{1}$ & 1.01 to 23.1 & 2.1 to 18.0 & 4.28 to 13.1 \\
$\mathrm{a}_{2}$ & 336 to 4600 & 86.0 to 4040 & 112 to 1580 \\
\hline $\mathrm{b}_{1}$ & $0.754 \pm 0.397$ & $0.591 \pm 0.122$ & $0.738 \pm 0.248$ \\
$\mathrm{~b}_{2}$ & $1.98 \pm 0.479$ & $1.90 \pm 0.358$ & $2.07 \pm 0.242$ \\
\hline $\mathrm{M}_{1}$ & $19.5 \pm 3.5$ & $30.3 \pm 3.25$ & $54.0 \pm 5.2$ \\
$\mathrm{M}_{2}$ & $41.6 \pm 5.12$ & $36.9 \pm 2.90$ & $27.2 \pm 2.82$ \\
$\mathrm{M}_{1}+\mathrm{M}_{2}$ & 57 to 63 & 66 to 68 & 79 to 84 \\
\hline \hline
\end{tabular}

Notes: Rate constants: $a_{1}$ and $a_{2}$ vary greatly with temperature but not SOC.

Reaction order: $b_{1}$ and $b_{2}$ are nearly temperature and SOC independent.

Upper bounds: $\mathrm{M}_{1}$ and $\mathrm{M}_{2}$ are nearly temperature independent.

$\mathrm{M}_{1}$ increases with SOC, while $\mathrm{M}_{2}$ decreases with SOC; The sum $\left(\mathrm{M}_{1}+\mathrm{M}_{2}\right)$ increases with SOC. 
(a)

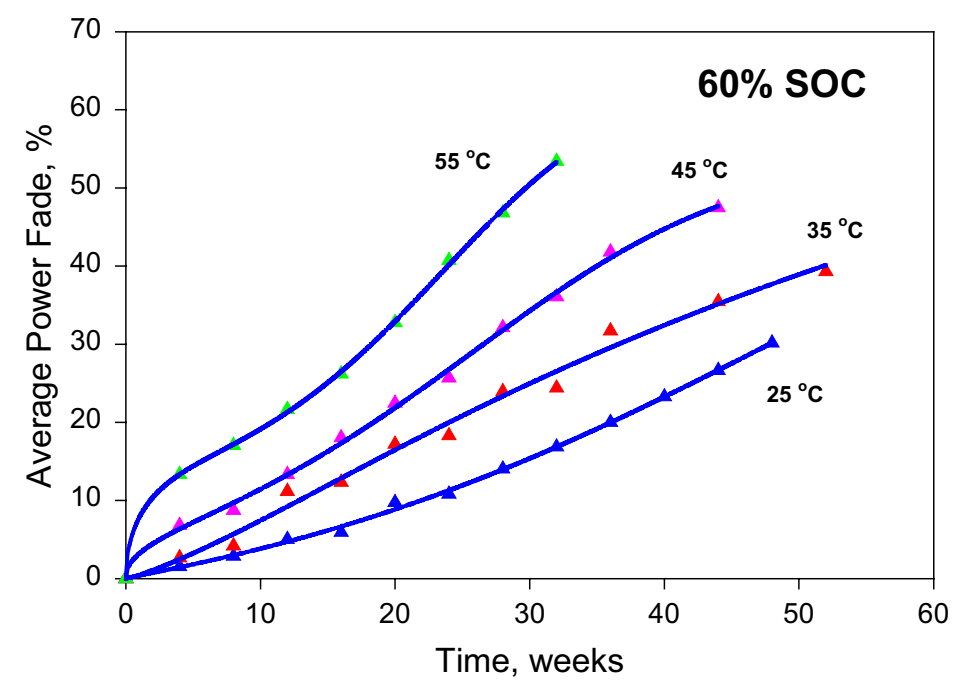

(b)

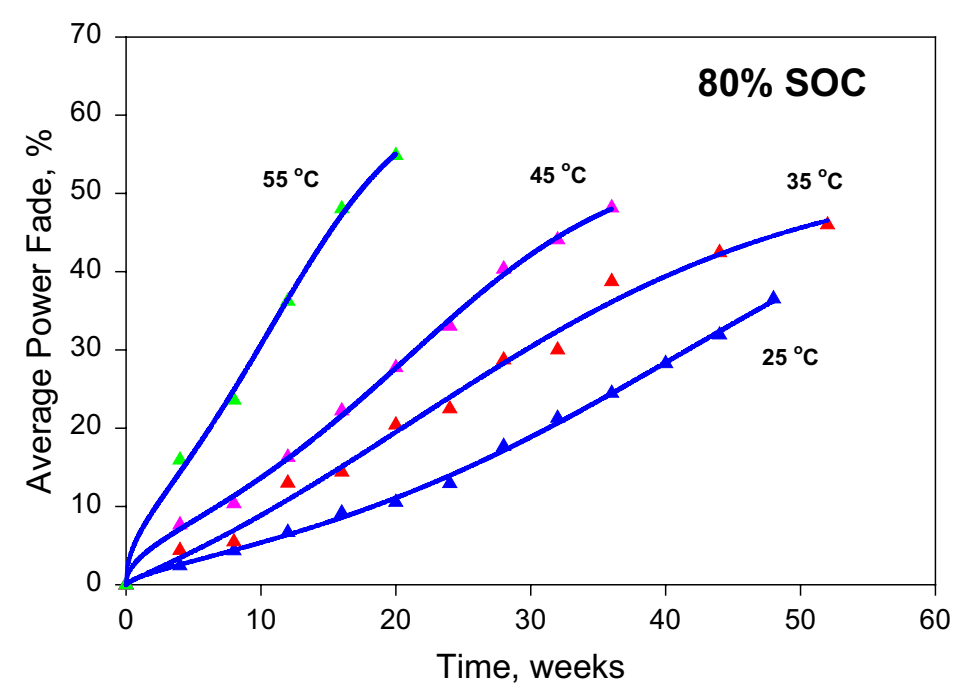

(c)

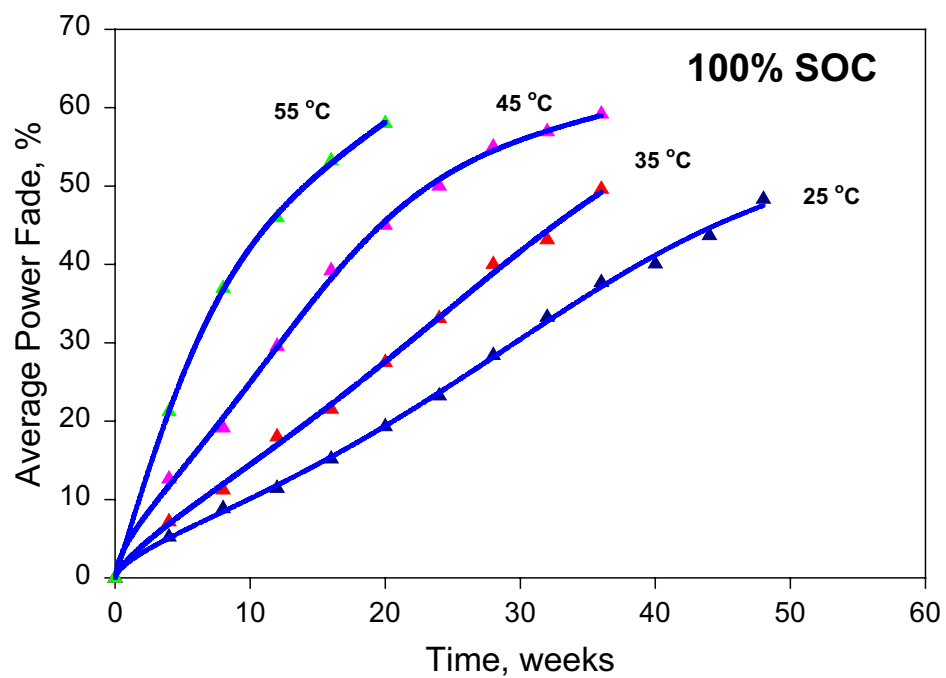

Figure 85. DSM fits for the accelerated-life average power fade at (a) $60 \%$, (b) $80 \%$, and (c) $100 \%$ SOC. 


\subsection{Performance Summary}

The average discharge capacity fades (both $C_{1} / 1$ and $C_{1} / 25$ ), power fade, and EIS growth for the Baseline and Variant $\mathrm{C}$ calendar- and cycle-life cells are summarized in Table 7 . In accordance with the end-of-test criteria (Section 3.4), the last remaining cell(s) were aged to approximately $50 \%$ power fade. As expected, the number of weeks on test reduced with increasing temperature for the Baseline cells. The Variant $\mathrm{C}$ cells lasted about as long as the $25^{\circ} \mathrm{C}$ Baseline cells. The $\mathrm{C}_{1} / 25$ discharge capacity fades show a weak temperature dependence, with the calendar-life test showing slightly more overall fade than the cycle-life test at $45^{\circ} \mathrm{C}$. Except at $55^{\circ} \mathrm{C}$, both the Baseline $\mathrm{C}_{1} / 1$ discharge capacity fade and EIS growth were similar, regardless of how long it took the cells to reach $50 \%$ power fade. The $55^{\circ} \mathrm{C} \mathrm{C}_{1} / 1$ capacity fade and EIS growth is significantly less, possibly due to a higher temperature mechanism that caused the power fade to increase more rapidly than at lower temperatures. Interestingly, the Variant $\mathrm{C} \mathrm{C}_{1} / 1$ capacity fade is very similar to the corresponding $\mathrm{C}_{1} / 25$ fade. The Variant $\mathrm{C}$ EIS growth is slightly higher, but comparable, to the corresponding Baseline cell degradation at 50\% power fade.

The average discharge capacity fades (both $\mathrm{C}_{1} / 1$ and $\mathrm{C}_{1} / 25$ ), and power fade for the Baseline accelerated-life cells at 60, 80, and 100\% SOC are summarized in Tables 8,9 , and 10, respectively. The fades generally increase with increasing temperature and SOC. For the cell groups that reached 50\% power fade, the $\mathrm{C}_{1} / 1$ and $\mathrm{C}_{1} / 25$ capacity fades are somewhat similar to the calendar- and cycle-life Baseline cells.

Table 7. End-of-life summary for the calendar- and cycle-life cells.

\begin{tabular}{cccccccc}
\hline \hline \multirow{2}{*}{ Test Group } & Temperature & $\begin{array}{c}\text { Weeks on } \\
\text { Test }\end{array}$ & $\begin{array}{c}\mathrm{C}_{1} / 1 \\
\text { fade }\end{array}$ & $\begin{array}{c}\mathrm{C}_{1} / 25 \\
\text { fade }\end{array}$ & $\begin{array}{c}\text { Power } \\
\text { Fade }\end{array}$ & $\begin{array}{c}\text { EIS } \\
\text { Growth }\end{array}$ \\
\hline \hline \multirow{3}{*}{ Baseline } & \multirow{3}{*}{ Cycle-Life } & $25^{\circ} \mathrm{C}$ & 140 & $32.0 \%$ & $16.7 \%$ & $50.2 \%{ }^{\mathrm{a}}$ & $126.1 \%$ \\
& & $45^{\circ} \mathrm{C}$ & 68 & $30.1 \%$ & $20.5 \%$ & $51.0 \%{ }^{\mathrm{a}}$ & $129.0 \%$ \\
\cline { 3 - 8 } & \multirow{3}{*}{ Calendar-Life } & $45^{\circ} \mathrm{C}$ & $88^{\mathrm{b}}$ & $34.4 \%$ & $23.6 \%$ & $50.9 \%$ & $125.8 \%$ \\
& $55^{\circ} \mathrm{C}$ & 40 & $18.5 \%$ & $24.8 \%$ & $46.1 \%$ & $78.2 \%$ \\
\hline \multirow{2}{*}{ Variant C } & Cycle-Life & $45^{\circ} \mathrm{C}$ & 124 & $16.9 \%$ & $16.9 \%$ & $49.6 \%$ & $138.5 \%$ \\
& Calendar-Life & $45^{\circ} \mathrm{C}$ & $148^{\mathrm{b}}$ & $15.2 \%$ & $19.9 \%$ & $44.3 \%$ & $136.6 \%{ }^{\mathrm{c}}$ \\
\hline \hline
\end{tabular}

a. The average power fade is temperature compensated

b. Only one cell was aged to $50 \%$ power fade

c. Measurement at 136 weeks (no 148 week measurement available due to manpower limitations)

Table 8. End-of-life summary for the accelerated-life cells at $60 \%$ SOC.

\begin{tabular}{|c|c|c|c|c|c|c|}
\hline \multicolumn{2}{|c|}{ Test Group } & Temperature & $\begin{array}{c}\text { Weeks on } \\
\text { Test }\end{array}$ & $\begin{array}{l}\mathrm{C}_{1} / 1 \\
\text { fade }\end{array}$ & $\begin{array}{l}\mathrm{C}_{1} / 25 \\
\text { fade }\end{array}$ & $\begin{array}{c}\text { Power } \\
\text { Fade }\end{array}$ \\
\hline \multirow{4}{*}{ Baseline } & \multirow{4}{*}{$\begin{array}{l}\text { Accelerated- } \\
\text { Life }\end{array}$} & $25^{\circ} \mathrm{C}$ & 48 & $11.8 \%$ & $7.7 \%$ & $30.2 \%$ \\
\hline & & $35^{\circ} \mathrm{C}$ & 52 & $17.3 \%$ & $14.4 \%$ & $39.3 \%$ \\
\hline & & $45^{\circ} \mathrm{C}$ & 44 & $24.2 \%$ & $15.6 \%$ & $47.5 \%$ \\
\hline & & $55^{\circ} \mathrm{C}$ & 32 & $29.8 \%$ & $23.3 \%$ & $53.4 \%$ \\
\hline
\end{tabular}


Table 9. End-of-life summary for the accelerated-life cells at $80 \%$ SOC.

\begin{tabular}{|c|c|c|c|c|c|c|}
\hline \multicolumn{2}{|c|}{ Test Group } & Temperature & $\begin{array}{c}\text { Weeks on } \\
\text { Test }\end{array}$ & $\begin{array}{l}\mathrm{C}_{1} / 1 \\
\text { fade }\end{array}$ & $\begin{array}{l}\mathrm{C}_{1} / 25 \\
\text { fade }\end{array}$ & $\begin{array}{l}\text { Power } \\
\text { Fade }\end{array}$ \\
\hline \multirow{4}{*}{ Baseline } & \multirow{4}{*}{$\begin{array}{c}\text { Accelerated- } \\
\text { Life }\end{array}$} & $25^{\circ} \mathrm{C}$ & 48 & $17.7 \%$ & $11.7 \%$ & $36.5 \%$ \\
\hline & & $35^{\circ} \mathrm{C}$ & 52 & $24.1 \%$ & $16.9 \%$ & $46.0 \%$ \\
\hline & & $45^{\circ} \mathrm{C}$ & 36 & $30.2 \%$ & $19.3 \%$ & $48.2 \%$ \\
\hline & & $55^{\circ} \mathrm{C}$ & 20 & $31.9 \%$ & $21.9 \%$ & $54.9 \%$ \\
\hline
\end{tabular}

Table 10. End-of-life summary for the accelerated-life cells at $100 \%$ SOC.

\begin{tabular}{|c|c|c|c|c|c|c|}
\hline \multicolumn{2}{|c|}{ Test Group } & \multirow{2}{*}{$\begin{array}{c}\text { Temperature } \\
25^{\circ} \mathrm{C}\end{array}$} & \multirow{2}{*}{$\begin{array}{c}\text { Weeks on } \\
\text { Test } \\
48\end{array}$} & \multirow{2}{*}{$\begin{array}{c}\mathrm{C}_{1} / 1 \\
\text { fade } \\
24.1 \%\end{array}$} & \multirow{2}{*}{$\begin{array}{l}\mathrm{C}_{1} / 25 \\
\text { fade } \\
12.3 \%\end{array}$} & \multirow{2}{*}{$\begin{array}{c}\text { Power } \\
\text { Fade } \\
48.3 \%\end{array}$} \\
\hline \multirow{4}{*}{ Baseline } & \multirow{4}{*}{$\begin{array}{l}\text { Accelerated- } \\
\text { Life }\end{array}$} & & & & & \\
\hline & & $35^{\circ} \mathrm{C}$ & 36 & $25.5 \%$ & $15.0 \%$ & $49.9 \%$ \\
\hline & & $45^{\circ} \mathrm{C}$ & 36 & $35.9 \%$ & $21.2 \%$ & $59.8 \%$ \\
\hline & & $55^{\circ} \mathrm{C}$ & 20 & $28.5 \%$ & $19.9 \%$ & $58.0 \%$ \\
\hline
\end{tabular}

\subsection{Gen 2 GDR Cell Testing}

As mentioned in Section 1.2.1, six GDR cells (3 with the VEC electrolyte additive) were calendarlife aged for a direct comparison between the Baseline and Variant $\mathrm{C}$ cells. However, these cells were left in a glove box, unsealed, for about eight to nine months prior to testing, and, consequently, the results from this aging are inconclusive. The GDR cells were rated at $0.9 \mathrm{Ah}$ and the active electrode area was $810.7 \mathrm{~cm}^{2}$. They were aged for 40 weeks at $45^{\circ} \mathrm{C}$ and $60 \%$ SOC (see Table 3 ) in accordance with the same test procedures defined for the Baseline and Variant $\mathrm{C}$ cells. Thus, the experiment was intended to determine the effect of an alternative graphite on the negative electrode, and the new graphite plus VEC electrolyte additive on the aging characteristics of the Gen 2 cell chemistry.

Figure 86 shows the average $\mathrm{C}_{1} / 1$ discharge capacity of the GDR-only and GDR+VEC cells compared to the Baseline calendar-life cells. The initial capacities are lower due to the lower rating, but they do appear to retain their capacity better than the Baseline cell degradation. Figure 87 shows the corresponding $\mathrm{C}_{1} / 25$ results. Here, the trends for the GDR cells are very similar to the Baseline cells, including the initial capacities. The GDR-only cells appear to taper off a little compared to the GDR+VEC cells. More data are required to determine if the GDR cells would continue to mimic the Baseline $\mathrm{C}_{1} / 25$ results, and show steady fade rate without a mechanistic change. 


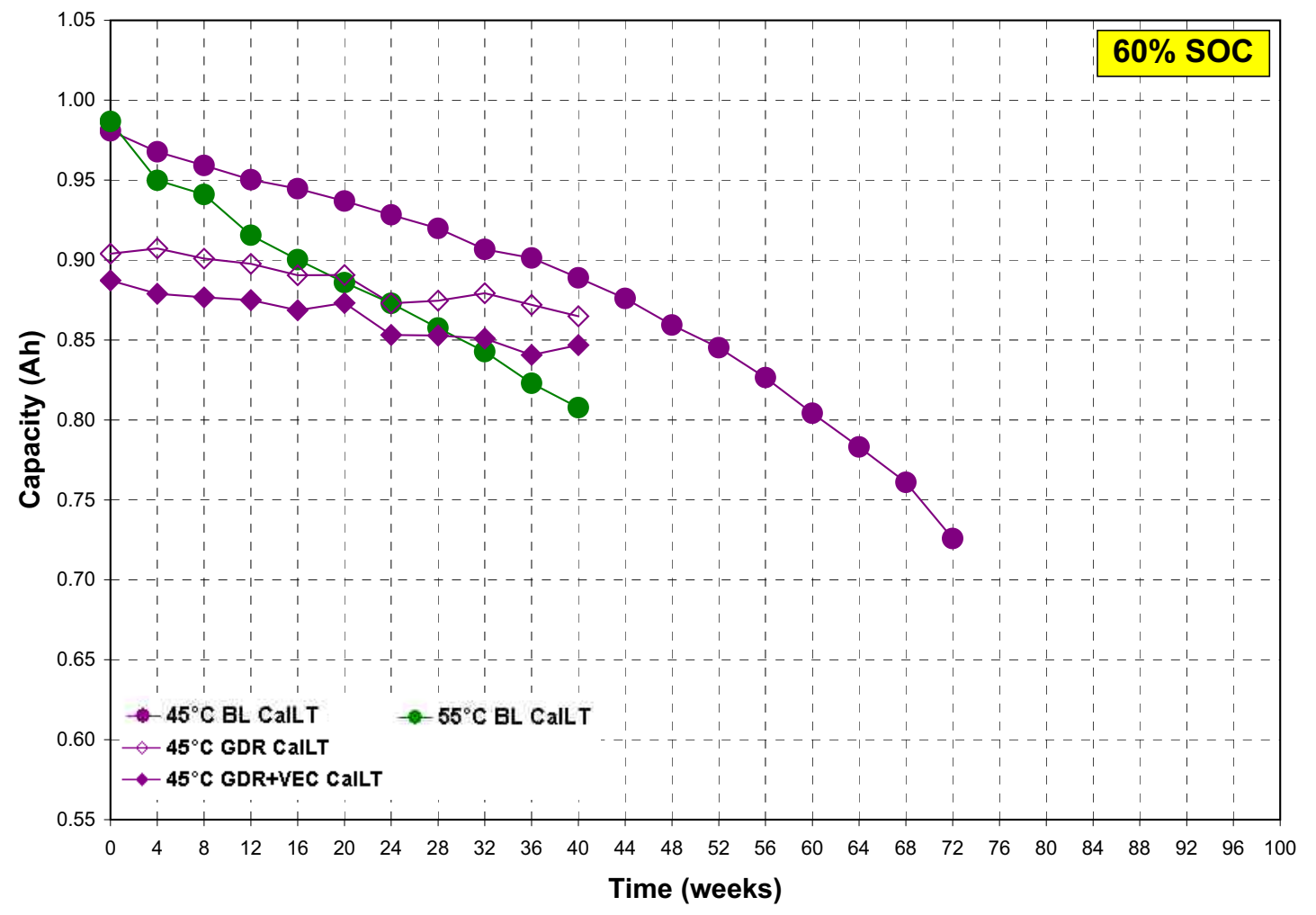

Figure 86 . Average $\mathrm{C}_{1} / 1$ capacity versus time for the GDR-only and GDR+VEC cells.

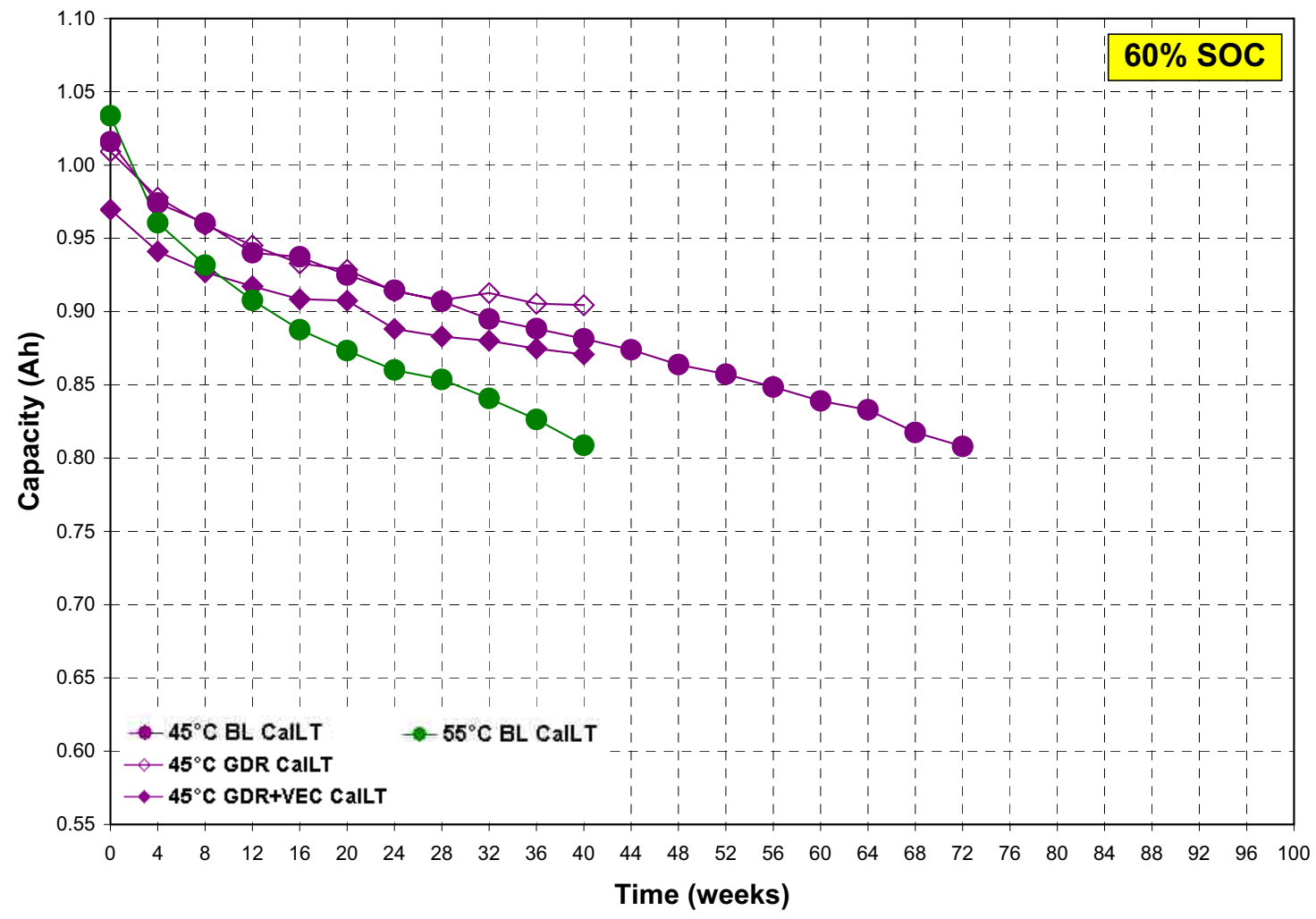

Figure 87 . Average $\mathrm{C}_{1} / 25$ capacity versus time for the GDR-only, GDR+VEC and Baseline cells. 
Figure 88 shows the average discharge ASI values for the GDR-only and GDR+VEC cells compared to the Baseline calendar-life cells. The Gen 2 Baseline and Variant C ASI data were reflected in the $\mathrm{C}_{1} / 1$ data (see Figures 81 and 82), but the GDR cells have a very different ASI behavior. This could be attributable to a large diffusional component to the GDR cells that shows up at higher C-rates (i.e., 5C) as a result of manufacturing. The average ASIs of the GDR-only cells increase, but the GDR+VEC cells seems to decrease after an initially rapid growth, then appear to somewhat level off. More data are needed to determine the actual trend and how long the ASI would have remained constant. Both GDR groups show significantly higher ASI growth rates than the corresponding $45^{\circ} \mathrm{C}$ Baseline calendar-life cells.

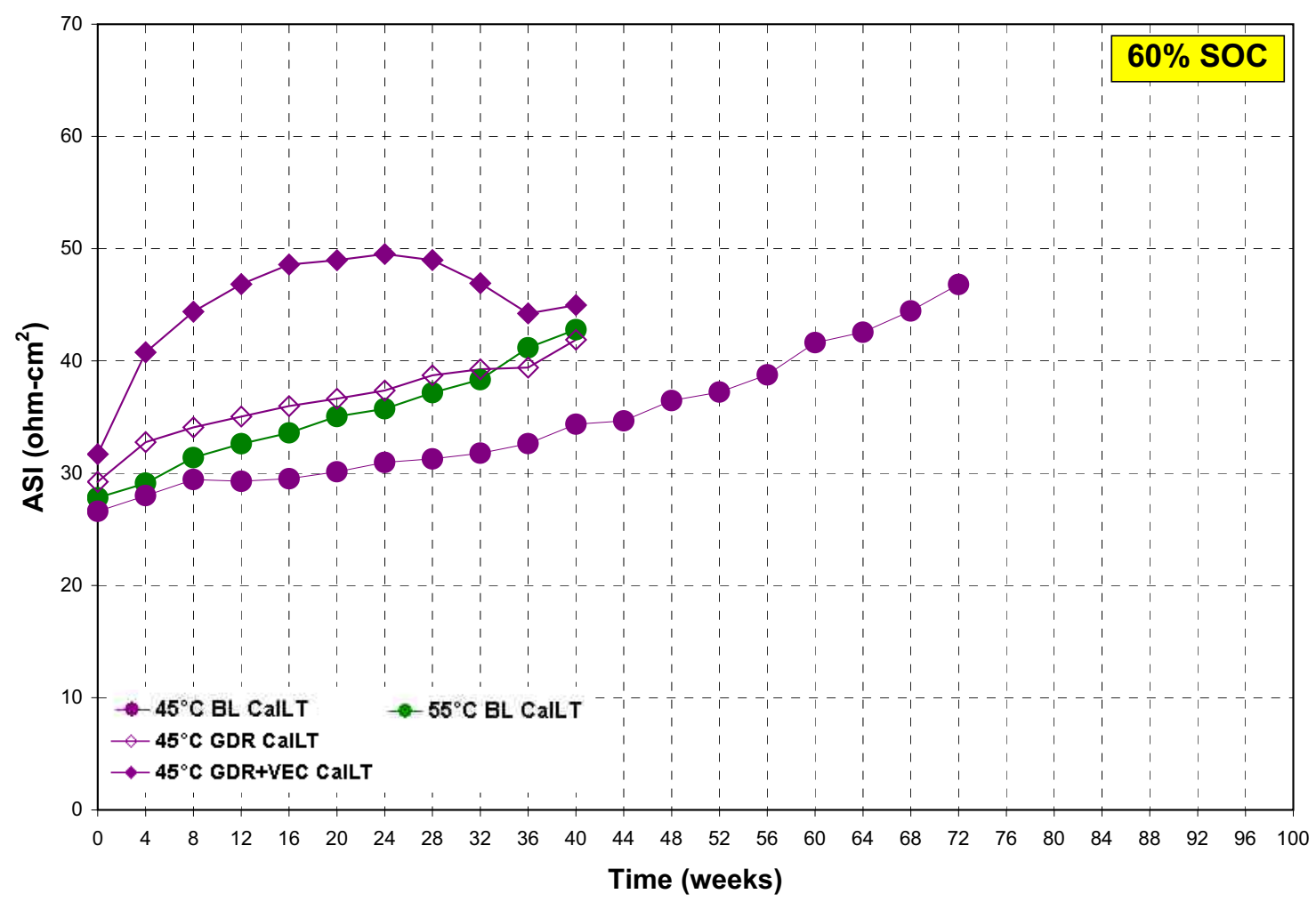

Figure 88. Average discharge ASI versus time for the GDR-only, GDR+VEC and Baseline cells.

Figure 89 shows the average available power at the 300-Wh for the GDR-only and GDR+VEC cells compared to the Baseline calendar-life cells. The BSF for the GDR-only and GDR+VEC cells was 591 and 654, respectively (compared to 553 for the Baseline cells). The fade rates for both GDR groups are higher than the Baseline cells. Although the GDR+VEC cells show a higher initial fade rate than the GDR-only cells, they appear to reach a steady-state value while the GDR-only cells continue to increase.

Figures 90 and 91 show representative Nyquist plots for the GDR-only and GDR+VEC cells, respectively. Both show that interfacial impedance is increasing with time, but the change per RPT generally slows down later in life. Both cells show significantly greater impedance increase than the corresponding Baseline cell calendar-life tested at $45^{\circ} \mathrm{C}$ (Figure 58), and the GDR+VEC cell shows greater impedance than the GDR-only cell. It should be noted that the EIS test was stopped after 28 weeks of aging. 


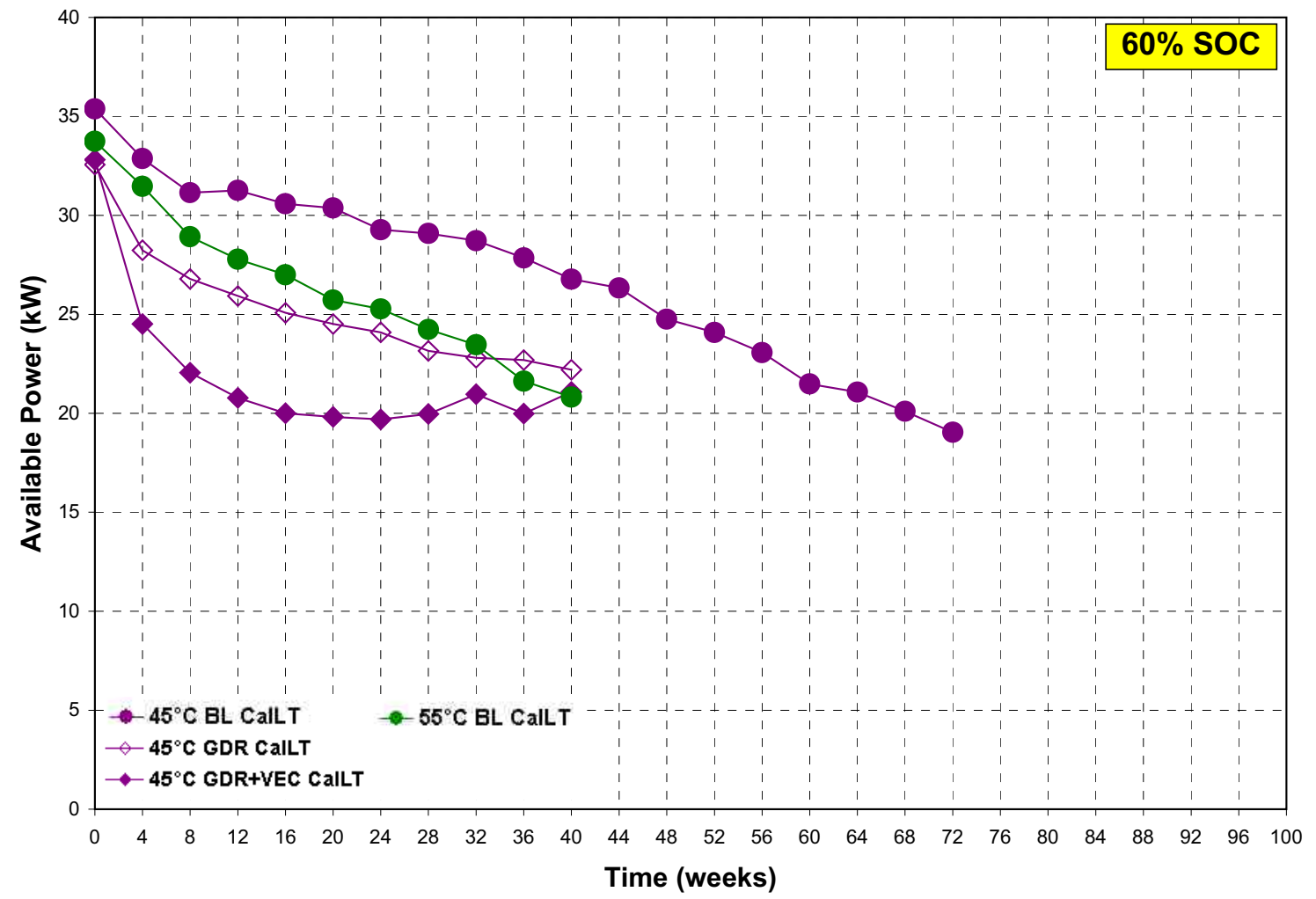

Figure 89. Average BSF-scaled power versus time for the GDR-only, GDR+VEC and Baseline cells.

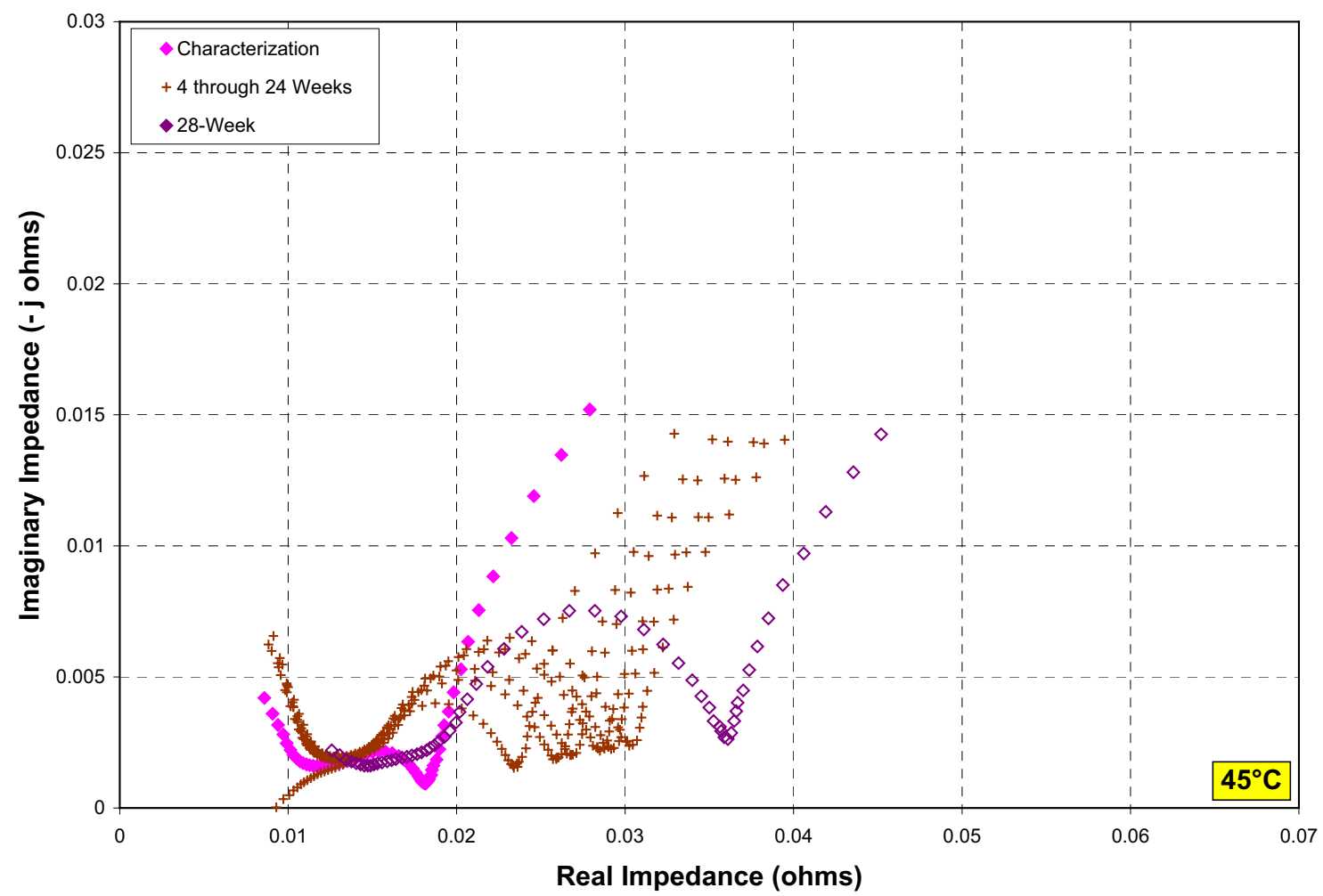

Figure $90.60 \%$ SOC EIS for a representative GDR-only cell. 


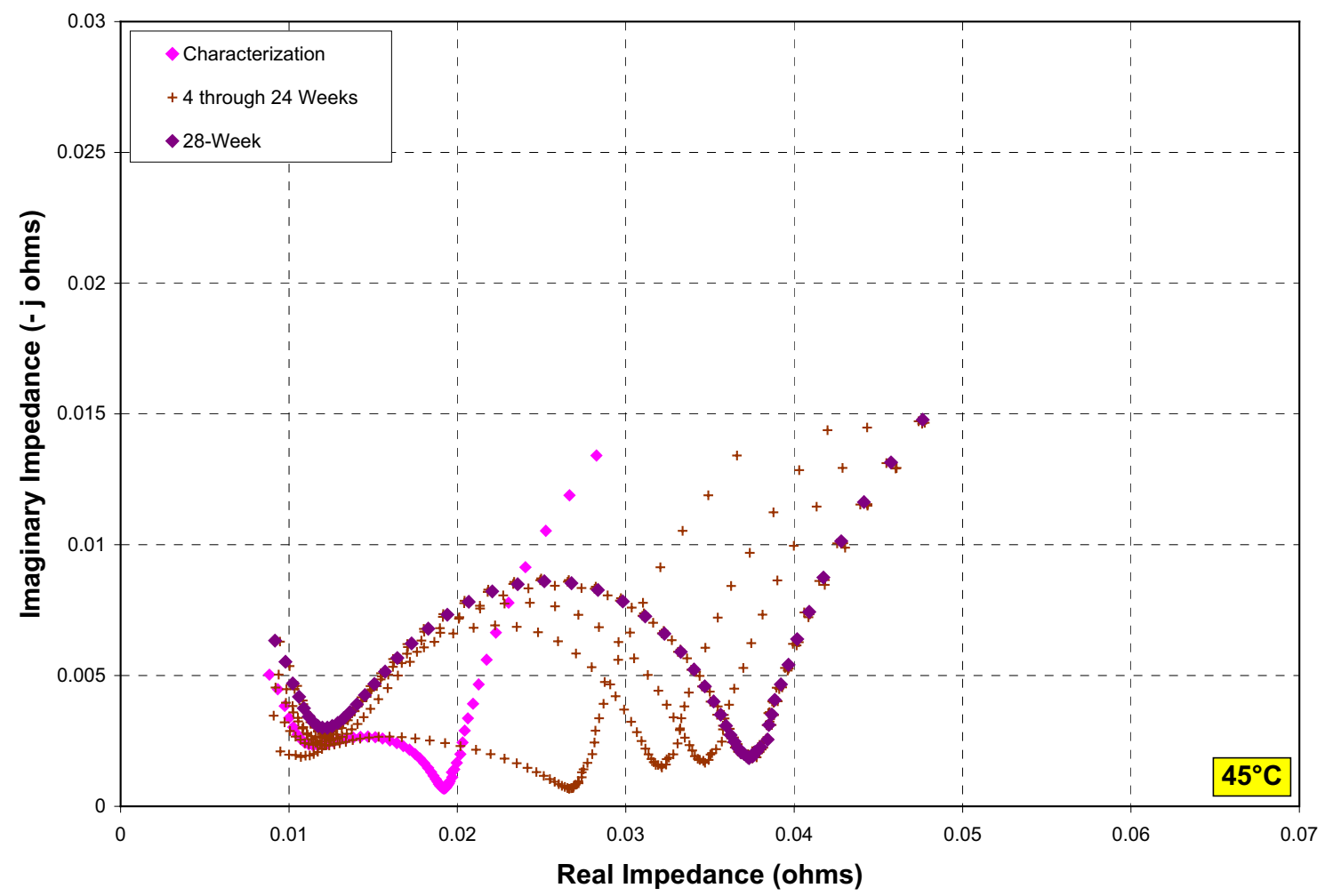

Figure $91.60 \%$ SOC EIS for a representative GDR+VEC cell.

\section{CONCLUSIONS}

Concurrent testing and analysis of the ATD Gen 2 Baseline and Variant C cells has been completed. The 18650-size cells, manufactured by Quallion consist of a baseline chemistry and variant chemistry (Variant C). These cells were distributed over a matrix of three life-testing protocols (calendar-, cycle-, and accelerated-life), four temperatures $\left(25,35,45\right.$, and $\left.55^{\circ} \mathrm{C}\right)$, and three SOCs $(60,80$, and $100 \%$ SOC). Calendar- and cycle-life testing is only performed at $60 \%$ SOC. All testing was performed in accordance with the PNGV Battery Test Manual, Revision 3, and the ATD Gen 2 test plans. Reference performance tests were conducted in four-week increments during life testing. From the RPTs, the $\mathrm{C}_{1} / 1$ and $\mathrm{C}_{1} / 25$ discharge capacities, area-specific impedances, available powers at $300 \mathrm{Wh}$, and impedance spectroscopy measurements were used to assess cell degradation over life. A second variant chemistry (GDR cells) was also investigated, but the cells were unsealed in a glove box for almost a year prior to testing. Consequently, the data showed significantly higher degradation rates than the Baseline cells, and results were inconclusive.

The Baseline cell degradation generally increased with increasing test temperature and SOC. The rate of degradation was also usually slowest for the calendar-life cells, in the middle for the cycle-life cells, and fastest for the accelerated-life cells at a given temperature and SOC. The data generally showed two different degradation rates during life testing. The degradation rate was initially slow, but then started to increase more rapidly later in life. The switch from the slower to faster rate usually occurred earlier in life with increasing test temperature and SOC. The $45^{\circ} \mathrm{C}$ Variant $\mathrm{C}$ cells showed very different behavior, with an initially large degradation, but slowing down significantly later in life. At end-of-test, the Variant $\mathrm{C}$ behavior more closely resembled the $25^{\circ} \mathrm{C}$ Baseline cells results. 
Since the $C_{1} / 25$ test was at very low currents, it indicated the amount of accessible capacity, and was useful for investigating the relationship between potential and capacity under pseudo-equilibrium conditions using differential analysis. The differential capacity curves showed that the loss in available capacity occurs predominately at three different peak locations. The two higher SOC peaks tend to shift towards each other as a function of test time, which may be attributable to the alteration of the crystalline lattice in the electrodes. The differential voltage analysis was used to collect thermodynamic and some kinetic information about individual electrodes compared to half-cell data. It was determined that side reactions are the major source of capacity loss, and the reactions occur primarily on the negative electrode.

Various models have been developed based on the Gen 2 data, each showing two different mechanisms operating on the cell. The empirical model was fit to the accelerated-life cell data, and showed an initially rapid degradation, followed by a $t^{3 / 2}$ kinetics. The first mechanism is very rapid (nearly complete with the first four weeks of aging) and may be attributable to an incomplete formation process. The two-step model provides a simple mechanistic explanation for the two different degradation rates observed during life. The initial degradation mechanism (with a square root of time dependence) may be attributable to a thermal diffusion process for the formation of an SEI layer. The second mechanism (with a linear time dependence) could be attributable to the steady-state formation of the SEI layer. The double sigmoid model can be linked to physical parameters within the cell, most notably the effective capacity or the net active surface of each electrode. This model shows very good predictions for cell failure out to $50 \%$ power fade. 


\section{REFERENCES}

1. Tien Q. Duong et al., "Energy Storage Research \& Development: FY 2004 Annual Progress Report," U.S. DOE FCVT, January 2005.

2. J. P. Christophersen, C. G. Motloch, I. D. Bloom, V. S. Battaglia, E. P. Roth, and T. Q. Duong, "Advanced Technology Development For Lithium-Ion Batteries: Gen 2 Performance Evaluation Interim Report," INEEL/EXT-03-00095, February 2003.

3. Gary Henriksen, "ATD Program Background and Introduction," ATD Merit Review presentation, Argonne, IL, June 2004.

4. PNGV Battery Test Manual, Revision 3, DOE/ID-10597, February 2001.

5. PNGV Test Plan for Advanced Technology Development Gen 2 Lithium-Ion Cells, EVH-TP-121, Revision 6, October 2001.

6. SNL Test Plan for Advanced Technology Development Gen 2 Lithium-Ion Cells, SNL-ATD G2-TP, Revision 3, November 2002.

7. Advanced Technology Development Program For Lithium-Ion Batteries: Battery Technology Life Verification Test Manual, INEEL/EXT-04-01986, February 2005.

8. J. P. Christophersen, C. D. Ho, G. L. Henriksen, and D. Howell, "Advanced Technology Development For Lithium-Ion Batteries: Gen 2 GDR Performance Evaluation Report,” INL/EXT06-11488, July 2006.

9. Handbook of Batteries. David L. Linden, ed., and Thomas B. Reddy, ed., 3rd ed., New York: McGraw Hill, 2002.

10. I. Bloom, A. N. Jansen, D. P. Abraham, J. Knuth, S. A. Jones, V. S. Battaglia, and G. L. Henriksen, "Differential voltage analyses of high-power, lithium-ion cells: 1. Technique and application," $J$. Power Sources, 139, 295-303 (2005).

11. I. Bloom, J. Christophersen and K. Gering, "Differential voltage analyses of high-power, lithiumion cells: 2. Applications,” J. Power Sources, 139, 304-313 (2005).

12. I. Bloom, J. P. Christophersen, D. P. Abraham and K. L. Gering, "Differential voltage analyses of high-power lithium-ion cells: 3. Another anode phenomenon," J. Power Sources, 157, 537-542 (2006).

13. R. Fong, U. von Sacken, and J. R. Dahn, "Studies Of Lithium Interclation Into Carbons Using NonAqueous Electrochemical Cells,” J. Electrochem. Soc., 137, 2009-2013 (1990).

14. J. O. Besenhard, M. Winter, J. Yang, and W. Biberacher, "Filming mechanism of lithium-carbon anodes in organic and inorganic electrolytes," J. Power Sources, 54, 228-231 (1995).

15. M. Inaba, Z. Siroma, Y. Kawatate, A. Funabiki, and Z. Ogumi, "Electrochemical scanning tunneling microscopy analysis of the surface reactions on graphite basal plane in ethylene carbonate-based solvents and propylene carbonate," J. Power Sources, $\underline{68}$, 221-226 (1997). 
16. M. Inaba, Z. Siroma, A. Funabiki, Z. Ogumi, T. Abe, Y. Mizutana, and M. Asano, "Electrochemical Scanning Tunneling Microscopy Observation of Highly Oriented Pyrolytic Graphite Surface Reactions in an Ethylene Carbonate-Based Electrolyte Solution," Langmuir, 12, 1535-1540 (1996).

17. M. Winter, J. O. Besenhard, M. E. Spahr, and P. Novák, "Insertion Electrode Materials for Rechargeable Lithium Batteries,” Adv. Mater., 10, 725 (1998).

18. J. O. Besenhard, "The electrochemical preparation and properties of ionic alkali metal-and $\mathrm{NR}_{4}$ graphite intercalation compounds in organic electrolytes," Carbon, 14, 111-115 (1976).

19. E. Peled, D. Bar Tow, A. Merson, A. Gladkich, L. Burstein, and D. Golodnitsky, "Composition, depth profiles and lateral distribution of materials in the SEI built on HOPG-TOF SIMS and XPS studies," J. Power Sources, 97-98, 52-57 (2001).

20. R. Yazami and Y. F. Reynier, "Mechanism of self-discharge in graphite-lithium anode," Electrochimica Acta, 47, 1217-1223 (2002).

21. D. Zhang, B. S. Haran, A. Durairajan, R. E. White, Y. Podrazhansky, and B. N. Popov, "Studies on capacity fade of lithium-ion cells," J. Power Sources, 91,122 (2000).

22. J. P. Christophersen, C. D. Ho, C. G. Motloch, D. Howell, and H. Hess, "Effects of Reference Performance Testing during Aging Using Commercial Lithium-Ion Cells," J. Electrochem Soc., 153 A1406-A1416 (2006).

23. J. P. Christophersen, D. F. Glenn, C. G. Motloch, R. B. Wright, C. D. Ho, and V. S. Battaglia, "Electrochemical Impedance Spectroscopy Testing on the Advanced Technology Development Program Lithium-Ion Cells," IEEE Trans. Veh. Technol., 56, 1851-1855 (2002).

24. E. V. Thomas, H. L. Case, D. H. Doughty, R. G. Jungst, G. Nagasubramanian, and E. P. Roth, “Accelerated Power Degradation of Li-Ion Cells," J. Power Sources, 124, 254-260 (2003).

25. E. V. Thomas, E. P. Roth, D. H. Doughty, and R. G. Jungst, "Experimental Design and Analysis for Accelerated Degradation Tests with Li-Ion Cells," SAND2003-2897, 2003.

26. Kofstad, P., High-Temperature Oxidation of Metals, John Wiley \& Sons, New York, 1966.

27. D. W. Aylmore, S. J. Gregg and W. B. Jepson, "Oxidation of Niobium in the Temperature Range of $350^{\circ}-750^{\circ} \mathrm{C}$, , J. Electrochem. Soc. 107495 (1960).

28. I. Bloom, S. A. Jones, V. S. Battaglia, G. L. Henriksen, J. P. Christophersen, R. B. Wright, C. D. Ho, J. R. Belt, C. G. Motloch, "Effect of cathode composition on capacity fade, impedance rise and power fade in high-power, lithium-ion cells," J. Power Sources, 124, 538-550 (2003).

29. J. P. Christophersen, C. G. Motloch, C. D. Ho, J. L. Morrison, R. C. Fenton, V. S. Battaglia, and T. Q. Duong, "Lumped Parameter Modeling as a Predictive Tool for a Battery Status Monitor," IEEE Trans. Veh. Technol., 58, 3257-3261 (2004). 



\section{Appendix A:}

Additional Gen 2 Studies and Supplemental Data 


\section{A. ADDITIONAL GEN 2 STUDIES AND SUPPLEMENTAL DATA}

\section{A.1 Lumped Parameter Modeling}

The lumped parameter model (LPM) is a simplified linear model that can be used to predict the voltage response of a battery under pulse conditions (e.g., L-HPPC or cycle-life pulsing). The LPM is based on the circuit diagram shown in Figure A.1 and defined in Reference 4. The parameters (i.e., $R_{0}$, $\mathrm{R}_{\mathrm{p}}, \mathrm{C}, \mathrm{OCV}, 1 / \mathrm{OCV}$, and $\tau=\mathrm{R}_{\mathrm{p}} \cdot \mathrm{C}$ ) are obtained through multivariable linear regression, where the load voltage $\left(\mathrm{V}_{\mathrm{L}}\right)$ is the dependent variable; the load current $\left(\mathrm{I}_{\mathrm{L}}\right)$, the integral of the load current $\left[\Sigma\left(\mathrm{I}_{\mathrm{L}} \Delta \mathrm{t}\right)\right]$, and the polarization current $\left(\mathrm{I}_{\mathrm{p}}\right)$ are the independent variables. The load voltage and current $\left(\mathrm{V}_{\mathrm{L}}\right.$ and $\left.\mathrm{I}_{\mathrm{L}}\right)$ are the measured voltage and current response of the battery during a pulse. The iterative process by which the resistances, OCVs, and capacitances are determined is explained in Reference 4, and it essentially consists of adjusting the time constant $(\tau)$ until the coefficient of determination $\left(\mathrm{r}^{2}\right)$ value is maximized. The ohmic resistance $\left(R_{o}\right)$ is the result of electrical conductivity, and the polarization resistance $\left(R_{p}\right)$ is controlled by mass transfer. The measured and estimated voltage responses during a L-HPPC and cyclelife pulse for a representative Baseline cell at 40\% DOD and 60\% SOC, respectively, are shown in Figures A.2 and A.3. These results show excellent fits, both with coefficients of determination $\left(\mathrm{r}^{2}\right)$ values of 0.9996 . Because the LPM can be applied to any type of pulse profile, and is sensitive to changes in temperature, pulse amplitudes, and pulse durations, it has also been investigated as possible tool for predictive health estimations during in-vehicle use (Reference 29).

Figures A.4 and A.5 show the average increase in both ohmic and polarization resistances (as determined from the L-HPPC test at 40\% DOD) as a function of test time for the cycle-life Baseline cells aged at 25 and $45^{\circ} \mathrm{C}$, respectively. As seen with the discharge ASI data at $60 \%$ SOC (Figure 40), the initial ohmic resistances are similar, but the growth rate of the $45^{\circ} \mathrm{C}$ cells increases more rapidly. The polarization resistance increase is significantly slower than the ohmic resistance growth, and is apparently independent of temperature. Figure A.6 shows the average LPM resistance increase for the Variant C cycle-life cells aged at $45^{\circ} \mathrm{C}$. As with the ASI growth (Figure 41), the initial ohmic resistance is higher for the Variant $\mathrm{C}$ cells, but the growth rate slows down later in life, and looks more similar to the $25^{\circ} \mathrm{C}$ Baseline cell growth rate. The Variant $\mathrm{C}$ polarization resistance is slightly smaller than the Baseline cells, but the growth rates are similar.

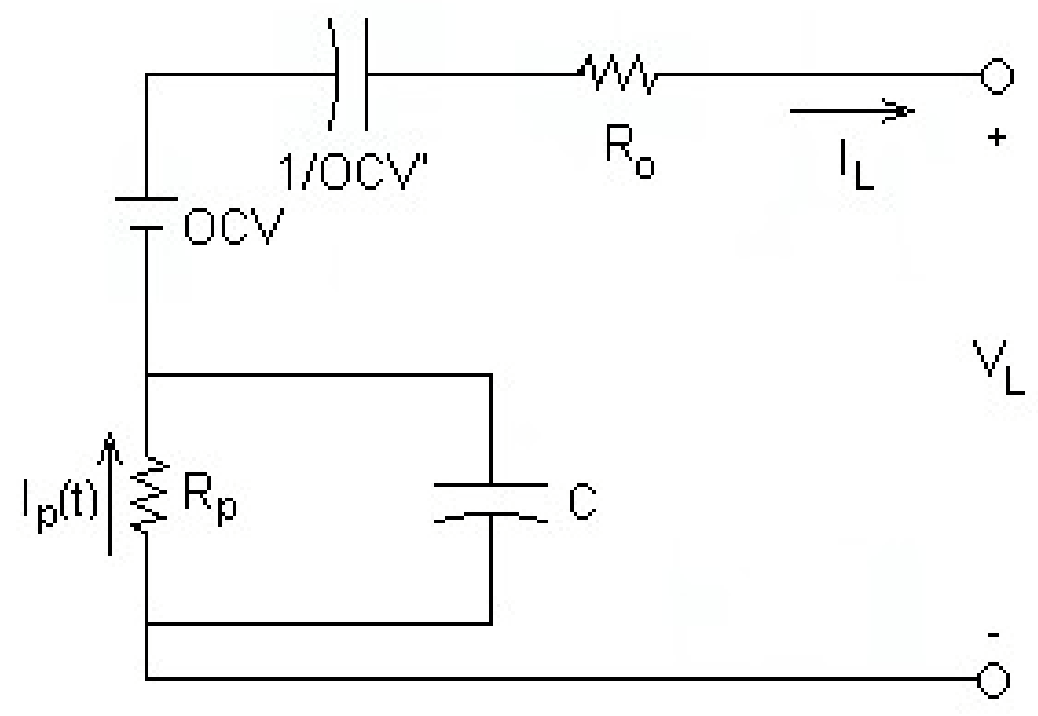

Figure A.1. Lumped parameter model circuit diagram. 


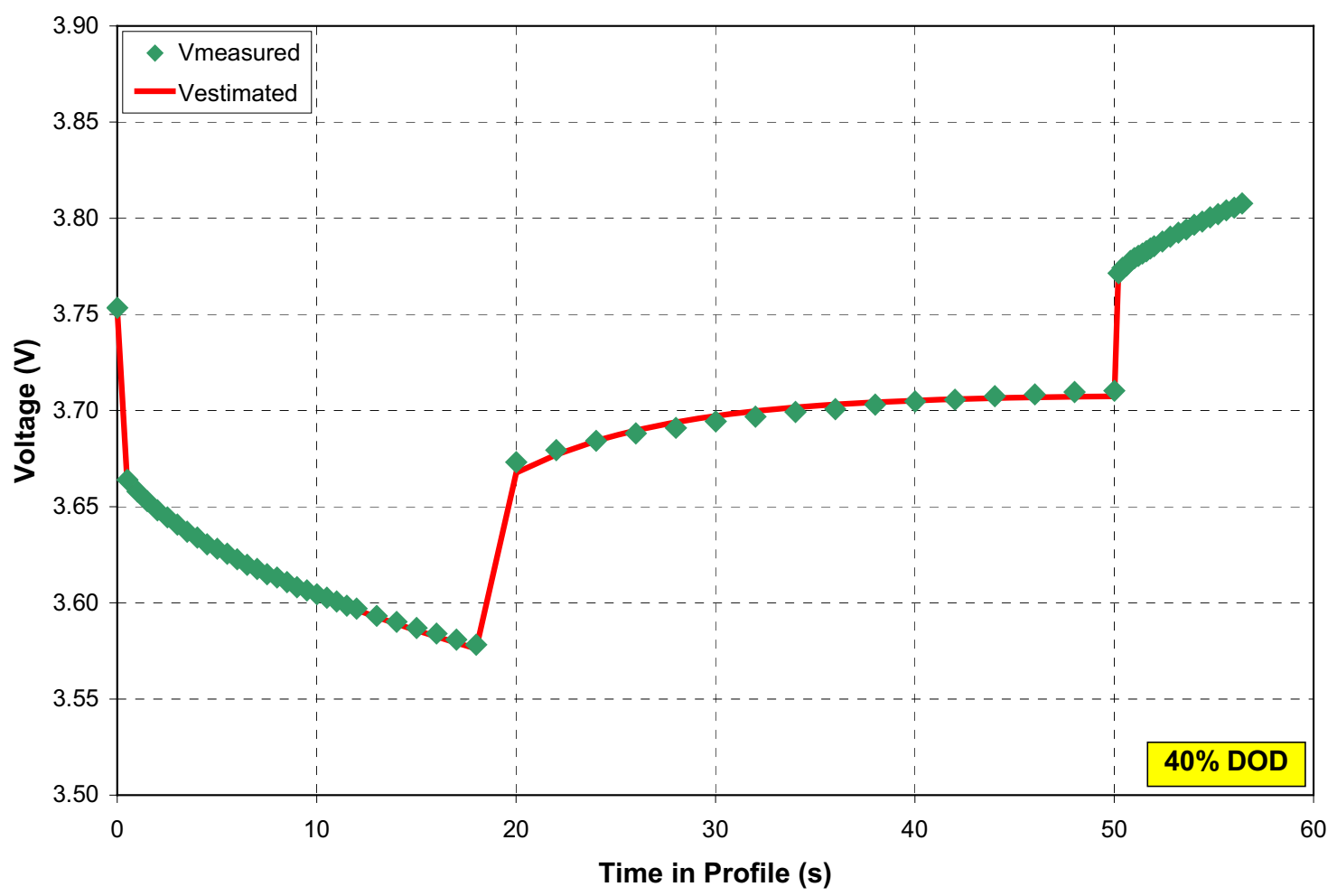

Figure A.2. LPM voltage response estimation for a L-HPPC pulse.

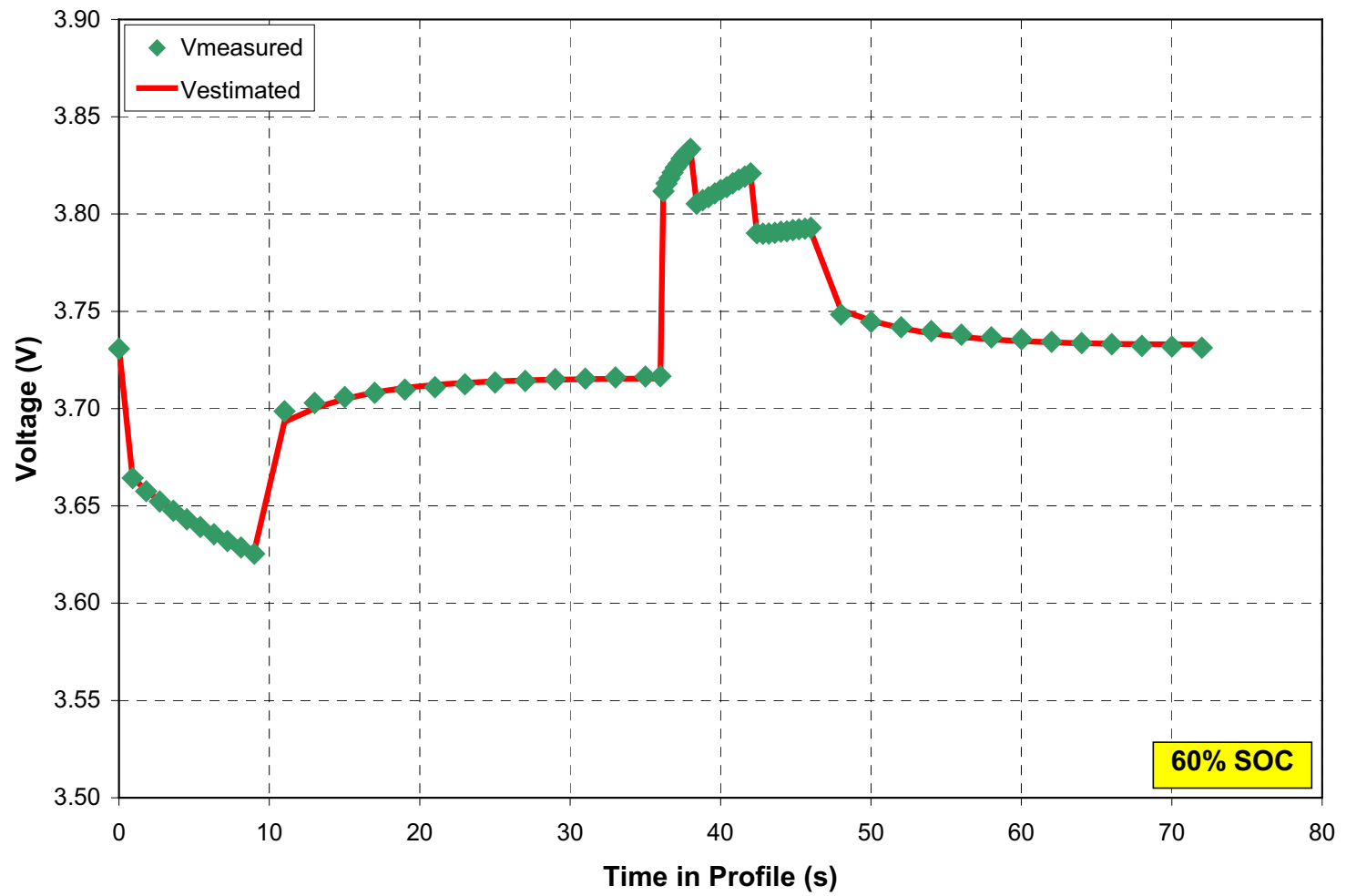

Figure A.3. LPM voltage response estimation for a cycle-life pulse. 


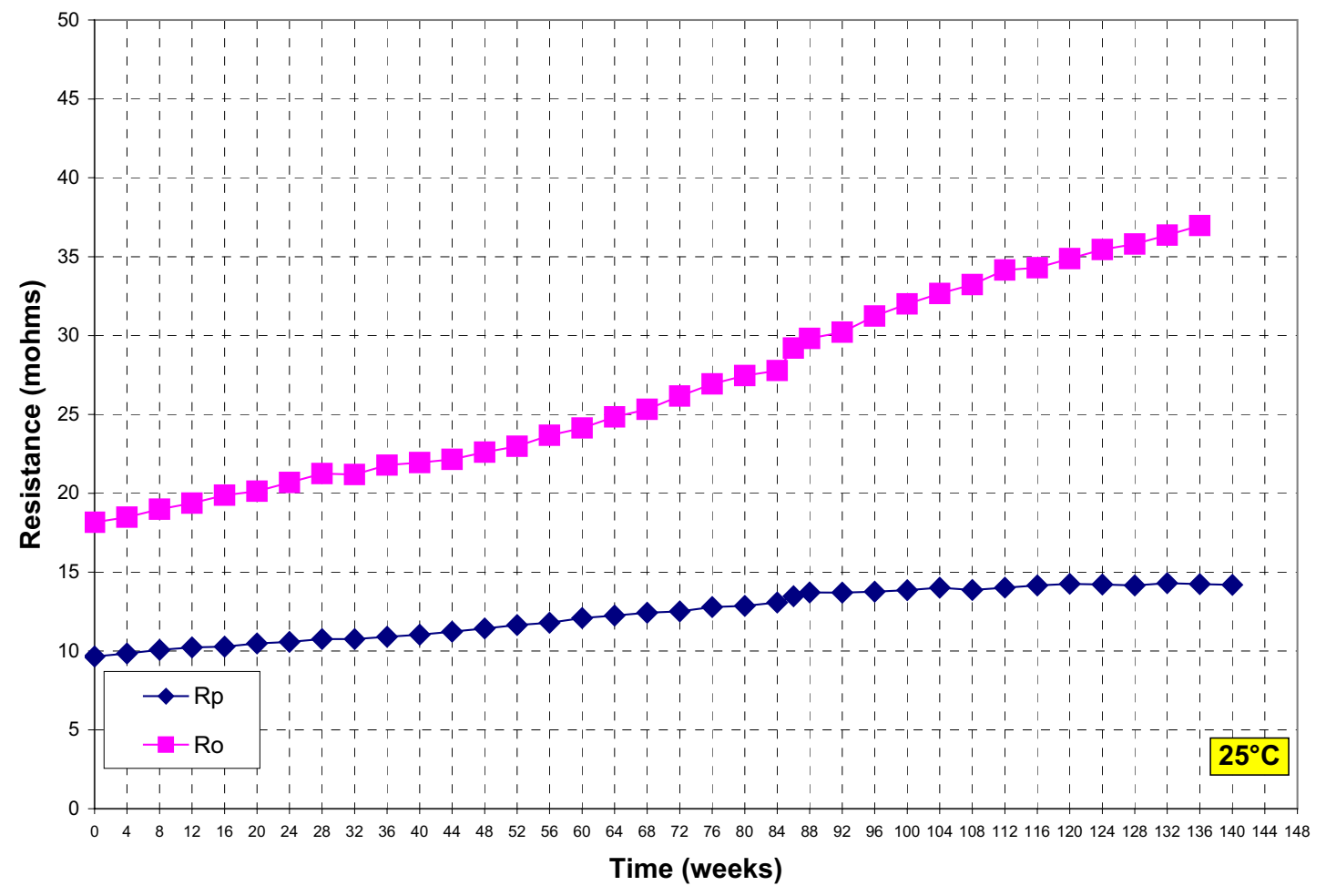

Figure A.4. Average ohmic and polarization resistance for the $25^{\circ} \mathrm{C}$ Baseline cycle-life cells.

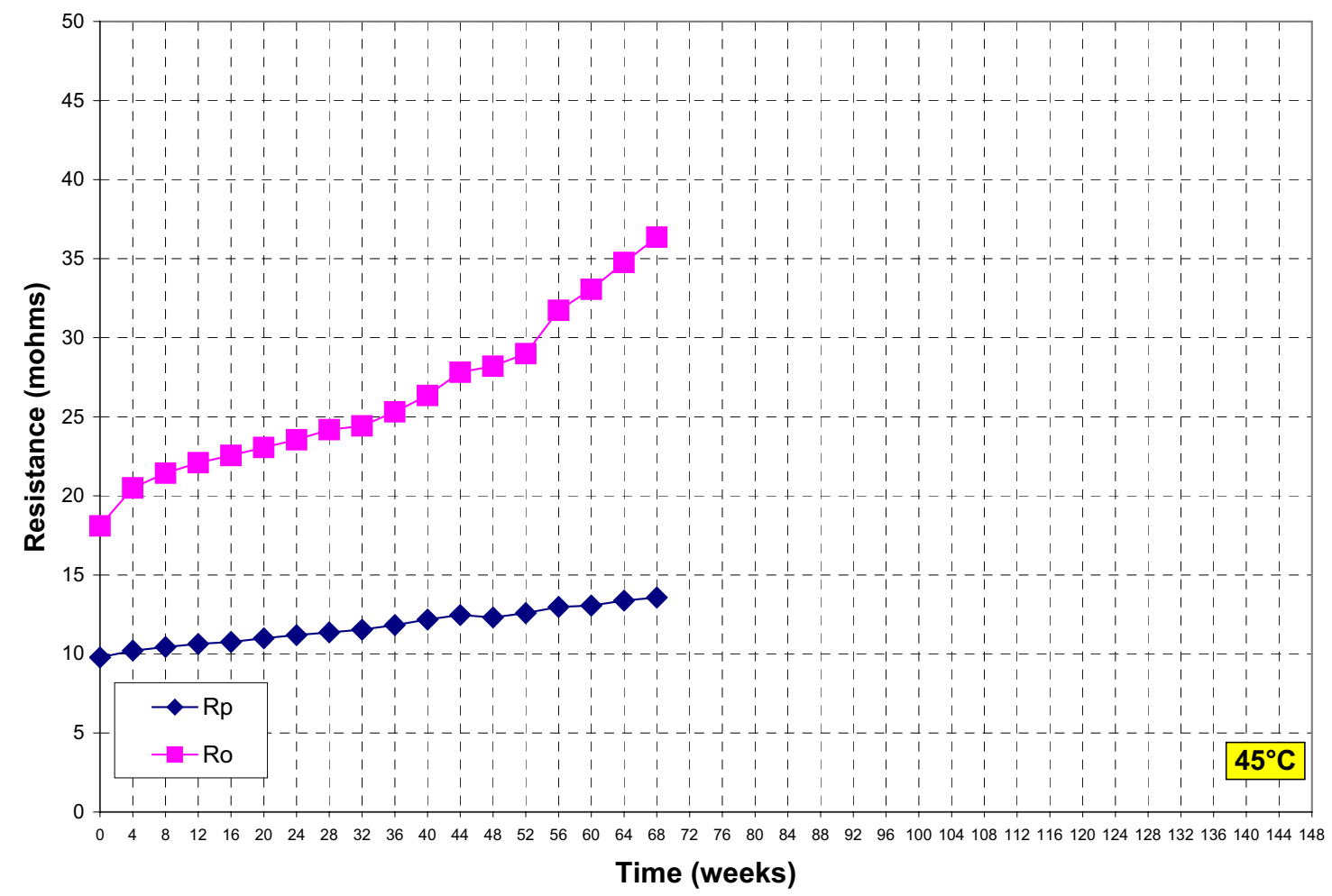

Figure A.5. Average ohmic and polarization resistance for the $45^{\circ} \mathrm{C}$ Baseline cycle-life cells. 


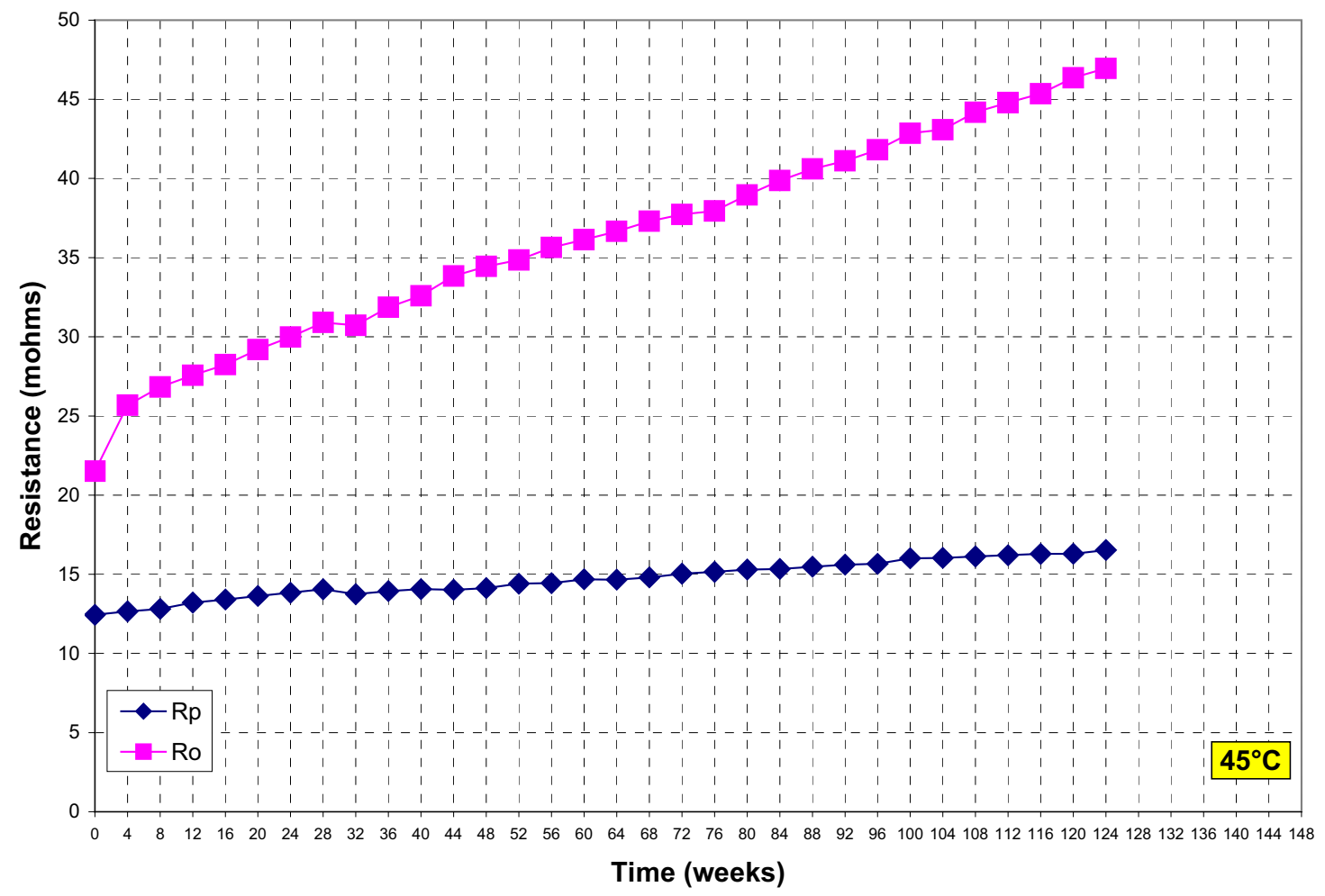

Figure A.6. Average ohmic and polarization resistance for the $45^{\circ} \mathrm{C}$ Variant $\mathrm{C}$ cycle-life cells.

\section{A.2 Additional Gen 2 Studies}

At the conclusions of standard ATD Gen 2 testing, the INL used two $25^{\circ} \mathrm{C}$ Baseline cells that had been aged to $50 \%$ power fade (INL Cells 114 and 115) and two fresh cells (INL Cells 180 and 181) for some low temperature performance studies that included EIS measurements and cold crank testing. This appendix discusses the results from these studies.

\section{A.2.1 EIS Measurements}

These cells were first used for a study of EIS measurements at different SOCs and temperatures. In the first experiment, EIS measurements were obtained at $25^{\circ} \mathrm{C}$ over a broader frequency range $(100 \mathrm{kHz}$ to $100 \mu \mathrm{Hz}$ ) at both 60 and $100 \%$ SOC. Figure A.7 shows the resulting spectra for a representative fresh and aged cell. As expected, the charge transfer resistance is larger for the aged cell. There is also an apparent SOC dependence, with the 100\% SOC spectra showing a greater charge transfer resistance than at $60 \%$ SOC for both the aged and fresh cell. The Warburg impedance is also impacted by cell aging; the fresh cell shows a significantly higher slope compared to the aged cell. Figure A.8 shows the same spectra zoomed in to a smaller frequency range $(2.5 \mathrm{kHz}$ to $10 \mathrm{mHz})$. These data show that the electrolyte resistance also increases slightly as a function of test time, but is apparently independent of SOC. 


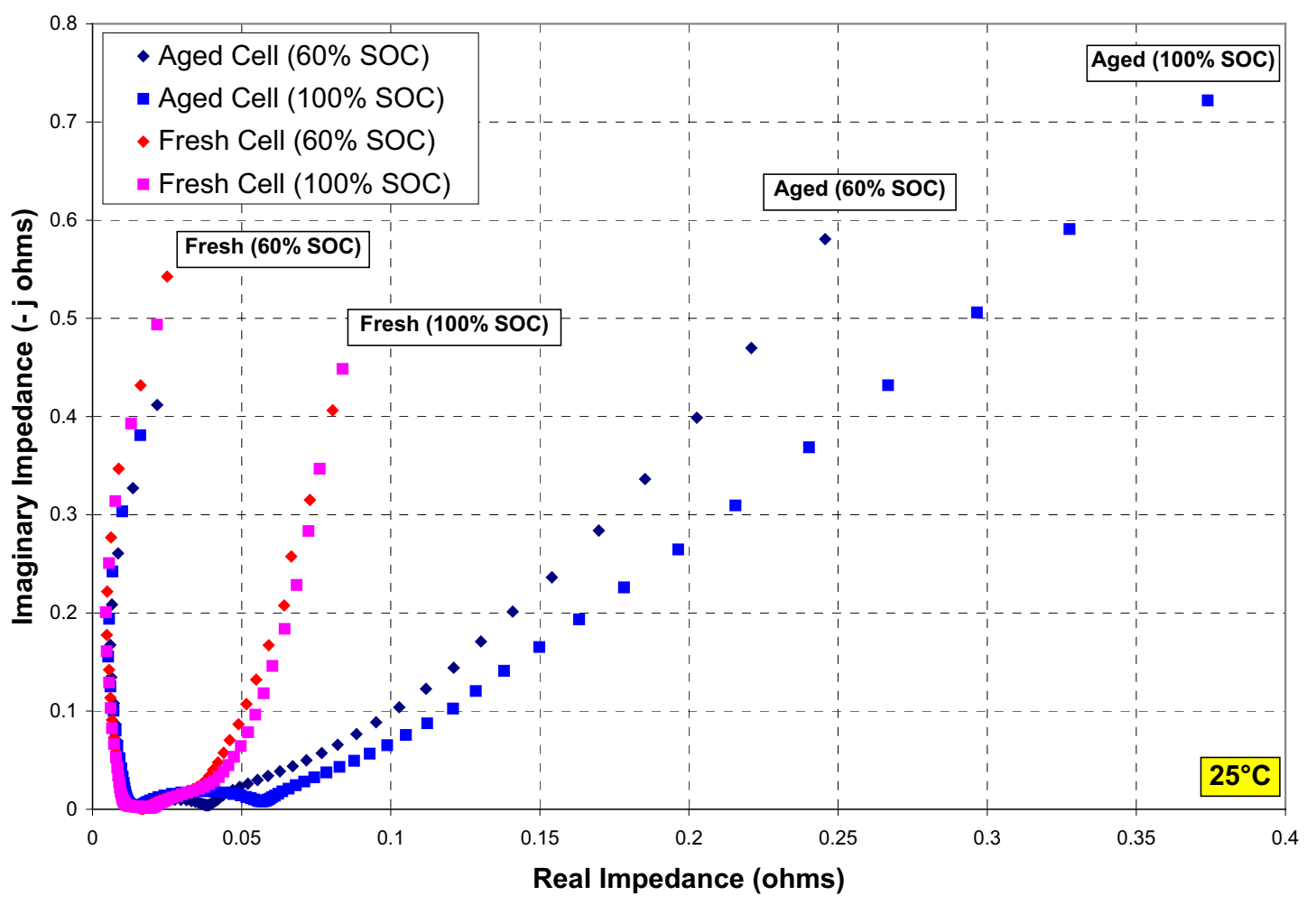

Figure A.7. $60 \%$ SOC EIS for a representative aged and fresh cell.

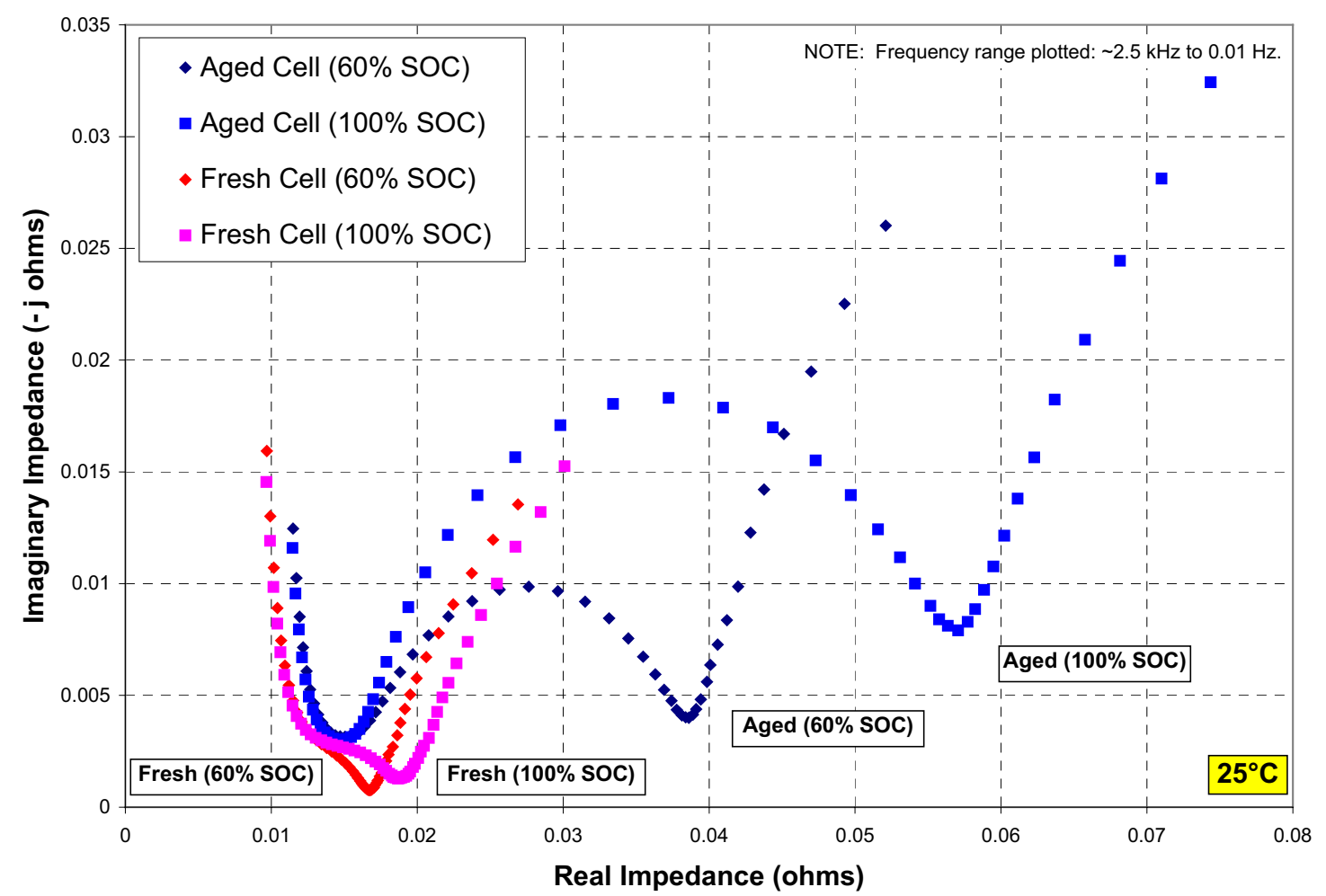

Figure A.8. 60\% SOC EIS for a representative aged and fresh cell (zoomed in). 
In the second experiment, EIS spectra were obtained over the normal frequency range $(10 \mathrm{kHz}$ to 10 $\mathrm{mHz}$ ) at both 60 and $100 \% \mathrm{SOC}$ at temperatures of $45,25,10,0,-10,-20$, and $-30^{\circ} \mathrm{C}$. Figure A.9 shows the Arrhenius plot of the conductance (i.e., 1 / impedance magnitude) at the semicircle trough for the $60 \%$ SOC measurements. The conductance decreases as a function of test temperature, with a phase transition somewhere between 25 and $10^{\circ} \mathrm{C}$. The fresh cells show a higher conductance (i.e., lower impedance) than the aged cells. Figure A.10 shows the comparable results for the EIS measurements at $100 \%$ SOC. Due to a programming glitch, the $10^{\circ} \mathrm{C}$ temperature data were not recorded. However, the same phase transition appears between 25 and $0^{\circ} \mathrm{C}$. Although the values of the conductance at $100 \%$ SOC are lower than at $60 \% \mathrm{SOC}$, the slopes are similar. This indicates that the activation energy changes little with SOC (or age). One interpretation of this result is that the electrochemical nature of the SEI is largely unchanged with aging, but that is grows in thickness over time.

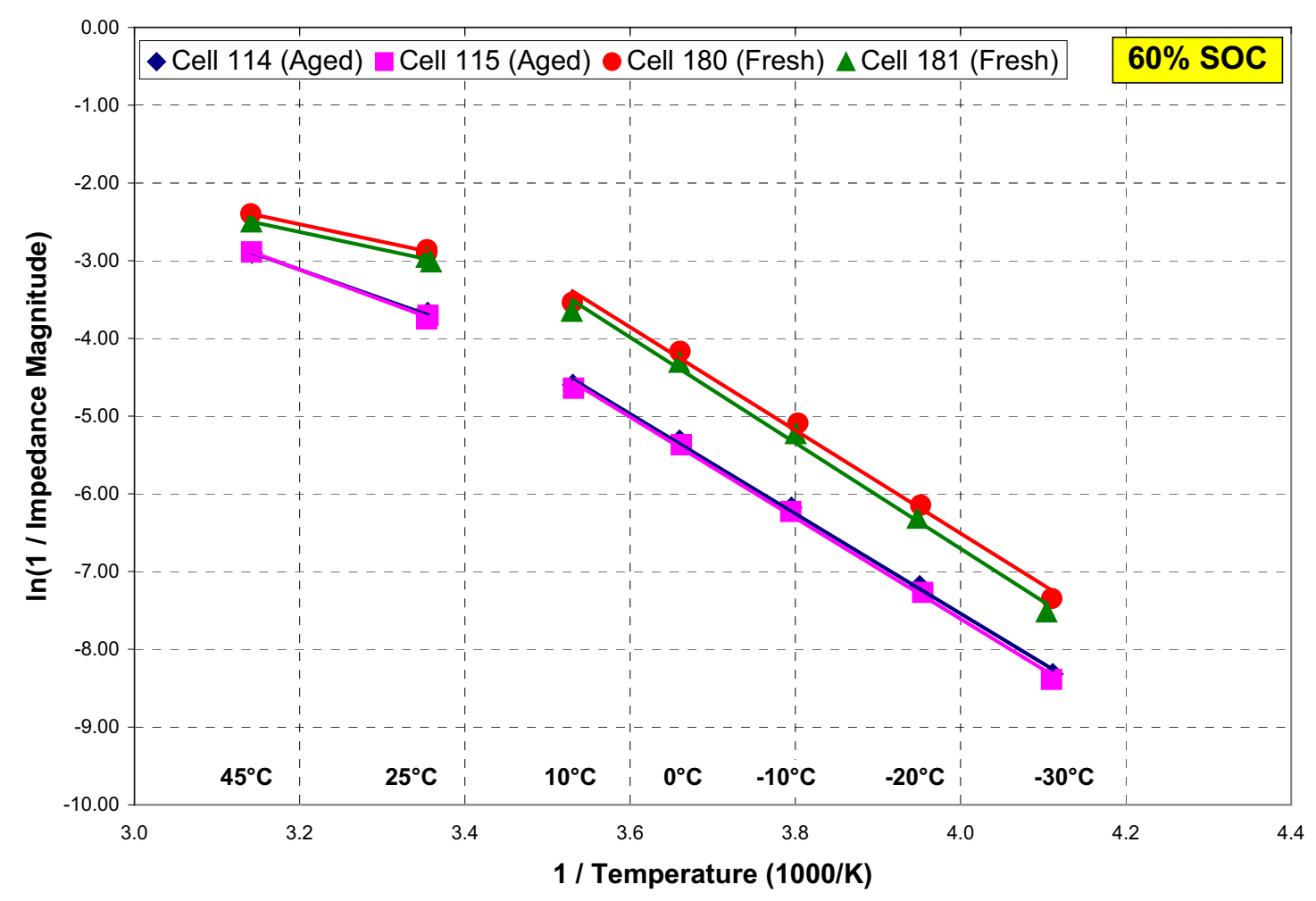

Figure A.9. $60 \% \mathrm{SOC} \mathrm{AC}$ impedance at the semicircle trough as a function of temperature. 


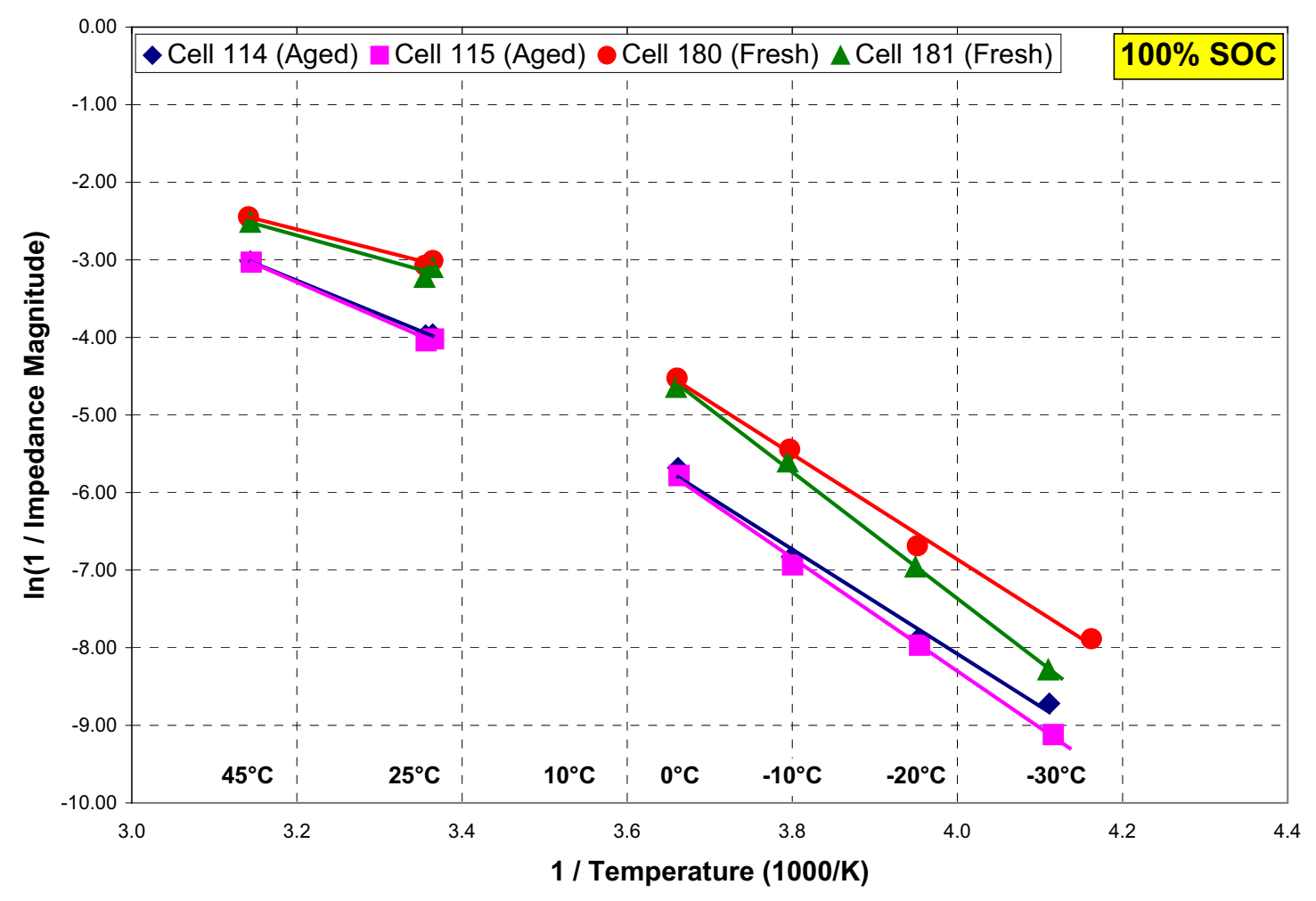

Figure A.10. 100\% SOC AC impedance at the semicircle trough as a function of temperature.

\section{A.2.2 Cold Cranking}

The four cells were then subjected to cold crank tests (Reference 4) of various durations (2-s and 5-s constant power profiles) and temperatures $\left(25,10,0,-10,-20\right.$, and $\left.-30^{\circ} \mathrm{C}\right)$ to investigate the relative changes in ohmic and polarization resistances. The cold crank test was then repeated for the three lowest test temperatures using a 2-s profile, but with a lower voltage limit of $2.5 \mathrm{~V}$ instead of the standard $3.0 \mathrm{~V}$. These tests were performed at a temperature-based constant voltage to get as close to constant SOC as possible without thermal cycling back to $25^{\circ} \mathrm{C}$ prior to each temperature change. This was achieved by observing the voltage after an appropriate soak period at OCV following a temperature change, then taper charging back to that observed voltage immediately before the next temperature change.

Figure A.11 shows the cold crank capability during the third pulse at each test temperature. The cells could not meet the $5 \mathrm{~kW}$ FreedomCAR goal at approximately -15 and $-5^{\circ} \mathrm{C}$ for the fresh and aged cells, respectively. The slope of the Arrhenius curve is similar for the fresh and aged cells, but it increases slightly when the lower voltage limit is reduced to $2.5 \mathrm{~V}$. Using the lower voltage limit also helped improve power performance slightly. Figures A.12 and A.13 show the ohmic and polarization resistances (as calculated from the lumped parameter model defined in Reference 4) for a fresh and aged cell, respectively. For both the fresh and aged cell, using a 5-s discharge pulse resulted in an increased ohmic resistance $\left(\mathrm{R}_{\mathrm{O}}\right)$, but a small decrease in polarization resistance $\left(\mathrm{R}_{\mathrm{P}}\right)$ compared to the 2-s pulse. As expected, using a lower voltage limit generally resulted in lower ohmic and polarization resistances. 


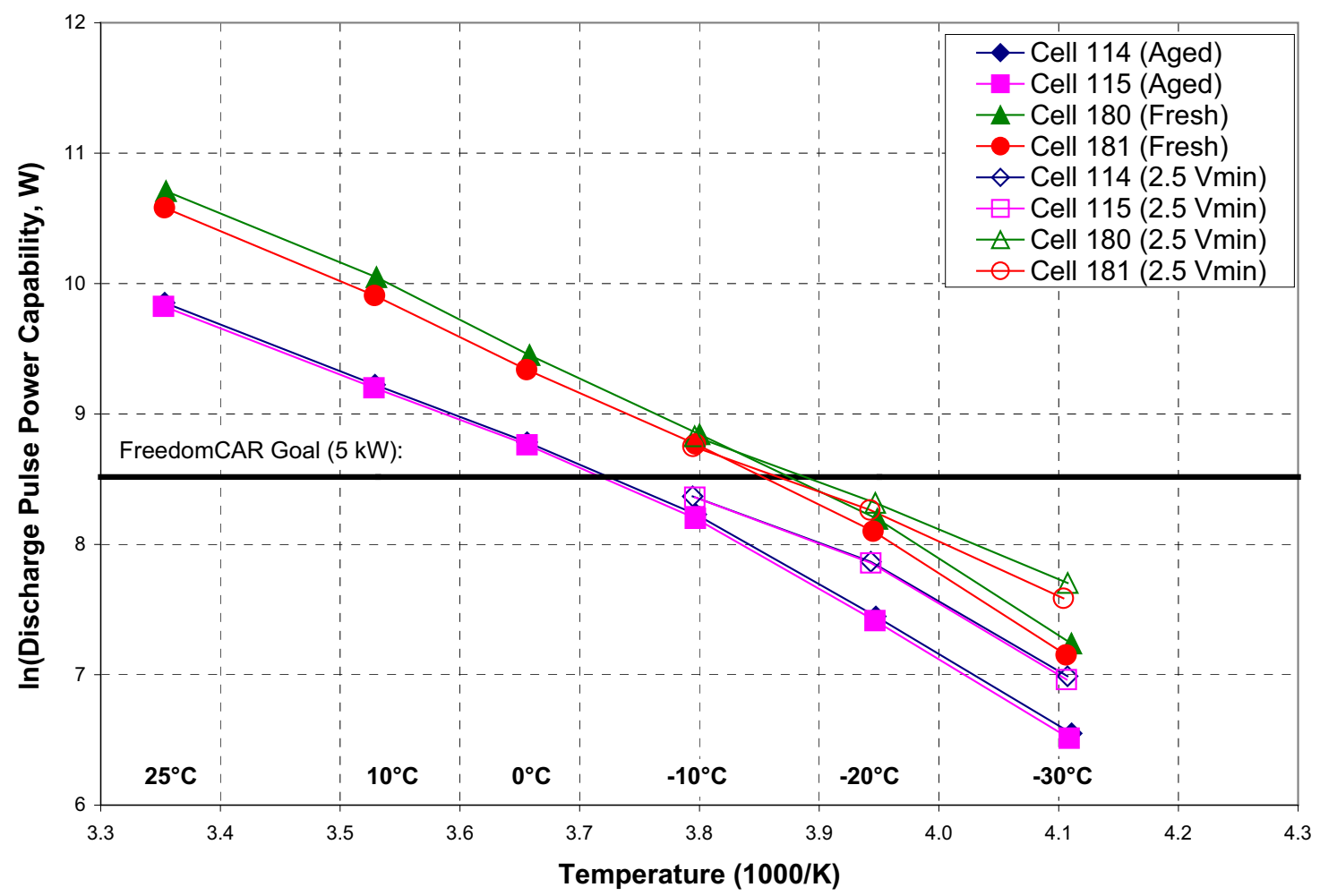

Figure A.11. Cold crank capability for the third discharge pulse.

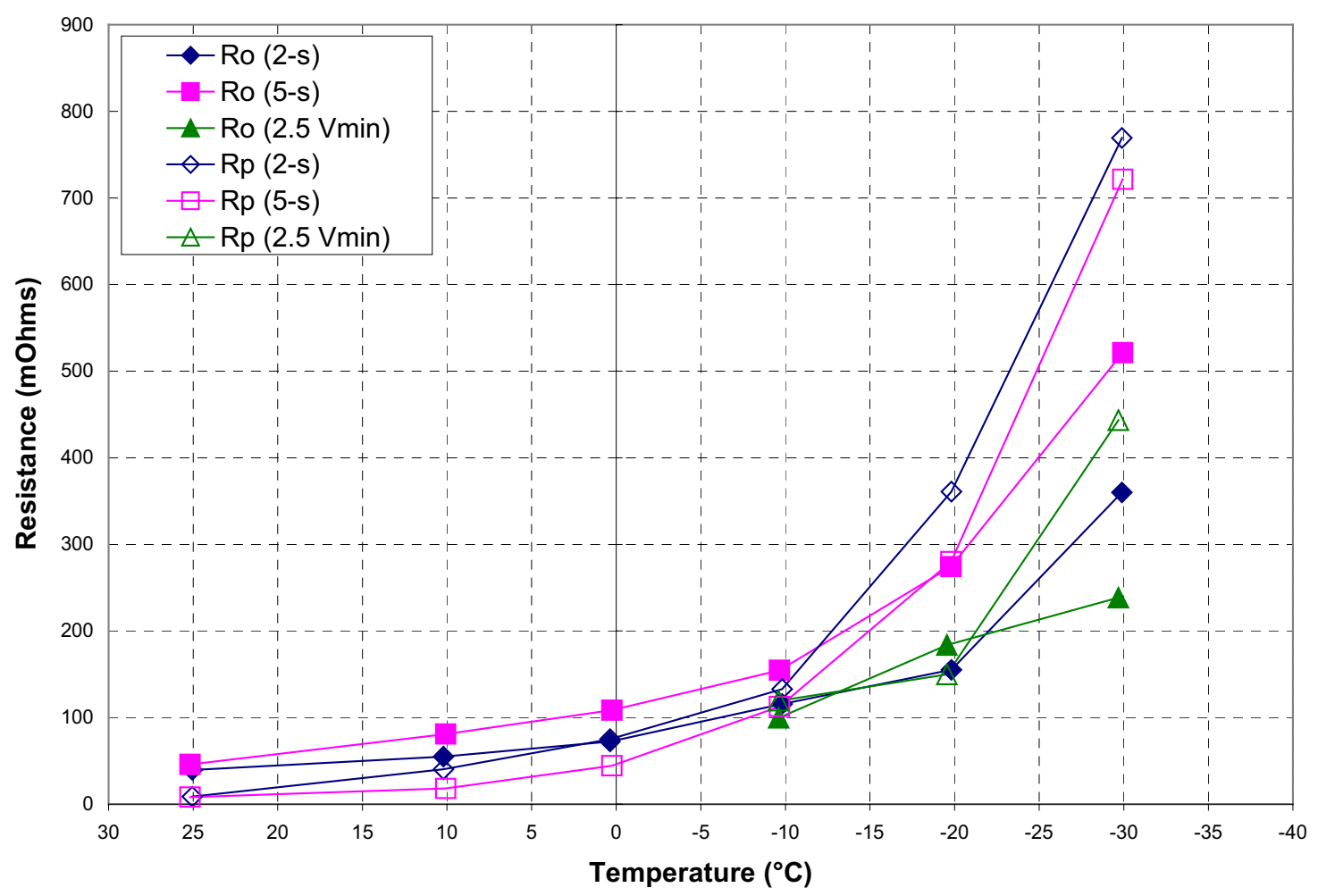

Figure A.12. Cold cranking ohmic and polarization resistances for a fresh cell. 


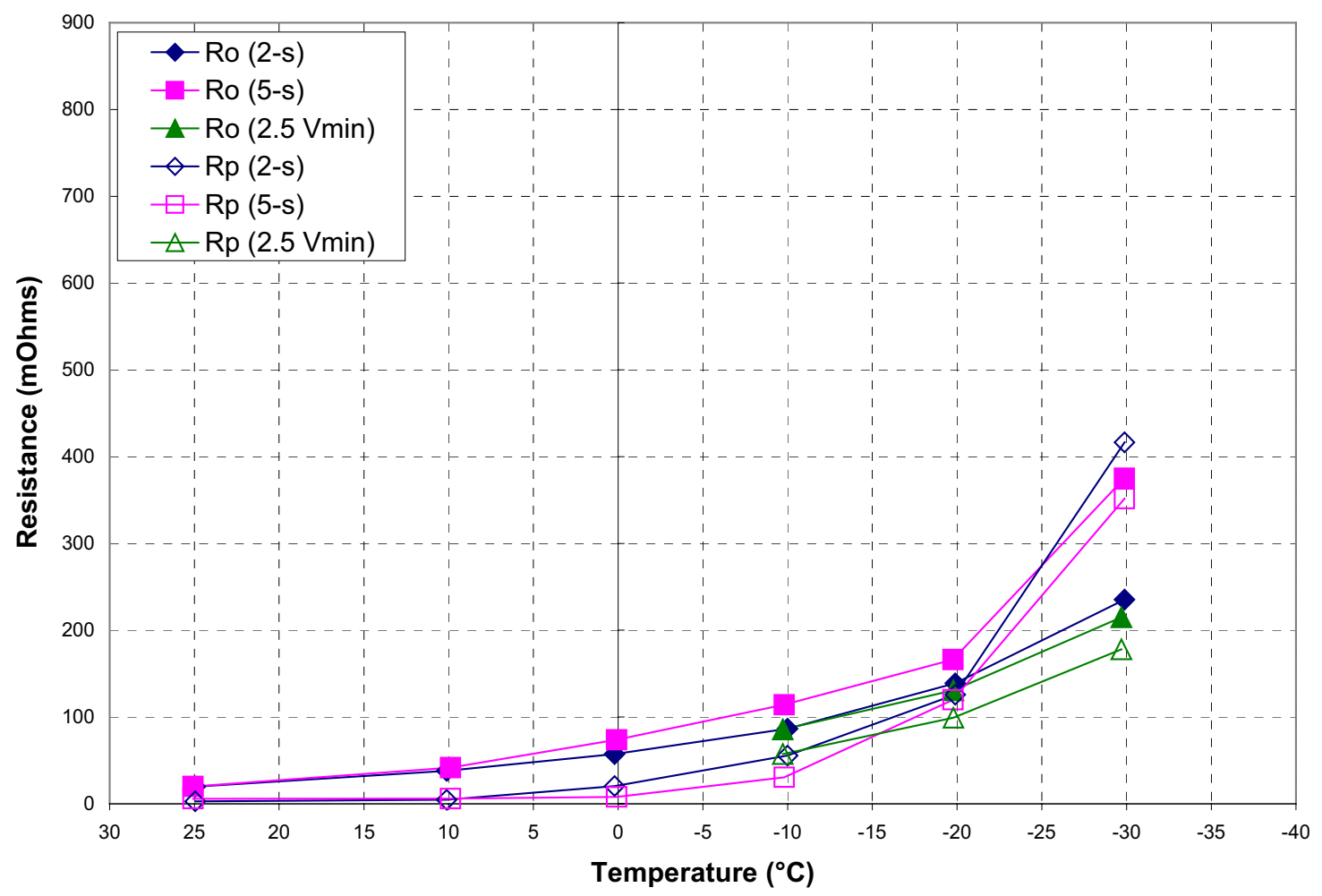

Figure A.13. Cold cranking ohmic and polarization resistances for an aged cell.

\section{A.3 Commercial Cells}

The purpose of the Gen 2 RPT was to explore new tests as possible alternative measures of cell degradation. Consequently, in addition to the standard FreedomCAR RPT of a $\mathrm{C}_{1} / 1$ and L-HPPC test, the cells were also subjected to a $\mathrm{C}_{1} / 25$ discharge and EIS at $60 \%$ SOC. Due to the nature of the acceleratedlife cells, even more tests were included every four weeks of aging, as summarized in Table C.1 (see Appendix C). However, the Gen 2 cell test results indicated that the RPTs also had an impact on the rate of cell degradation. Figure A.14 shows the average power fade at $300 \mathrm{Wh}$ for the Baseline calendar-, cycle-, and accelerated-life cells aged at $45^{\circ} \mathrm{C}$. The cycle-life cells show greater power fade than the calendar-life cells, but this is primarily due to the life test since the RPTs were the same. However, the accelerated-life cells (which was essentially a calendar-life test, see Section 3.2.3) showed a significantly greater fade rate.

The effect of RPTs on life was studied at the INL using commercially available PowerfLite cells. These cells have a $\mathrm{LiCoO}_{2}$ cathode, a graphite anode, and $\mathrm{LiPF}_{6}$ salt in $\mathrm{EC} / \mathrm{DEC} / \mathrm{DMC}$ electrolyte. They were prismatic shape and rated at $1 \mathrm{Ah}$ over a voltage range 4.2 to $2.75 \mathrm{~V}$. These cells were cycle-life tested using the profile show in Figure 3 at $25^{\circ} \mathrm{C}$ and $60 \%$ SOC. Each group of cells were subjected to "partial" RPTs every 2 weeks during aging. The "partial" RPTs consisted of a control group (no RPT interruption), a group with seven $\mathrm{C}_{1} / 1$ and one $\mathrm{C}_{1} / 25$ discharges (each followed by a $\mathrm{C}_{1} / 1$ charge), a group with only a single $\mathrm{C}_{1} / 1$ discharge and charge, a group with an EIS measurement at only $60 \%$ SOC and another group at only $100 \% \mathrm{SOC}$, a group with a $\mathrm{C}_{1} / 1$ and L-HPPC at $25^{\circ} \mathrm{C}$, and another group with a $\mathrm{C}_{1} / 1$ and L-HPPC at $0^{\circ} \mathrm{C}$. Each group was subjected to a $\mathrm{C}_{1} / 1$ and L-HPPC test at the beginning and end of test. 


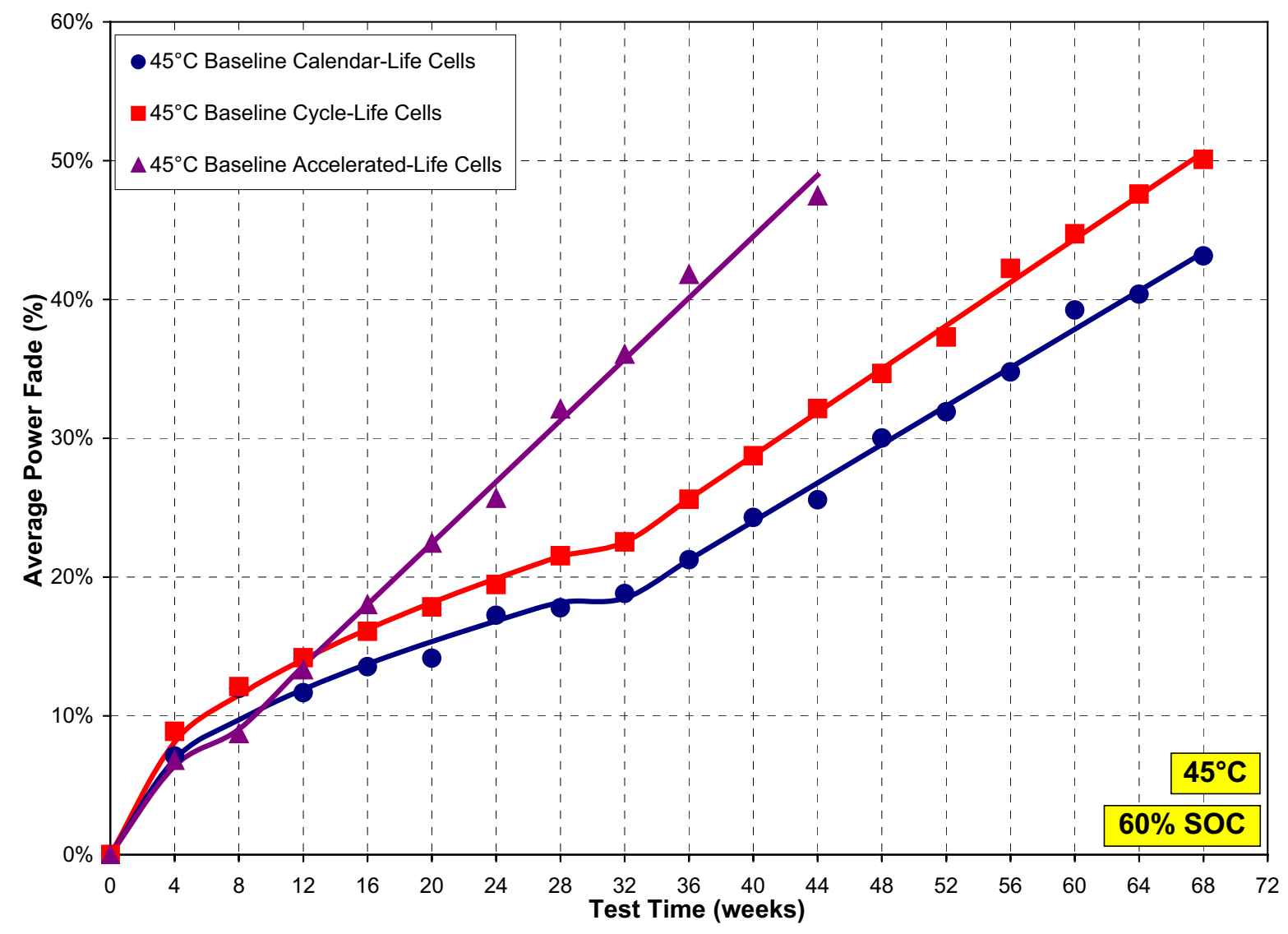

Figure A.14. Average power fade for the $45^{\circ} \mathrm{C}$ Baseline calendar-, cycle-, and accelerated-life cells.

Figure A.15 shows the average capacity and power fade for each "partial" RPT group after 12 weeks of aging. The most damaging component of the RPT is the multiple discharges and charges $(17.0 \%$ power fade and $6.4 \%$ capacity fade). The Gen 2 cycle- and calendar-life cells were subjected to the equivalent of four full discharges and charges at each RPT, whereas the accelerated-life cells had approximately twelve full discharges and charges. Consequently, the accelerated-life cells faded a lot more quickly. Similarly, the $0^{\circ} \mathrm{C}$ L-HPPC test also contributed to the rapid failure of the accelerated-life cells. Although EIS is a relatively benign test, the SOC at which measurements are taken does impact degradation. The $60 \%$ SOC EIS cell group showed similar power fade to the control cells, but the $100 \%$ SOC EIS group showed much more rapid degradation. Additional details about this study are provided in Reference 22. 


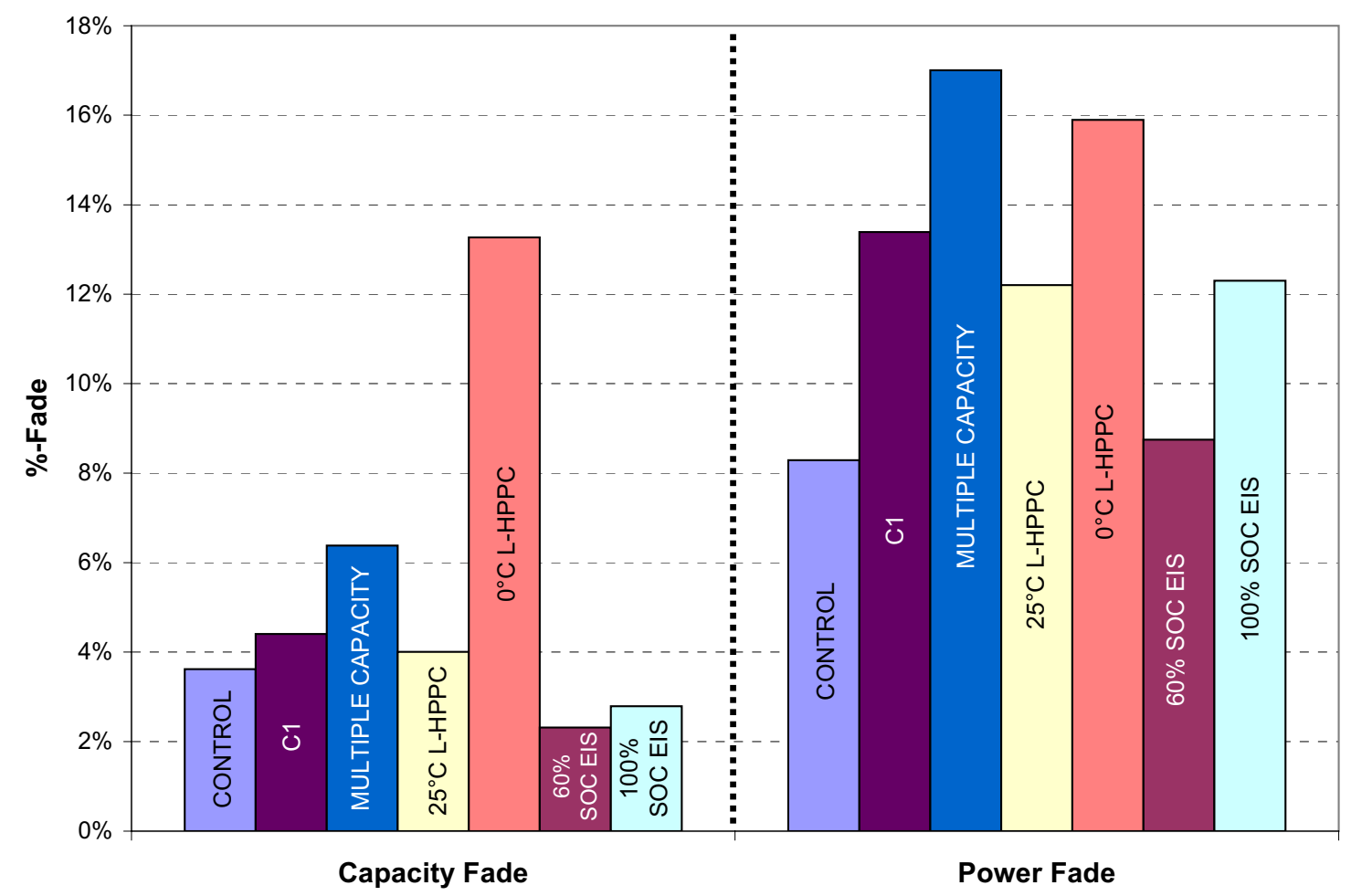

Figure A.15. Average capacity and power fade for each "partial" RPT group PowerfLite cells.

\section{A.4 Button Cells}

Button cells are a quick and economical means of assessing key performance issues such as formation and low temperature performance. INL has the capability to fabricate and test numerous button or coin cells to accommodate key questions regarding performance for a given chemistry. The cells are of the CR2032 configuration (assembled dimensions $20 \mathrm{~mm}$ diameter $\times 3.2 \mathrm{~mm}$ height), giving an effective electrode area of $1.6 \mathrm{~cm}^{2}$ each. The button cells are assembled in an argon-purged, low moisture glovebox, and go on test within one hour of manufacture. All cells are tested in individual fixtures housed in environmental chambers maintained at specified temperatures. These cells have proven useful for inquiries involving cell formation and low temperature performance.

Cell-to-cell variability among INL button cells is summarized in Table A.1, based on two independent groups of cells produced in FY 2005 with the ATD Gen 2 electrode chemistry (see Table 1). The button cell electrolyte varied slightly from the 18650 cell chemistry, with a 2:8 mass ratio of EC to EMC with $1.2 \mathrm{M} \mathrm{LiPF}_{6}$. As built, the button cells have a theoretical capacity rating of $2 \mathrm{mAh}$, and an average $\mathrm{C}_{1} / 1$ capacity of roughly $1.75 \mathrm{mAh}$. It is seen that variability in the $\mathrm{C}_{1} / 1$ capacity at $\mathrm{BOL}$ is less than ten percent. 
Table A.1. Button cell variability using the Gen 2 chemistry.

\begin{tabular}{cccc}
\hline \hline Measure & Group A (20 cells) & Group B (15 cells) & Average \\
\hline \hline $\mathrm{C}_{1} / 1$ Capacity $(\mathrm{mAh})$ & 1.67 & 1.79 & 1.72 \\
Std. Dev.* & \pm 0.17 & \pm 0.12 & \pm 0.15 \\
\hline ASI at 60\% SOC $\left(\Omega-\mathrm{cm}^{2}\right)$ & 27.4 & 26.4 & 27.0 \\
Std. Dev.* & \pm 5.36 & \pm 4.02 & \pm 4.79 \\
\hline \hline
\end{tabular}

$*$ at $68 \%$ confidence level

\section{A.4.1 Polarization Study}

Following formation, the cells underwent at least 400 full $\mathrm{C}_{1} / 1$ charge/discharge cycles (from 4.1 to $3.0 \mathrm{~V}$ ) at $30^{\circ} \mathrm{C}$ to evaluate the impact of cycling on capacity fade and impedance rise. Finally, the cells were subjected to a "polarization matrix" consisting of various charge and discharge rates $\left(\mathrm{C}_{1} / 1, \mathrm{C}_{1} / 3\right.$, $\left.\mathrm{C}_{1} / 5, \mathrm{C}_{1} / 10\right)$ and temperatures $\left(30,10,0,-10,-20,-30^{\circ} \mathrm{C}\right)$. Figure A.16 shows the result of this polarization test, wherein the family of capacity curves is a unique thumbprint of performance limitations tied to the chosen battery chemistry.

Several observations can be made from Figure A.16. First, relatively good capacity retention is seen for temperatures down to $-10{ }^{\circ} \mathrm{C}$ and cycling rates as high as $\mathrm{C}_{1} / 3$. However, there appears to be a transition region between -10 and $-20{ }^{\circ} \mathrm{C}$ and between $\mathrm{C}_{1} / 3$ and $\mathrm{C}_{1} / 1$ rates wherein the battery performance starts to fall off significantly (in some cases by more than three orders of magnitude). Additionally, the charge capacity degrades more than the discharge capacity, developing a "chargelimited" condition wherein the cell is less able to receive charge than deliver charge. These results imply that there are one or more mechanisms present that severely impact capacity at colder conditions and higher cycling rates. Doubtless, concentration polarization (CP) is a key contributor to the decrease in achievable charge and discharge capacities. Another contributor could be a CP-promoted reversible EC phase separation that masks electrode particles and thereby reduces the effective capacity, particularly regarding carbonaceous anode particles under charge conditions. It is surmised that the observed behavior is not due solely to lithium plating since the cells exhibit practically no irreversible performance loss when they resume operation at room temperature following the low temperature cycling. Lastly, there could be interfacial diffusive limitations introduced as lithium desolvation kinetics becomes more problematic at lower temperatures. 


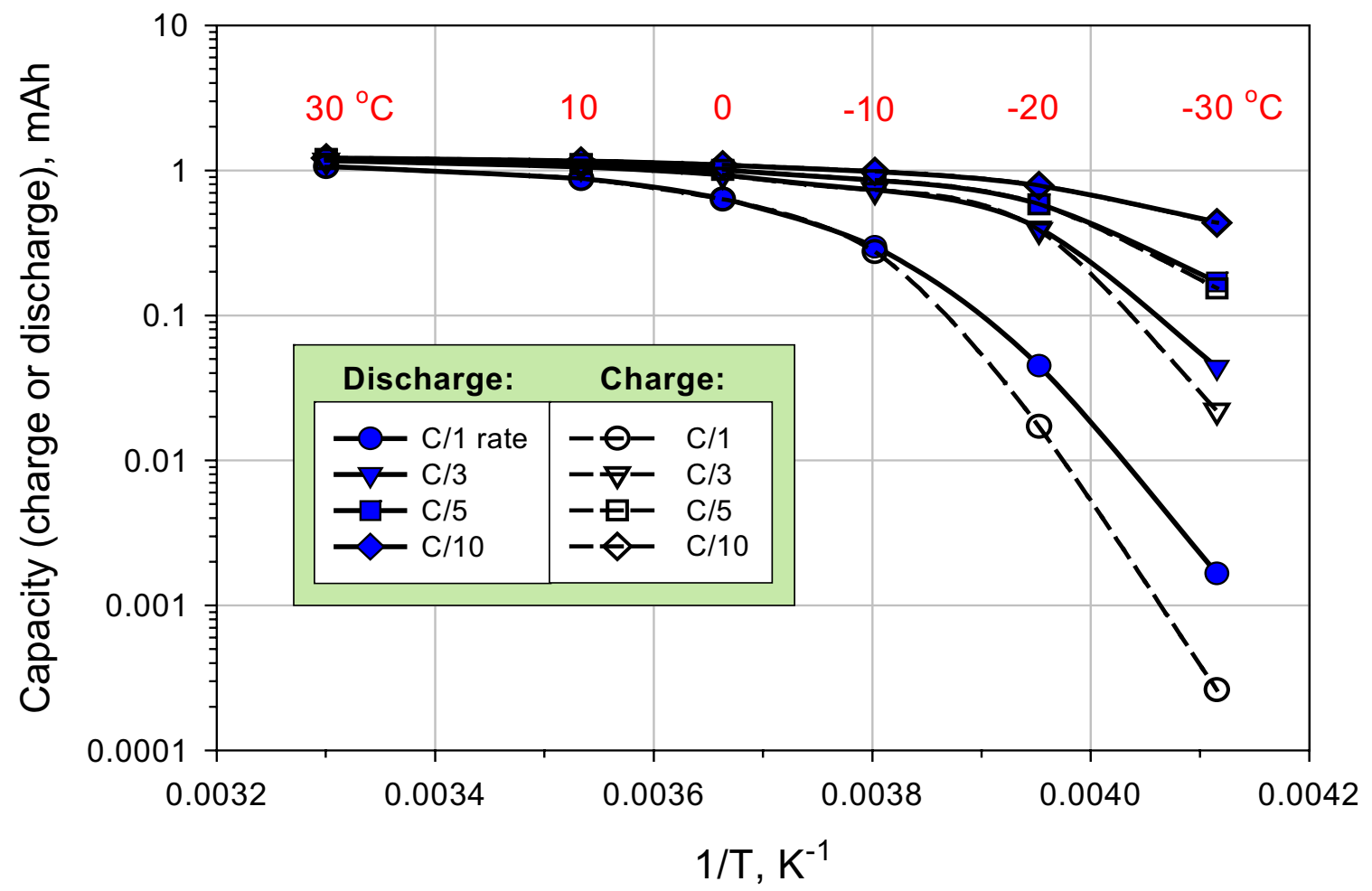

Figure A.16. Polarization plots obtained from button cells.

\section{A.4.2 Differential Capacity}

Button cells provide a good platform for evaluating differential capacity of a given chemistry. Shown in Figure A.17 are differential capacity results from a representative INL button cell (ATD Gen 2 chemistry), cycled at a $\mathrm{C}_{1} / 10$ rate over various temperatures. These results indicate a charge-limited condition that worsens at lower temperatures, in agreement with the results seen in Figure A.16. The relative shift and shrinkage of $\mathrm{dQ} / \mathrm{dV}$ peaks as temperature is lowered provides a unique picture of performance that can yield insights into power-limiting mechanisms. 


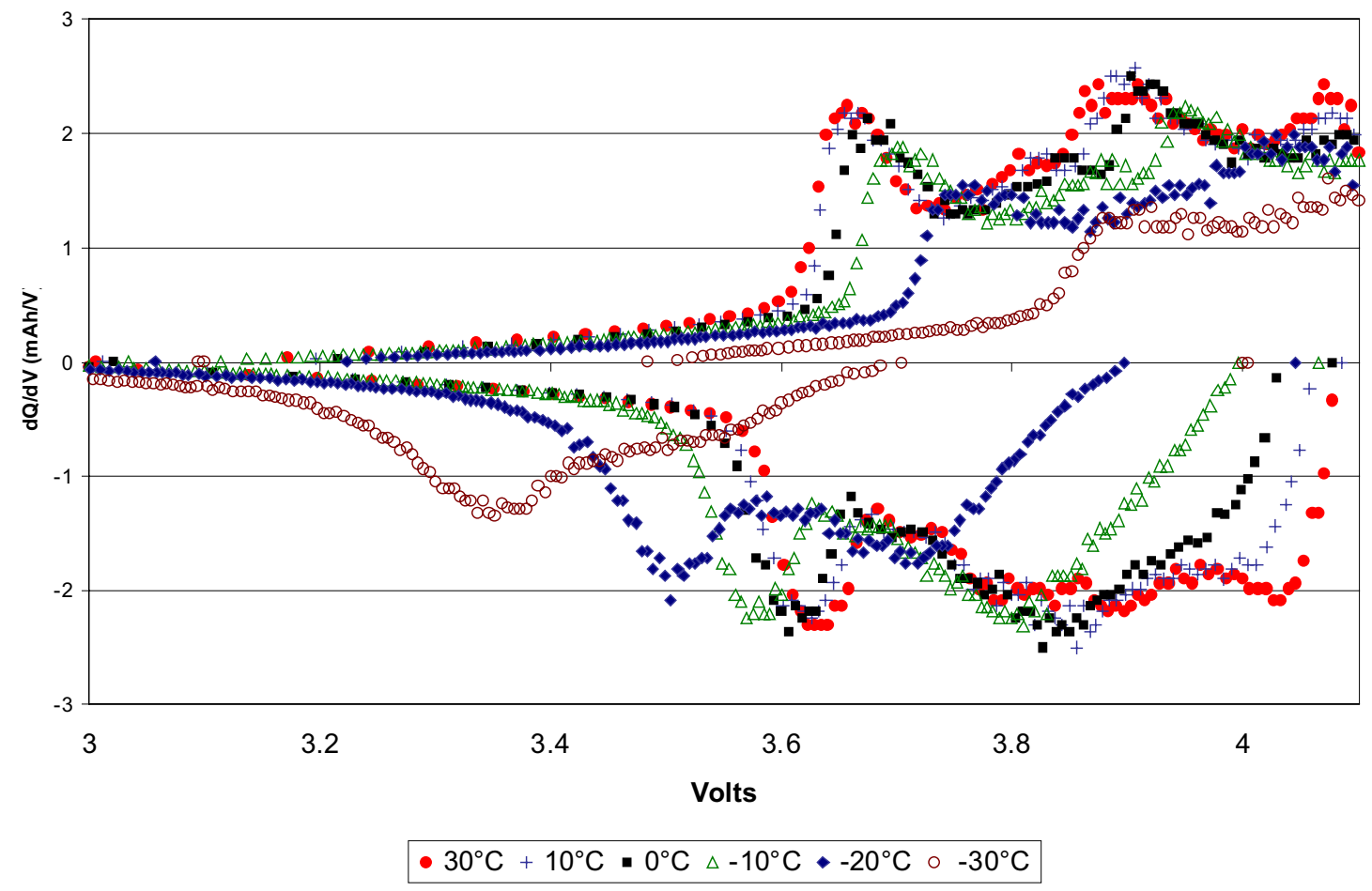

Figure A.17. Differential capacity vs. temperature at a $C_{1} / 10$ rate. 
Appendix B

Special Considerations 


\section{B. SPECIAL CONSIDERATIONS}

This appendix discusses testing issues and considerations from all three testing laboratories.

\section{B.1 Lot Numbers}

The 30 Baseline cycle-life and 22 Baseline calendar-life cells came from Quallion Lot Number S00J051. The 54 Baseline accelerated-life cells came from Lot Number S00J-201. The width of each electrode from Lot S00J-201 was made $1.5 \mathrm{~mm}$ smaller than Lot S00J-051 to achieve better manufacturability at Quallion. Although this modification was within specifications, it resulted in a 20-mAh drop in capacity. Lot S00J-201 also had a different electrode preparation date. Otherwise, there were no differences in material and process. All Variant $\mathrm{C}$ cells came from the same lot (VARIANT C).

\section{B.2 ATD Labeling Scheme}

An ATD labeling scheme was established to provide the diagnostic laboratories with succinct information regarding the EOT status of the test cells. The label is updated periodically as testing progresses and is finalized at EOT. It is in the form of GX[X].AABCC.DEEE.FF.TT.PP.Z.S, where:

$\begin{array}{lll}\mathrm{GX}[\mathrm{X}] & =\mathrm{G} 2[\mathrm{C}],[\mathrm{G}], \text { or }[\mathrm{V}] \\ \mathrm{AA} & = & \text { test matrix state-of-charge }(\%) \\ \mathrm{B} & = & \text { test matrix profile }(\mathrm{A}, \mathrm{L}, \text { or } \mathrm{C}) \\ \mathrm{CC} & = & \text { test matrix temperature }\left({ }^{\circ} \mathrm{C}\right) \\ \mathrm{D} & = & \text { original DOE laboratory }(\mathrm{A}, \mathrm{B}, \mathrm{I}, \mathrm{L}, \text { or } \mathrm{S}) \\ \mathrm{EEE} & = & \text { lab-specific cell number } \\ \mathrm{FF} & = & \text { target power fade }(\%) \\ \mathrm{TT} & = & \text { time at life testing }(\text { weeks }) \\ \mathrm{PP} & = & \text { power fade }(\%) \\ \mathrm{Z} & = & \text { abnormal condition flag } \\ \mathrm{S} & = & \text { status. }\end{array}$

The label begins with either $\mathrm{G} 2$ for the Baseline cells, G2C for the Variant C cells, G2G for the GDR-only cells, or G2V for the GDR+VEC cells. The test matrix SOC, profile, and temperature (i.e., $A A B C C)$ identify the type of test, where accelerated-life (A), cycle-life (L), or calendar-life (C) testing is performed at a designated SOC and temperature. Next, the original DOE laboratory is identified $(\mathrm{A}=$ $\mathrm{ANL}, \mathrm{B}=\mathrm{BNL}, \mathrm{I}=\mathrm{INL}, \mathrm{L}=\mathrm{LBNL}$, and $\mathrm{S}=\mathrm{SNL}$ ), along with the laboratory-specific cell number. The testing laboratories established a sequential numbering scheme such that all INL cells are numbered from 101 to $1 \mathrm{XX}$, all ANL cells are numbered from 201 to $2 \mathrm{XX}$, and all SNL cells are numbered from 301 to $3 \mathrm{XX}$ and 401 through $4 \mathrm{XX}$.

The target power fade (i.e., FF) is the desired power fade at EOT (Section 3.4). Once the actual power fade (i.e., PP) meets or exceeds the target power fade, the cell is removed from test and shipped to a diagnostic laboratory. The time at life testing (i.e., TT) shows the number of weeks the cell has been aging in four -week increments. If the cell has only been characterized, a target power fade cannot be established (Appendix C in Reference 5), and power fade is 0\% (Section 3.3). Therefore, slots FF.TT.PP are identified as 00.CC.00 to indicate characterization testing only. If, however, a cell fails before characterization testing, the three slots are labeled 00.NA.NA. If a target power fade is not identified (e.g., the accelerated-life Baseline cells), this slot is marked as NA.

The abnormal condition flag identifies any problems, such as shorting (S), venting (V), leaking (L), puncturing $(\mathrm{P})$, or damaged tab(s) $(\mathrm{T})$. Otherwise, the cell is marked good $(\mathrm{G})$. The status flag either 
shows that the cell is still on test $(\mathrm{T})$, has finished testing $(\mathrm{F})$, or has been sent to a diagnostic laboratory (e.g., A, L, B, or Q for Quallion).

For example, G2.60L25.I110.14.36.16.G.L is INL Cell 110, a Gen 2 Baseline cell. It was cycle-life tested at $60 \% \mathrm{SOC}$ and $25^{\circ} \mathrm{C}$ for 36 weeks before being taken off test with $16 \%$ power fade, having exceeded the target power fade of $14 \%$. The cell was in good condition when it was shipped to LBNL for diagnostic analysis.

\section{B.3 Calendar-Life Special Considerations}

\section{B.3.1 Tab Welds}

The receipt inspection of the Variant $\mathrm{C}$ cells prior to testing showed fragile tabs. The cell ends were burned, and the heat-affected zone in the weld area was dull instead of bright. There was no indication of these problems during the receipt inspection of the Baseline cells.

\section{B.3.2 Early Cell Failures}

Five of the Variant $\mathrm{C}$ cells arrived with OCVs less than the minimum discharge voltage of $3.0 \mathrm{~V}$ (Section 2.1). As a result, these cells were removed from the test matrix and returned to Quallion for analysis prior to testing.

\section{B.3.3 Low Power Fade}

The calendar-life cells that were tested at $55^{\circ} \mathrm{C}$ were originally slated to test at $45^{\circ} \mathrm{C}$. However, the initial power fade after four weeks of testing for some cells at $45^{\circ} \mathrm{C}$ were low. As shown in the cell status summary sheets provided on the CD with this report, some cells (e.g., G2.60C55.A211.30.40.31.G.L) showed little or no fade while others (e.g., G2.60C55.A214.33.40.34.G.L) showed an increase in available power during the first four weeks of aging. As a result, the test temperature was increased to $55^{\circ} \mathrm{C}$ to accelerate cell degradation.

\section{B.4 Cycle-Life Special Considerations}

\section{B.4.1 Receipt Inspection}

The receiving inspection conducted before testing confirmed that no cells were damaged other than G2C.60L45.I173.00.NA.NA.L.Q (see Section B.4.5 for additional information on this cell). This included visual inspection and measuring cell weights, OCVs, and impedance at $1 \mathrm{kHz}$. Figure B.1 shows the 15 Variant $C$ cells that arrived on July 30, 2001. Table B.1 summarizes the average receipt inspection measurements for the $25^{\circ} \mathrm{C}$ Baseline cell, the $45^{\circ} \mathrm{C}$ Baseline cell, and the $45^{\circ} \mathrm{C}$ Variant $\mathrm{C}$ cell groups, respectively. All three cell groups show similar weights and $\mathrm{OCVs}$, but the Variant $\mathrm{C}$ cells show a lower impedance at $1 \mathrm{kHz}$. (The Variant $\mathrm{C}$ cell group average does not include Cell 173, which was returned to Quallion due to poor performance.) 


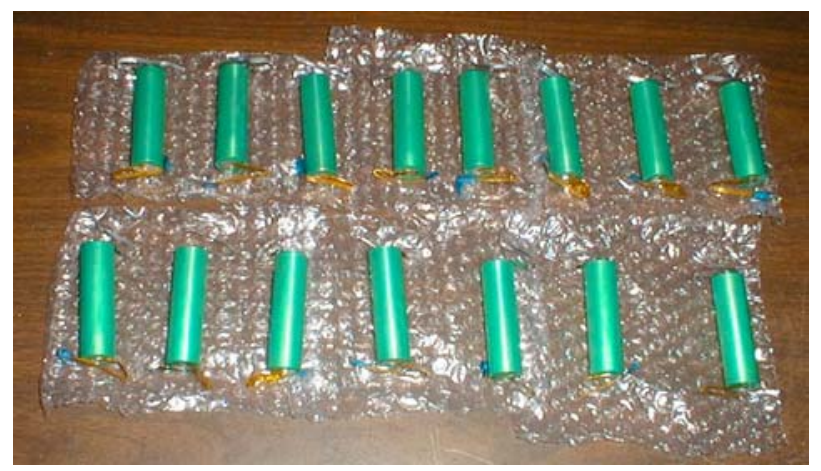

Figure B.1. Fifteen Variant C cells, as received.

Table B.1. Receipt inspection measurements for the three cycle-life cell groups.

\begin{tabular}{ccccc}
\hline \hline $\begin{array}{c}\text { Cycle-Life Cell } \\
\text { Group }\end{array}$ & $\begin{array}{c}\text { Receipt } \\
\text { Inspection Date }\end{array}$ & $\begin{array}{c}\text { Weight } \\
(\mathrm{g} \pm \sigma)\end{array}$ & $\begin{array}{c}\text { OCV } \\
(\mathrm{V} \pm \sigma)\end{array}$ & $\begin{array}{c}\text { Real Impedance at } \\
1 \mathrm{kHz}(\mathrm{m} \Omega \pm \sigma)\end{array}$ \\
\hline \hline Baseline Cells at $25^{\circ} \mathrm{C}$ & $01 / 09 / 01$ & $38.85 \pm 0.28$ & $3.56 \pm 0.04$ & $12.67 \pm 0.97$ \\
Baseline Cells at $45^{\circ} \mathrm{C}$ & $01 / 09 / 01$ & $38.76 \pm 0.14$ & $3.58 \pm 0.03$ & $12.26 \pm 0.21$ \\
Variant C Cells at $45^{\circ} \mathrm{C}$ & $07 / 30 / 01$ & $38.33 \pm 0.21$ & $3.53 \pm 0.25$ & $10.61 \pm 0.42$ \\
\hline \hline
\end{tabular}

\section{B.4.2 Temperature Control}

All testing was performed with cells placed in environmental chambers to control ambient temperature. The chambers control the temperature to within $\pm 3^{\circ} \mathrm{C}$, as specified in the test plan (Reference 5). Also, all Gen 2 cells have been placed in thermal blocks in order to more uniformly control the cell temperature and minimize temperature transients. Before testing Gen 2 cycle-life cells, two thermal block temperature control experiments were conducted. Ten 1.5-W heaters were placed in a block to simulate the Gen 2 cells under representative testing loads. Thermocouples were placed on each heater, and seven additional thermocouples were placed in various positions on the block itself. The ambient temperature was brought to $25^{\circ} \mathrm{C}$, and after five minutes, the heat sources were activated. After 30 minutes, the heat sources were deactivated. This procedure was then repeated at 35,45 , and $55^{\circ} \mathrm{C}$. The first control experiment involved controlling the ambient temperature using the resistance temperature detector (RTD) in the environmental chamber. Figure B.2 shows the results from a block that was controlled using the RTD. The heater (simulated cell) temperatures rise monotonically and become steady at about $5^{\circ} \mathrm{C}$ hotter than the control (ambient) temperature. The second test involved controlling the ambient temperature using the thermocouples embedded in the block. The results are presented in Figure B.3. At lower temperatures (i.e., 25 and $35^{\circ} \mathrm{C}$ ), this yielded nonsteady heater temperatures that varied by $\pm 2^{\circ} \mathrm{C}$ around the target temperature. At higher temperatures (i.e., 45 and $55^{\circ} \mathrm{C}$ ), the heater temperature was steady. For both Figures B.2 and B.3, the block temperatures are slightly higher than the heater temperatures, since the thermocouples on the heaters were insulated. These figures demonstrate that controlling the ambient temperature using the RTD is more stable.

Figure B.4 shows seven Gen 2 cycle-life cells in a thermal block. The sense lead wires were secured to a stress relief fastener above and to the right of each cell, and another fastener on the top of the block. Figure B.4 also shows the thermocouple attached to each cell using adhesive tape. The adhesive tape is secured to the cell with cable tie. All thermocouple wires are cable-tied together with the voltage and current sense leads, and held in place with a strength relief fastener (as shown on the far left fastener on the top of the thermal block). These restraints allow for some movement of the sense lead wires (e.g., plugging and unplugging the leads from the tester) without stressing the cell tabs. 


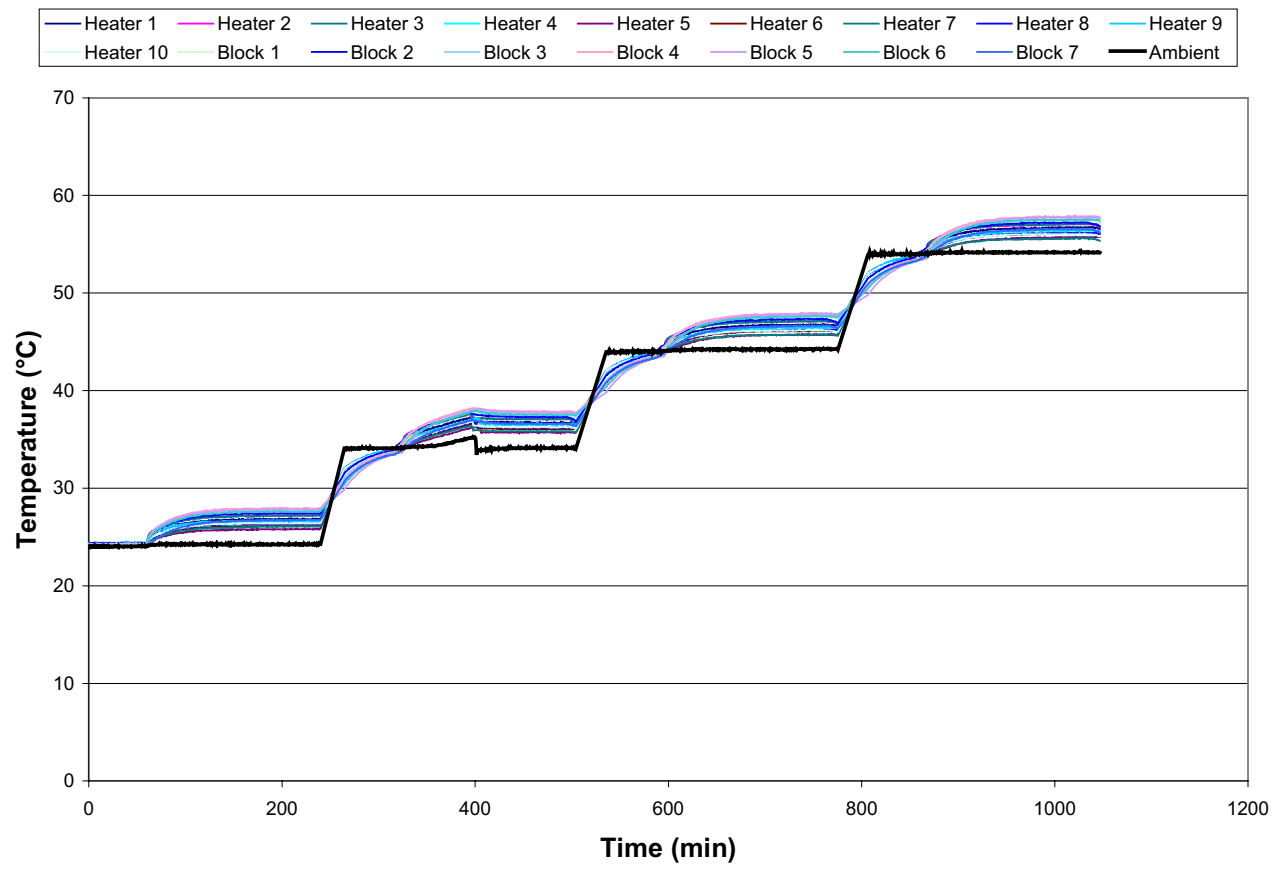

Figure B.2. Thermal block temperature control experiment with ten heat sources (RTD control).

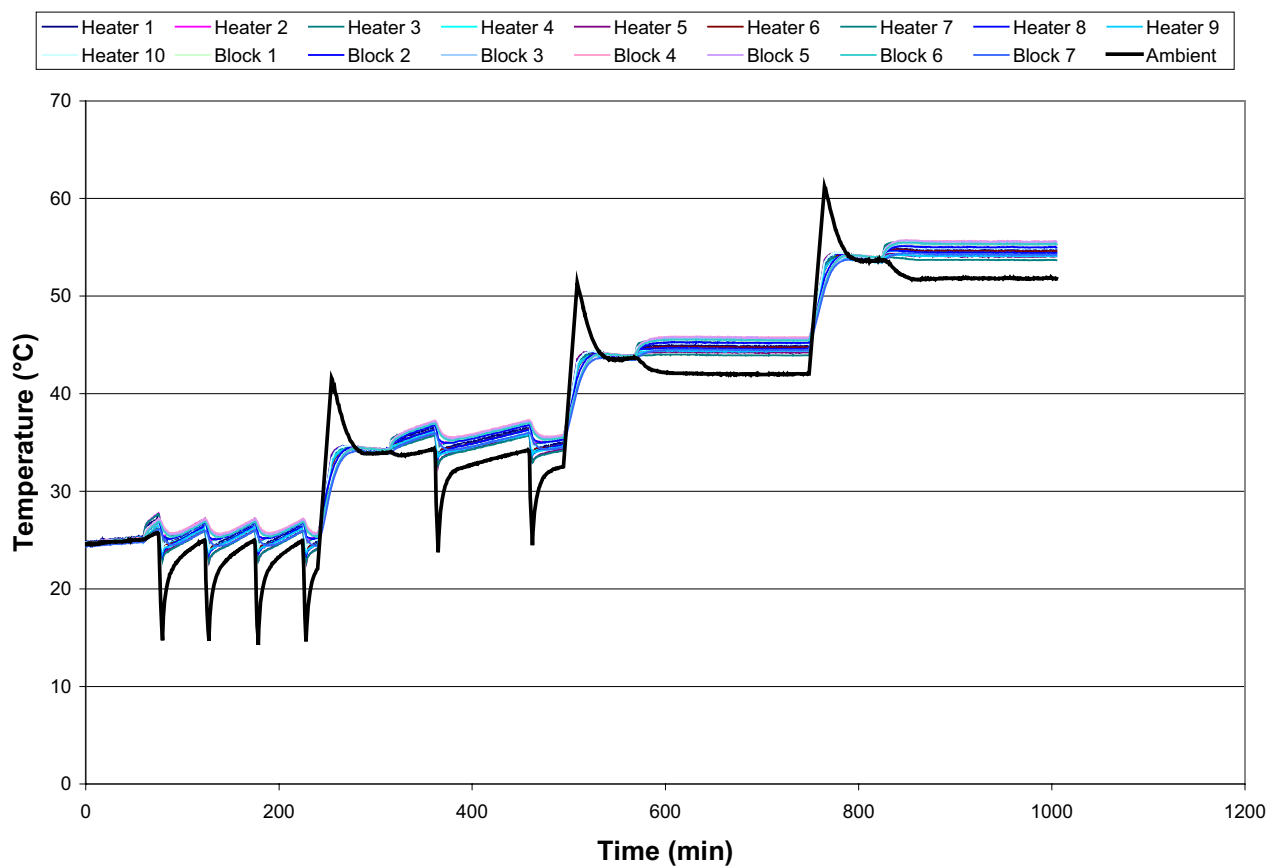

Figure B.3. Thermal block temperature control experiment with ten heat sources (block control). 


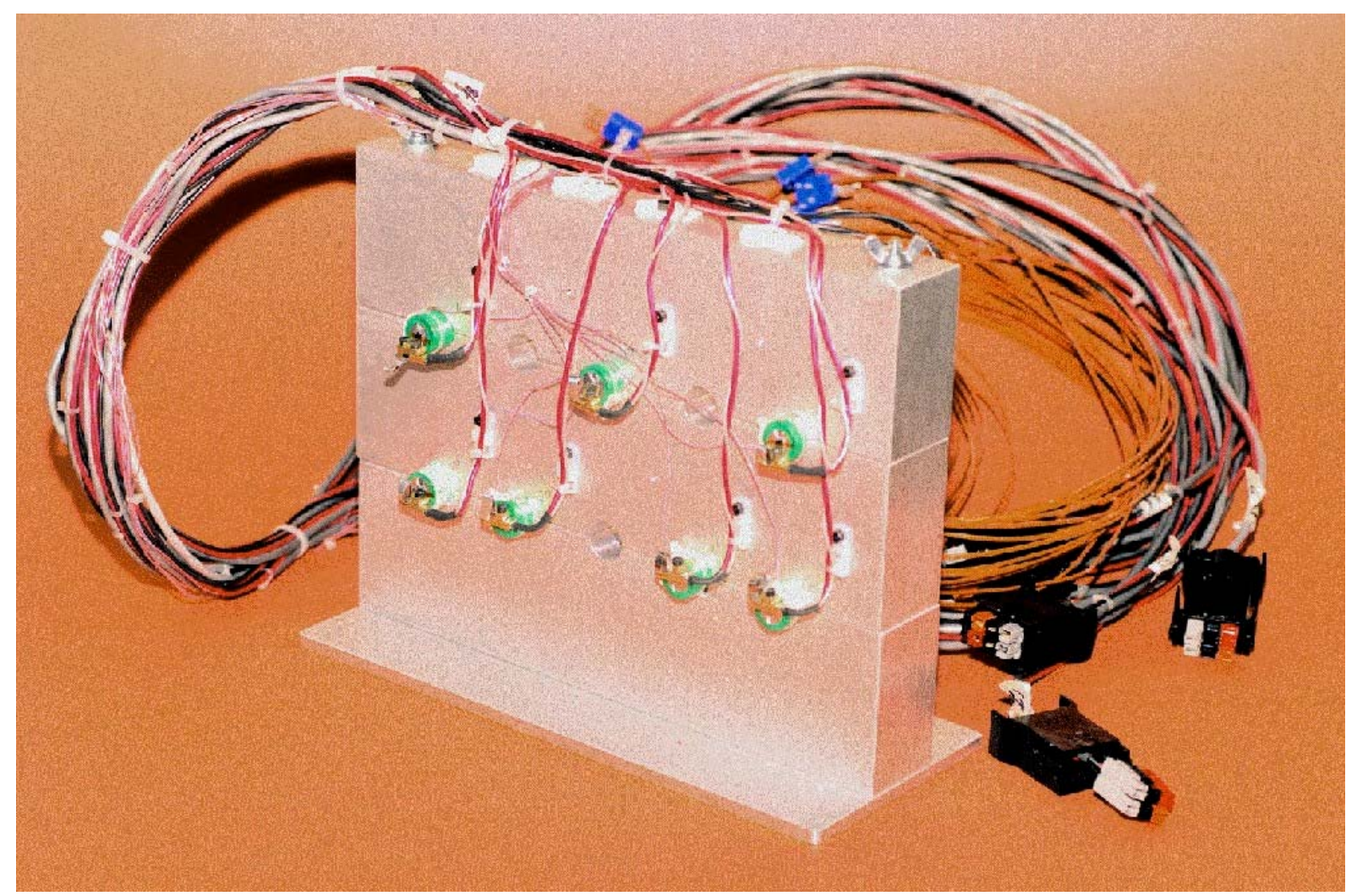

Figure B.4. Thermal block with seven Gen 2 cycle-life cells.

\section{B.4.3 Tab Issue}

The Gen 2 cells arrived with aluminum positive tabs and high-impedance nickel negative tabs. Since the tab welds were very weak and it was difficult to attach test leads, $1 / 8$ - by $1 / 4$-in. brass connectors were built for all cycle-life cells. The tester voltage and current sense leads were soldered into the brass connectors. In addition, to minimize the tab impedance, thin round vellum insulators (with a small slit in the middle for the tab) were installed on the negative end of each cell. Their purpose is to provide electrical isolation and allow the connectors to be attached as close to the cell as possible, thereby minimizing the impedance of the tab to the tester connector. Figure B.5 shows a close-up of a cycle-life cell on a thermal block. The vellum insulator and brass connectors on the negative tab are shown, along with the voltage and current sense lead wires (black wires) attached to the cell tab through the brass connector. 


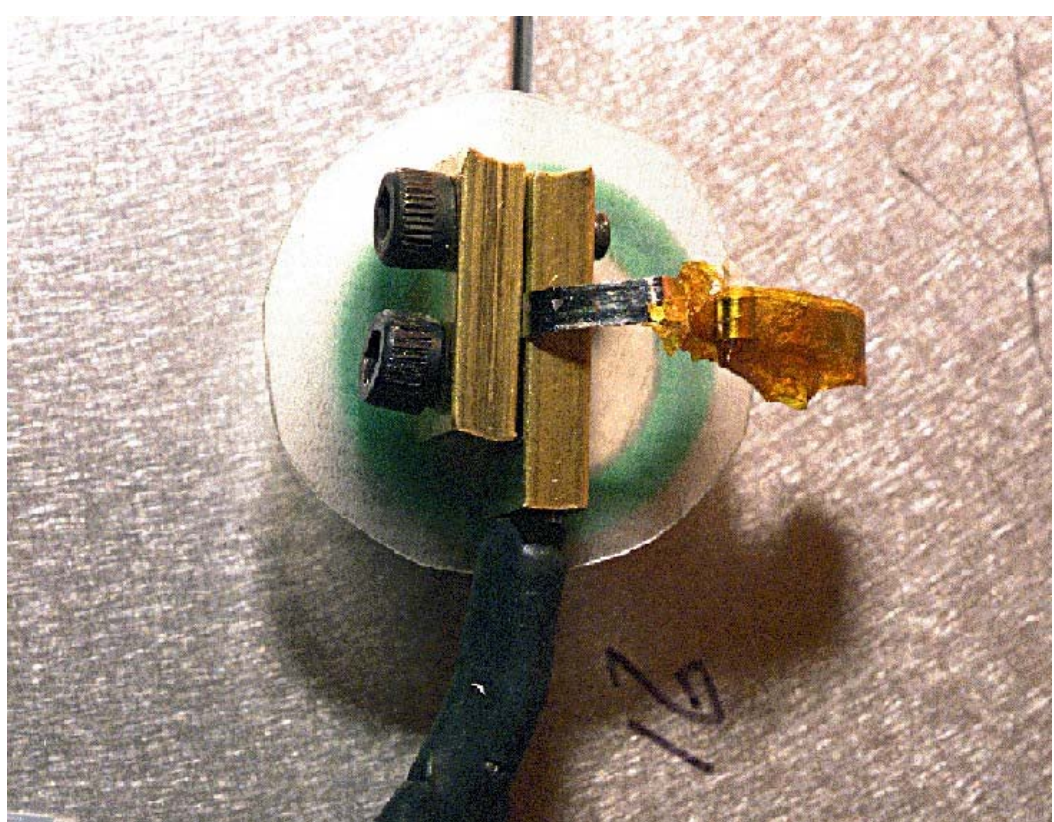

Figure B.5. ATD Gen 2 cycle-life cell with brass connectors and vellum insulator on the negative tab.

\section{B.4.4 Tab Failure}

On January 23, 2001, the INL hooked up one cell (G2.60L25.I101.00.NA.NA.T.A) to the tester and began characterization testing in accordance with the cell-specific test plan (Attachment 1). Shortly after completing five $\mathrm{C}_{1} / 1$ static capacity tests and three electrochemical impedance spectroscopy tests at $60 \%$ SOC (test descriptions are provided in Section 3.0), it was discovered that the negative tab had failed. The OCV was measured and it was still at the target, corresponding to $60 \%$ SOC (Appendix D of Reference 5). The cell may have been inadvertently shorted, resulting in a melted tab. The cell did not appear to have any internal damage, and there was no evidence of venting. As directed by the ATD Program Manager, the cell was shipped to ANL for diagnostic work, and the INL received a replacement cell (G2.60L25.I176.00.CC.00.G.B) on February 5, 2001. Figure B.6 shows the failed negative tab on G2.60L25.I101.00.NA.NA.T.A.

\section{B.4.5 Vent Failure}

The receipt inspection (Section B.4.1) of the cycle-life Variant C cells revealed that one of the cells (G2C.60L45.I173.00.NA.NA.L.Q) had self-discharged below the $3.0 \mathrm{~V}$ minimum. This cell also showed high impedance at $1 \mathrm{kHz}(15.0-\mathrm{j} 2.5 \mathrm{~m} \Omega$ compared to an average of $10.6-\mathrm{j} 0.2 \mathrm{~m} \Omega)$. Two days later, when all Variant $\mathrm{C}$ cells were connected to the tester for $\mathrm{C}_{1} / 1$ testing, the open-circuit voltage $(\mathrm{OCV})$ of G2C.60L45.I173.00.NA.NA.L.Q had drifted down to 0.92 V. The $C_{1} / 1$ capacity test showed only 0.67 $\mathrm{A} \cdot \mathrm{h}$. Therefore, as directed by the ATD Program Manager, the cell was returned to Quallion. Quallion discovered that the vent on this cell was broken, and some electrolyte had leaked out. Figure B.7 shows the hole in the vent, along with the electrolyte leakage. 


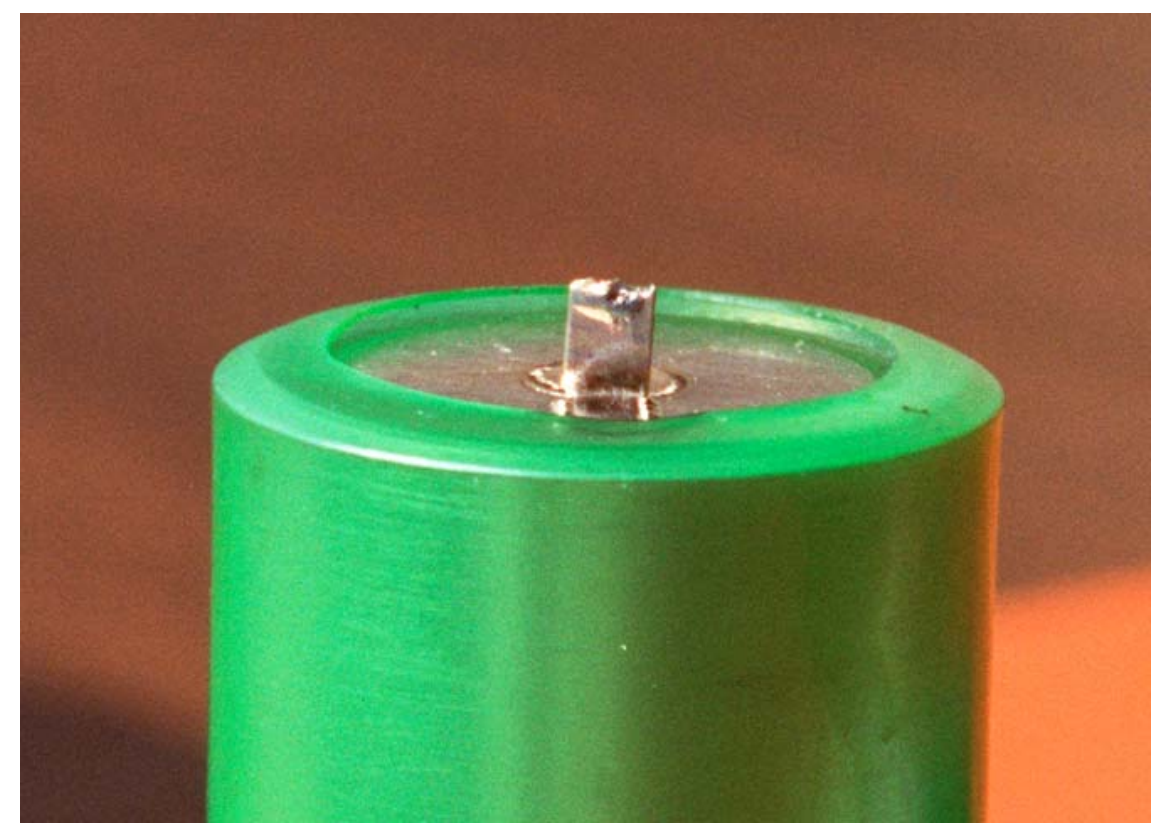

Figure B.6. G2.60L25.I101.00.NA.NA.T.A with failed tab.

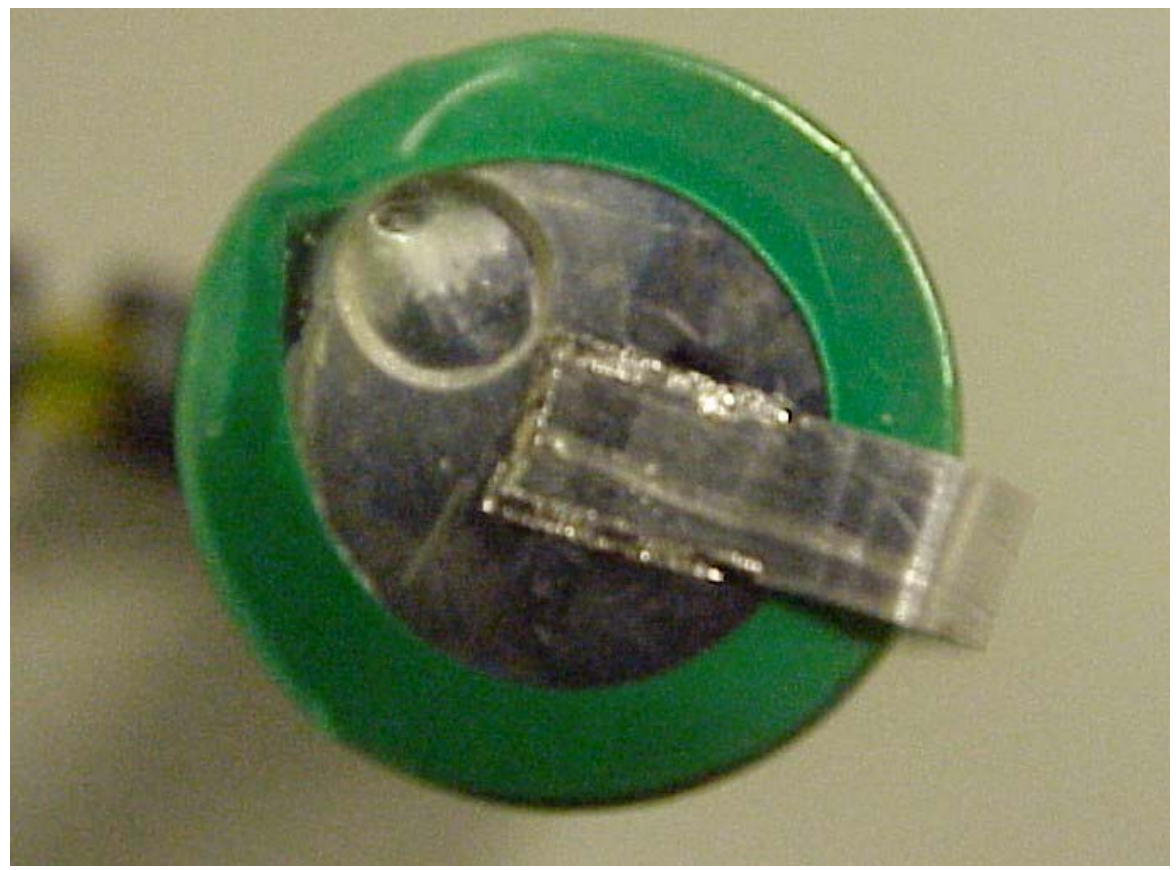

Figure B.7. G2C.60L45.I173.00.NA.NA.L.Q with broken vent and electrolyte leakage.

\section{B.4.6 Test Channel Failure}

After the 72-week RPT, the Maccor test channel for INL Cell G2C.60L45.I162.50.124.50.G.A reported a "lost current control" error. The fuses and cable connections were okay, so the failure was due to the brick. On October 10, 2003 (approximately 4000 cycles into the $19^{\text {th }}$ set of cycle-life testing), the brick was replaced and testing resume. The impact of the brick only appeared to affect the $\mathrm{C}_{1} / 25$ data, and these data indicate that the brick may have started failing as early as 44 weeks into life testing. 


\section{B.4.7 Temperature Chamber Failure}

After the 84 weeks RPT, the temperature chamber holding the four remaining $25^{\circ} \mathrm{C}$ Baseline cells was showing fluctuations of approximately $5^{\circ} \mathrm{C}$, so the cells were moved to a different test chamber. However, since one was not immediately available, the cells ended up sitting at OCV for approximately three weeks at room temperature prior to resuming testing. Consequently, another RPT was performed on these cells, typically denoted the 86-week RPT, prior to the start of the next cycle-life set.

\section{B.5 Accelerated-Life Special Considerations}

\section{B.5.1 Tab Failure}

The receipt inspection conducted prior to testing the accelerated-life Baseline cells revealed very fragile tab welds. Specifically, the weld on the positive tab could easily be torn with gentle handling. Figure B.8 shows how the aluminum/nickel weld can "unzip." Therefore, prior to testing, all acceleratedlife cells were reinforced with an aluminum strip. The strip was LASER welded to the positive tabs, as shown in Figure B.9.

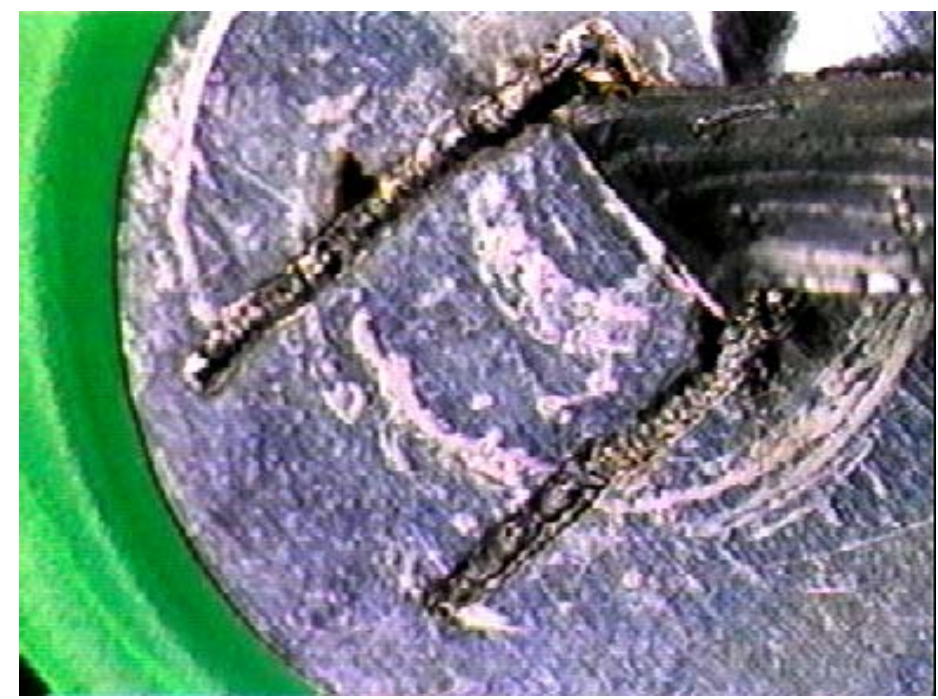

Figure B.8. Aluminum/nickel welds on the positive tab

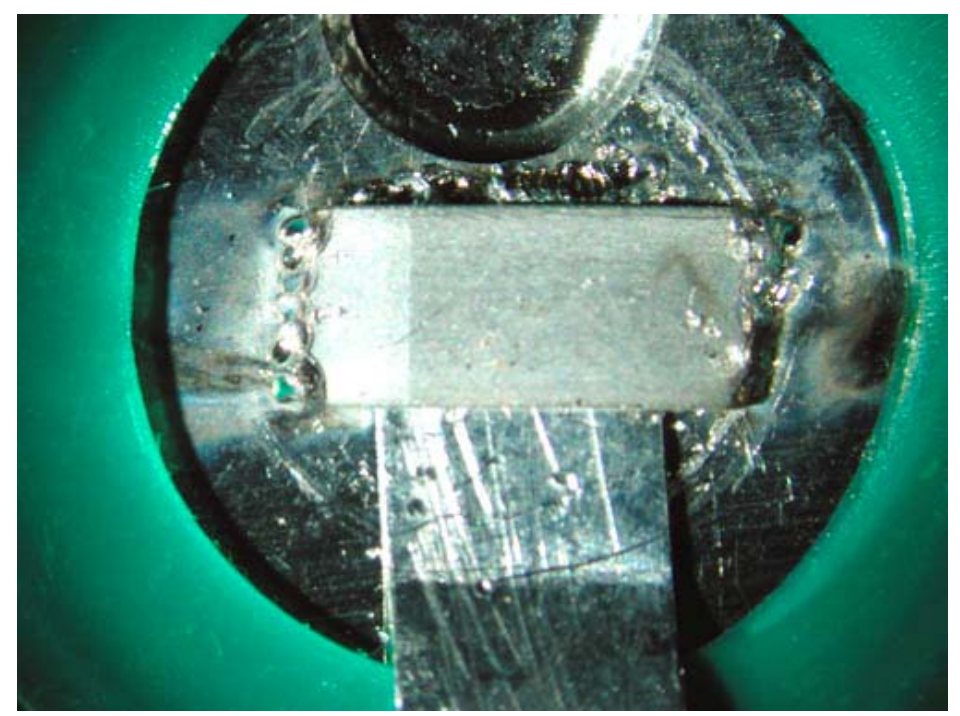

Figure B.9. Reinforcement aluminum strip on the positive tabs. 


\section{B.5.2 Early Cell Failures}

Eight of the accelerated-life cells failed prior to any testing. Seven had self-discharged below the minimum discharge voltage of $3.0 \mathrm{~V}$ (Section 2.1). The other cell was punctured at the vent by the probe of a voltmeter. As a result, these cells were removed from the test matrix.

Four cells failed during accelerated-life testing due to equipment or handling problems. Cell G2.60A25.S341.NA.20.11.V.F vented on the $27^{\text {th }}$ or $28^{\text {th }}$ day of aging on February 19, 2002. It was later determined that the cell was testing on a bad Maccor channel. Cell G2.100A25.S342.NA.08.09.D.F was removed from test on October 15, 2002 due to a probable overcharge. It was replaced in the testing matrix with G2.100A25.S434.NA.28.30.G.T. Cell G2.100A35.S435.NA.24.32.D.F was removed from test on April 24, 2002 due to a possible over discharge while discharging to the target SOC for an EIS test. Cell G2.80A25.S447.NA.16.12.D.F was removed from test on January 14, 2002 due to an overcharge during a $\mathrm{C}_{1} / 10$ test. These cells failed because the test leads were incorrectly reattached to the cells following an EIS test. 


\section{Appendix C}

Testing 


\section{TESTING}

This appendix presents additional testing details not discussed in Section 3.0 of the main report.

\section{C.1 Characterization Testing}

The characterization tests performed for the calendar-, cycle-, and accelerated-life tests are summarized in Table C.1. As shown, the accelerated-life cells were subjected to an additional EIS at $100 \% \mathrm{SOC}$ and a $0^{\circ} \mathrm{C} \mathrm{L}-\mathrm{HPPC}$ test.

Table C.1. Characterization tests performed at each laboratory.

\begin{tabular}{clll}
\hline \hline Temperature $\left({ }^{\circ} \mathrm{C}\right)$ & \multicolumn{1}{c}{ Calendar-Life } & \multicolumn{1}{c}{ Cycle-Life } & Accelerated-Life \\
\hline \hline 25 & $5 \mathrm{C}_{1} / 1$ discharges & $5 \mathrm{C}_{1} / 1$ discharges & $5 \mathrm{C}_{1} / 1$ discharges \\
25 & $\mathrm{C}_{1} / 25$ discharge & $\mathrm{C}_{1} / 25$ discharge & $\mathrm{C}_{1} / 25$ discharge \\
25 & $\mathrm{C}_{1} / 25$ charge & $\mathrm{C}_{1} / 25$ charge & \\
25 & & & EIS at $100 \%$ SOC \\
25 & EIS at $60 \%$ SOC & EIS at $60 \%$ SOC & EIS at $60 \%$ SOC \\
25 & L-HPPC & $\mathrm{C}_{1} / 1$ and L-HPPC & L-HPPC \\
0 & & & L-HPPC \\
\hline \hline
\end{tabular}

The specific equipment used for EIS measurements on the calendar-, cycle- and accelerated-life cells varies, as shown in Table C.2. Although the equipment is identical for the calendar- and cycle-life cells, the cycle-life cell equipment is much older. This may result in a much higher high-frequency capacitive tail, as seen with the cycle-life EIS results compared to the calendar-life cells (e.g., see Figures 57 and 58). EIS measurement issues are discussed in Appendix D.

Table C.2. EIS equipment.

\begin{tabular}{llll}
\hline \multicolumn{1}{c}{ Equipment } & Calendar Life & Cycle Life & Accelerated Life \\
\hline \hline EG\&G potentiostat/galvanostat & Model 273A & Model 273A & Model 273A \\
Solartron frequency analyzer & Model 1260 & Model 1260 & Model 1255 \\
Control software & Zplot & Zplot & M398 \\
\hline \hline
\end{tabular}

\section{C.2 Reference Performance Testing}

The sequence and order of tests for the calendar-, cycle- and accelerated-life RPTs is summarized in Table C.3. In addition to the standard RPT, the accelerated-life cells were also regularly subjected to the $\mathrm{L}-\mathrm{HPPC}$ test at $0^{\circ} \mathrm{C}$. Its purpose was to magnify the changes in cell degradation as well as give an indication of the change in rate of the power fade. However, no dramatic effect was realized, and this test was eliminated after the 24 -week RPT. The $\mathrm{C}_{1} / 10$ static capacity test was also initiated after eight weeks of aging on the accelerated-life cells as another measure of available capacity. It should also be noted that in some cases the accelerated-life RPT interval was increased to eight weeks after 36 weeks of aging. This was applied to the 35 and $45^{\circ} \mathrm{C}$ cell groups aged at $60 \% \mathrm{SOC}$, and the $35^{\circ} \mathrm{C}$ cells aged at $80 \% \mathrm{SOC}$. 
Table C.3. Reference performance test sequence.

\begin{tabular}{clll}
\hline \hline Temperature $\left({ }^{\circ} \mathrm{C}\right)$ & \multicolumn{1}{c}{ Calendar-Life } & \multicolumn{1}{c}{ Cycle-Life } & \multicolumn{1}{c}{ Accelerated-Life } \\
\hline \hline 25 & $\mathrm{C}_{1} / 1$ discharge & $\mathrm{C}_{1} / 1$ discharge & $5 \mathrm{C}_{1} / 1$ discharges \\
25 & $\mathrm{C}_{1} / 25$ discharge & L-HPPC & $\mathrm{C}_{1} / 25$ discharge \\
25 & $\mathrm{C}_{1} / 25$ charge & $\mathrm{C}_{1} / 25$ discharge & EIS at $60 \%$ SOC \\
25 & EIS at $60 \%$ SOC & $\mathrm{C}_{1} / 25$ charge & EIS at $100 \%$ SOC \\
25 & L-HPPC & EIS at $60 \%$ SOC & $2 \mathrm{C}_{1} / 1$ discharges \\
25 & & & $\mathrm{C}_{1} / 10$ discharge \\
25 & & & L-HPPC \\
0 & & & L-HPPC \\
\hline \hline
\end{tabular}


Appendix D

Supporting Methodologies 


\section{SUPPORTING METHODOLOGIES \\ D.1 HPPC Calculations}

From the L-HPPC test (Section 3.1), discharge and regen resistances are calculated as the ratio of the change in voltage $(\Delta \mathrm{V})$ divided by the change in current $(\Delta \mathrm{I})$ at specified times during the pulse at each $10 \%$ DOD increment, as shown in Equations (D.1) and (D.2).

$$
\begin{aligned}
& \mathrm{R}_{\text {discharge }}=\left.\frac{\Delta \mathrm{V}_{18 \mathrm{~s}}}{\Delta \mathrm{I}_{18 \mathrm{~s}}}\right|_{\text {discharge }} \\
& \mathrm{R}_{\text {regen }}=\left.\frac{\Delta \mathrm{V}_{2 \mathrm{~s}}}{\Delta \mathrm{I}_{2 \mathrm{~s}}}\right|_{\text {regen }}
\end{aligned}
$$

Since the ATD Gen 2 cells are testing under the PNGV Power Assist goals, the data required include the 18 -s discharge resistance and the 2-s regen resistance. Figure D. 1 shows these resistances at each DOD increment as a function of OCV for a representative Baseline cell at BOL. As expected, the 18-s discharge resistances are consistently higher than the 2-s regen resistances. These resistances can also be scaled by the electrode area $\left(846.3 \mathrm{~cm}^{2}\right.$ for the Gen 2 Baseline and Variant C cells) to find the area specific impedance (ASI) in $\Omega-\mathrm{cm}^{2}$.

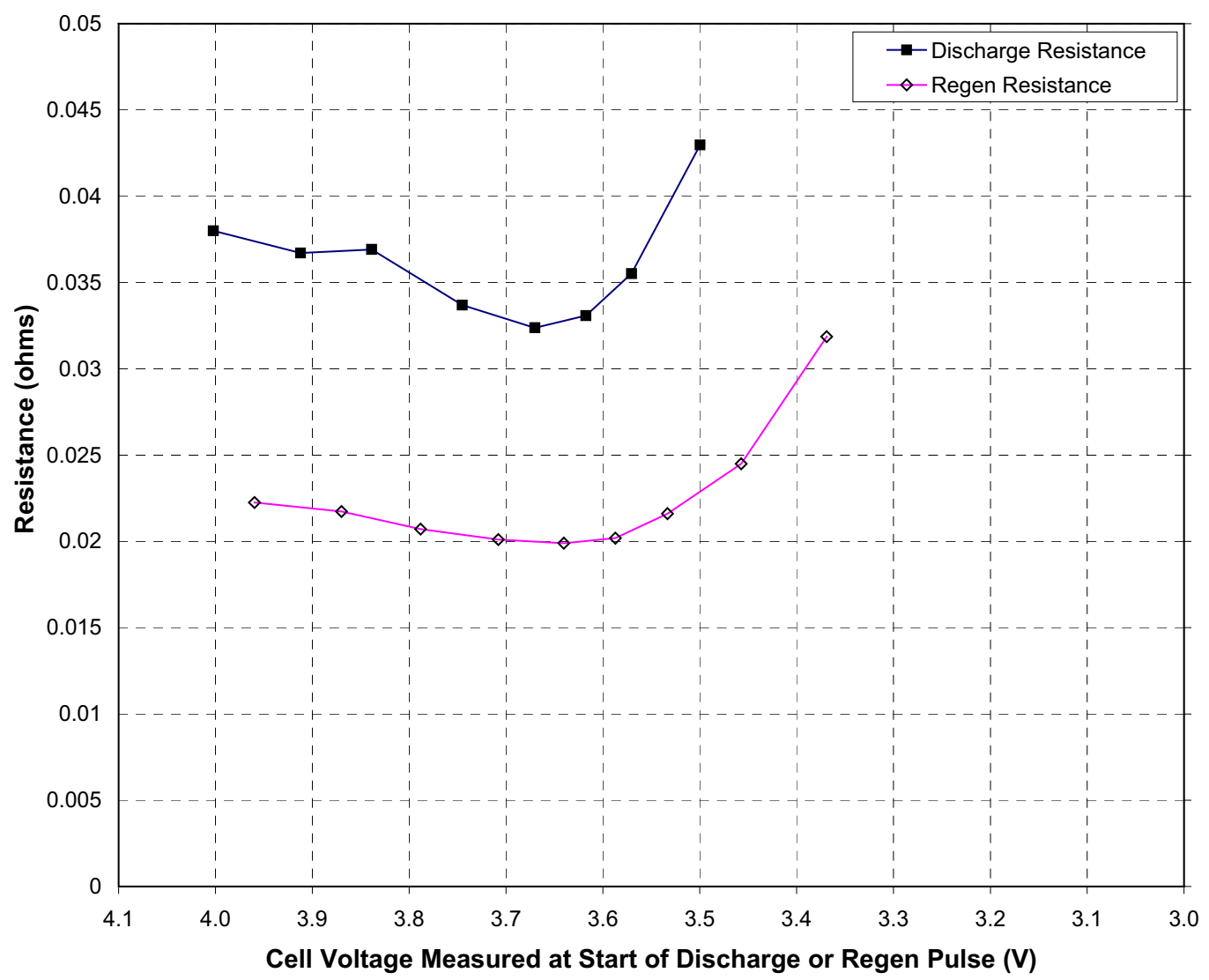

Figure D.1. Pulse resistance for a representative Baseline cell at BOL. 
The resistance data are then used to calculate the discharge and regen pulse power capability $\left(\mathrm{P}_{\text {discharge }}\right.$ and $\left.\mathrm{P}_{\text {regen }}\right)$ using Equations (D.3) and (D.4), respectively:

$$
\begin{aligned}
& P_{\text {discharge }}=\frac{\mathrm{V}_{\text {min }}\left(O C V-V_{\text {min }}\right)}{R_{\text {discharge }}} \\
& P_{\text {regen }}=\frac{V_{\text {max }}\left(V_{\text {max }}-O C V_{\text {regen }}\right)}{R_{\text {regen }}}
\end{aligned}
$$

where $\mathrm{V}_{\min }$ and $\mathrm{V}_{\max }$ are the specified L-HPPC voltage limits (3.0 and 4.1 V, see Section 2.1), the OCV is the voltage immediately prior to the pulse, and $\mathrm{R}_{\text {discharge }}$ and $\mathrm{R}_{\mathrm{regen}}$ are the corresponding 18-s and 2-s discharge and regen resistances, respectively, calculated from Equations (D.1) and (D.2). Since the regen pulse occurs after a 32-s rest (see Figure 1), the voltage immediately prior to the pulse does not reflect the $\mathrm{OCV}$ at true equilibrium. Consequently, the OCV is linearly interpolated based on the discharge OCV at the current and next L-HPPC pulse (i.e., over a 10\% DOD swing, see Reference 5).

The pulse power capabilities at each DOD increment are then related to the corresponding amount of energy discharged at a $C_{1} / 1$ rate to that point (i.e., the energy removed during the full $C_{1} / 1$ discharge performed prior to the L-HPPC test). Figure D.2 shows the discharge and regen pulse power capabilities versus the cumulative energy removed for the same representative cell shown in Figure D.1. Note that the regen power is normalized to the discharge power through a scaling factor of 1.2 (i.e., the $30-\mathrm{kW}$ Power Assist regen goal divided by the $25 \mathrm{~kW}$ Power Assist discharge goal).

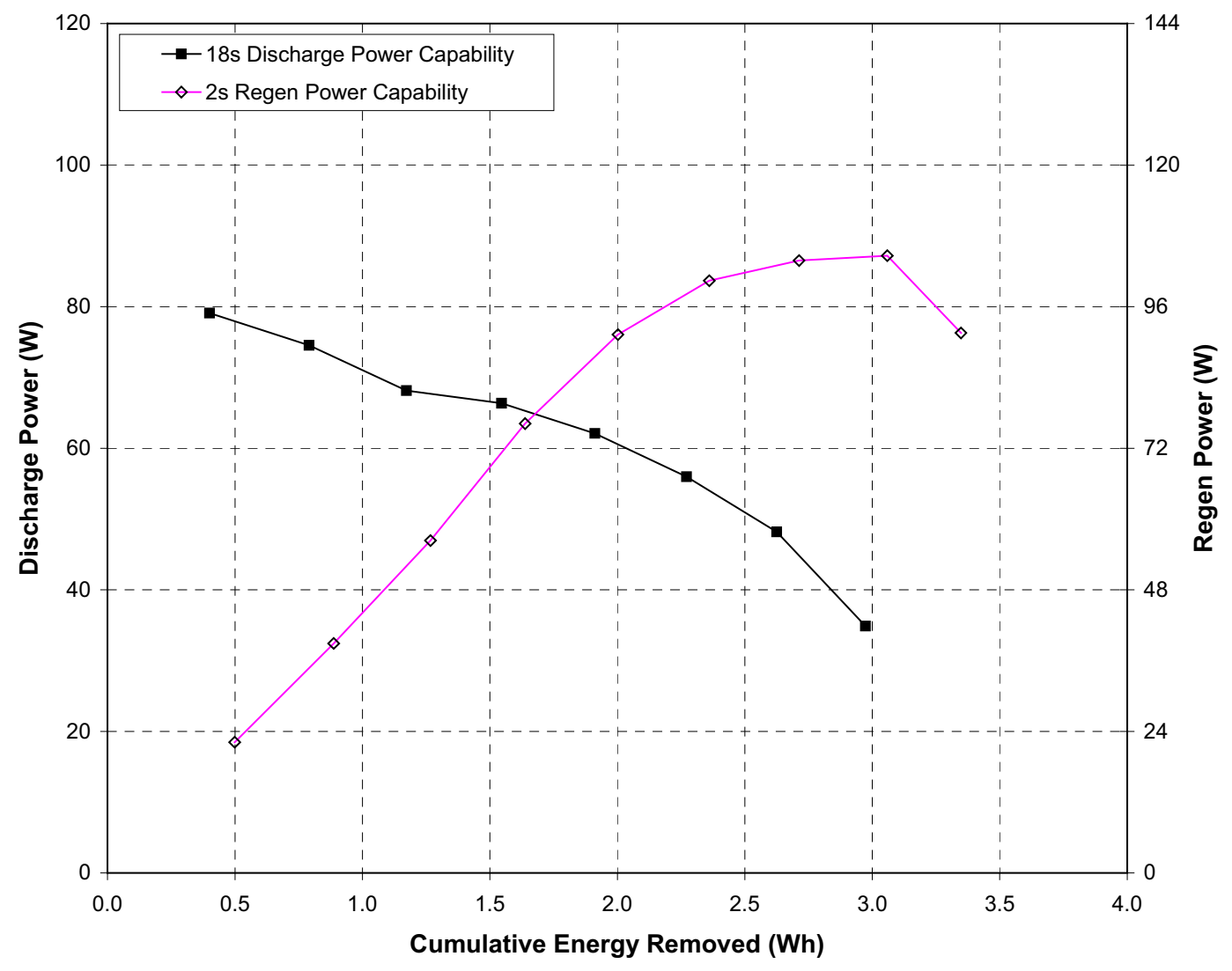

Figure D.2. Pulse power capability for a representative Baseline cell at BOL. 
From the pulse power capability curves (Figure D.2), the available energy as a function of discharge power can be calculated by taking the difference in energy between the discharge power curve and regen power curve, as shown in Equation (D.5).

$$
\text { Available Energy }=E_{\text {discharge }}-E_{\text {regen }} \text {. }
$$

Figure D.3 shows the resulting available energy curve for the same representative cell shown in Figures D.1 and D.2. The dashed-line in Figure D.3 has a slope equal to the ratio of the PNGV Power Assist energy goal (i.e., $300 \mathrm{Wh}$ ) divided by the PNGV discharge power goal plus a 30\% BOL power margin (i.e., $25 \mathrm{~kW} * 1.3$ ). The point at which the dashed line intersects the available energy curve is where the PNGV goals are optimally met for this representative cell. This intersection point is used to calculate the battery size factor (BSF) by dividing the energy at this point by the PNGV energy goal (or, alternatively dividing the power at this point by the PNGV power goal with a $30 \%$ margin). This calculation was performed on each ATD Gen 2 cell. The Baseline cells have an average BSF of 553, and the Variant $\mathrm{C}$ cells have an average BSF of 651 . The BSF is used to scale the cycle-life test profiles as well as all subsequent power and energy curves for direct comparison with the PNGV goals.

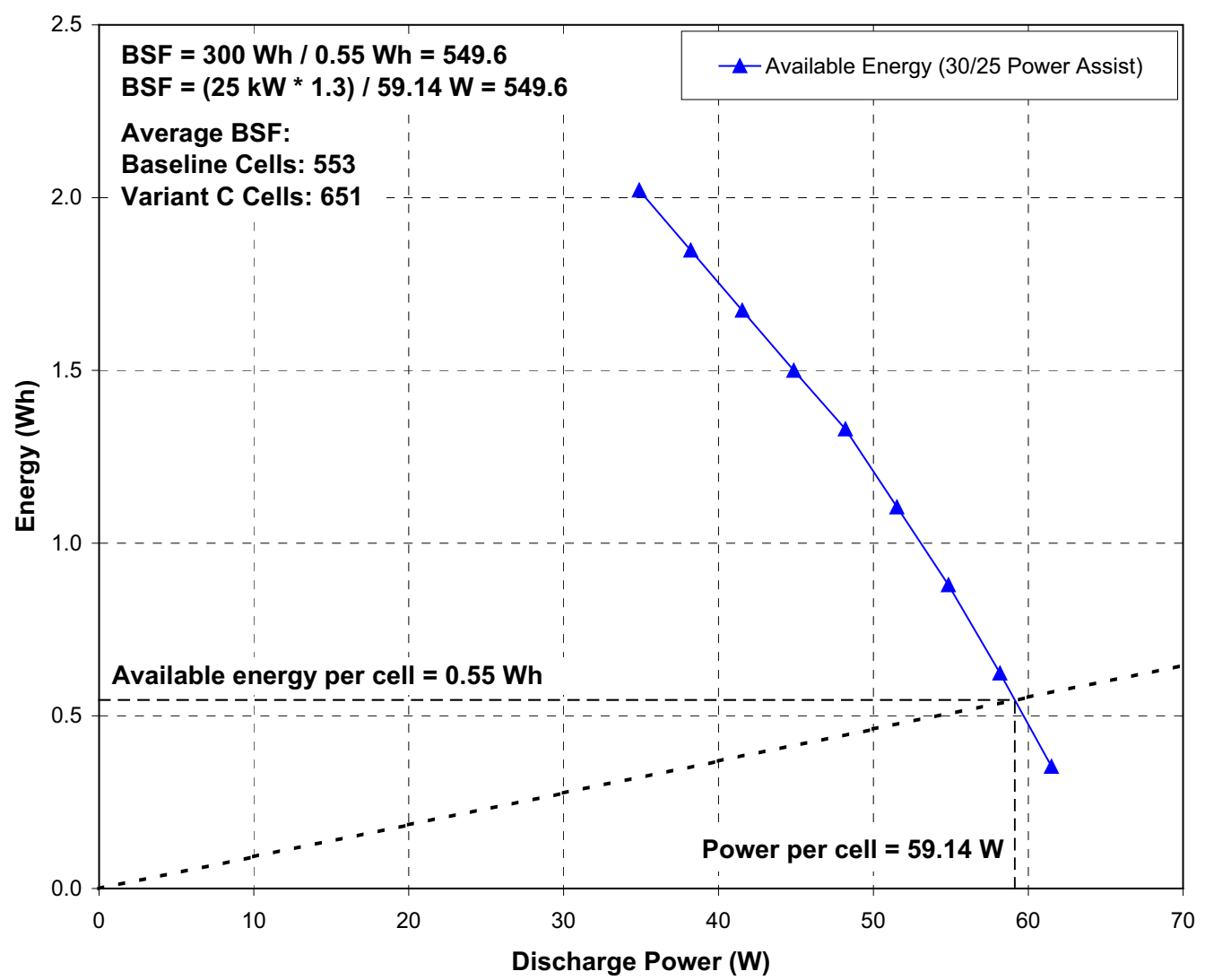

Figure D.3. Available energy for a representative Baseline cell at BOL.

\section{D.2 ElS Round Robin}

Prior to testing the Gen 2 cells, the three test laboratories (INL, ANL, and SNL) validated their respective EIS equipment and measurement processes using a test circuit dummy cell manufactured by SNL. The test cell circuit is shown in Figure D.4. The theoretical response of this circuit was calculated using Equation (D.6) and is shown in Figure D.5. 


$$
\mathrm{Z}=\left[\mathrm{R}_{1}+\frac{\mathrm{R}_{2}+\omega^{2} \mathrm{C}^{2} \mathrm{R}_{2} \mathrm{R}_{3}\left(\mathrm{R}_{2}+\mathrm{R}_{3}\right)}{1+\omega^{2} \mathrm{C}^{2}\left(\mathrm{R}_{2}+\mathrm{R}_{3}\right)^{2}}\right]-\mathrm{j}\left[\frac{\omega \mathrm{CR}_{2}{ }^{2}}{1+\omega^{2} \mathrm{C}^{2}\left(\mathrm{R}_{2}+\mathrm{R}_{3}\right)^{2}}\right]
$$

The actual responses from the three testing laboratories, along with the theoretical response, are shown in Figure D.6. As shown, the different equipment combinations yield different results. All test cell measurements show higher solution resistances than the theoretical response. This is primarily due to the placement of the connectors on the cell tabs. The cell tabs have high impedance and it has been verified that a slight adjustment of the connectors will significantly affect the position of semicircle but not the width. The ANL calendar- and INL cycle-life cells show a high-frequency capacitive tail due to the four-terminal connection. The SNL accelerated-life cells show an inductive high-frequency tail due to the three-terminal connection. A three-terminal connection also measures cable impedance and needs to be subtracted out.

Figure D.7 shows the EIS test cell measurements normalized to the theoretical response. This was done by subtracting the real impedance data by the difference between the point at which the test cell initially crosses (or is nearest to) zero and the initial real impedance of the theoretical response. As shown, the semicircles of the three testing laboratories match the theoretical response in faradaic resistance and amplitude. Therefore, although the high-frequency tail and the solution resistances are different among the testing laboratories, the percentage growth of the semicircles (Section 4.3.2) is comparable.

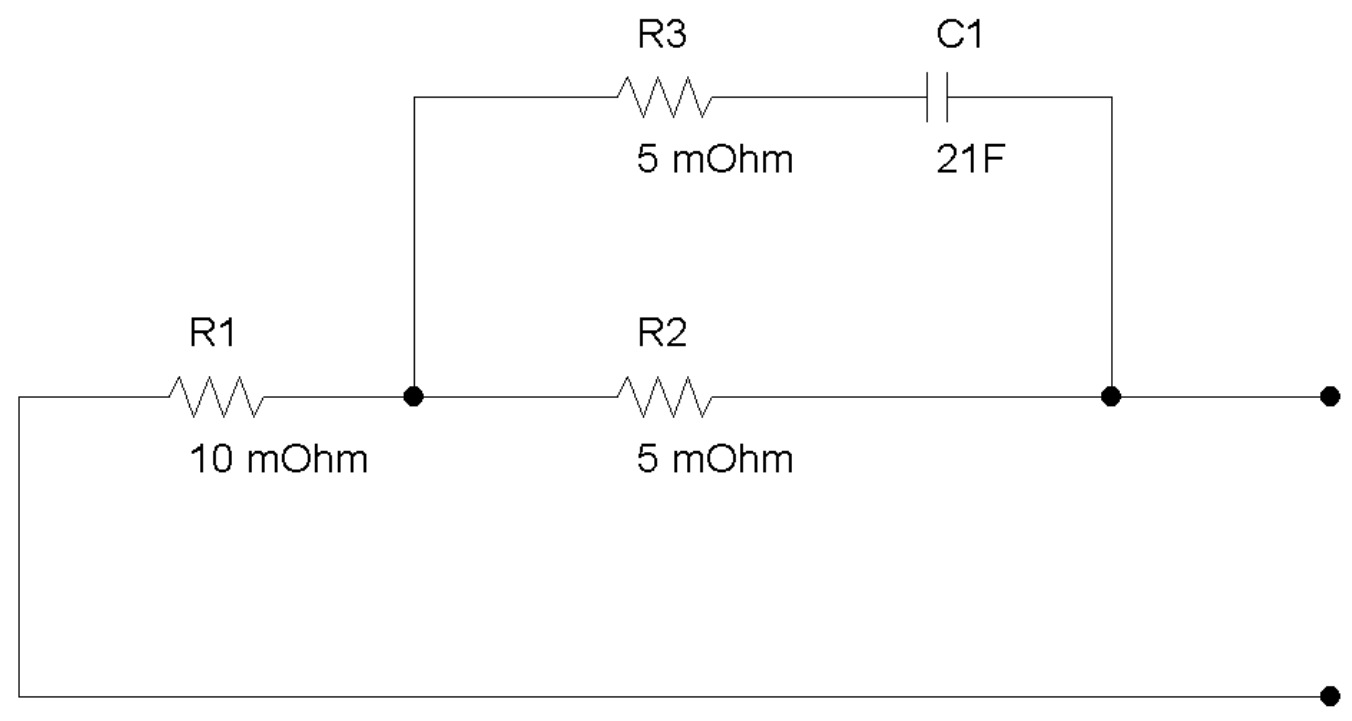

Figure D.4. Test cell circuit. 


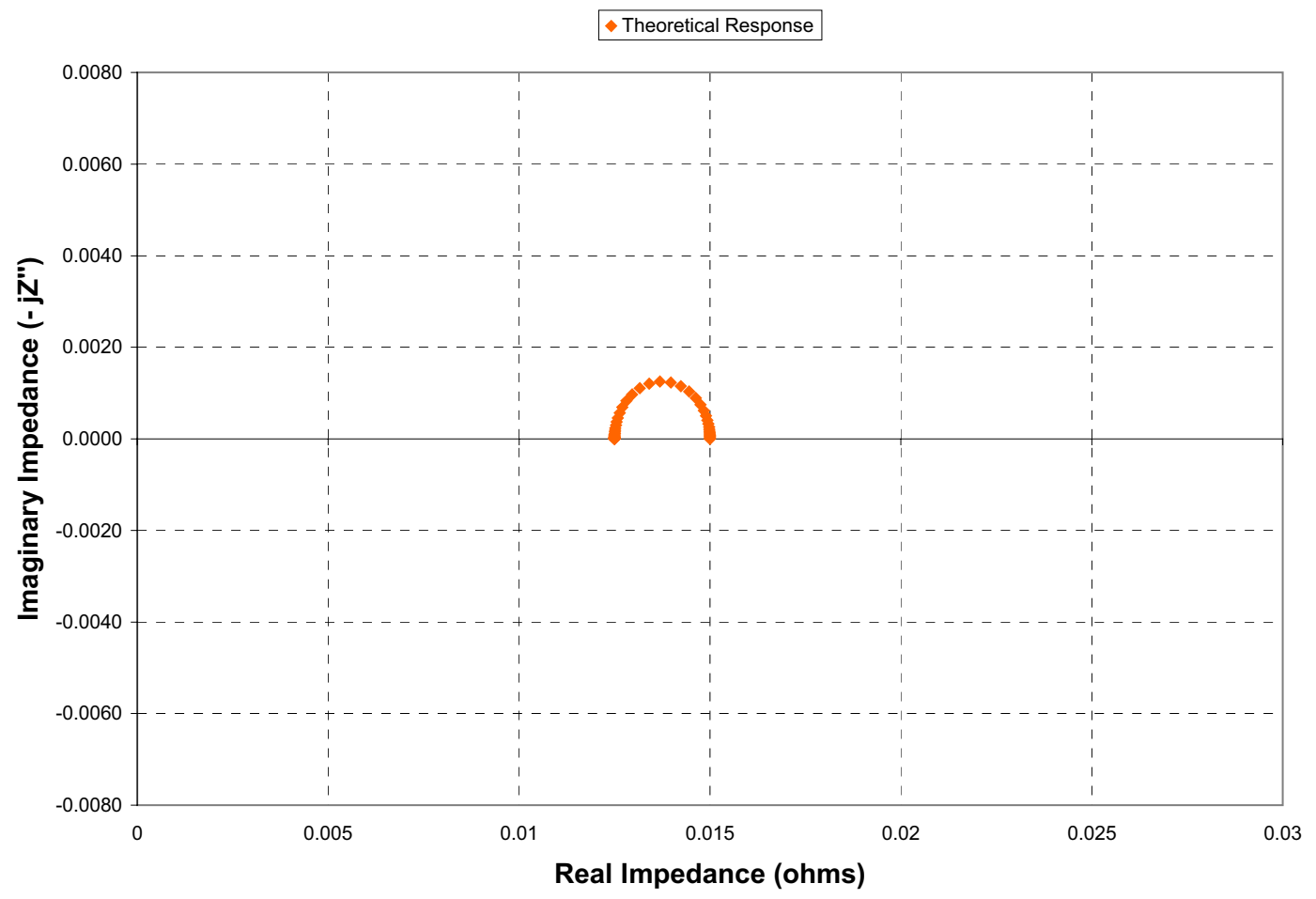

Figure D.5. Theoretical response of the test cell.

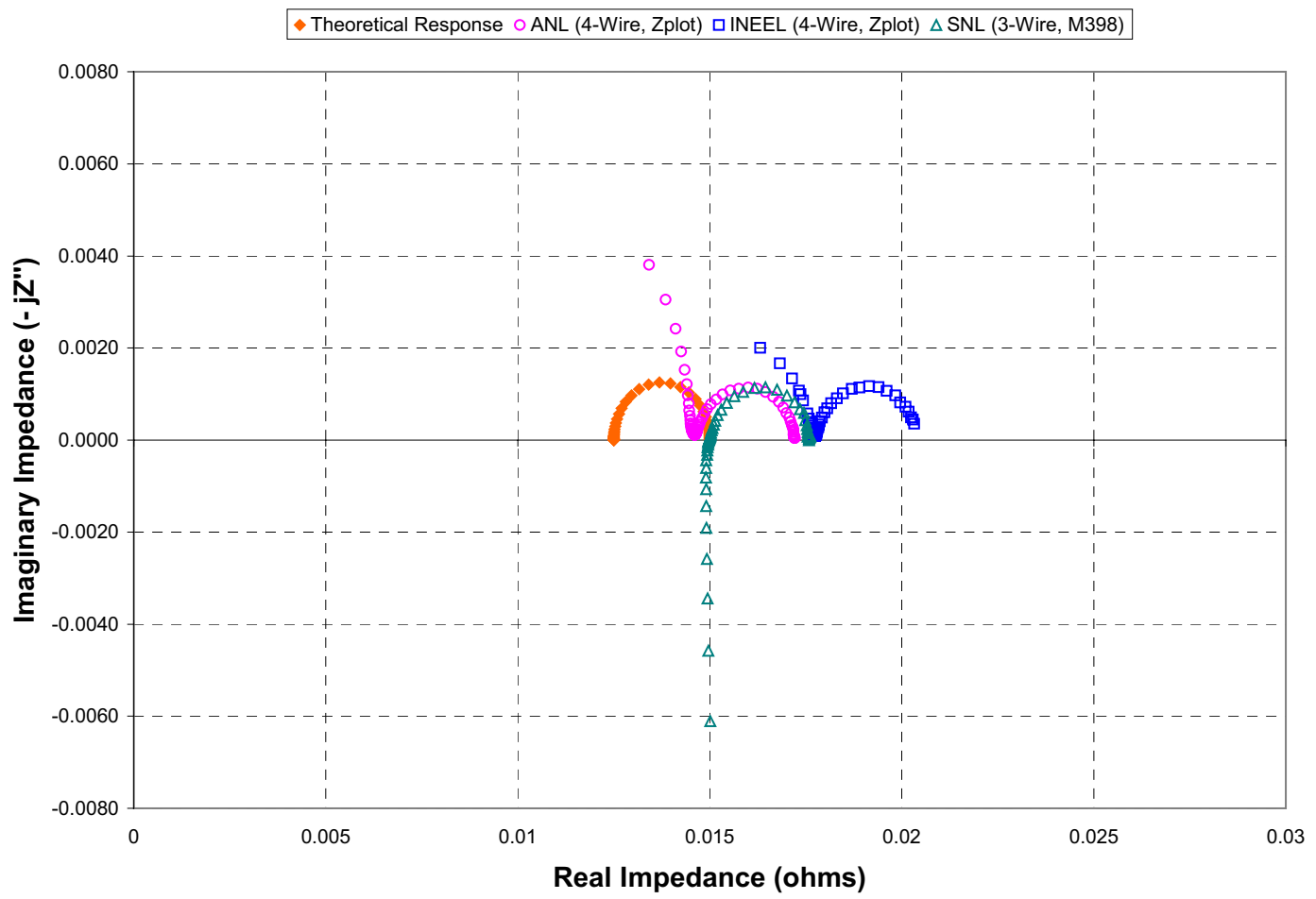

Figure D.6. Actual response to test cell. 


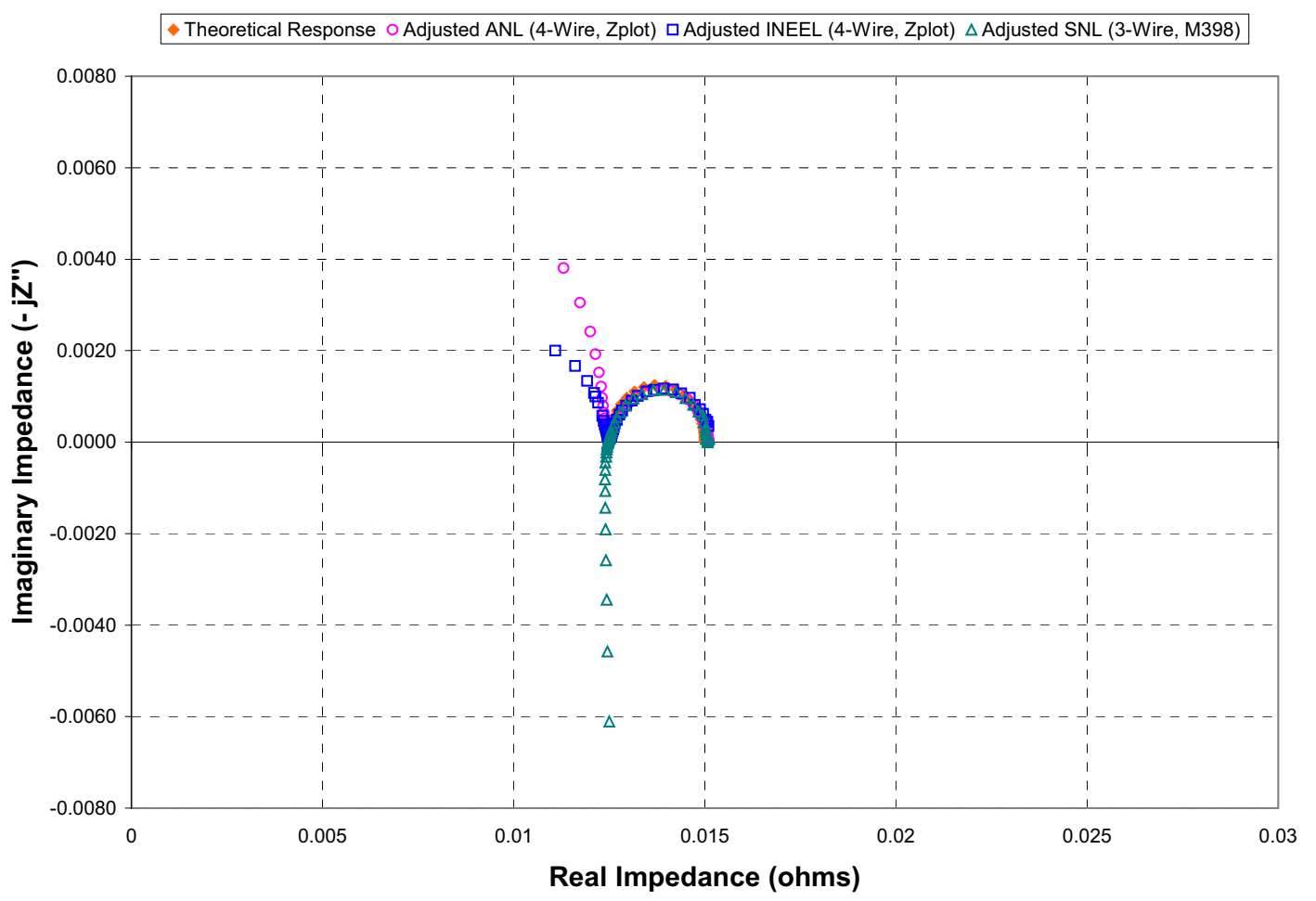

Figure D.7. Adjusted response to test cell.

\section{D.3 ElS Cable Studies}

Contributions to impedance spectra by overlooked peripheral apparatus (such as cabling, connectors, sample holders, etc.) can produce various types of experimental artifacts, especially at high frequencies. The artifacts can obscure and sometimes alter the true response of the cell. A systematic study of highfrequency artifacts arising from various cabling configurations was carried out by the INL using both ATD Gen 1 and Gen 2 cells, as well as commercially available Sony 18650 cells and standard D cell alkaline batteries. Instrumentation used in the study was a Solartron 1260 Impedance Analyzer and a Solartron 1286 Potentiostat/Galvanostat with one-meter BNC cables. For all cable configurations, a four terminal connection to the cell was used. Impedance measurements were taken from $10 \mathrm{kHz}$ to $10 \mathrm{mHz}$ at an AC amplitude of $20 \mathrm{mV}$.

Figures D.8 through D.11 show the impedance spectra along with the accompanying photo of the cable configuration to illustrate the effect of different cable interactions on the impedance measurements of an archived ATD Gen 1 cell. Figure D.8 shows that a simple four-terminal connection produces a small high frequency capacitive artifact. A small change in the position of the cabling reduces the size of the high frequency artifact (Figure D.9). Braiding the sense lead and working electrode lead (Figure D.10) further reduces the capacitive tail. Additional braiding of the cables (Figure D.11) changes the capacitive tail into a small inductive tail. Therefore, it is highly critical to maintain the same cable configuration at each RPT to get repeatable results. 


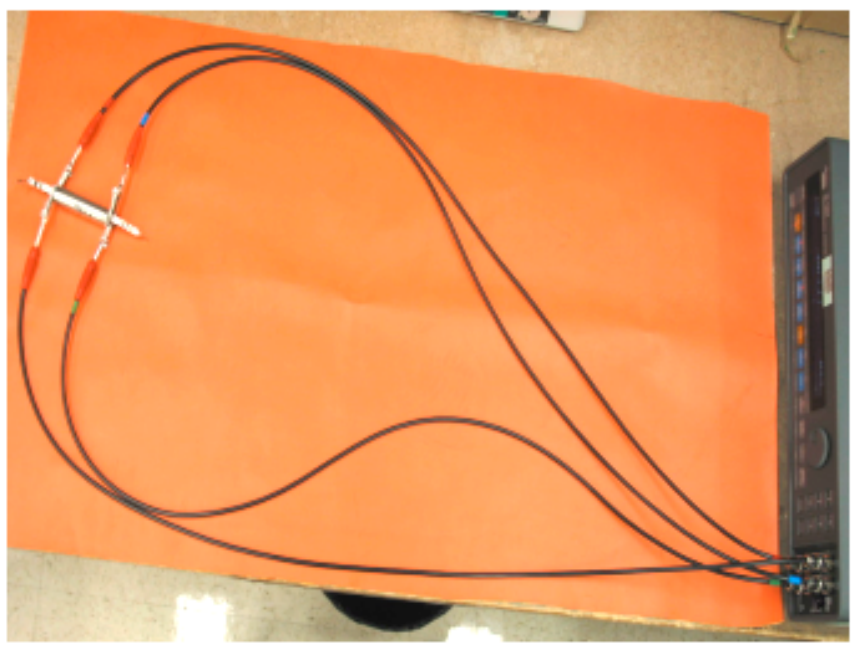

(a)

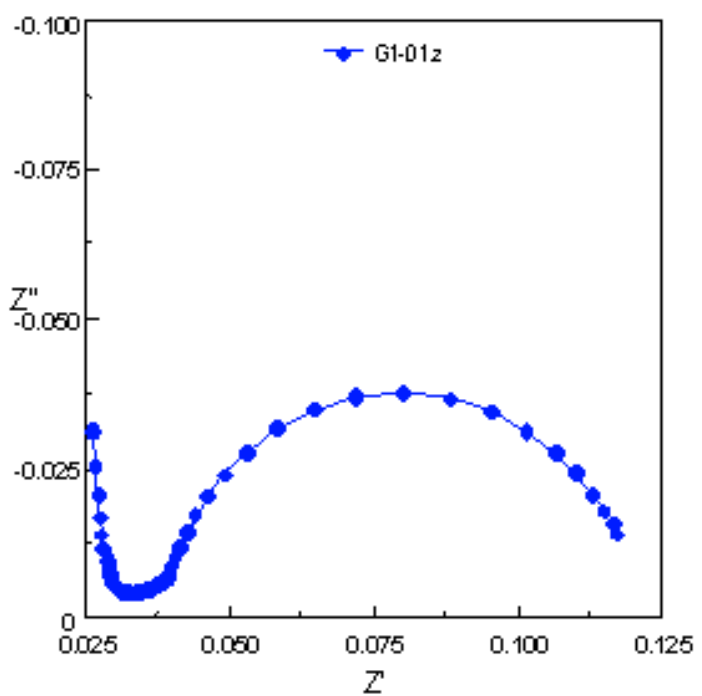

(b)

Figure D.8. (a) Simple four-terminal connection; (b) Resulting Nyquist curve.

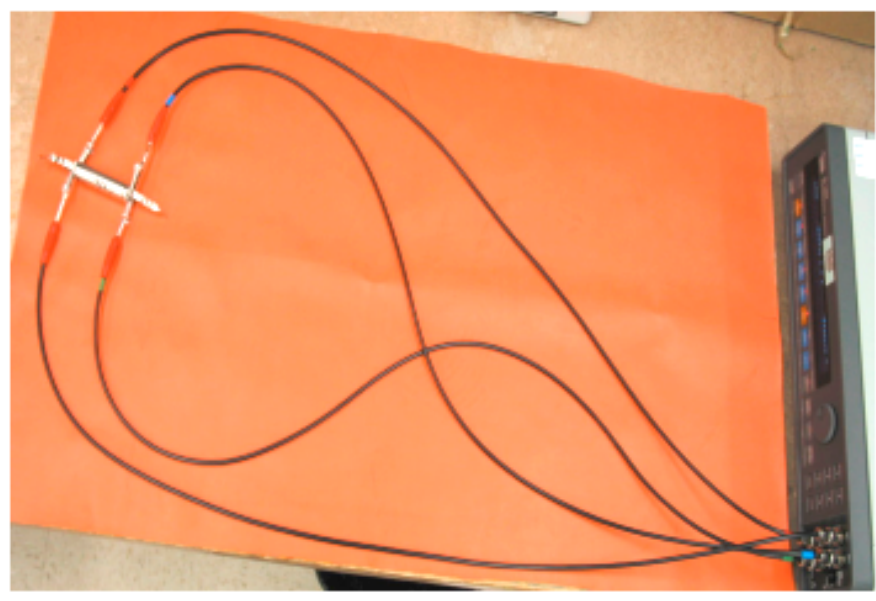

(a)

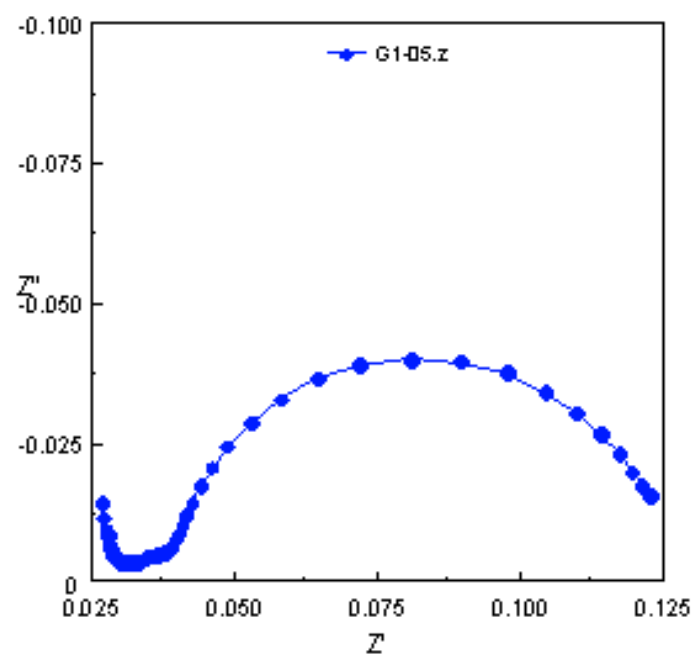

(b)

Figure D.9. (a) Small change in the simple four-terminal connection; (b) Resulting Nyquist curve. 


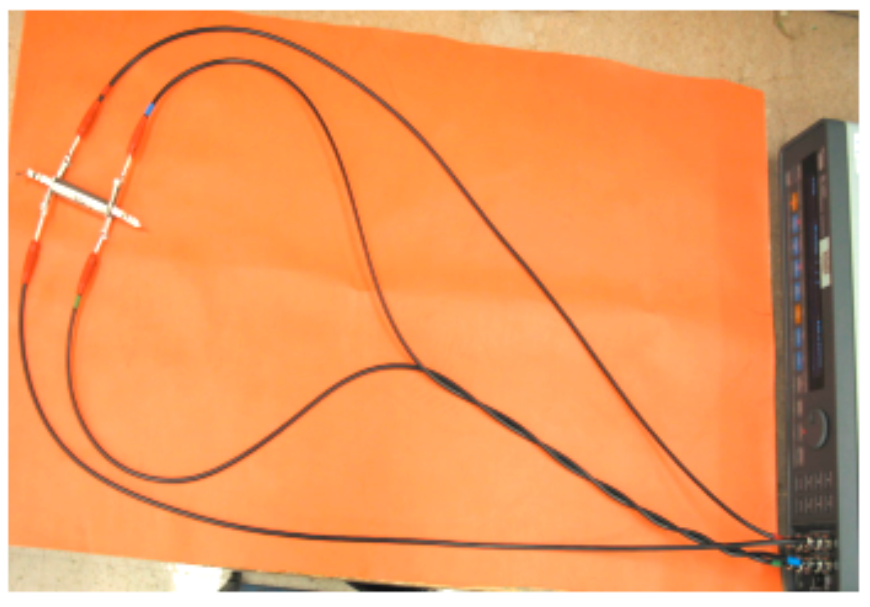

(a)

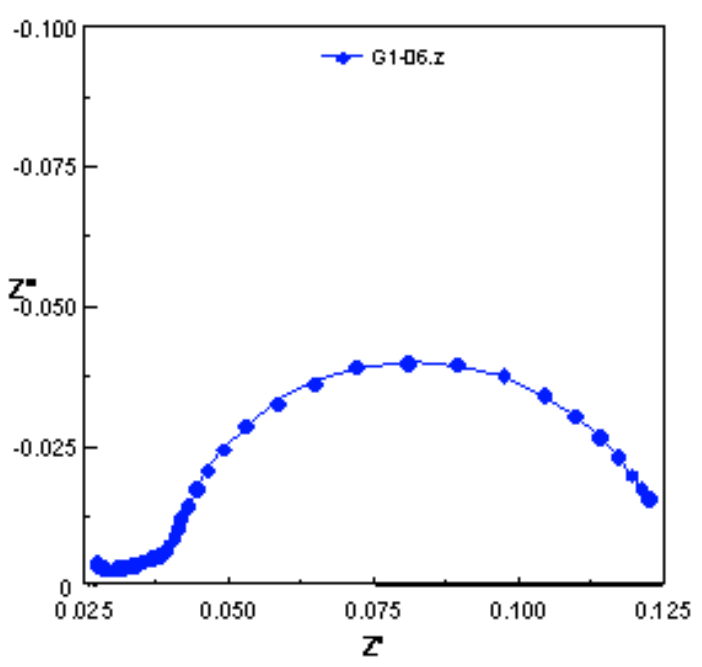

(b)

Figure D.10. (a) Braiding of the sense and working electrode leads; (b) Resulting Nyquist curve.

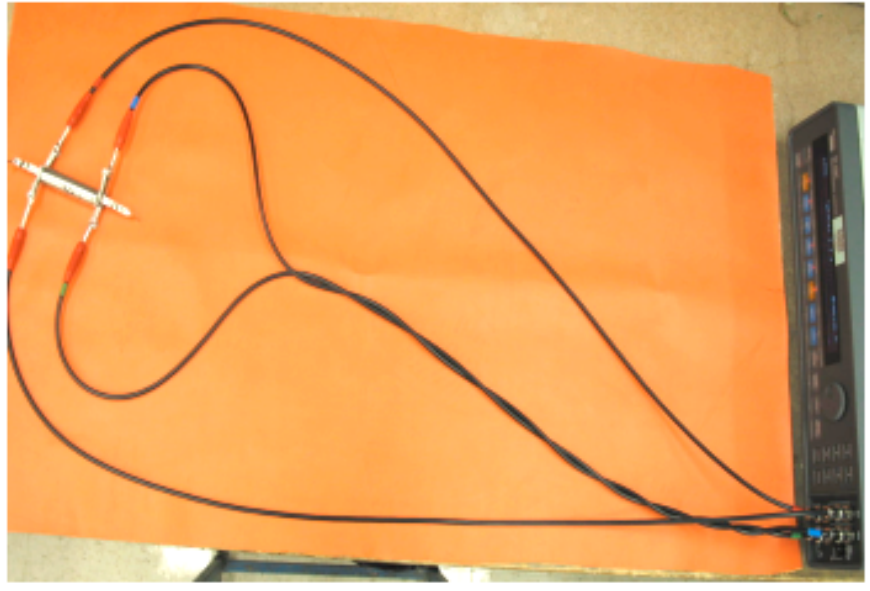

(a)

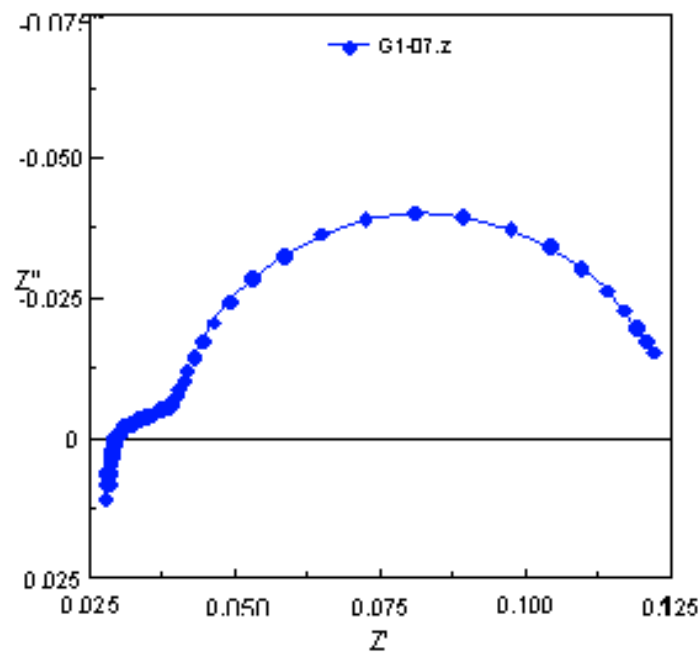

(b)

Figure D.11. (a) Further braiding of the sense and working electrode leads; (b) Resulting Nyquist curve. 